Supporting information for

\title{
Polyesterified Sesquiterpenoids from the Seeds of Celastrus paniculatus as Lifespan-Extending Agents for the Nematode Caenorhabditis elegans
}

Yifan Fu ${ }^{\dagger, *}$ and Weimin Zhao ${ }^{*},+, *$

†Shanghai Institute of Materia Medica, Chinese Academy of Sciences, Shanghai 201203, People's Republic of China

\#University of Chinese Academy of Sciences, Beijing 100049, People's Republic of China

Corresponding authors:

*Tel/Fax: 86-21-50806052. E-mail: wmzhao@simm.ac.cn (W.Z.) 


\section{Contents}

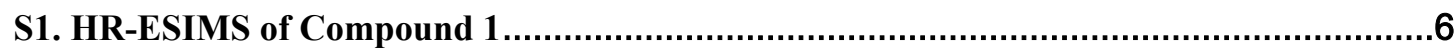

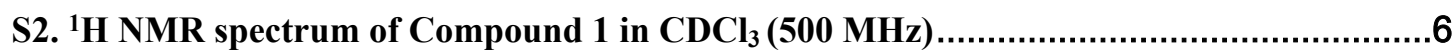

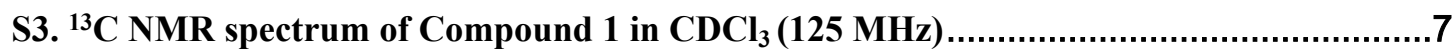

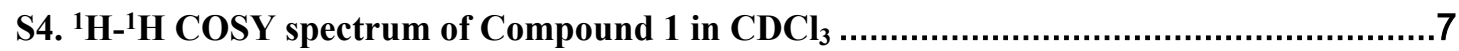

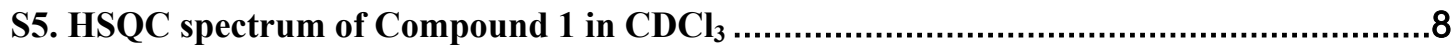

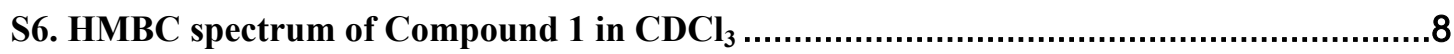

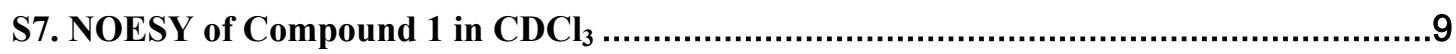

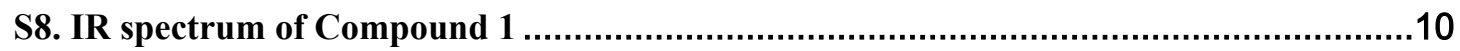

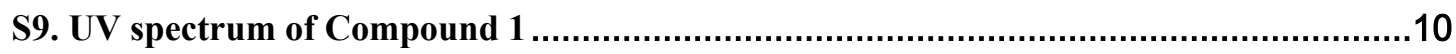

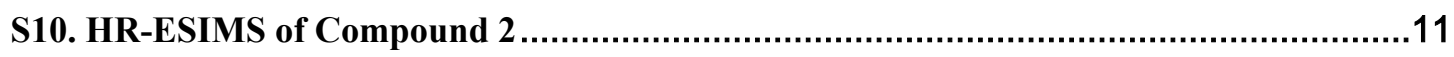

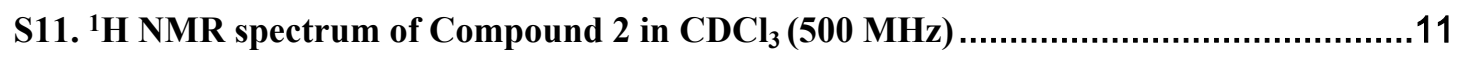

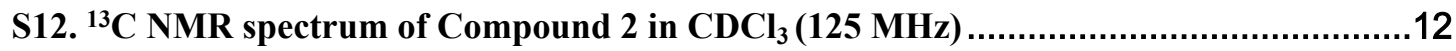


S13. HSQC spectrum of Compound 2 in $\mathrm{CDCl}_{3}$

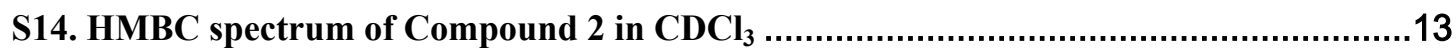

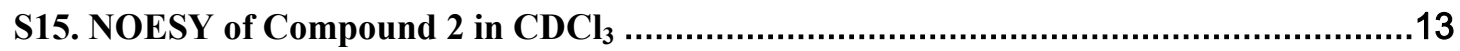

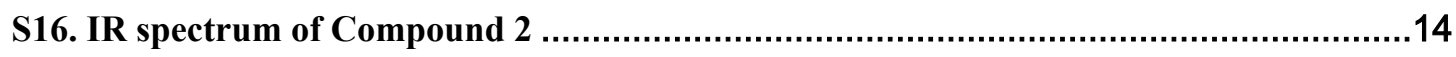

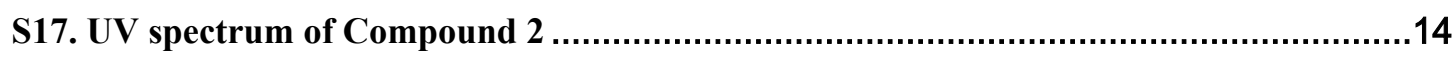

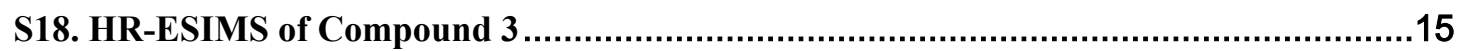

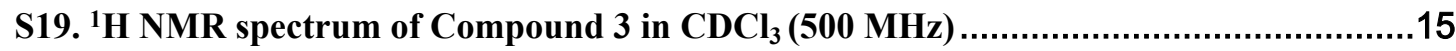

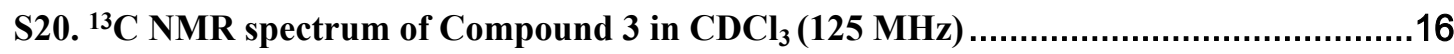

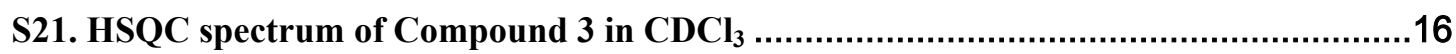

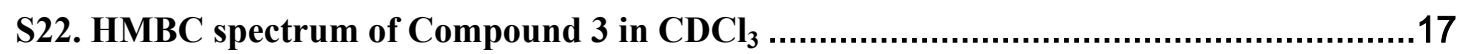

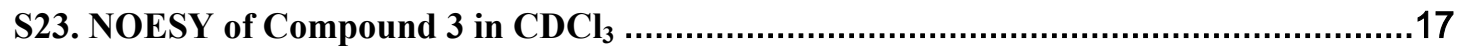

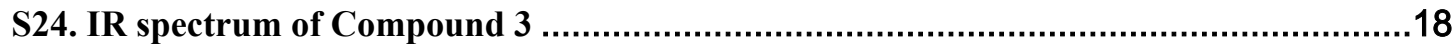

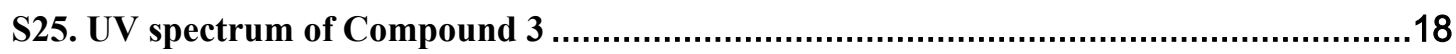

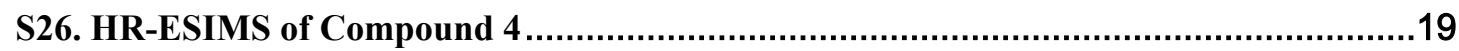

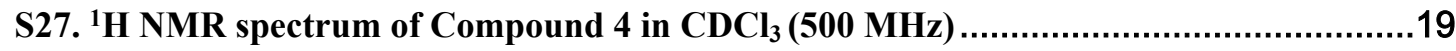

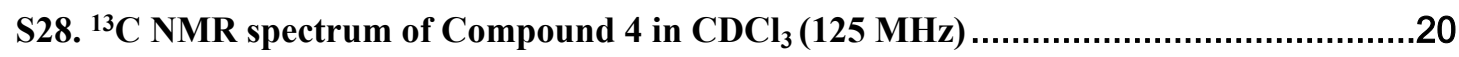

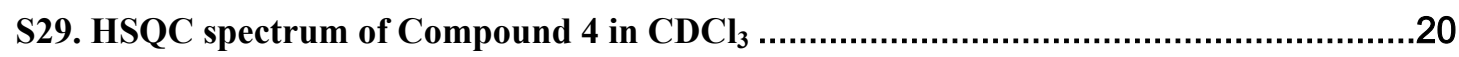

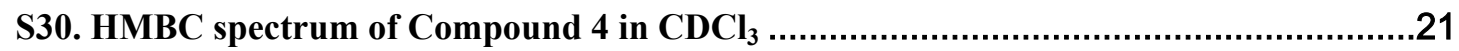

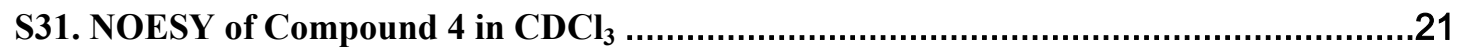

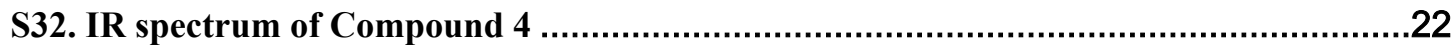

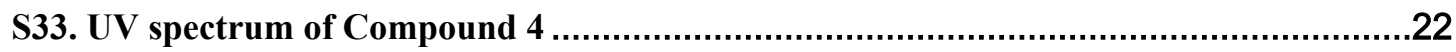

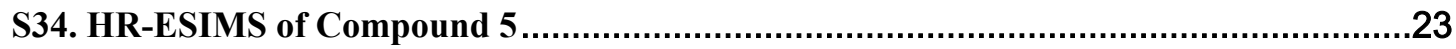


S35. ${ }^{1} \mathrm{H}$ NMR spectrum of Compound 5 in $\mathrm{CDCl}_{3}(500 \mathrm{MHz})$

S36. ${ }^{13} \mathrm{C}$ NMR spectrum of Compound 5 in $\mathrm{CDCl}_{3}(125 \mathrm{MHz})$.

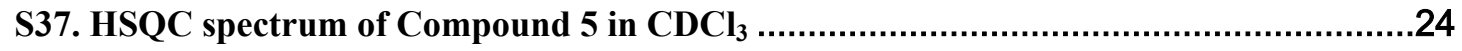

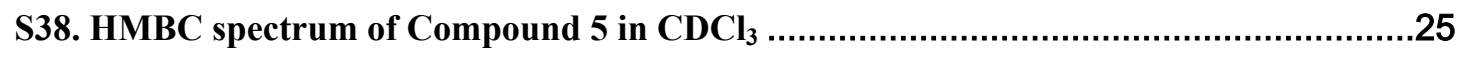

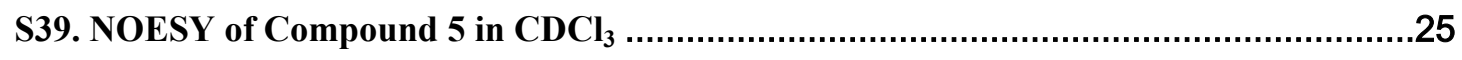

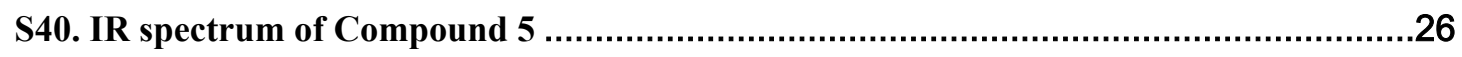

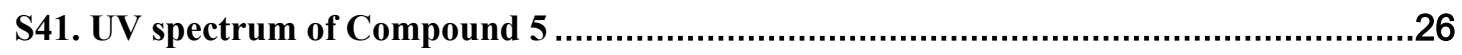

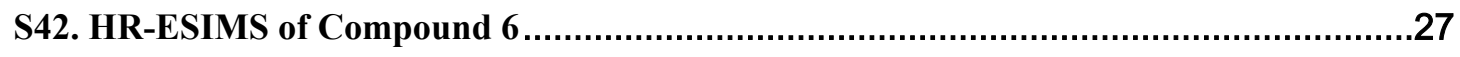

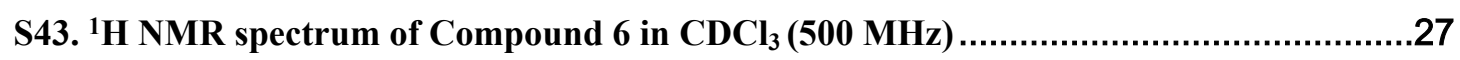

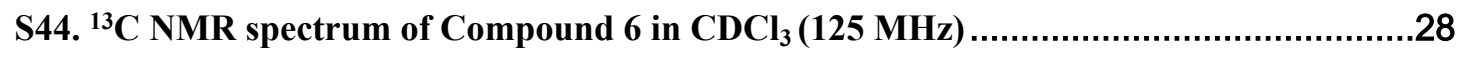

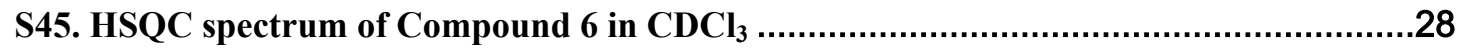

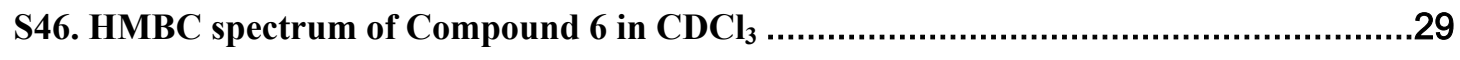

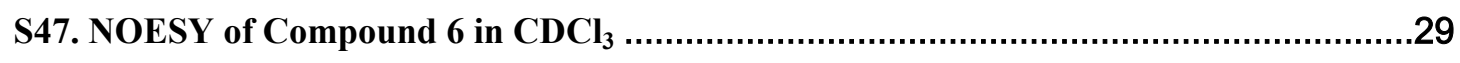

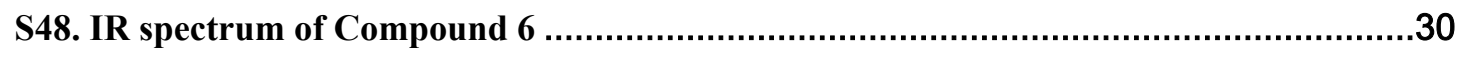

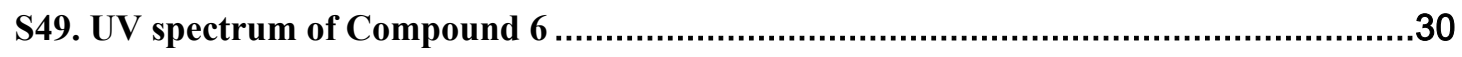

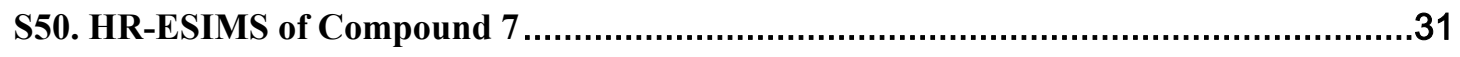

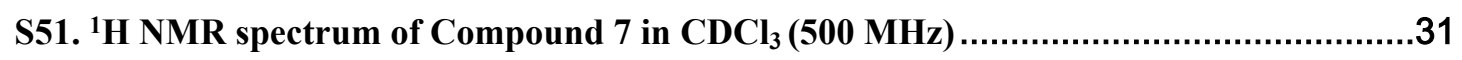

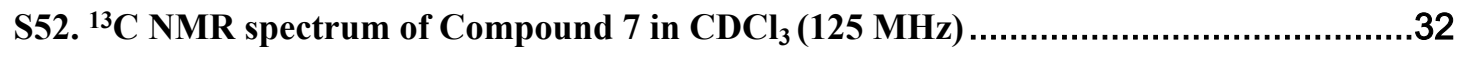

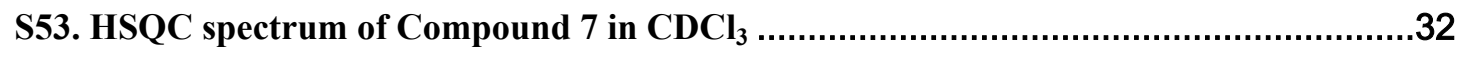

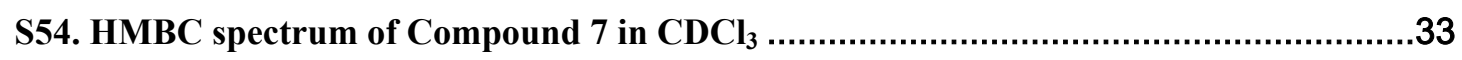

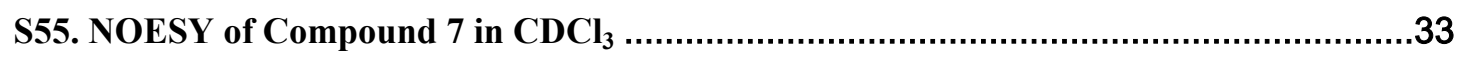

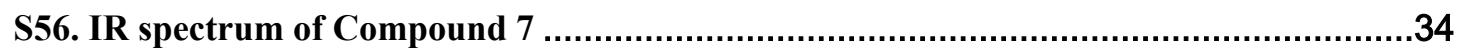


S57. UV spectrum of Compound 7

S58. HR-ESIMS of Compound 8

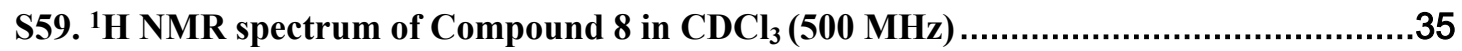

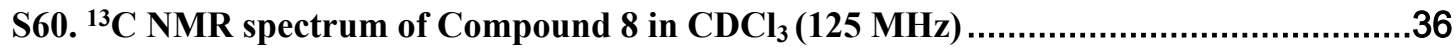

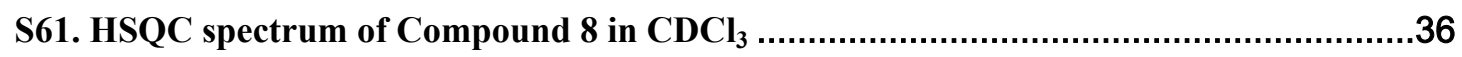

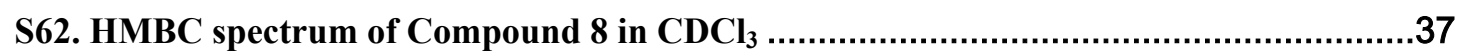

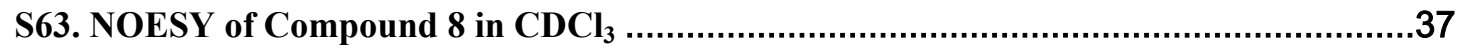

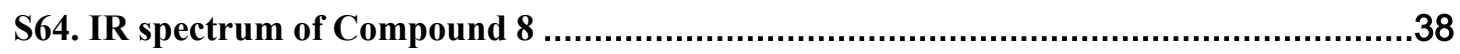

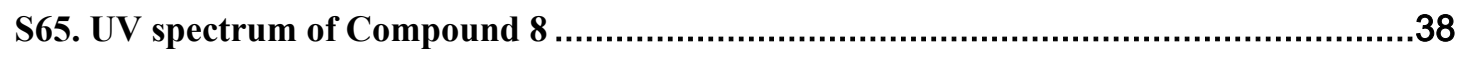

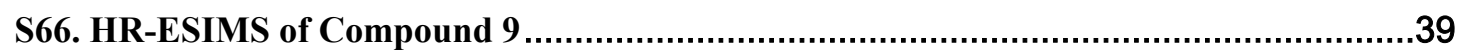

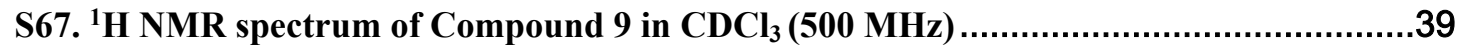

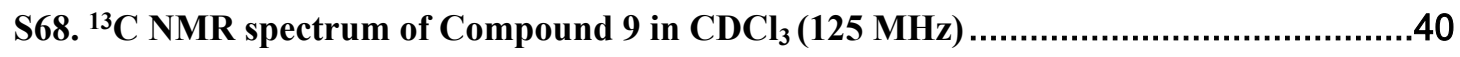

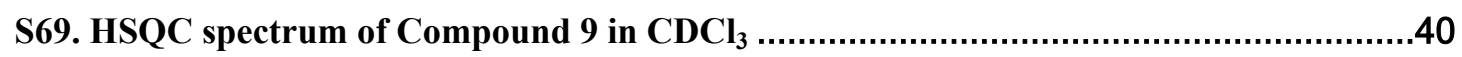

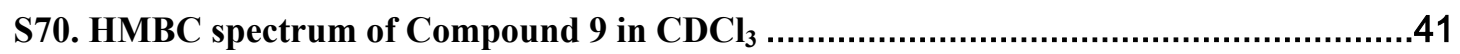

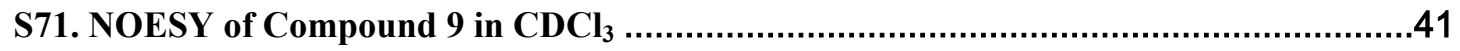

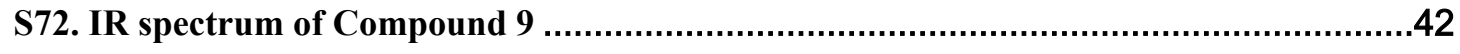

S73. UV spectrum of Compound 9 .........................................................................42

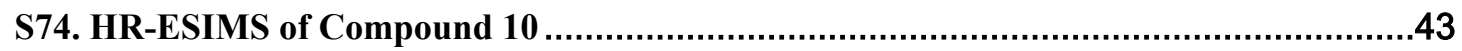

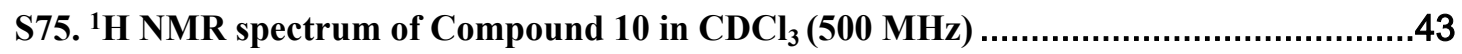

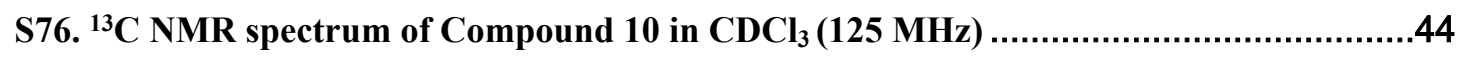

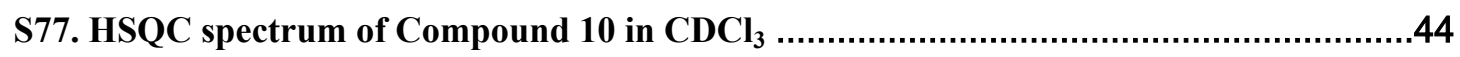

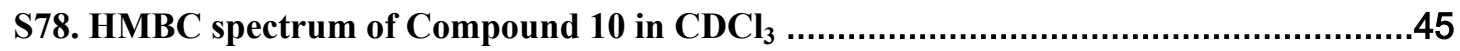


S79. NOESY of Compound 10 in $\mathrm{CDCl}_{3}$

S80. IR spectrum of Compound 10

S81. UV spectrum of Compound 10 .46

S82. HR-ESIMS of Compound 11 47

S83. ${ }^{1} \mathrm{H}$ NMR spectrum of Compound 11 in $\mathrm{CDCl}_{3}(500 \mathrm{MHz})$ 47

S84. ${ }^{13} \mathrm{C}$ NMR spectrum of Compound 11 in $\mathrm{CDCl}_{3}(125 \mathrm{MHz})$ .48

S85. HSQC spectrum of Compound 11 in $\mathrm{CDCl}_{3}$ .48

S86. HMBC spectrum of Compound 11 in $\mathrm{CDCl}_{3}$ 49

S87. NOESY of Compound 11 in $\mathrm{CDCl}_{3}$ .49

S88. IR spectrum of Compound 11 50

S89. UV spectrum of Compound 11 .50

S90. HR-ESIMS of Compound 12 51

S91. ${ }^{1} \mathrm{H}$ NMR spectrum of Compound 12 in $\mathrm{CDCl}_{3}(500 \mathrm{MHz})$ 51

S92. ${ }^{13} \mathrm{C}$ NMR spectrum of Compound 12 in $\mathrm{CDCl}_{3}(125 \mathrm{MHz})$ .52

S93. HSQC spectrum of Compound 12 in $\mathrm{CDCl}_{3}$ 52

S94. HMBC spectrum of Compound 12 in $\mathrm{CDCl}_{3}$ .53

S95. NOESY of Compound 12 in $\mathrm{CDCl}_{3}$ .53

S96. IR spectrum of Compound 12 .54

S97. UV spectrum of Compound 12 .54

S98. HR-ESIMS of Compound 13 55

S99. ${ }^{1} \mathrm{H}$ NMR spectrum of Compound 13 in $\mathrm{CDCl}_{3}(500 \mathrm{MHz})$ .55

S100. ${ }^{13} \mathrm{C}$ NMR spectrum of Compound 13 in $\mathrm{CDCl}_{3}(125 \mathrm{MHz})$ .56 
S101. HSQC spectrum of Compound 13 in $\mathrm{CDCl}_{3}$

S102. HMBC spectrum of Compound 13 in $\mathrm{CDCl}_{3}$

S103. NOESY of Compound 13 in $\mathrm{CDCl}_{3}$

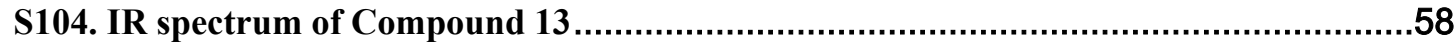

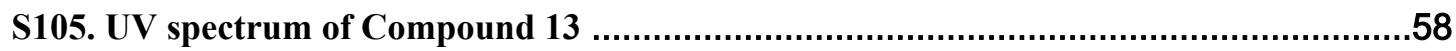

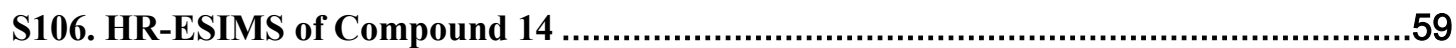

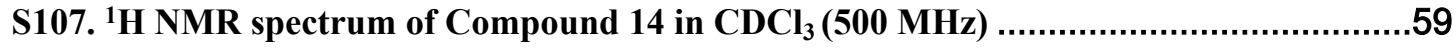

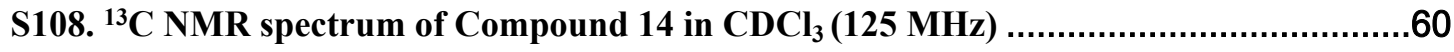

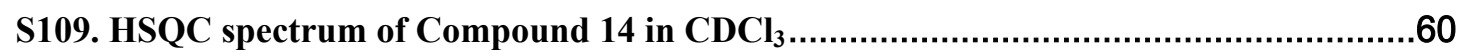

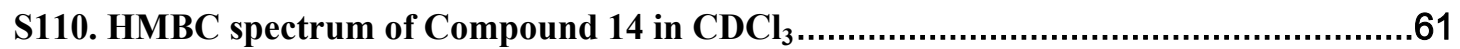

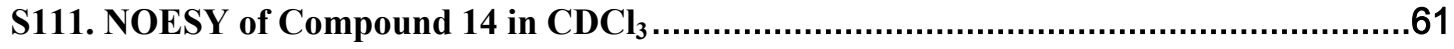

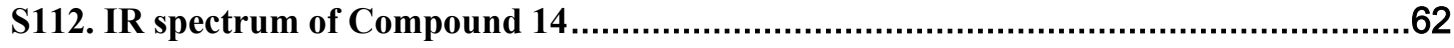

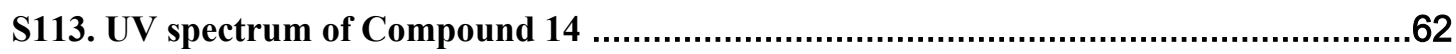

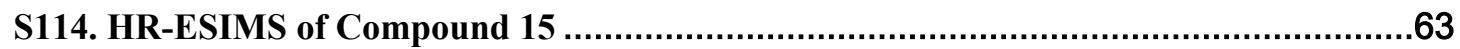

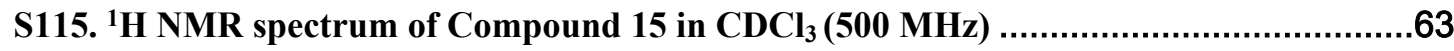

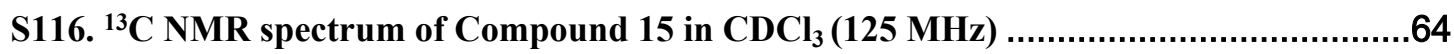

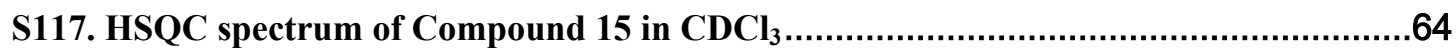

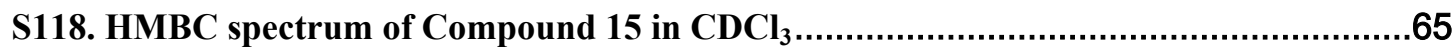

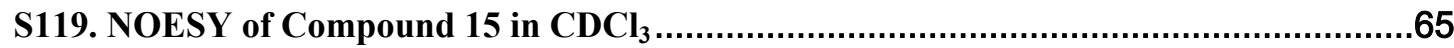

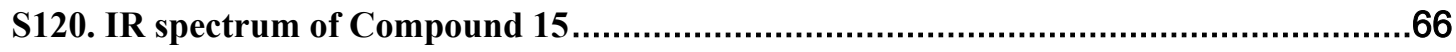

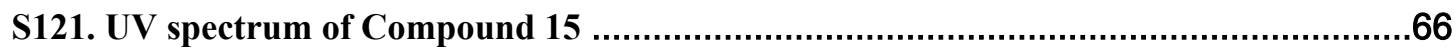

S122. HR-ESIMS of Compound 16 ...................................................................67 
S123. ${ }^{1} \mathrm{H}$ NMR spectrum of Compound 16 in $\mathrm{CDCl}_{3}(500 \mathrm{MHz})$

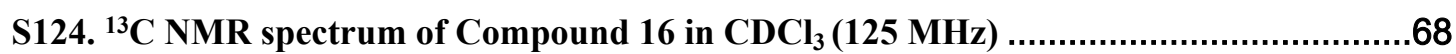

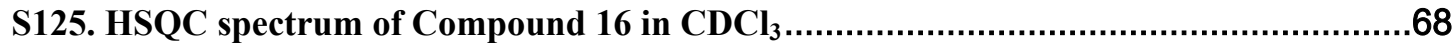

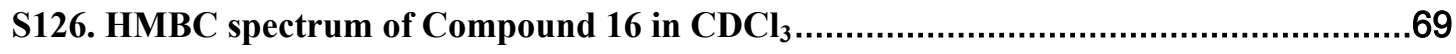

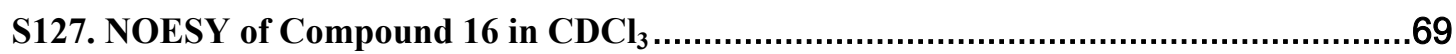

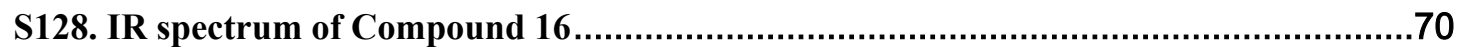

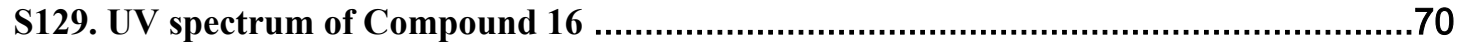

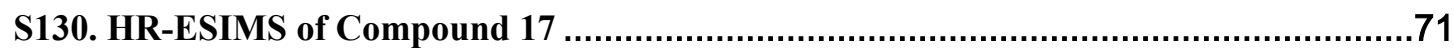

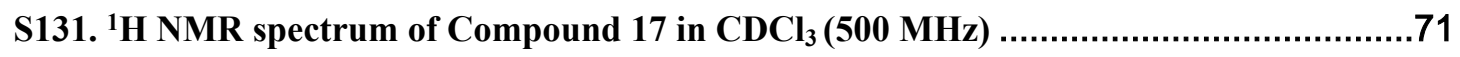

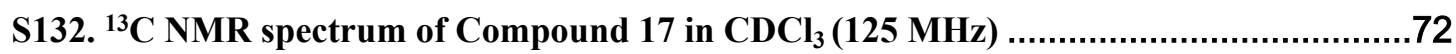

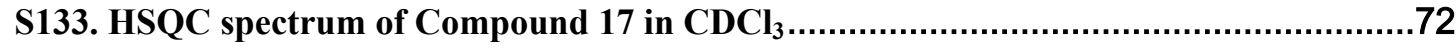

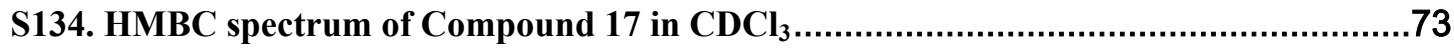

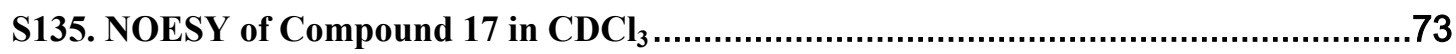

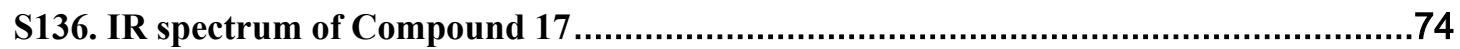

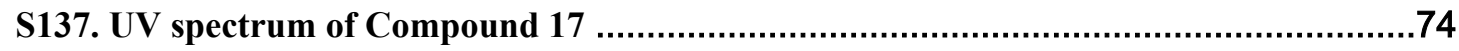

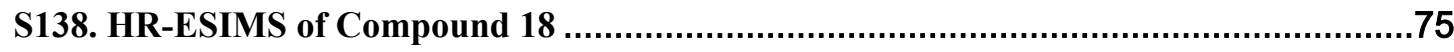

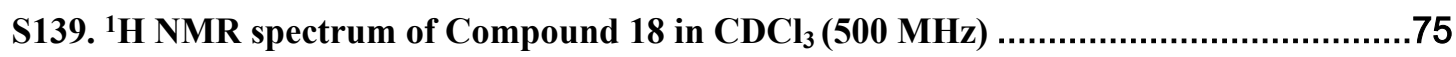

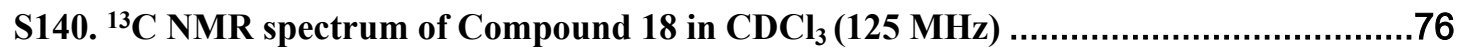

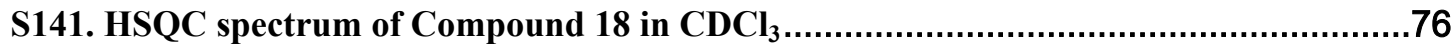

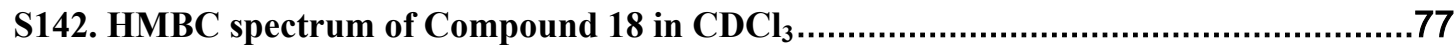

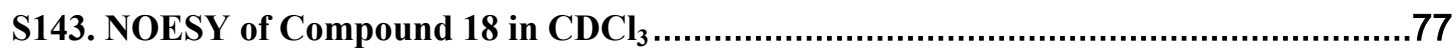

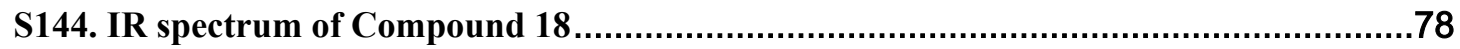


S145. UV spectrum of Compound 18

S146. General Experimental Procedures.

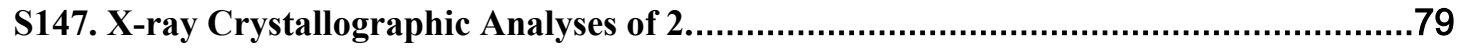

S148. Biological Assay. 81 


\section{S1. HR-ESIMS of Compound 1}

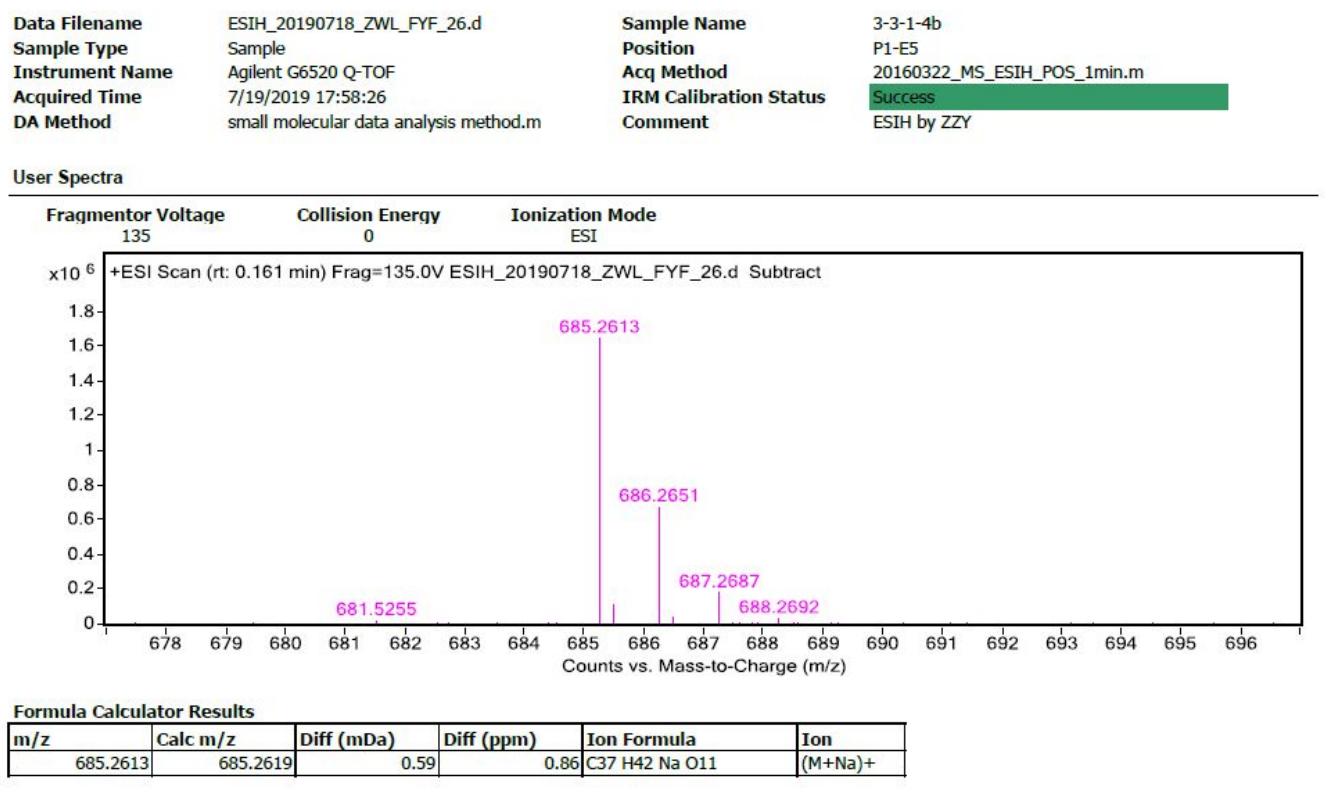

-- End of Report --

S2. ${ }^{1} \mathrm{H}$ NMR spectrum of Compound 1 in $\mathrm{CDCl}_{3}(500 \mathrm{MHz})$

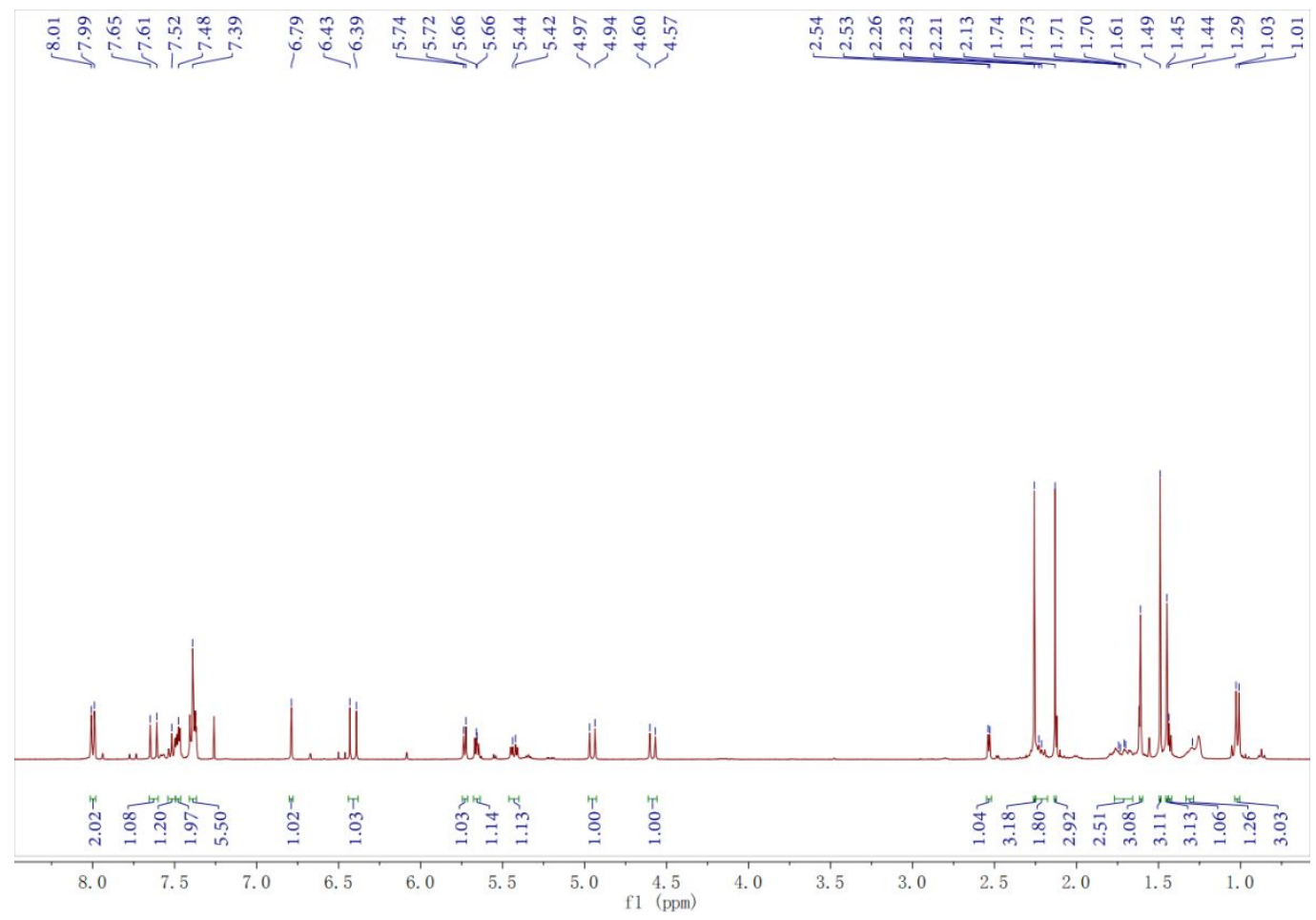


S3. ${ }^{13} \mathrm{C}$ NMR spectrum of Compound 1 in $\mathrm{CDCl}_{3}(125 \mathrm{MHz})$

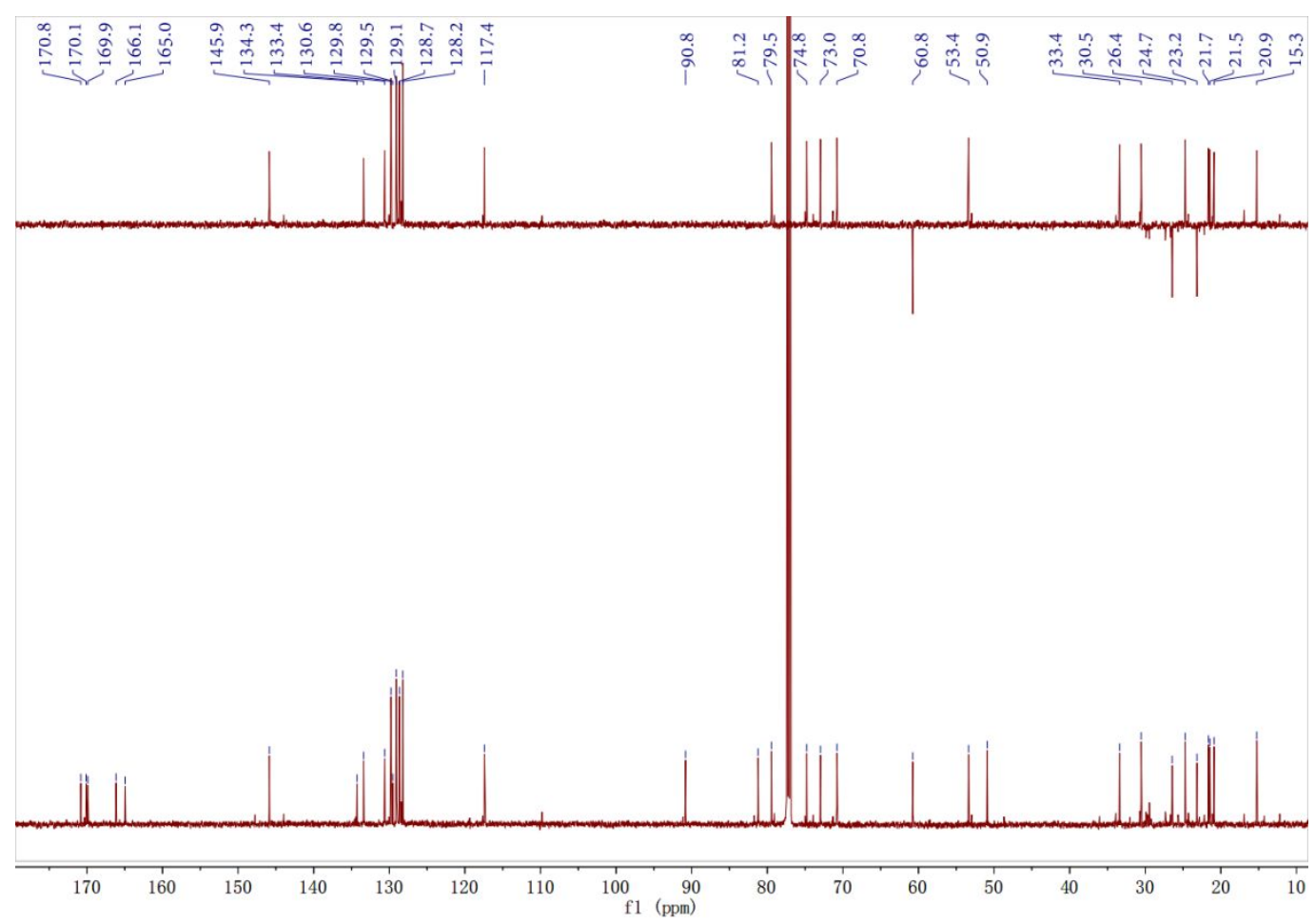

S4. ${ }^{1} \mathrm{H}-{ }^{1} \mathrm{H}$ COSY spectrum of Compound 1 in $\mathrm{CDCl}_{3}$

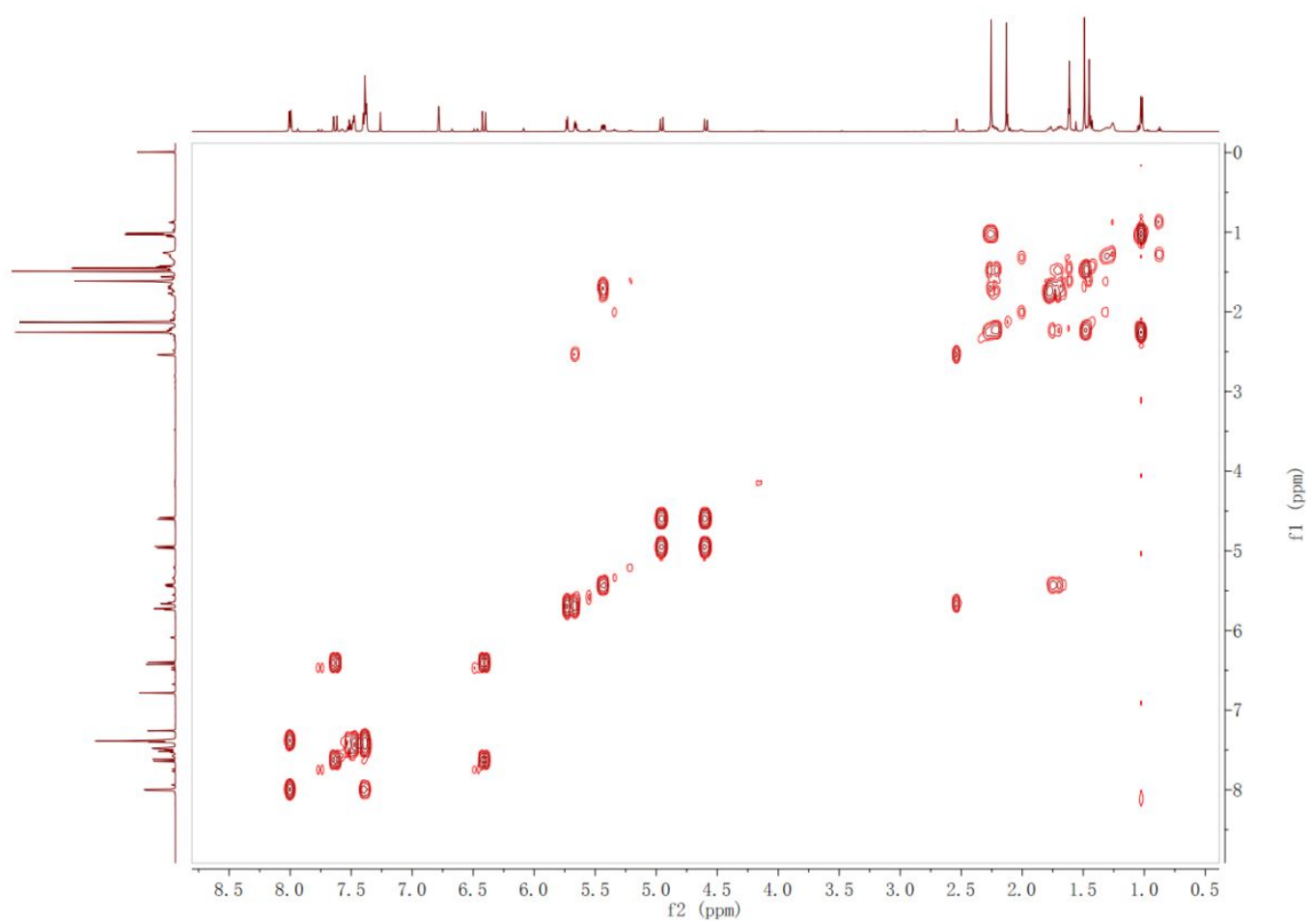


S5. HSQC spectrum of Compound 1 in $\mathrm{CDCl}_{3}$

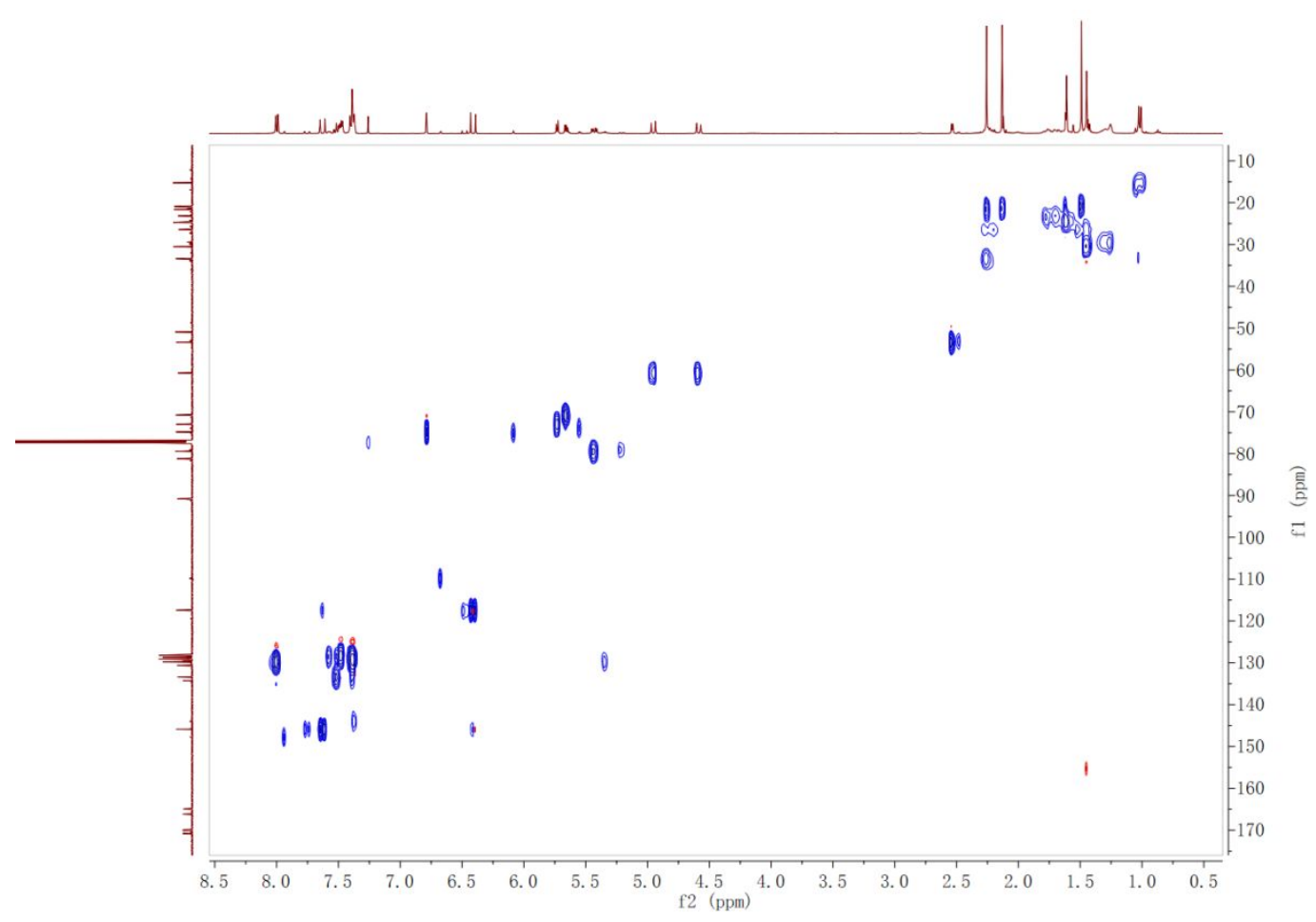

S6. HMBC spectrum of Compound 1 in $\mathrm{CDCl}_{3}$

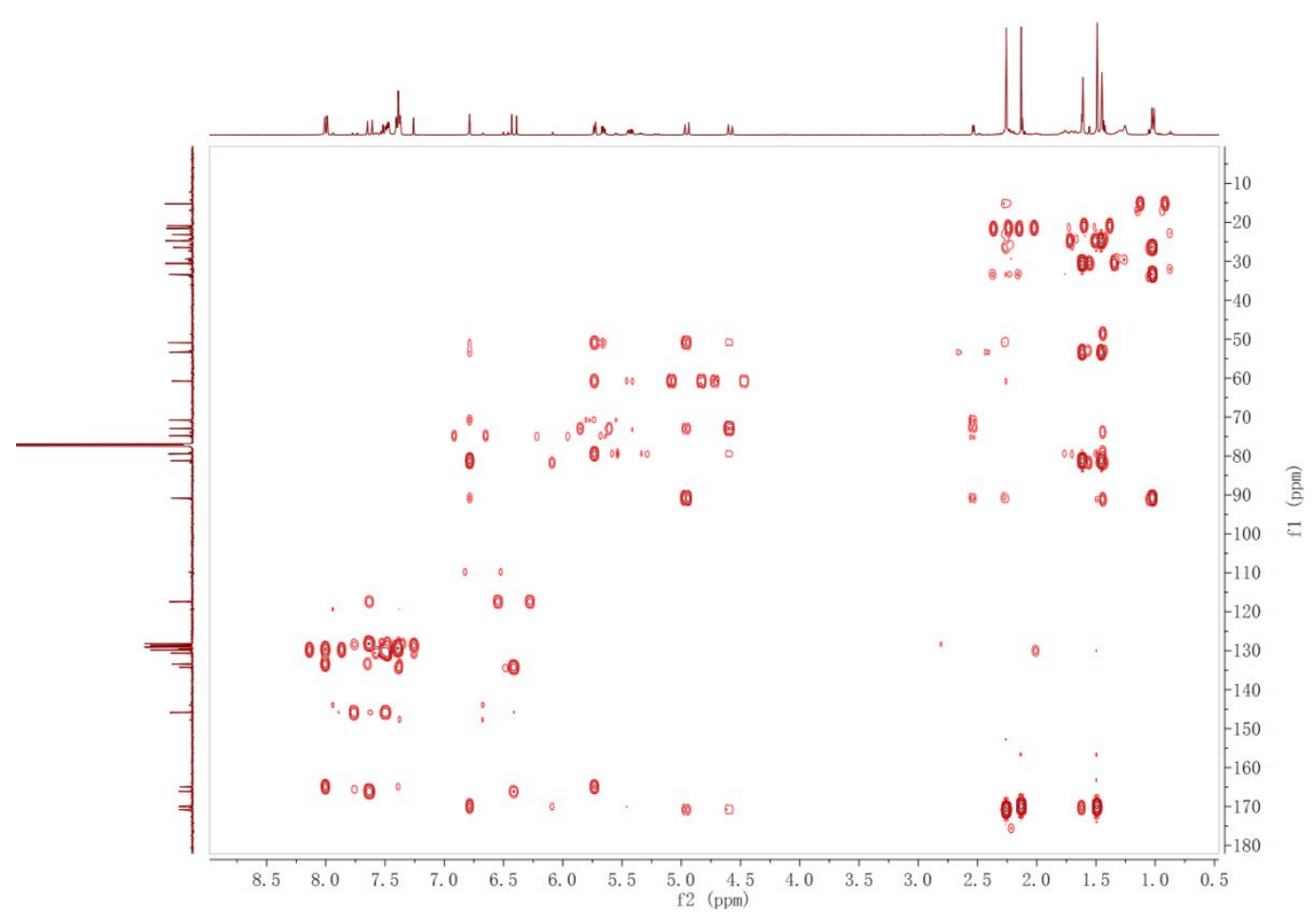


S7. NOESY of Compound 1 in $\mathrm{CDCl}_{3}$

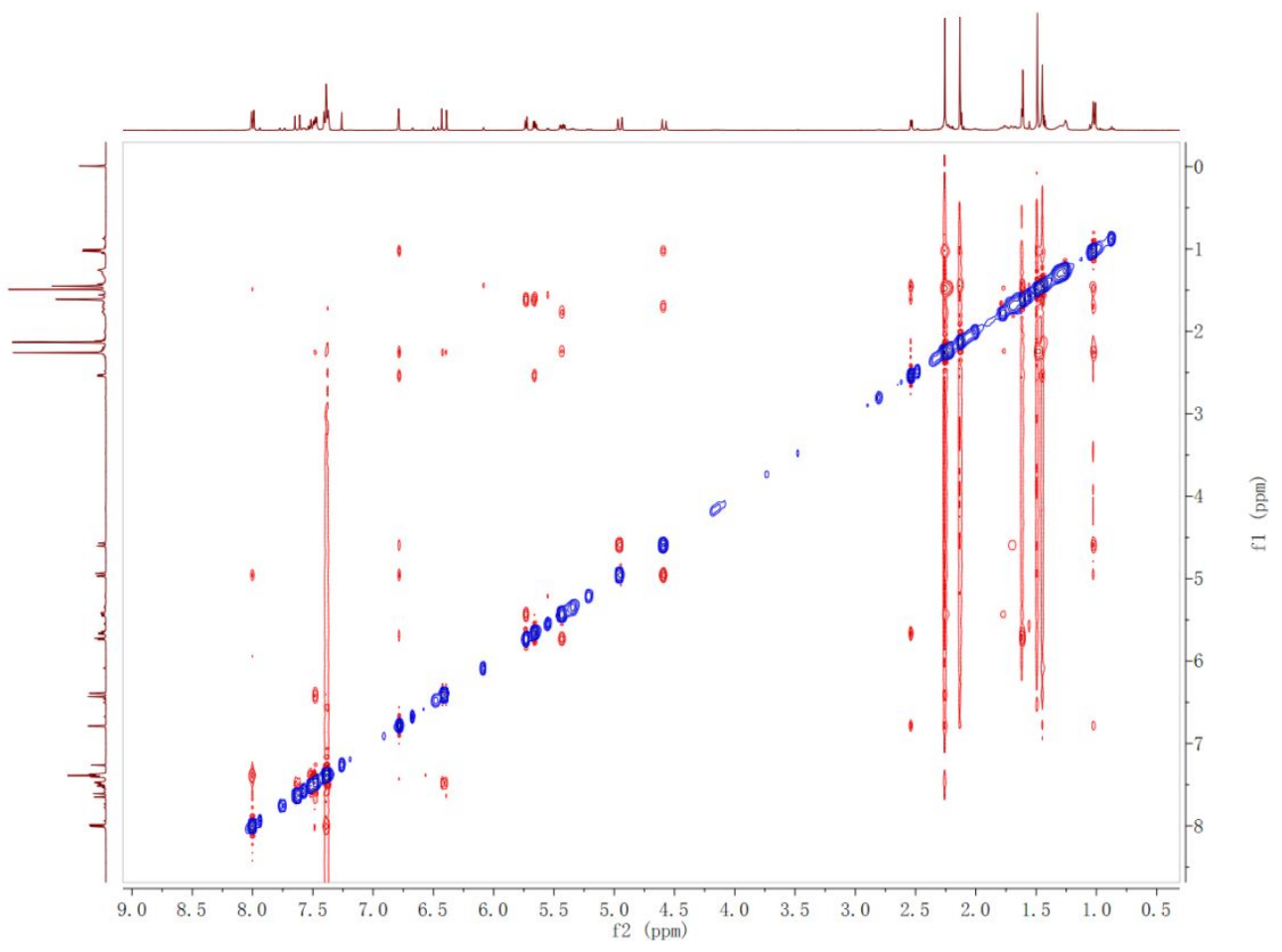

13 
S8. IR spectrum of Compound 1

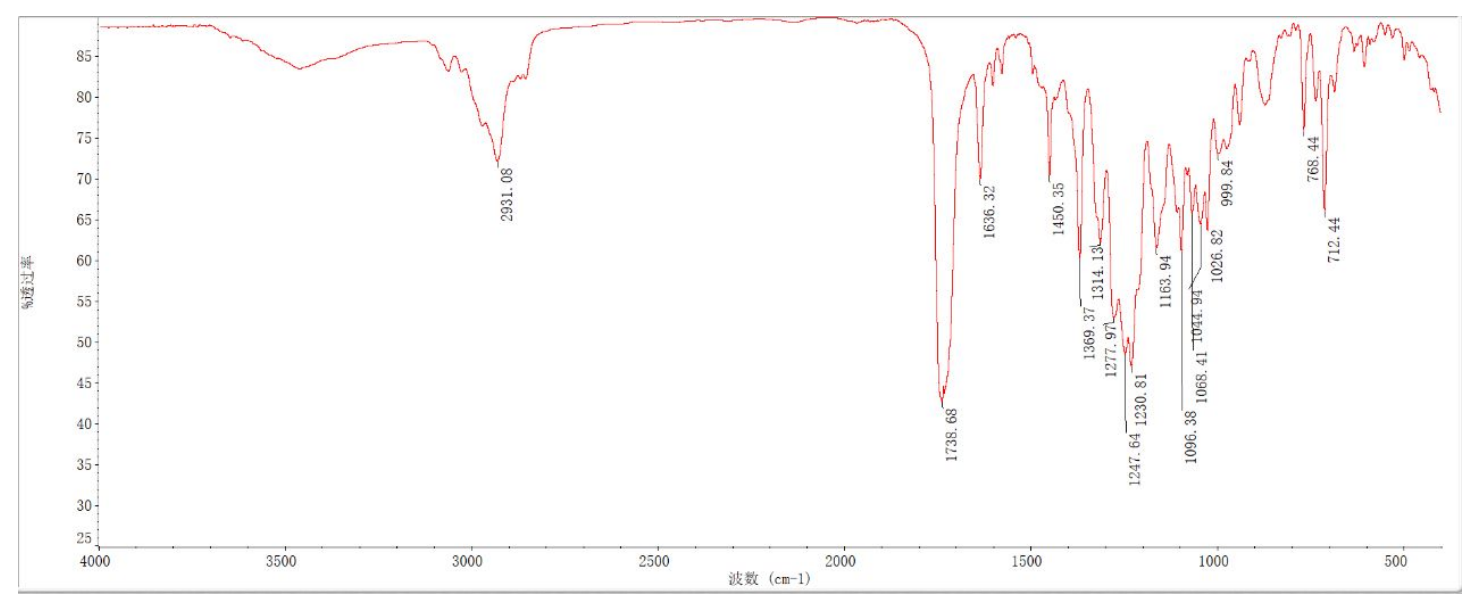

S9. UV spectrum of Compound 1

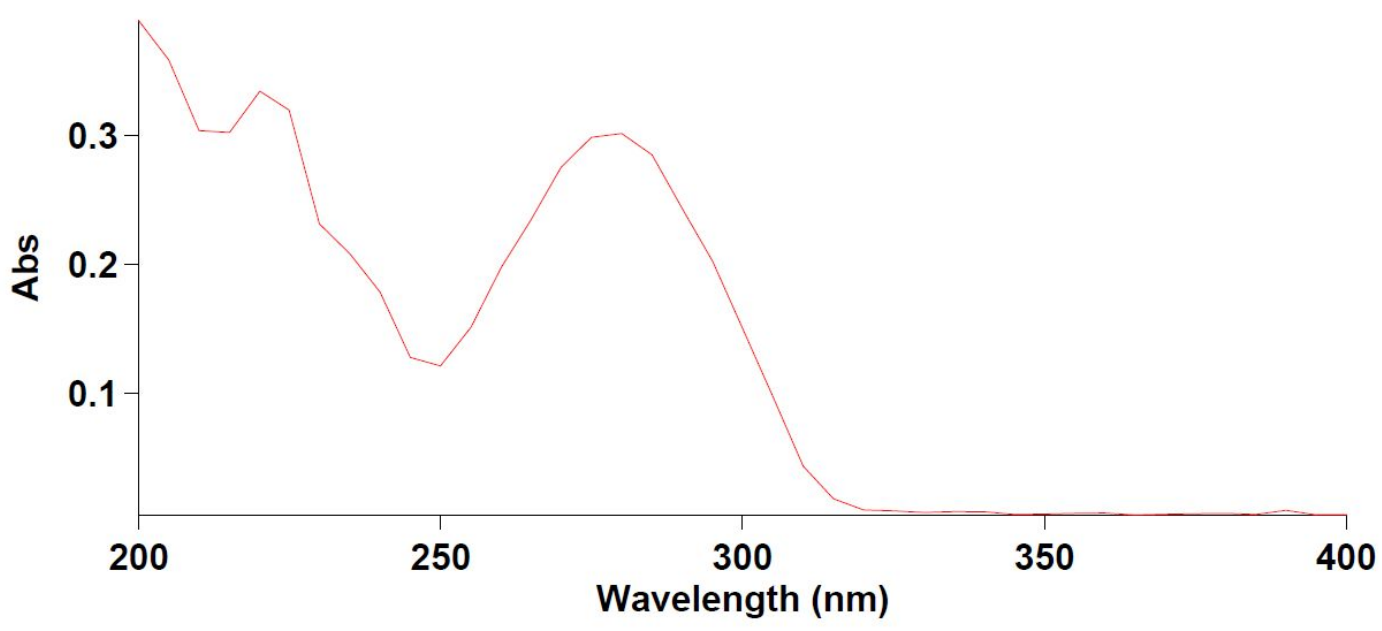


S10. HR-ESIMS of Compound 2

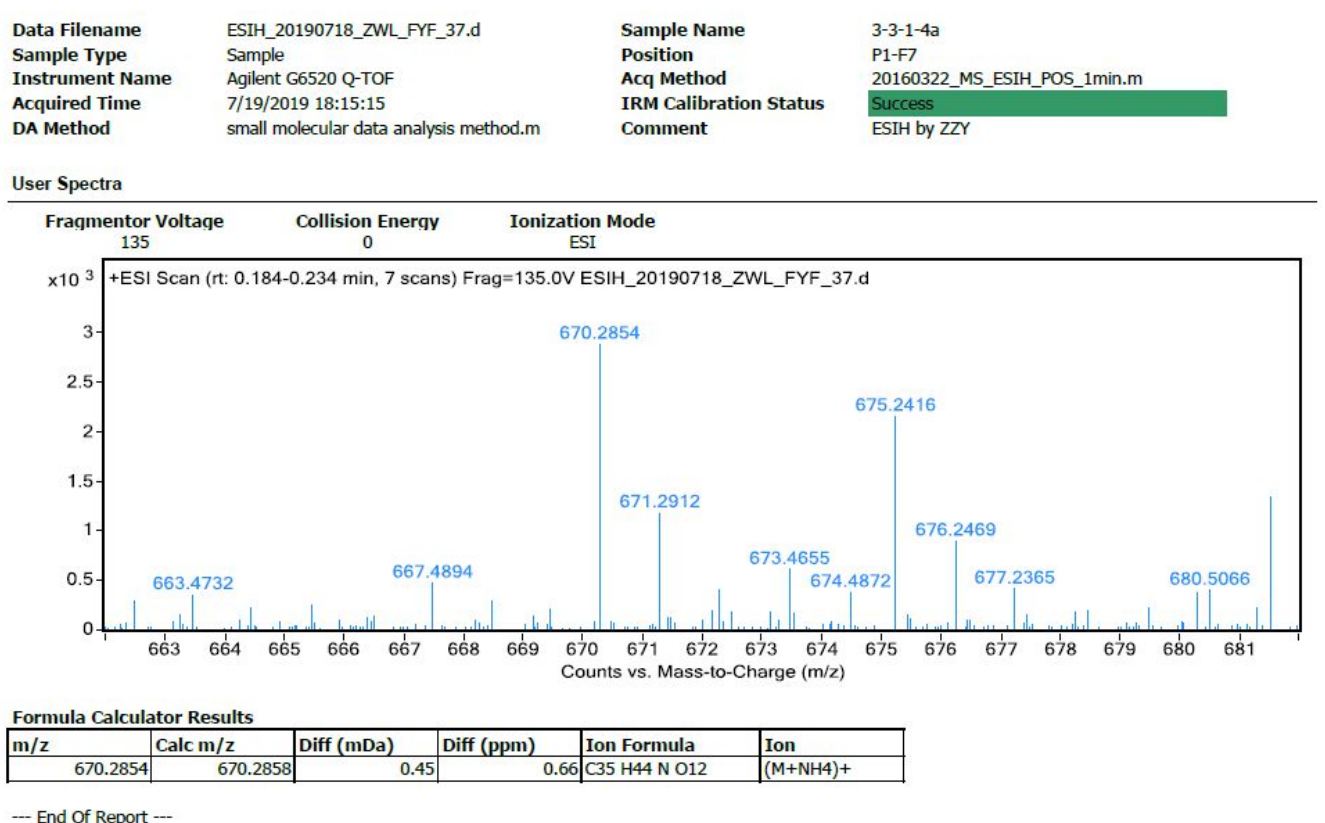

-- End Of Report --

S11. ${ }^{1} \mathrm{H}$ NMR spectrum of Compound 2 in $\mathrm{CDCl}_{3}(500 \mathrm{MHz})$

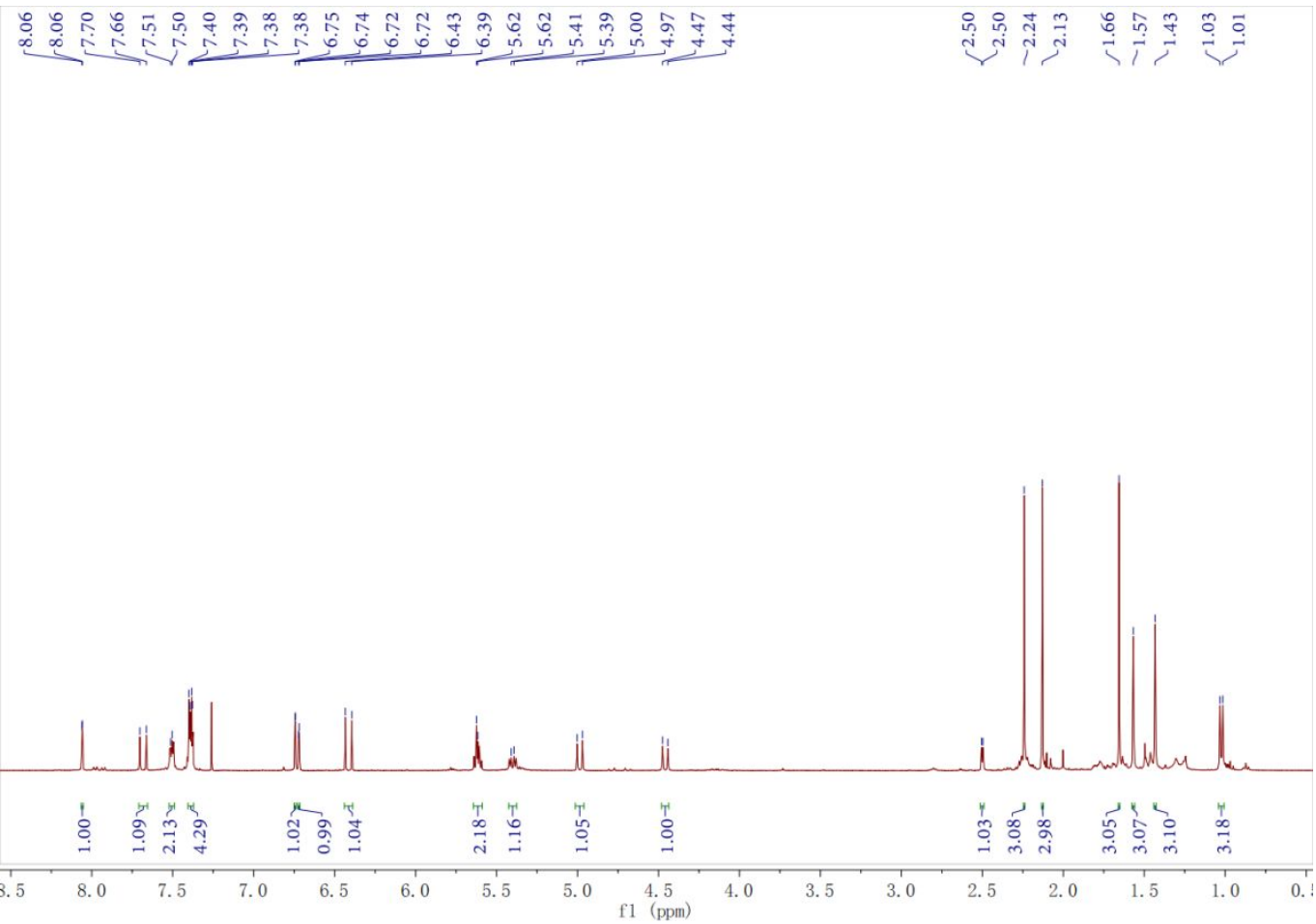


S12. ${ }^{13} \mathrm{C}$ NMR spectrum of Compound 2 in $\mathrm{CDCl}_{3}(125 \mathrm{MHz})$

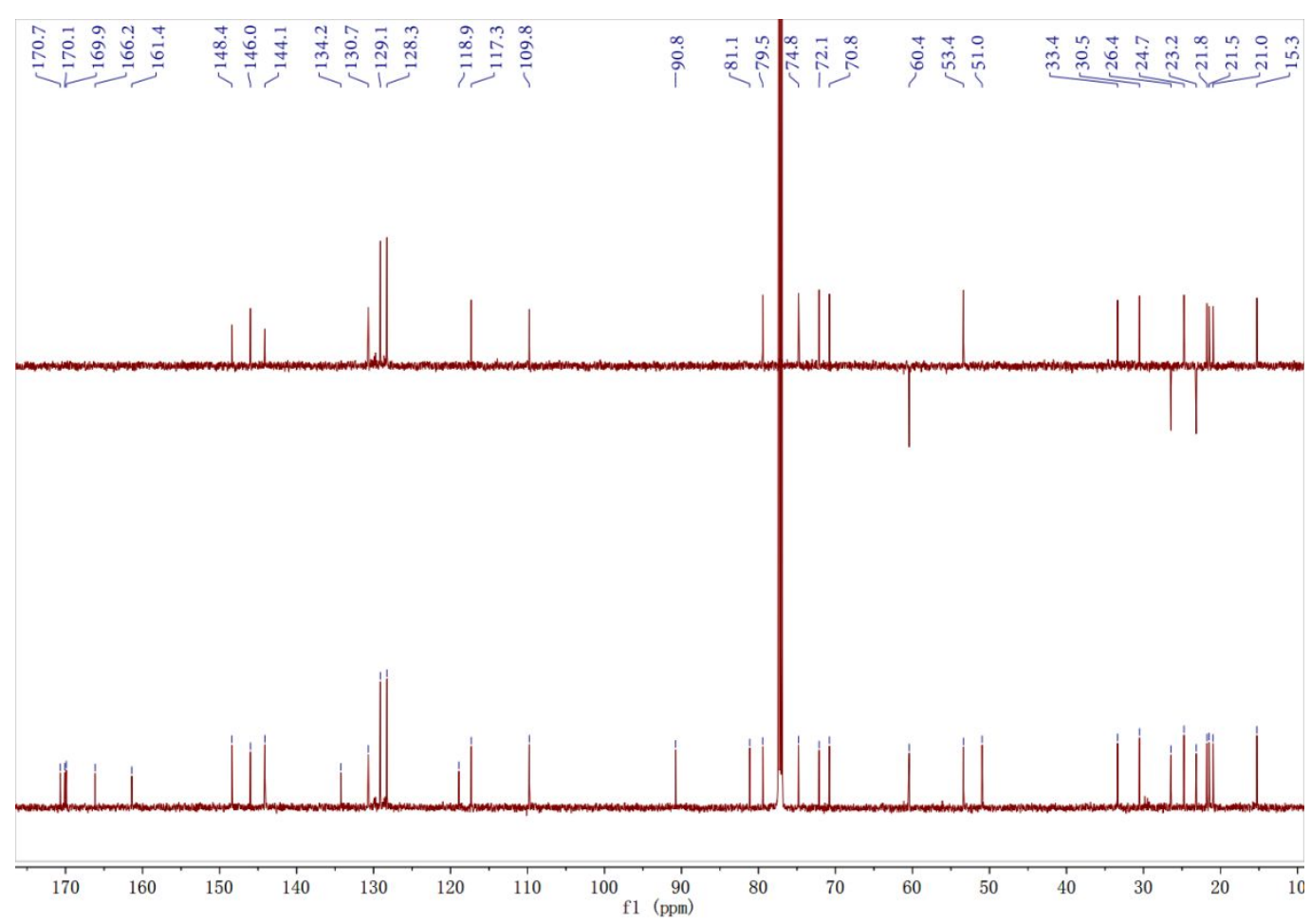


S13. HSQC spectrum of Compound 2 in $\mathrm{CDCl}_{3}$

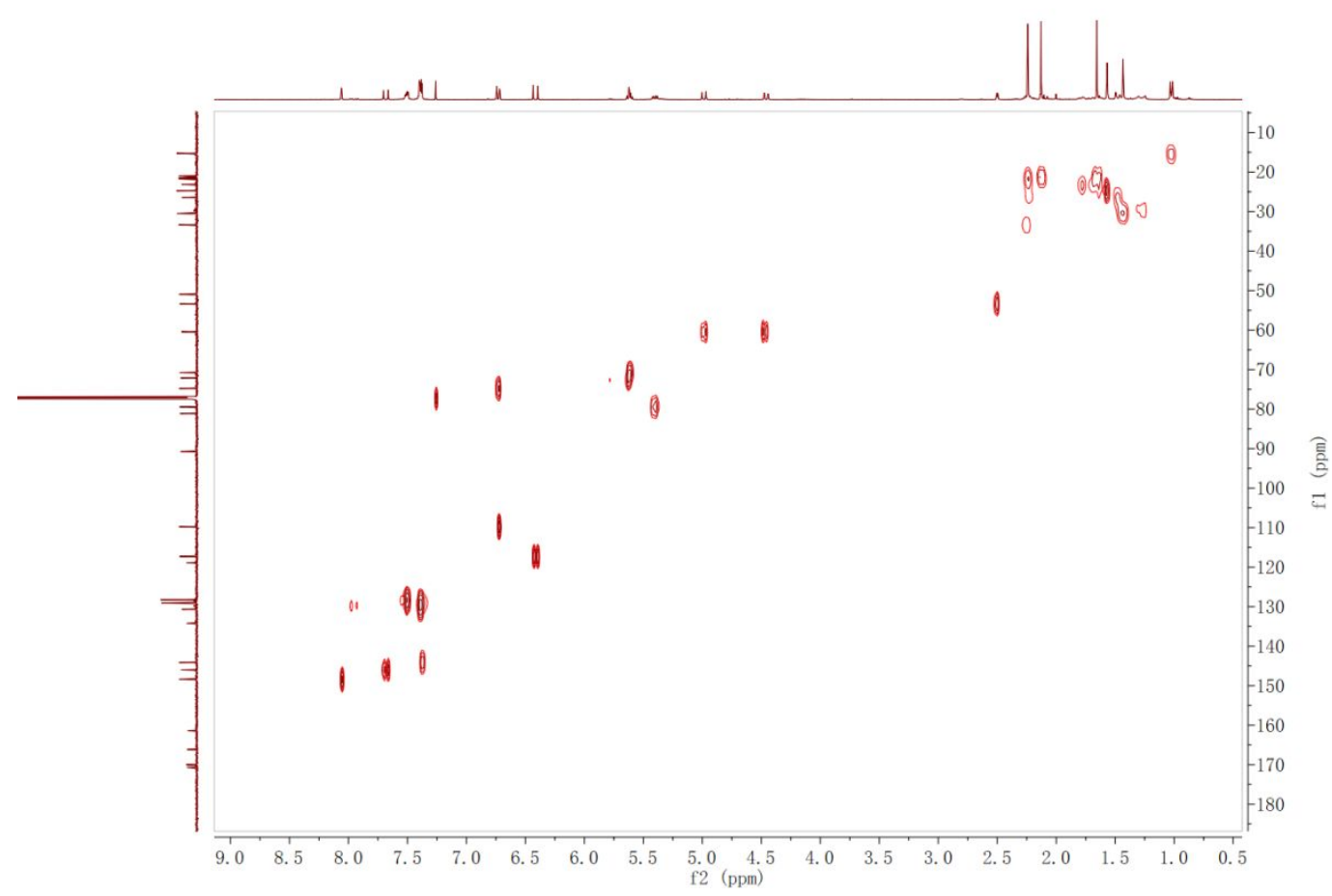

S14. HMBC spectrum of Compound 2 in $\mathrm{CDCl}_{3}$

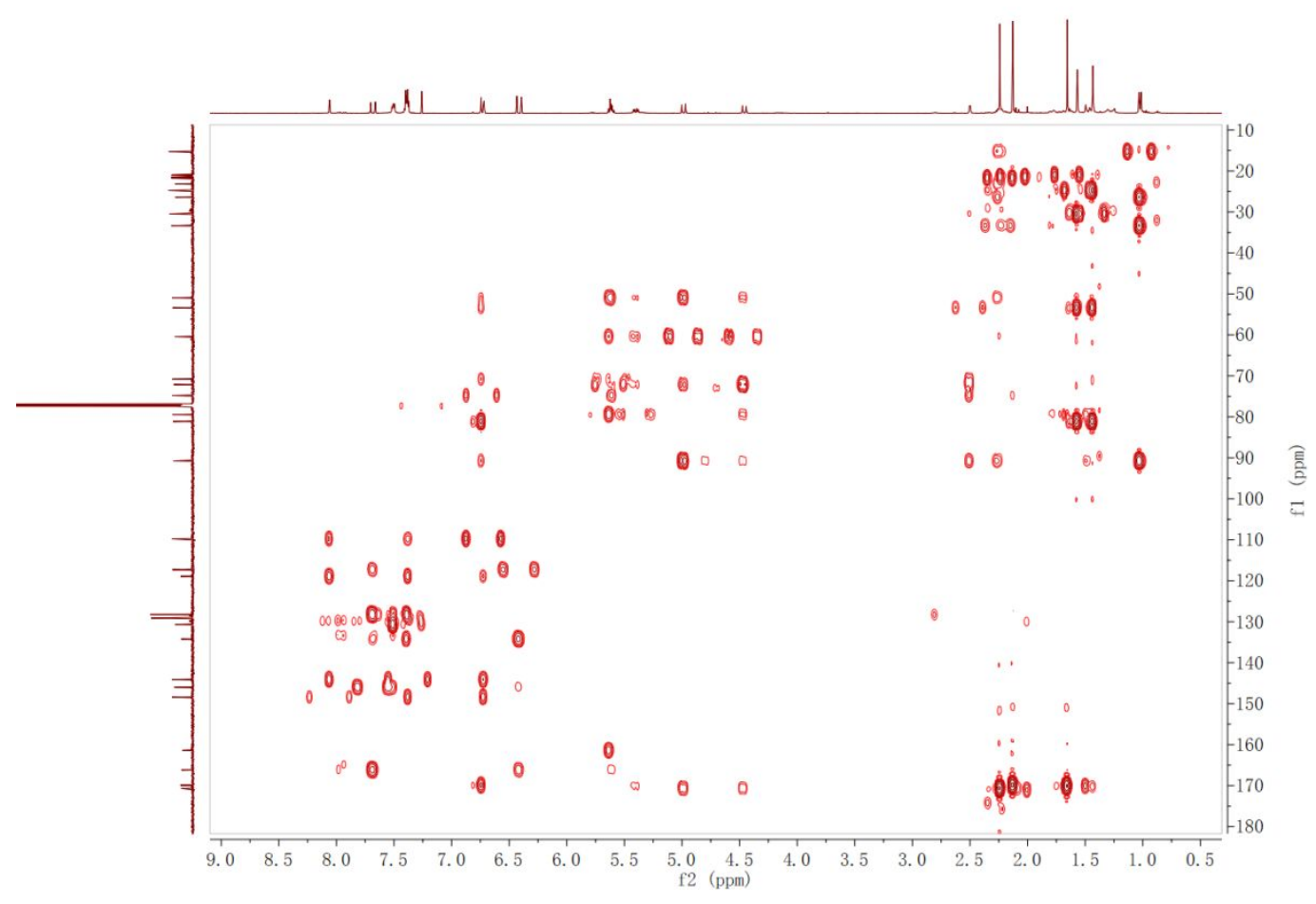


S15. NOESY of Compound 2 in $\mathrm{CDCl}_{3}$

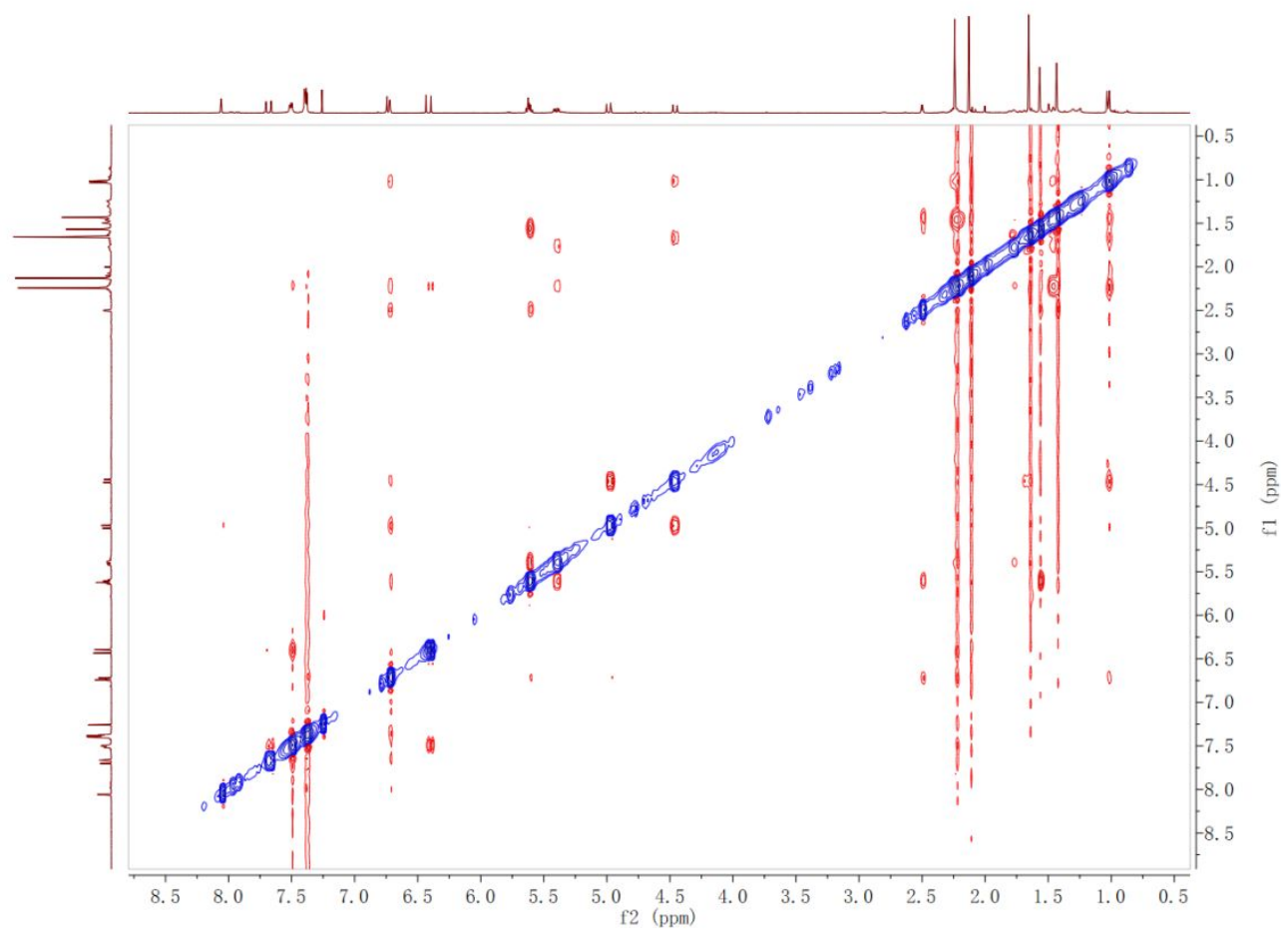

S16. IR spectrum of Compound 2

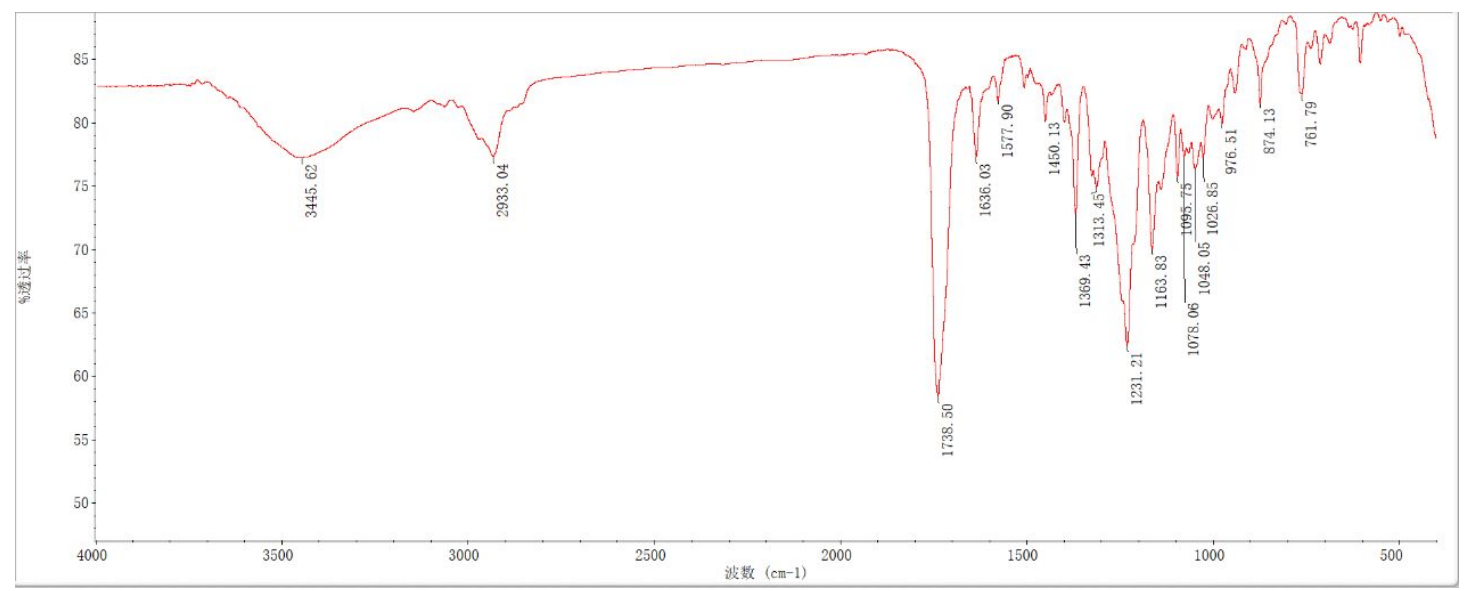


S17. UV spectrum of Compound 2

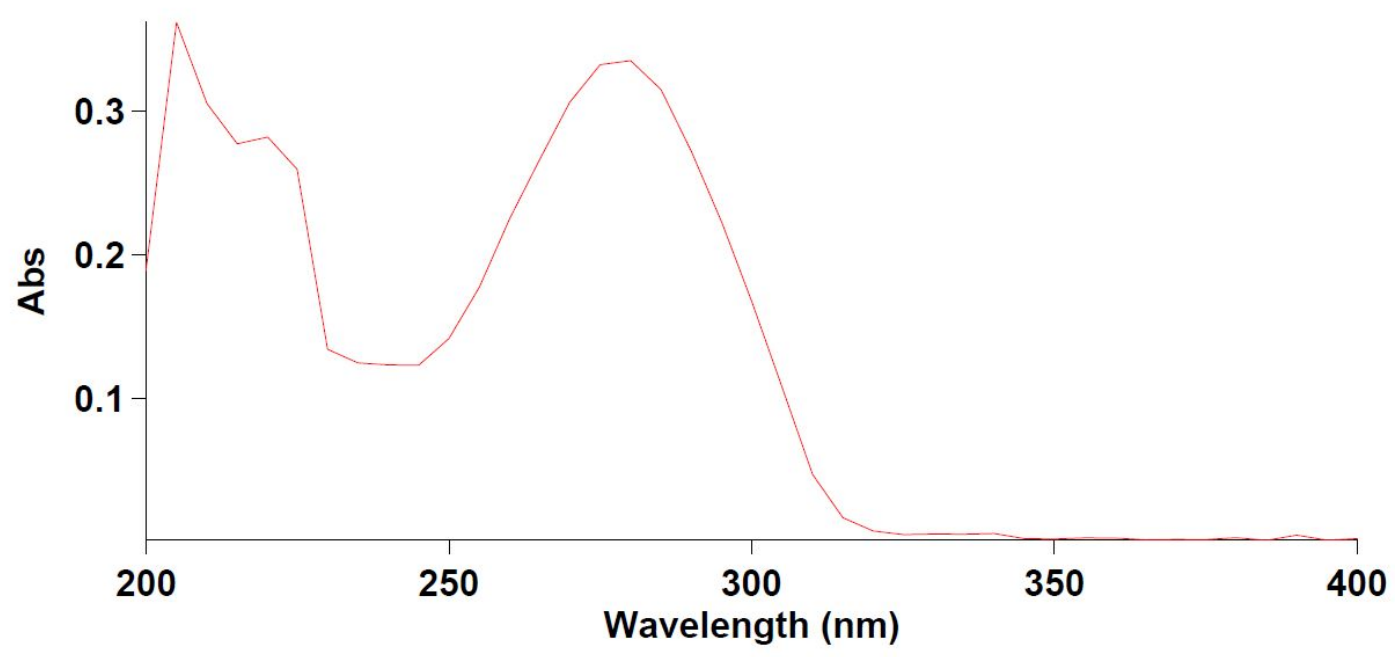

S18. HR-ESIMS of Compound 3

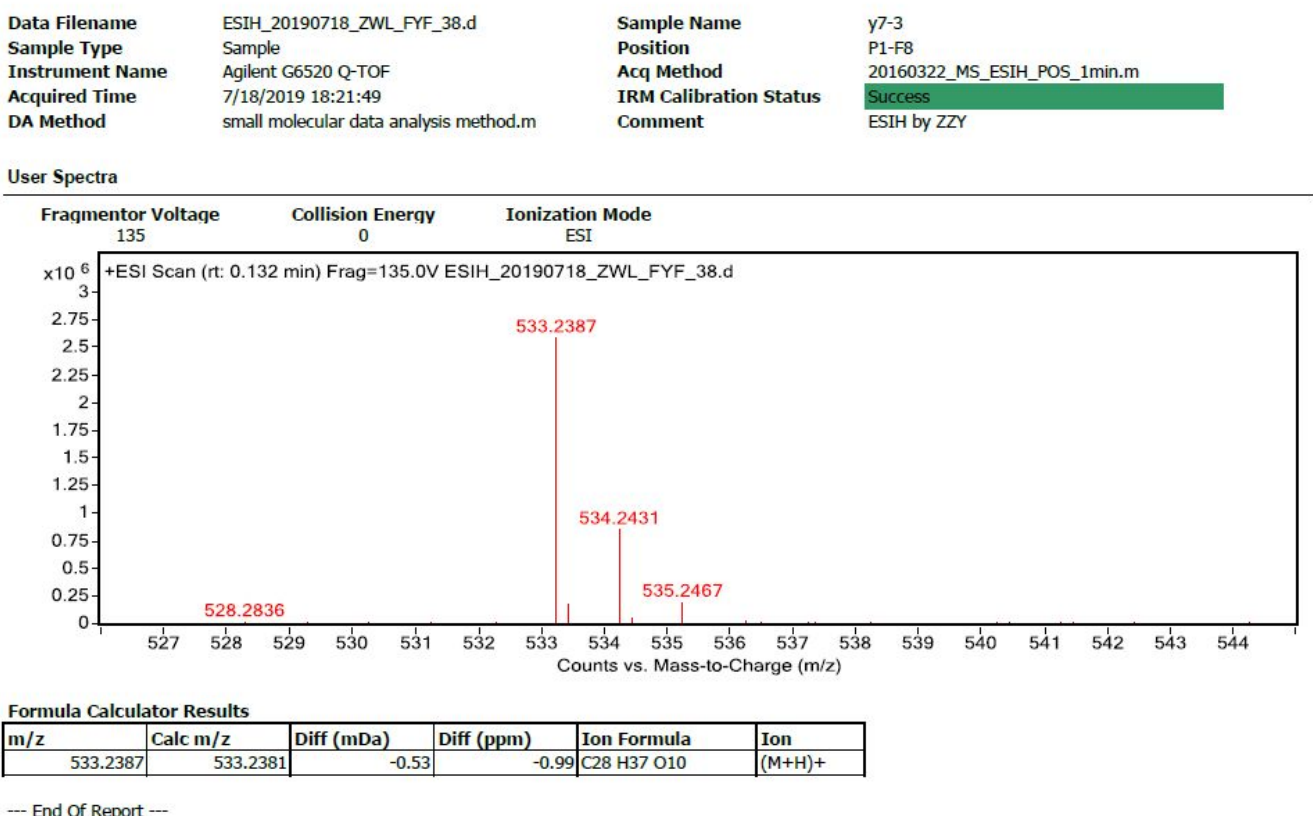


S19. ${ }^{1} \mathrm{H}$ NMR spectrum of Compound 3 in $\mathrm{CDCl}_{3}(500 \mathrm{MHz})$

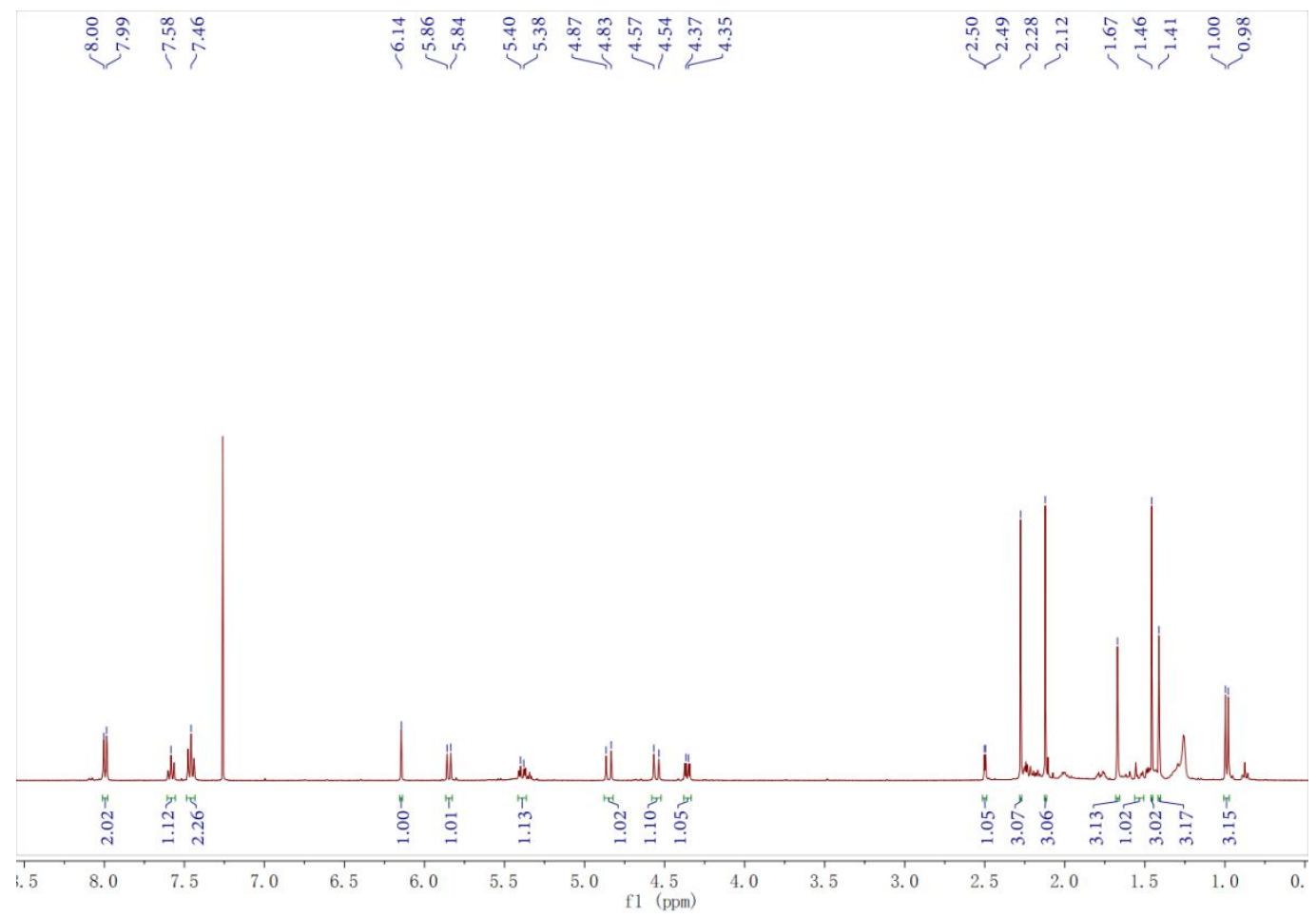


S20. ${ }^{13} \mathrm{C}$ NMR spectrum of Compound 3 in $\mathrm{CDCl}_{3}(125 \mathrm{MHz})$

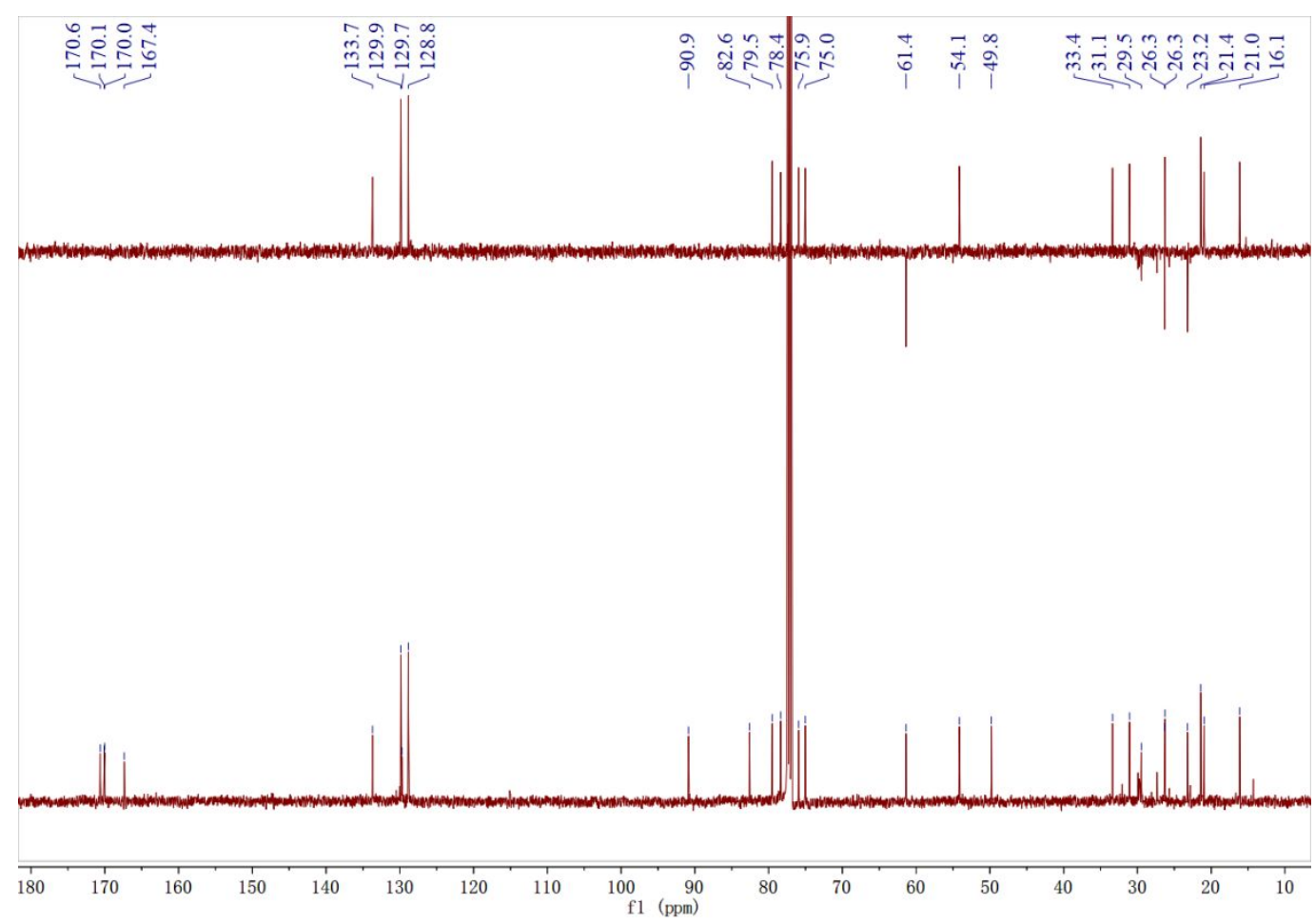

S21. HSQC spectrum of Compound 3 in $\mathrm{CDCl}_{3}$

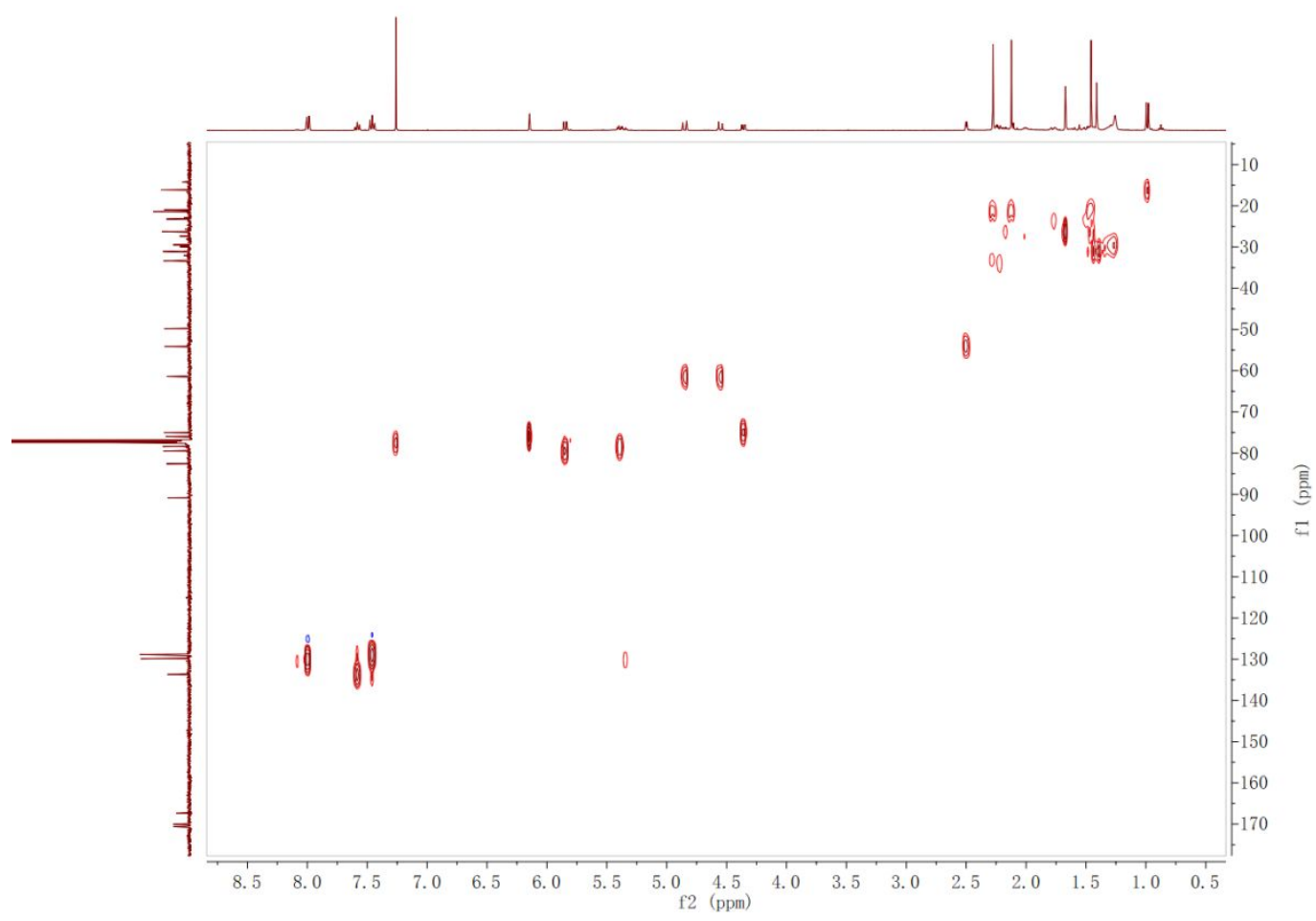


S22. HMBC spectrum of Compound 3 in $\mathrm{CDCl}_{3}$

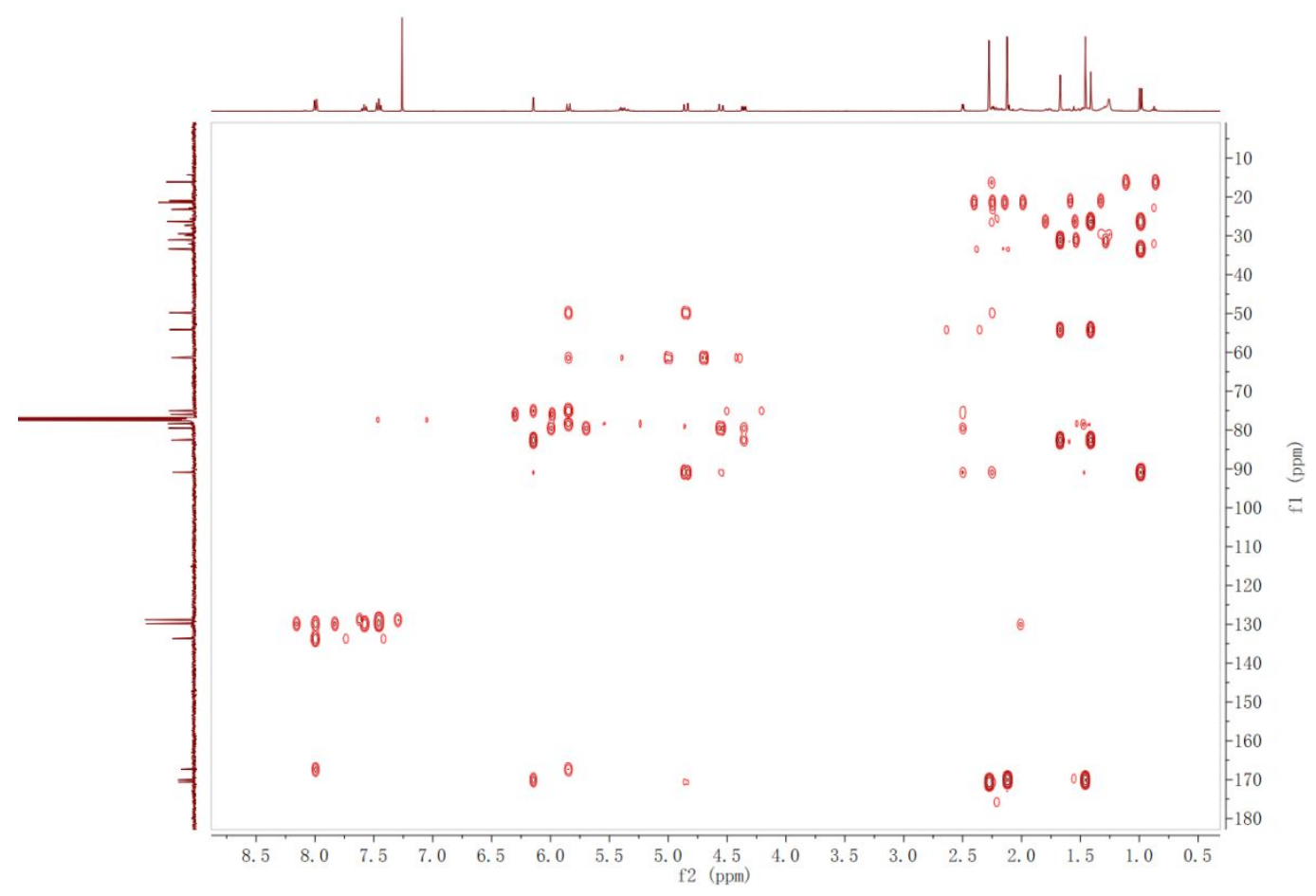

S23. NOESY of Compound 3 in $\mathrm{CDCl}_{3}$

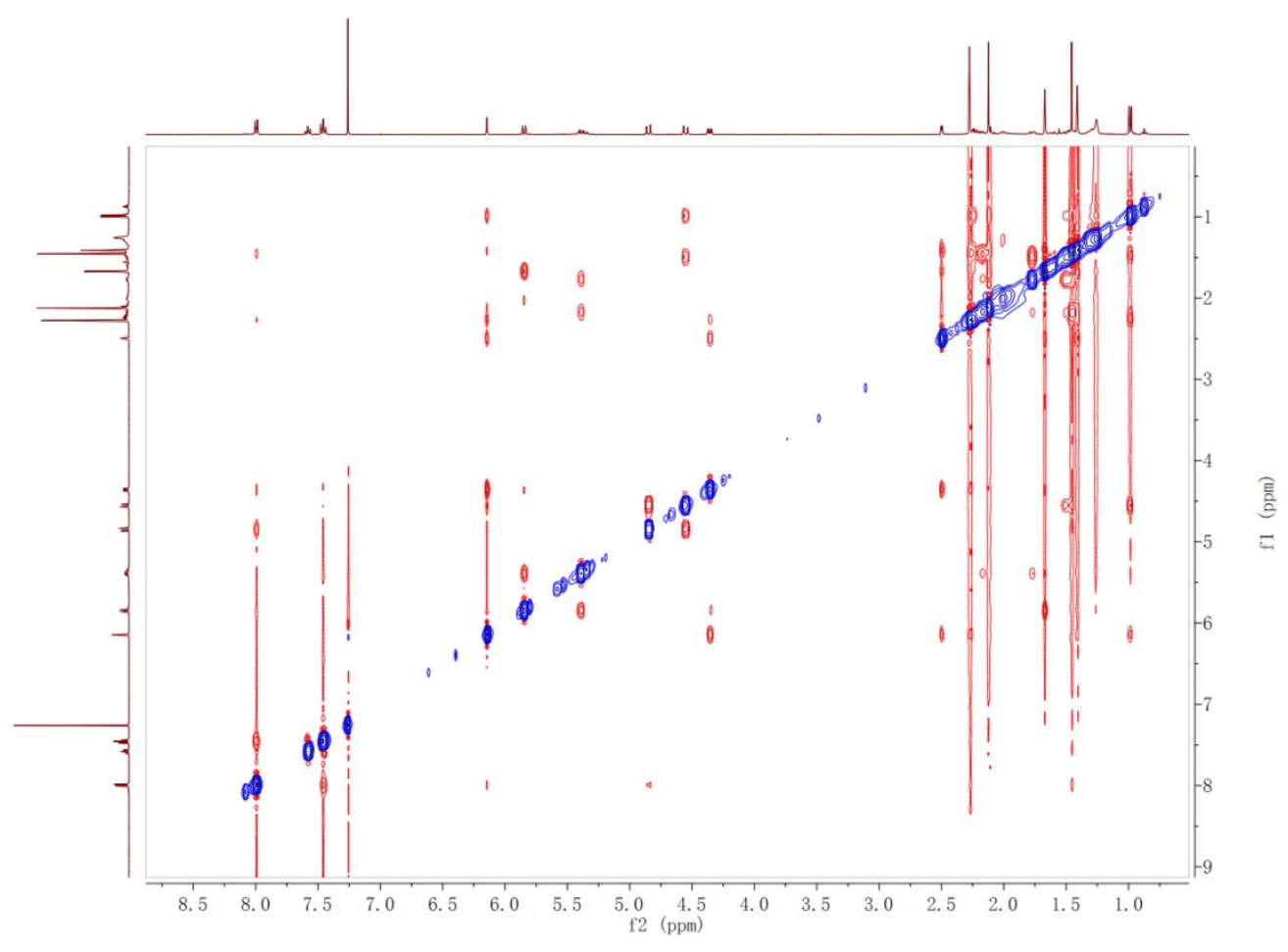


S24. IR spectrum of Compound 3

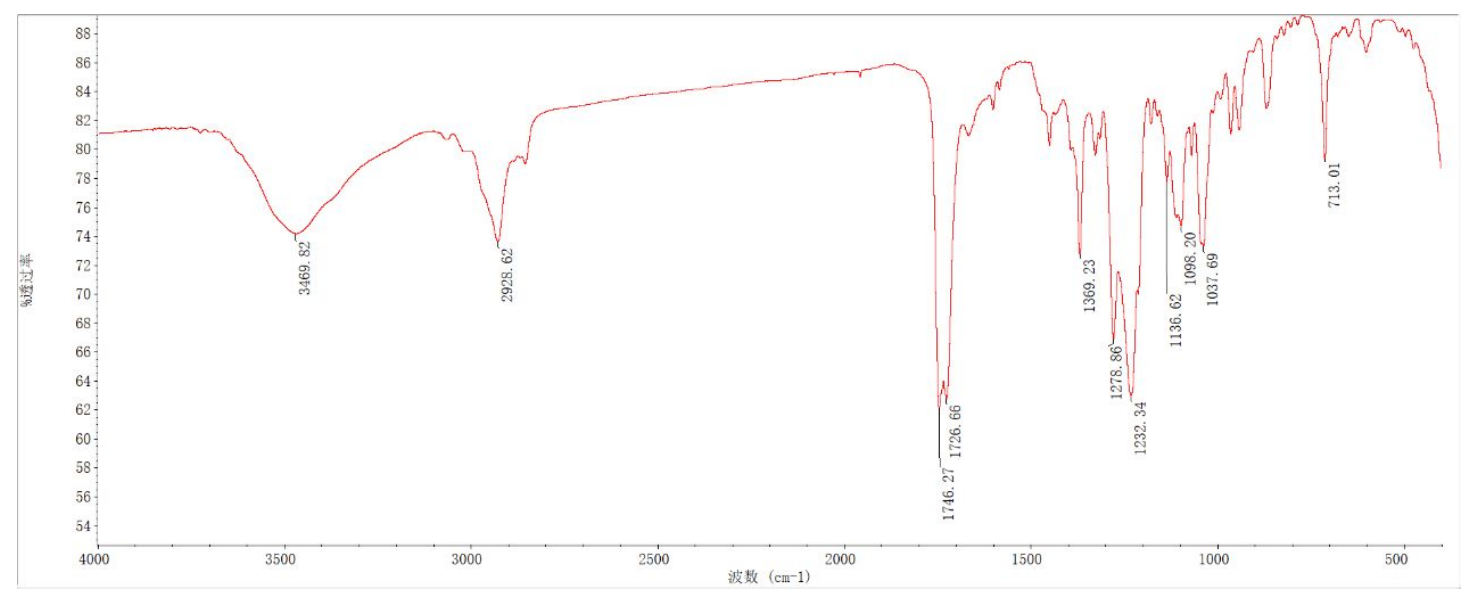

S25. UV spectrum of Compound 3

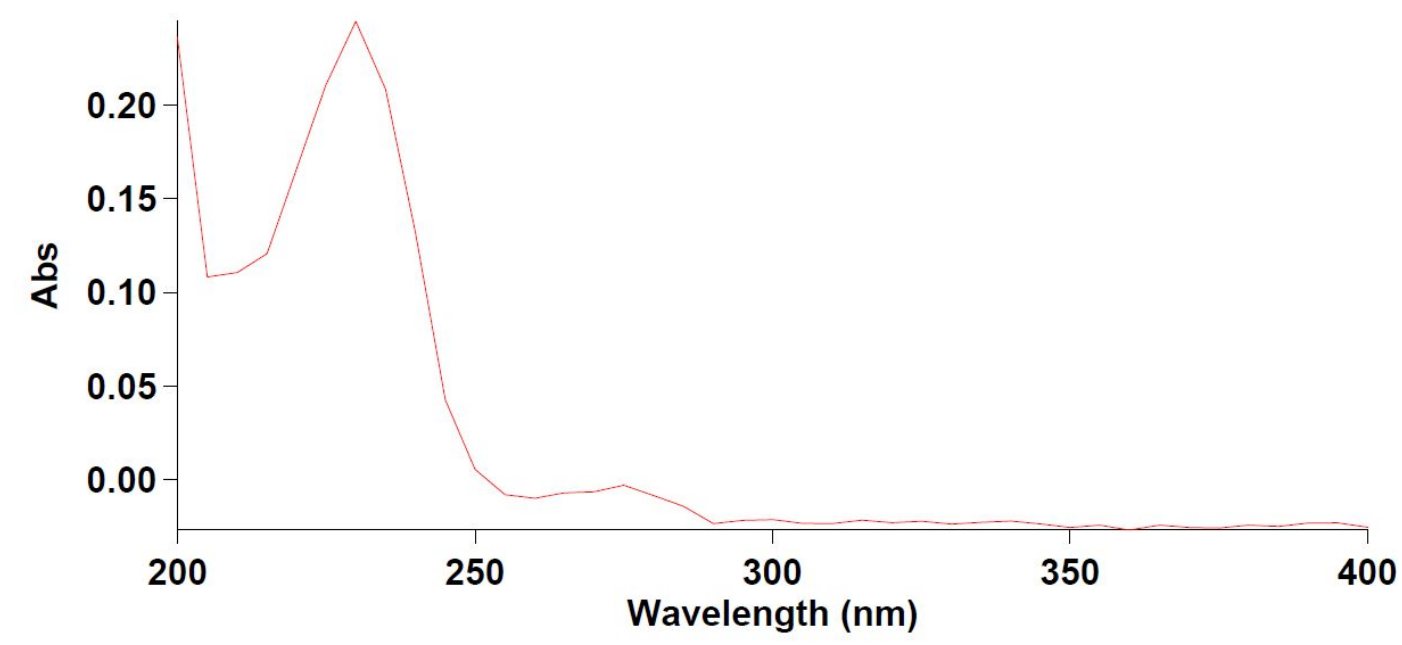


S26. HR-ESIMS of Compound 4

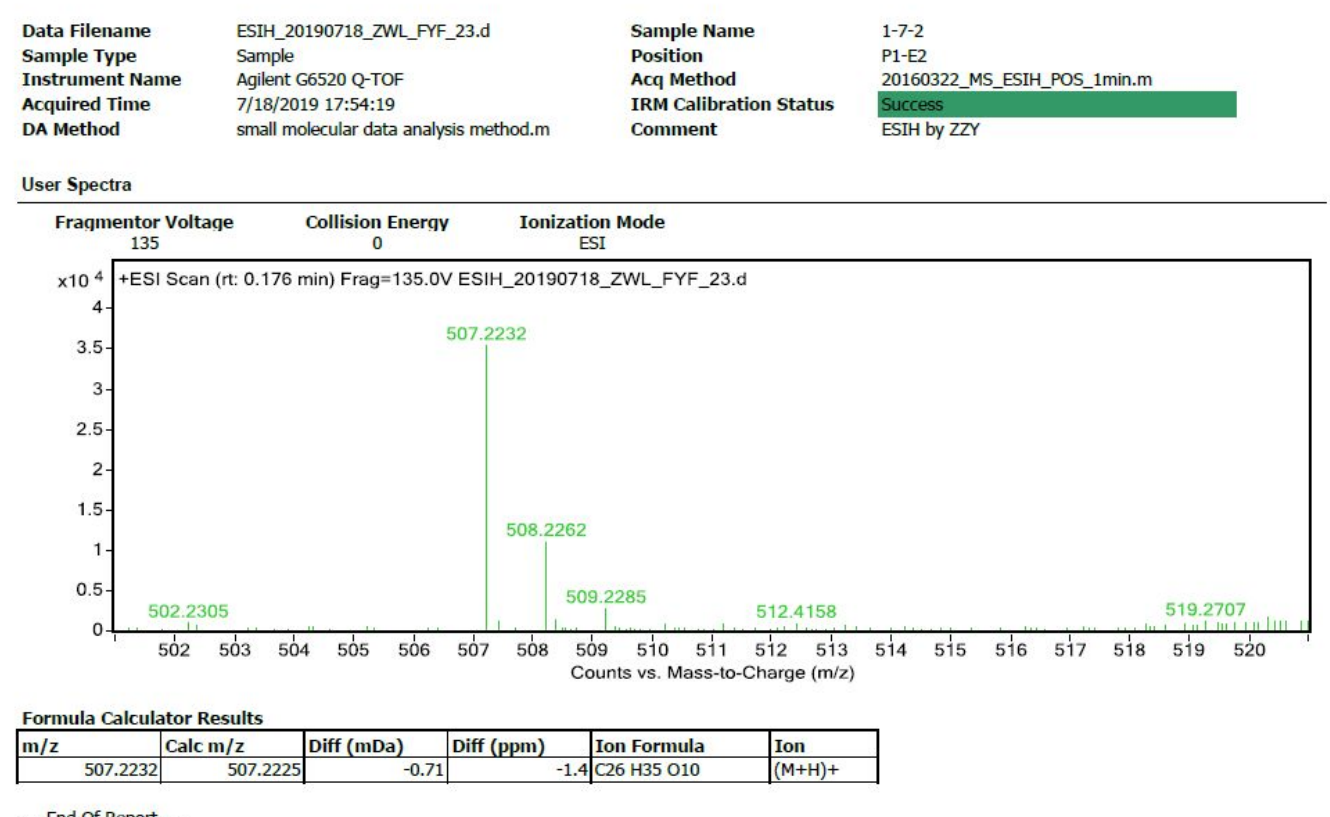

--- End of Report --

S27. ${ }^{1} \mathrm{H}$ NMR spectrum of Compound 4 in $\mathrm{CDCl}_{3}(500 \mathrm{MHz})$

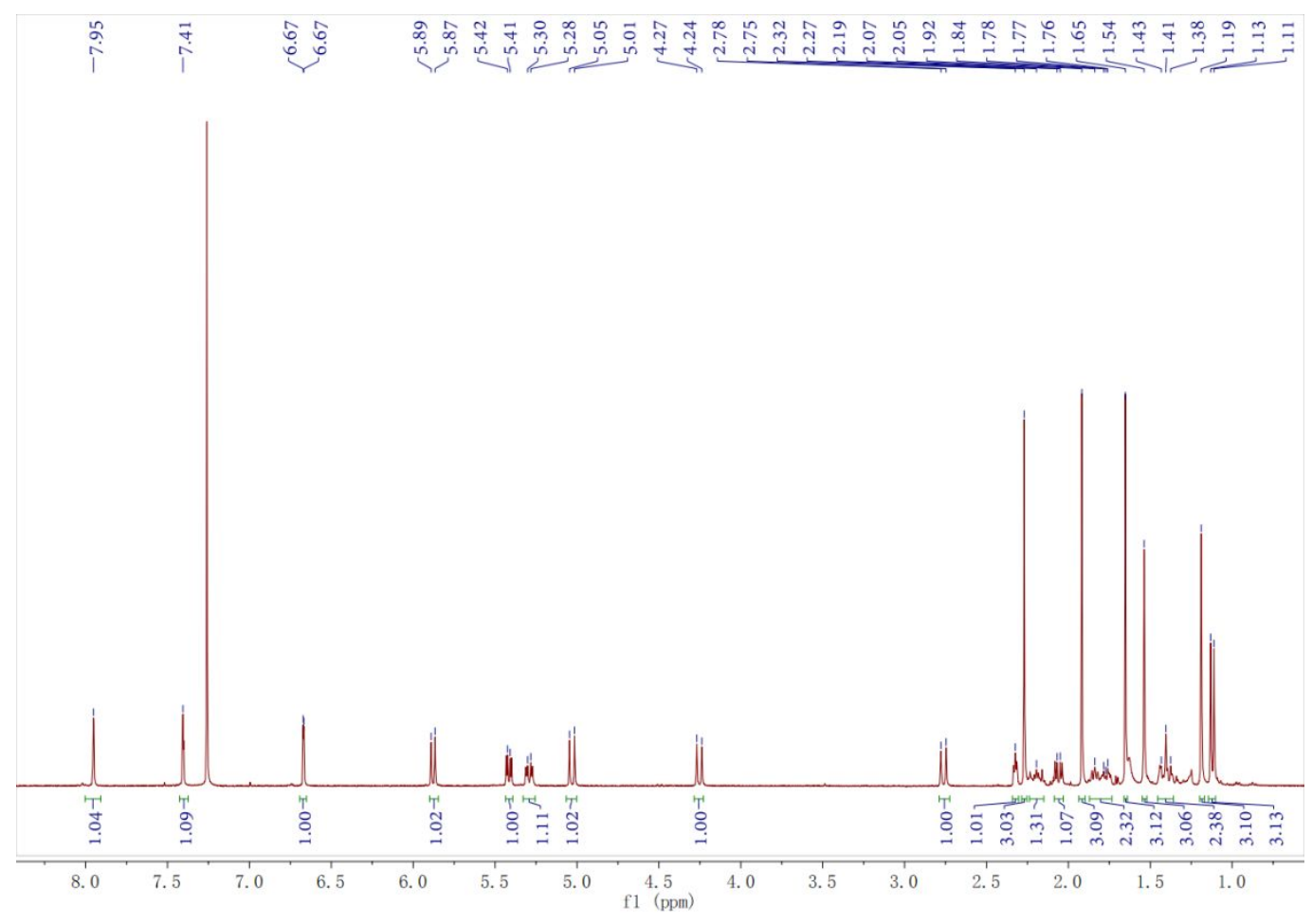


S28. ${ }^{13} \mathrm{C}$ NMR spectrum of Compound 4 in $\mathrm{CDCl}_{3}(125 \mathrm{MHz})$

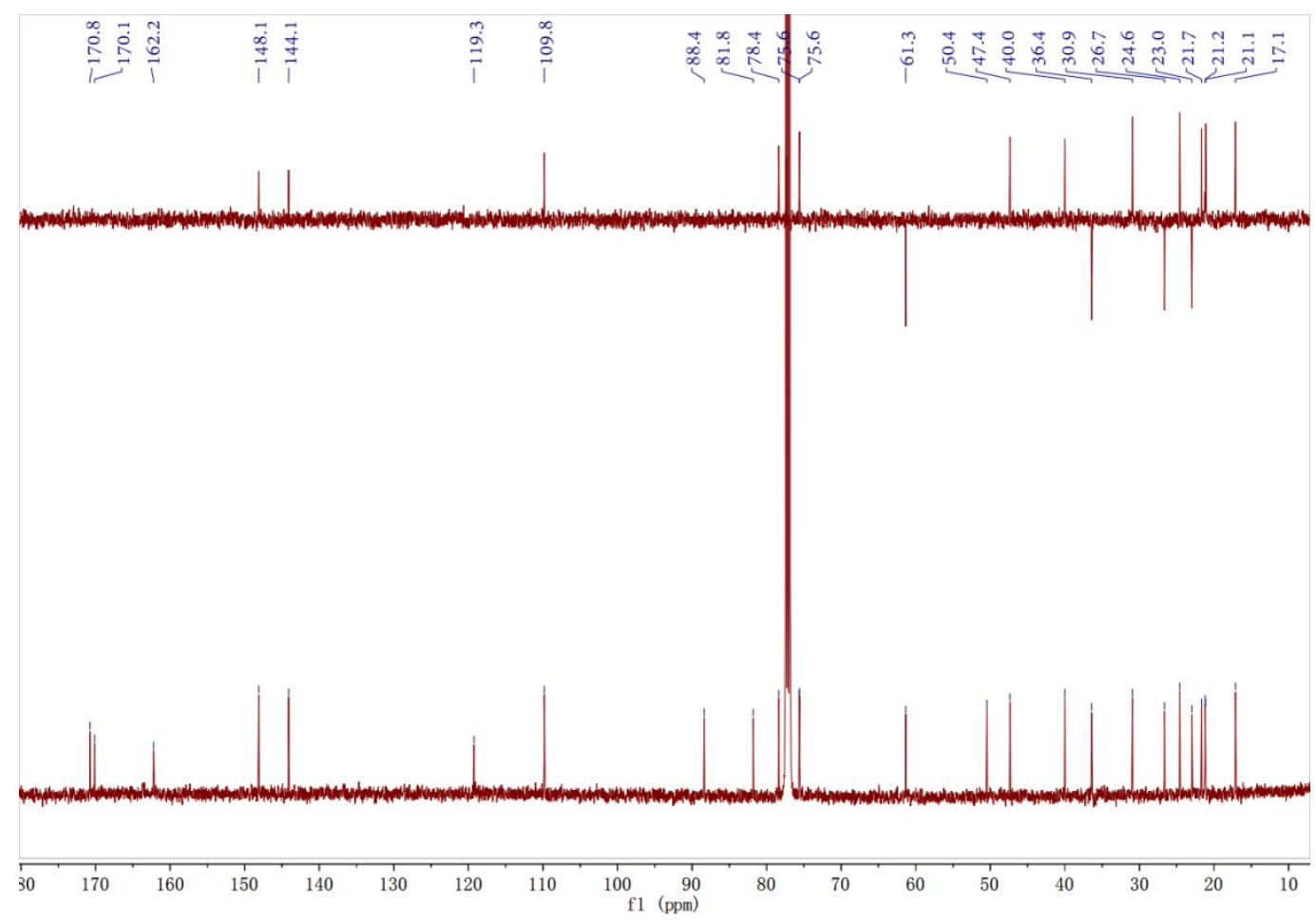


S29. HSQC spectrum of Compound 4 in $\mathrm{CDCl}_{3}$

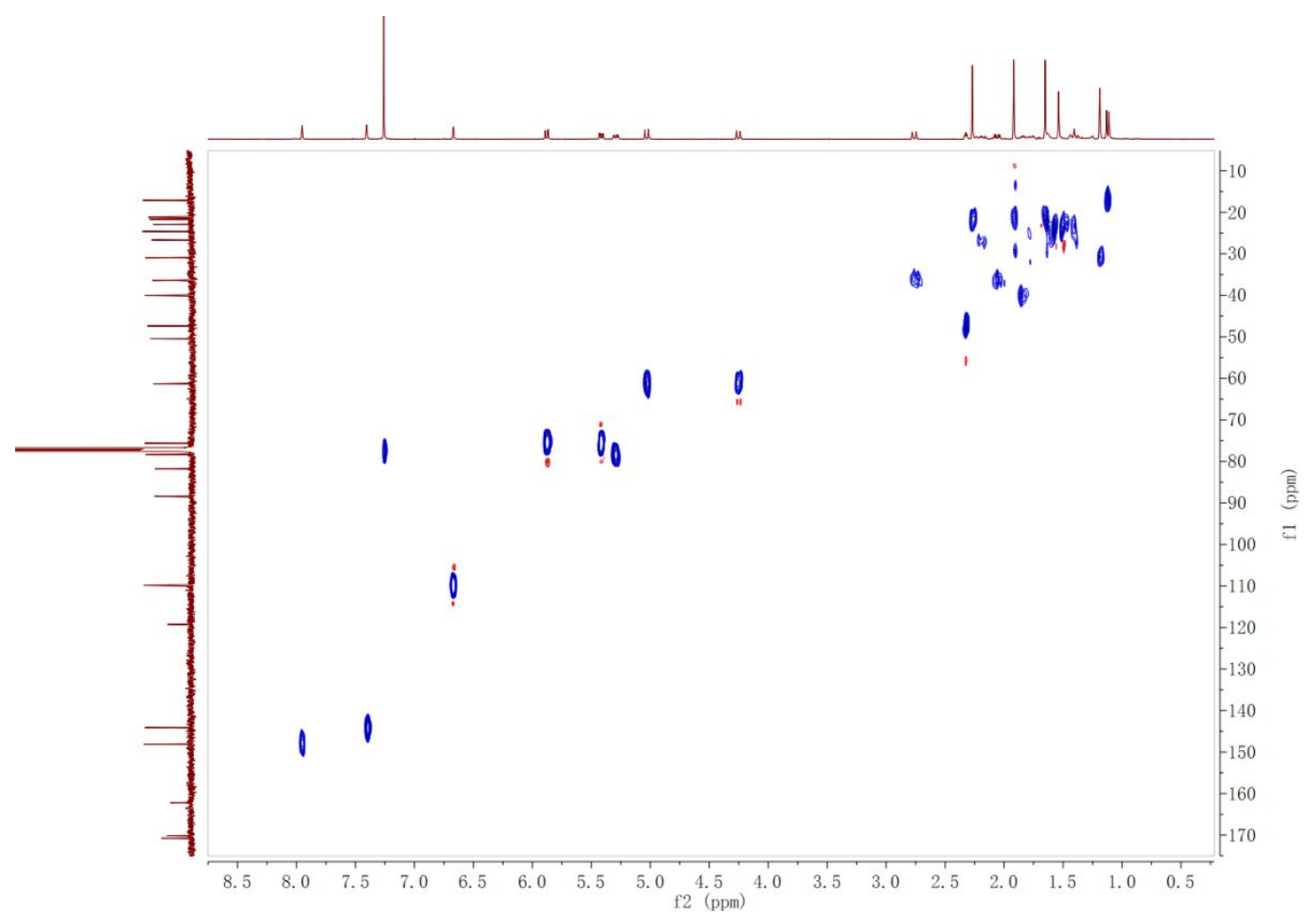

S30. HMBC spectrum of Compound 4 in $\mathrm{CDCl}_{3}$

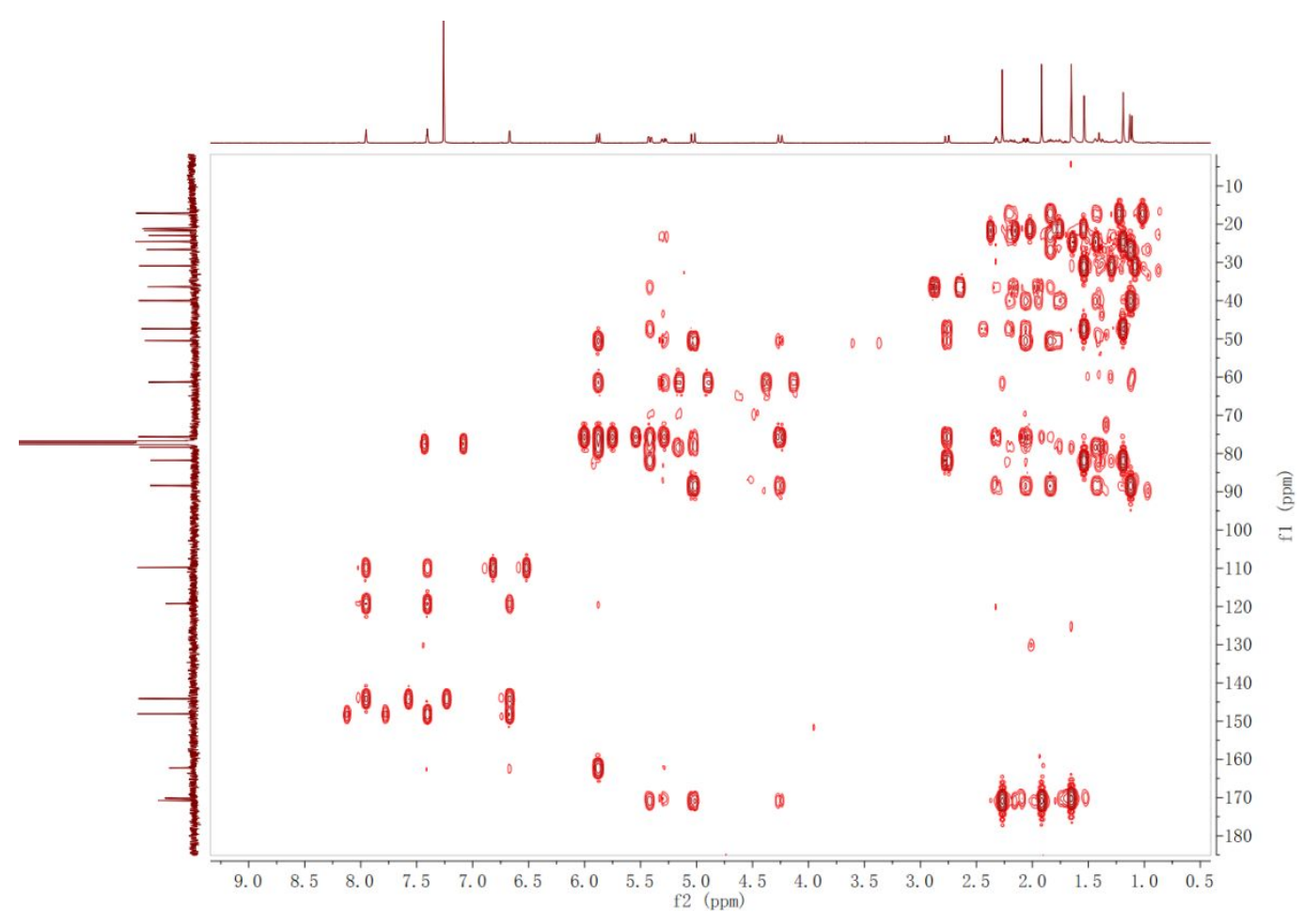


S31. NOESY of Compound 4 in $\mathrm{CDCl}_{3}$

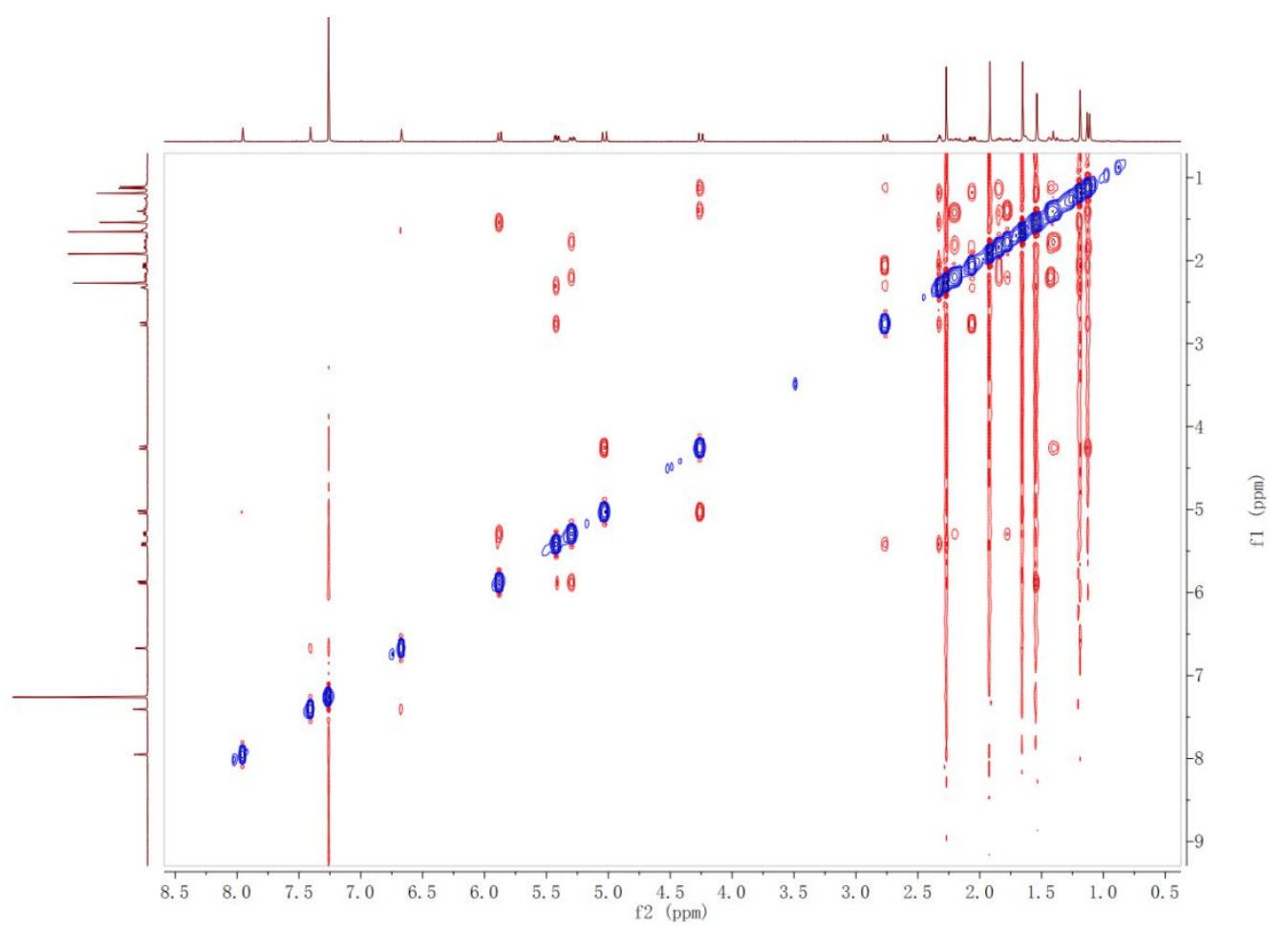

S32. IR spectrum of Compound 4

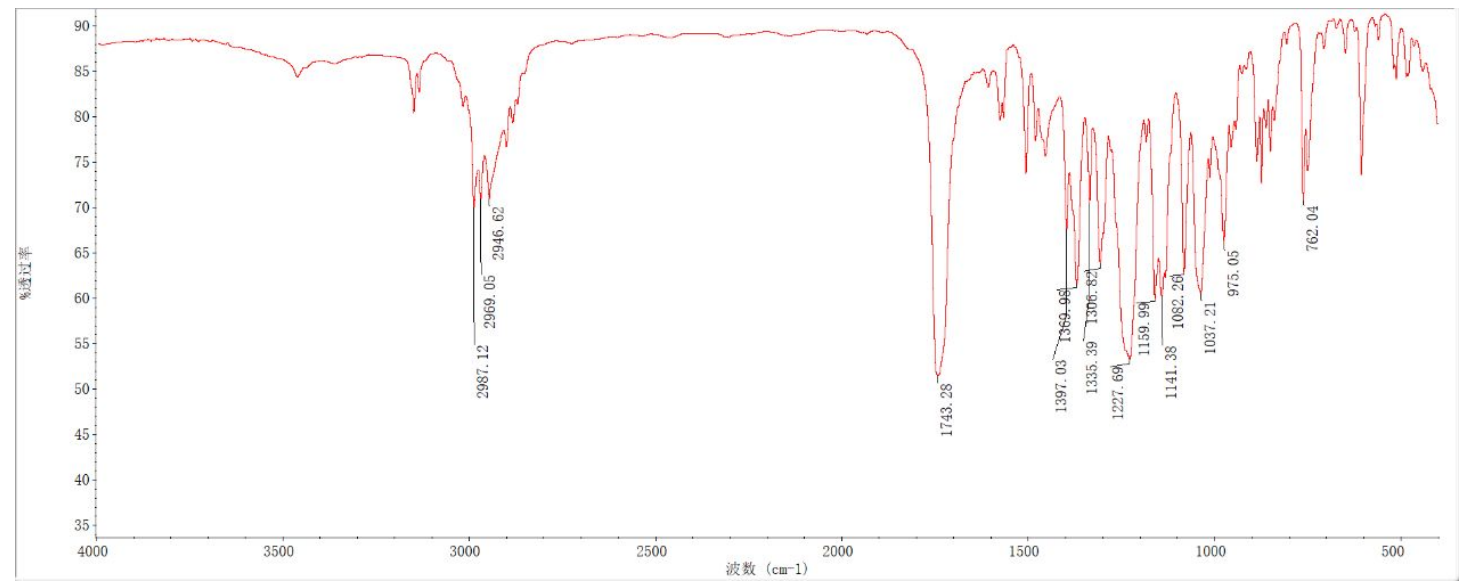


S33. UV spectrum of Compound 4

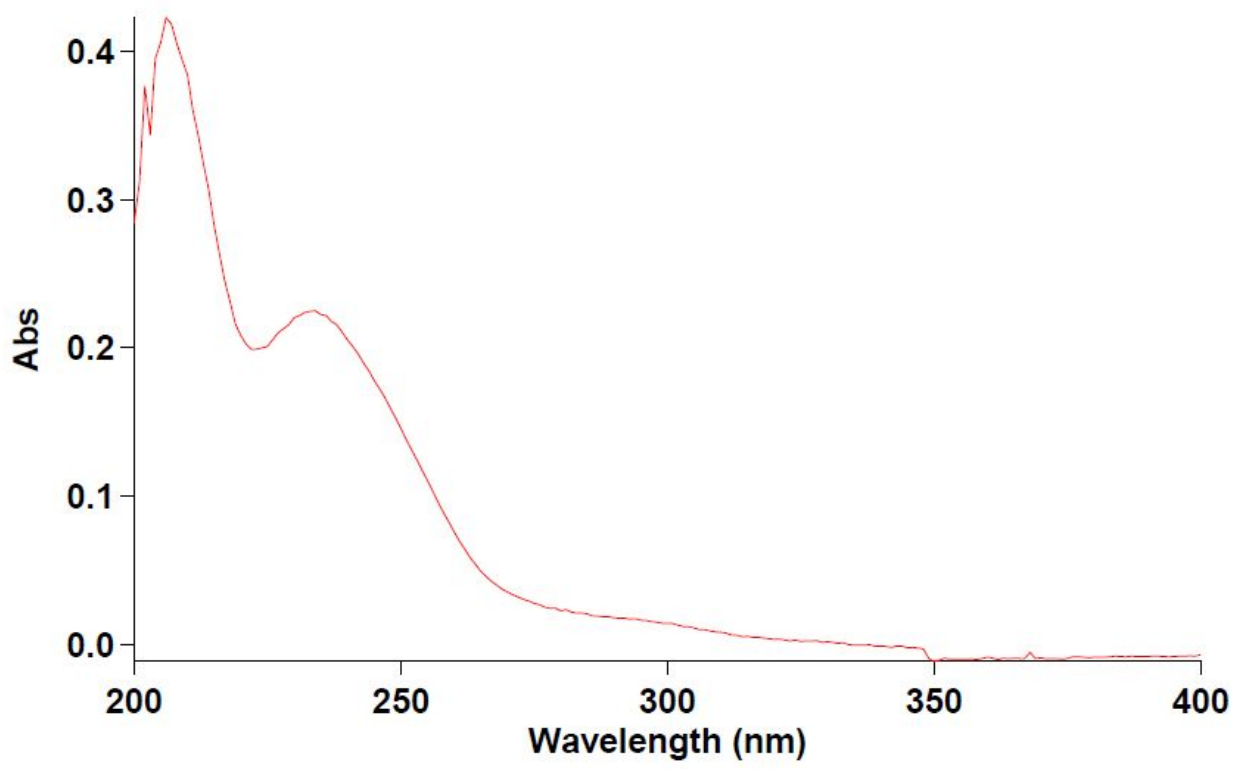


S34. HR-ESIMS of Compound 5

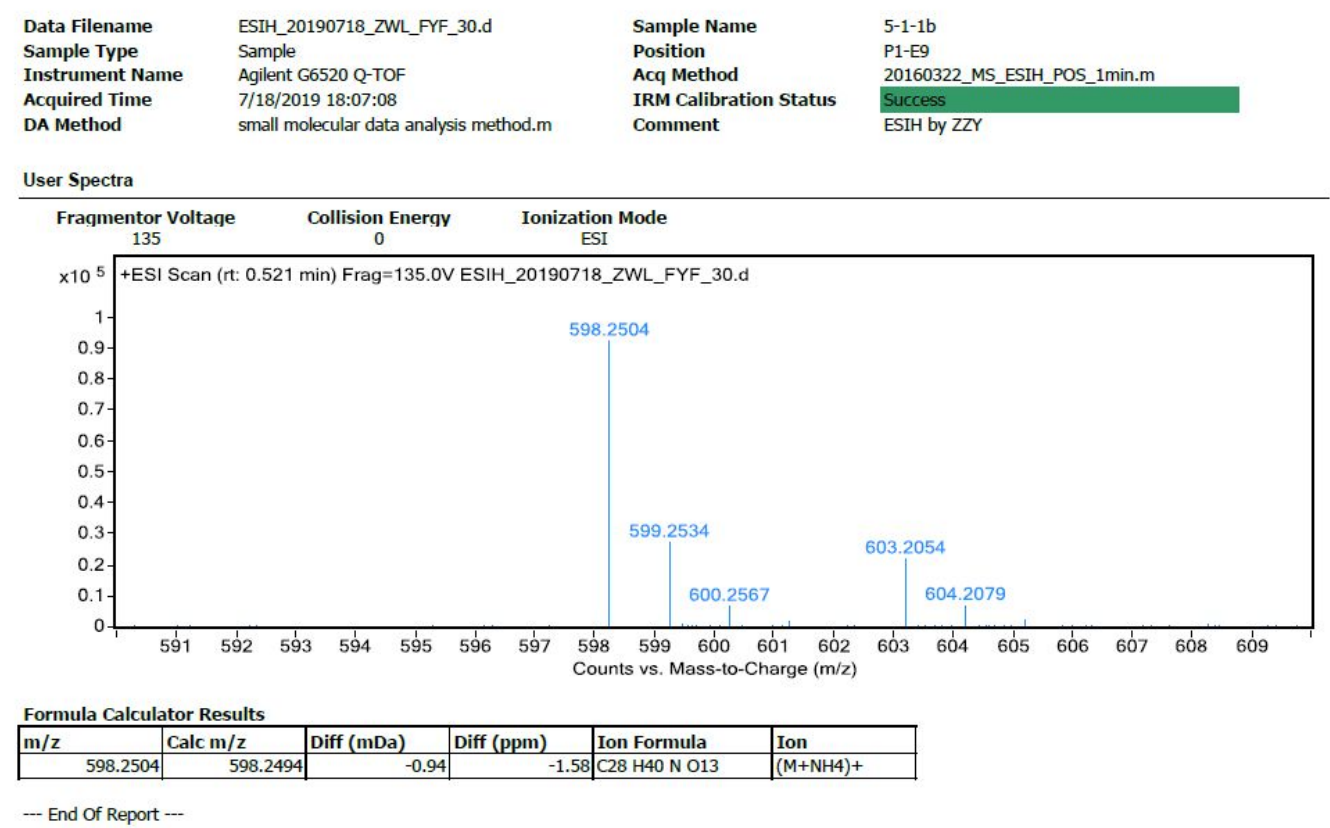

S35. ${ }^{1} \mathrm{H}$ NMR spectrum of Compound 5 in $\mathrm{CDCl}_{3}(500 \mathrm{MHz})$

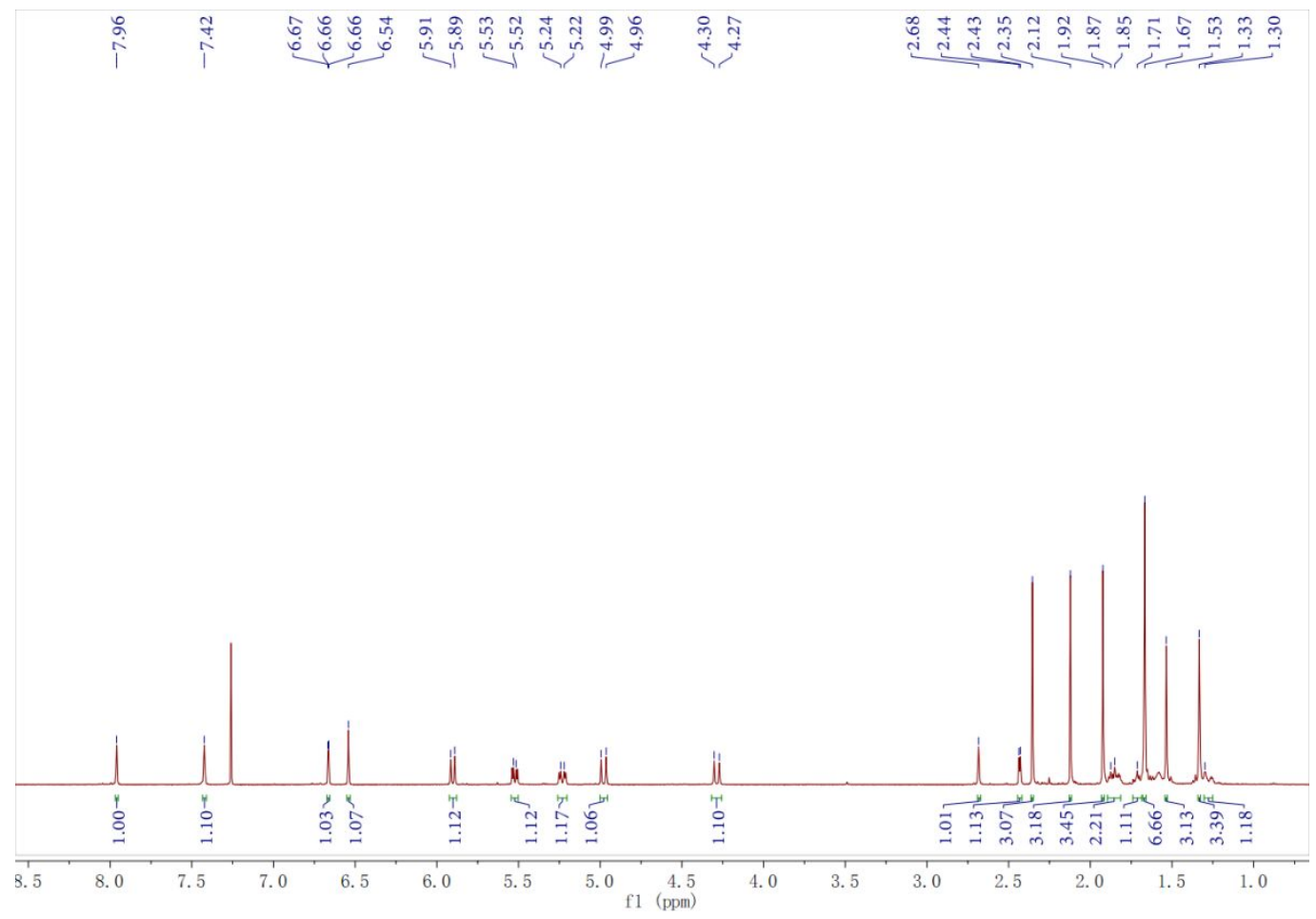


S36. ${ }^{13} \mathrm{C}$ NMR spectrum of Compound 5 in $\mathrm{CDCl}_{3}(125 \mathrm{MHz})$

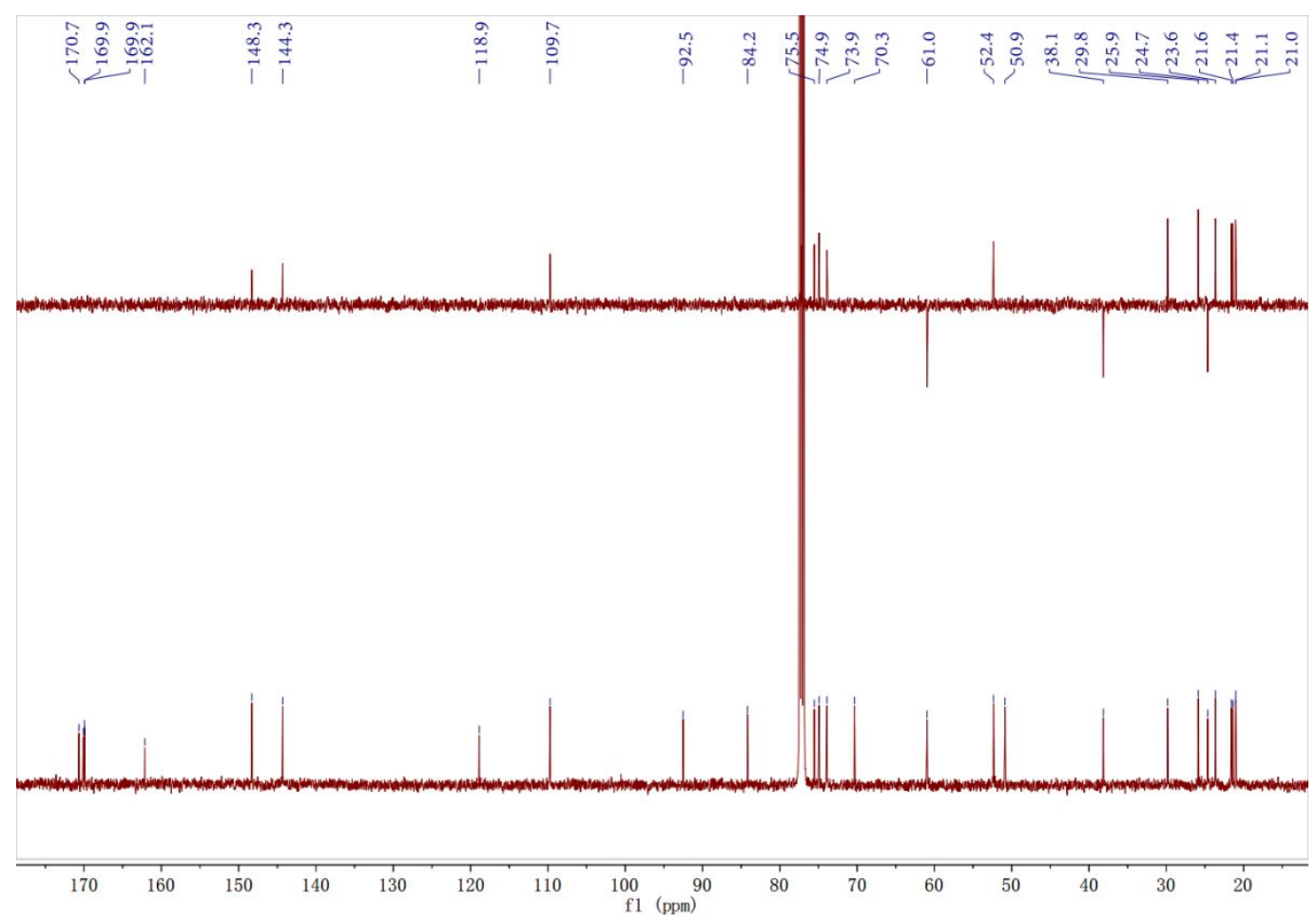

S37. HSQC spectrum of Compound 5 in $\mathrm{CDCl}_{3}$

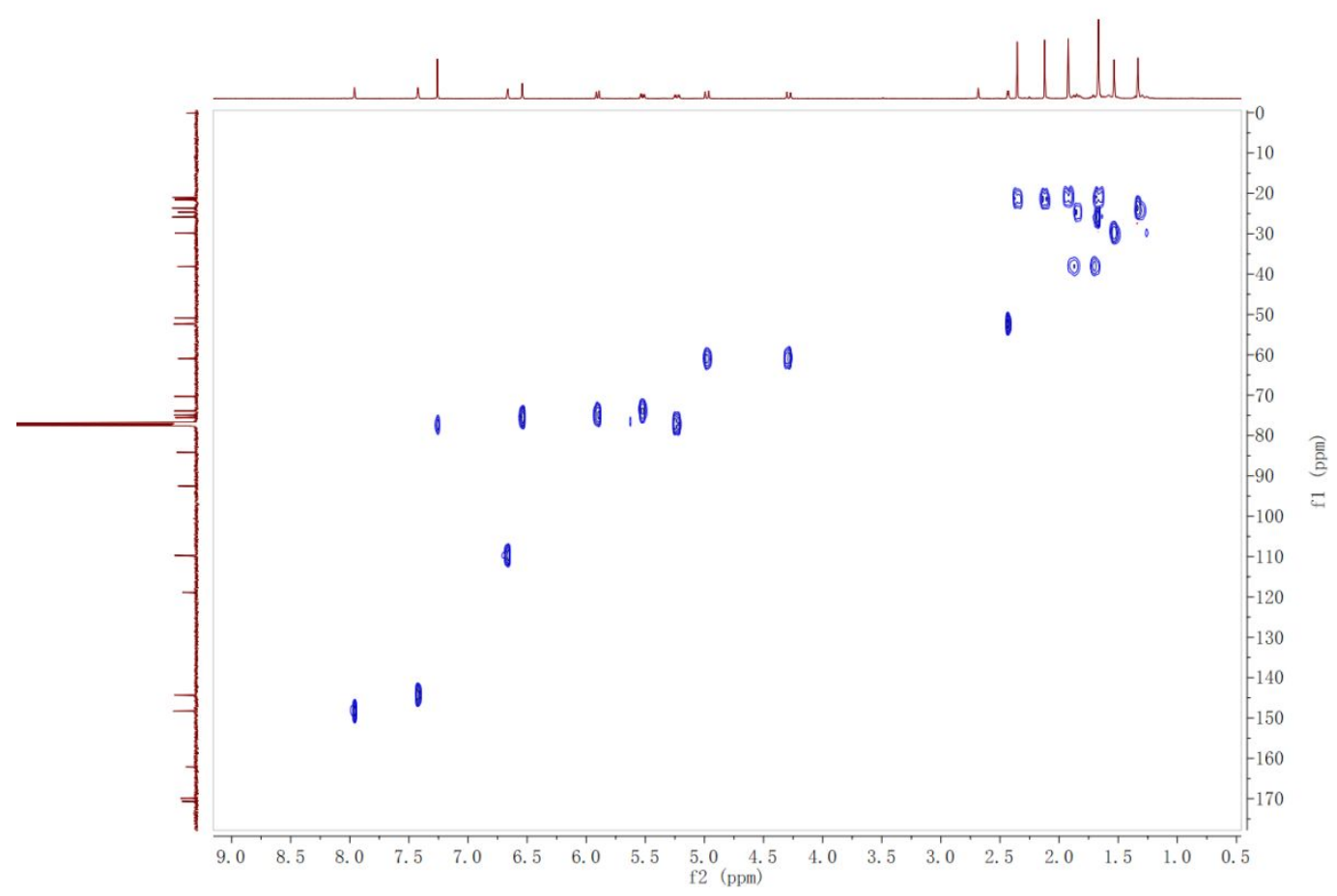


S38. HMBC spectrum of Compound 5 in $\mathrm{CDCl}_{3}$

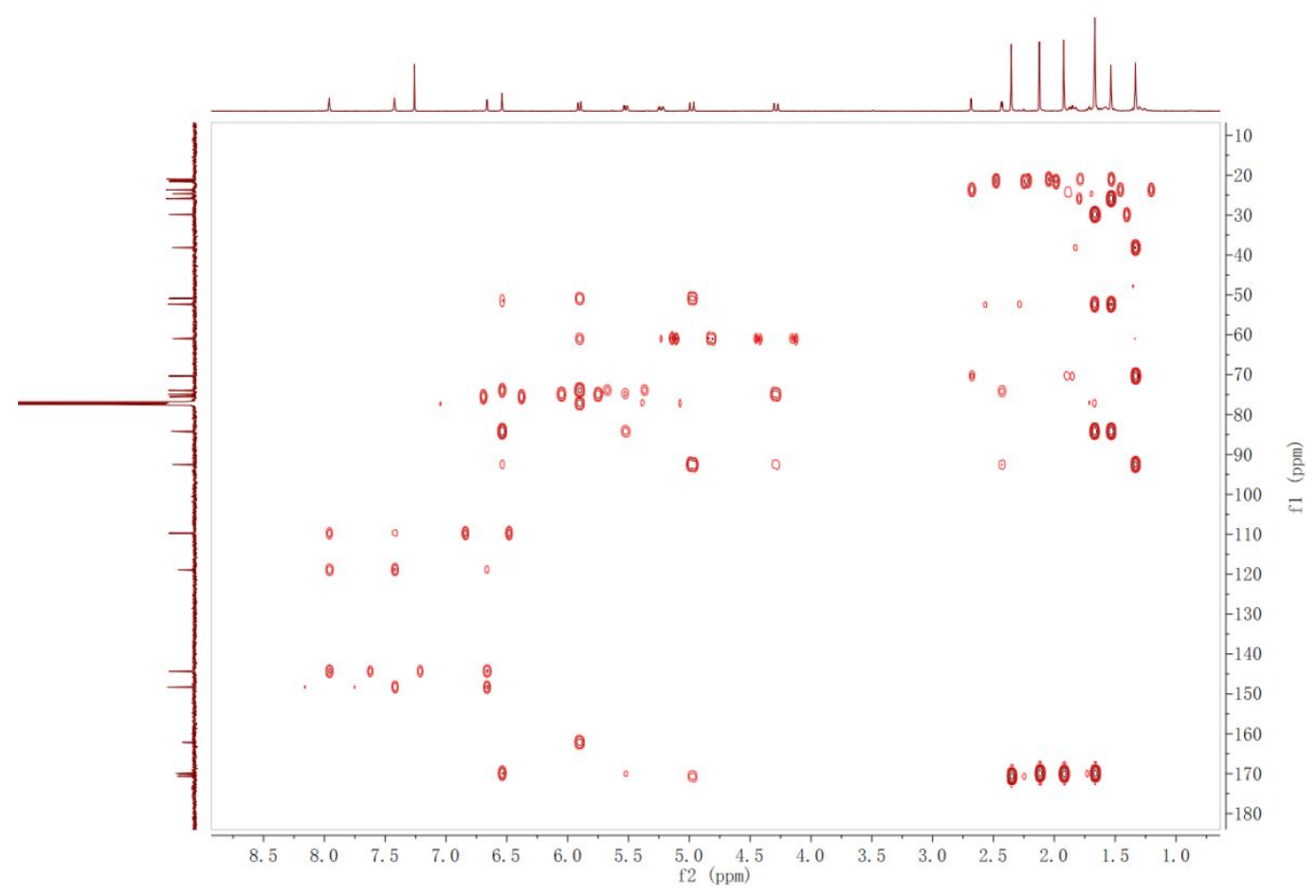

S39. NOESY of Compound 5 in $\mathrm{CDCl}_{3}$

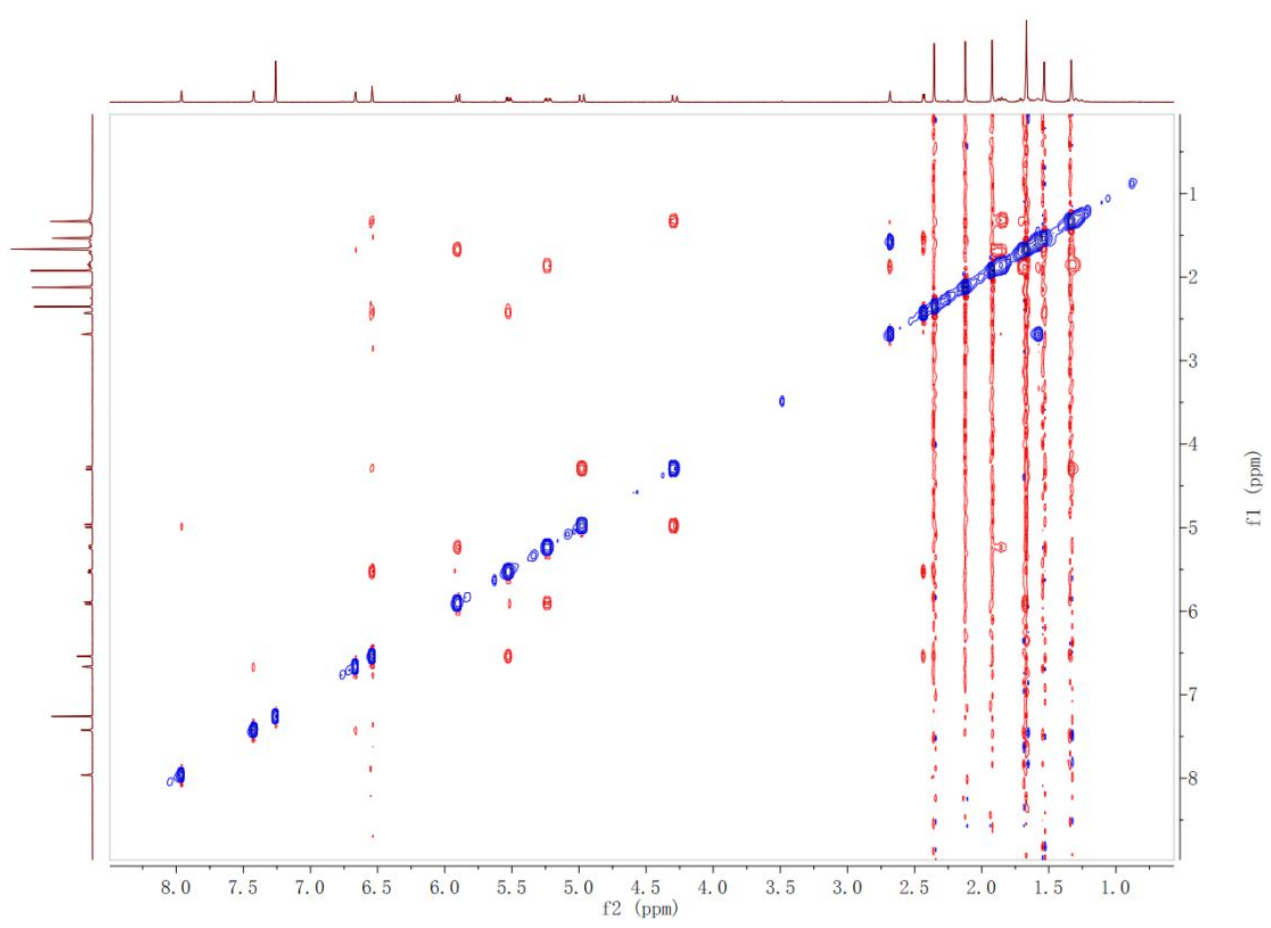


S40. IR spectrum of Compound 5

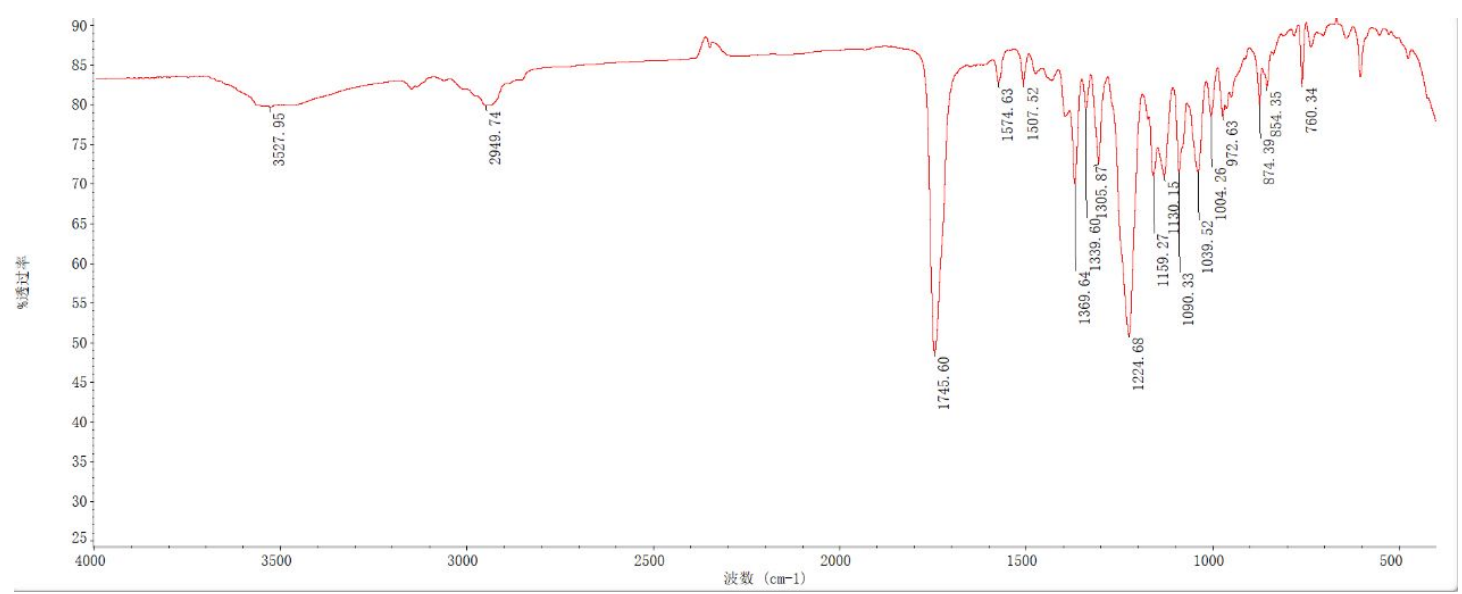

S41. UV spectrum of Compound 5

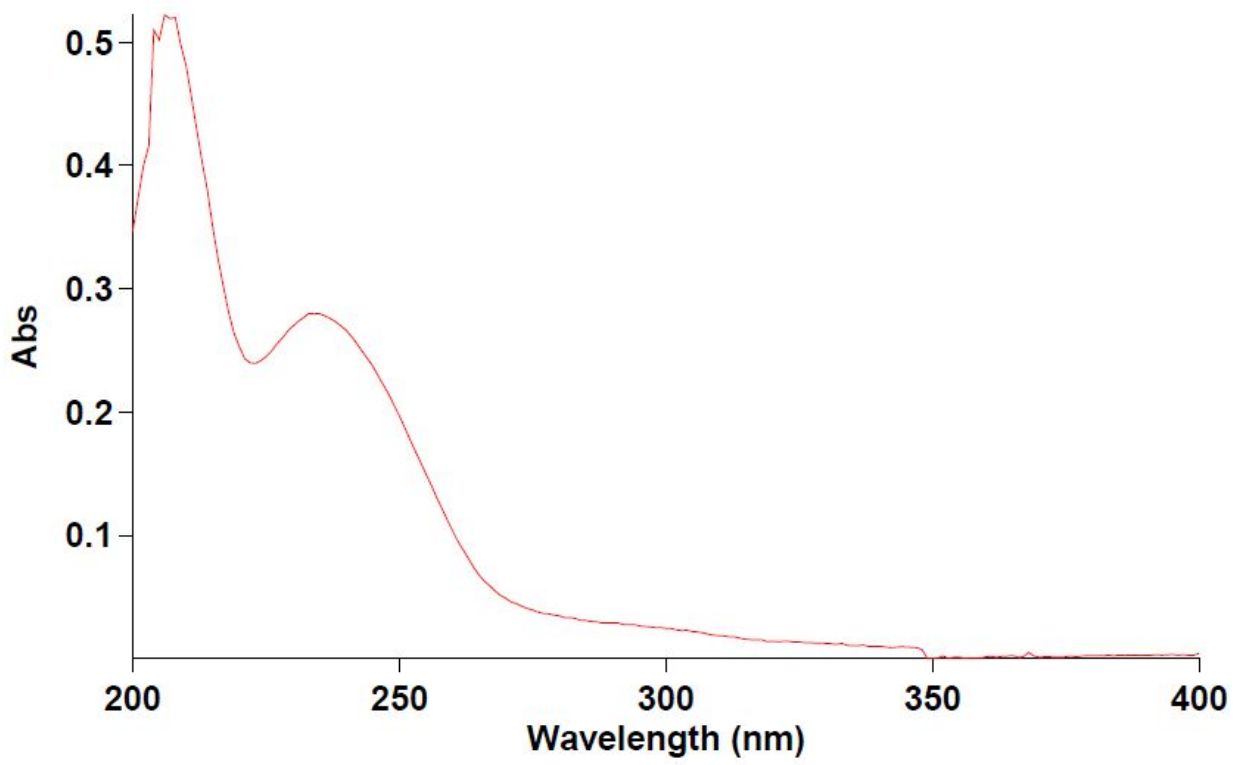


S42. HR-ESIMS of Compound 6

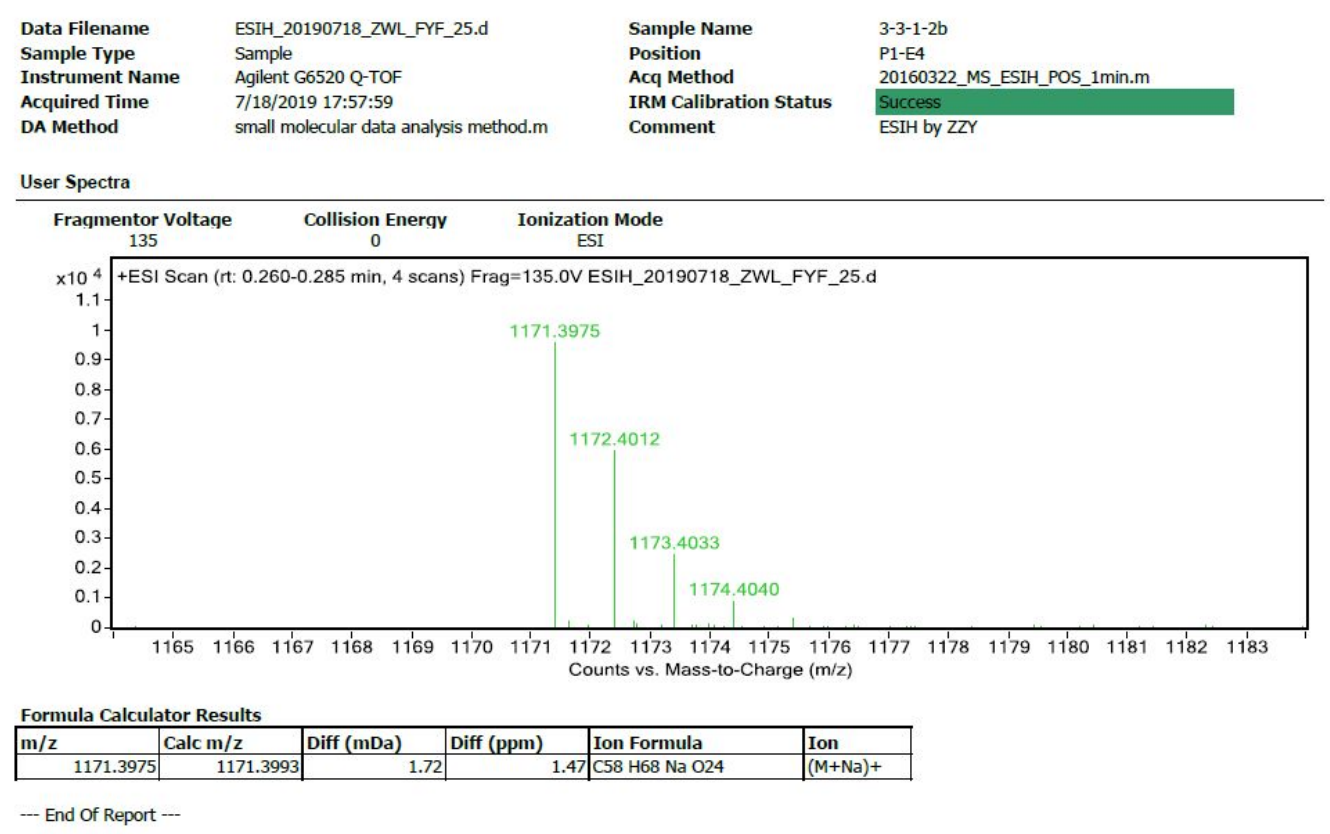


S43. ${ }^{1} \mathrm{H}$ NMR spectrum of Compound 6 in $\mathrm{CDCl}_{3}(500 \mathrm{MHz})$

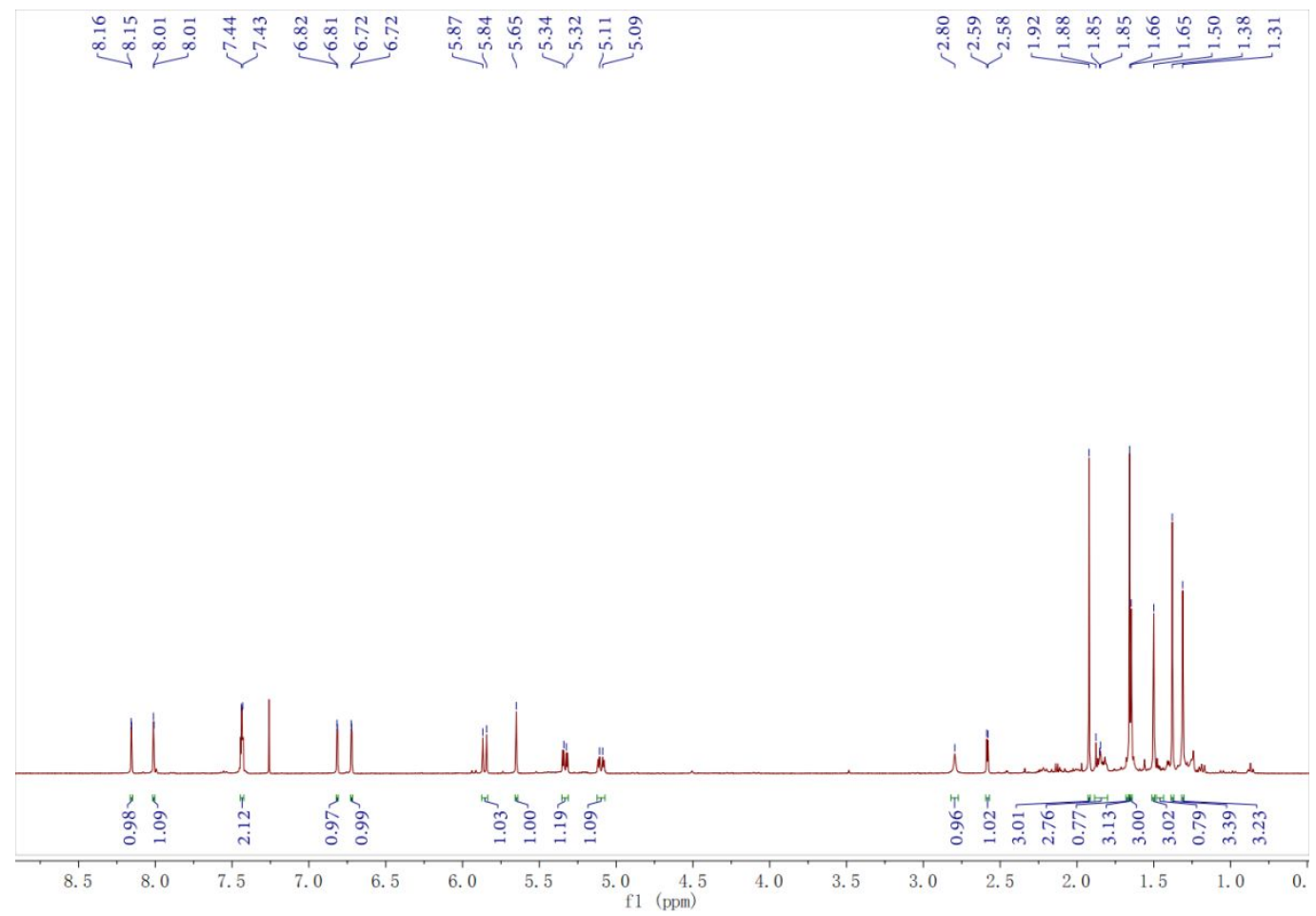


S44. ${ }^{13} \mathrm{C}$ NMR spectrum of Compound 6 in $\mathrm{CDCl}_{3}(125 \mathrm{MHz})$

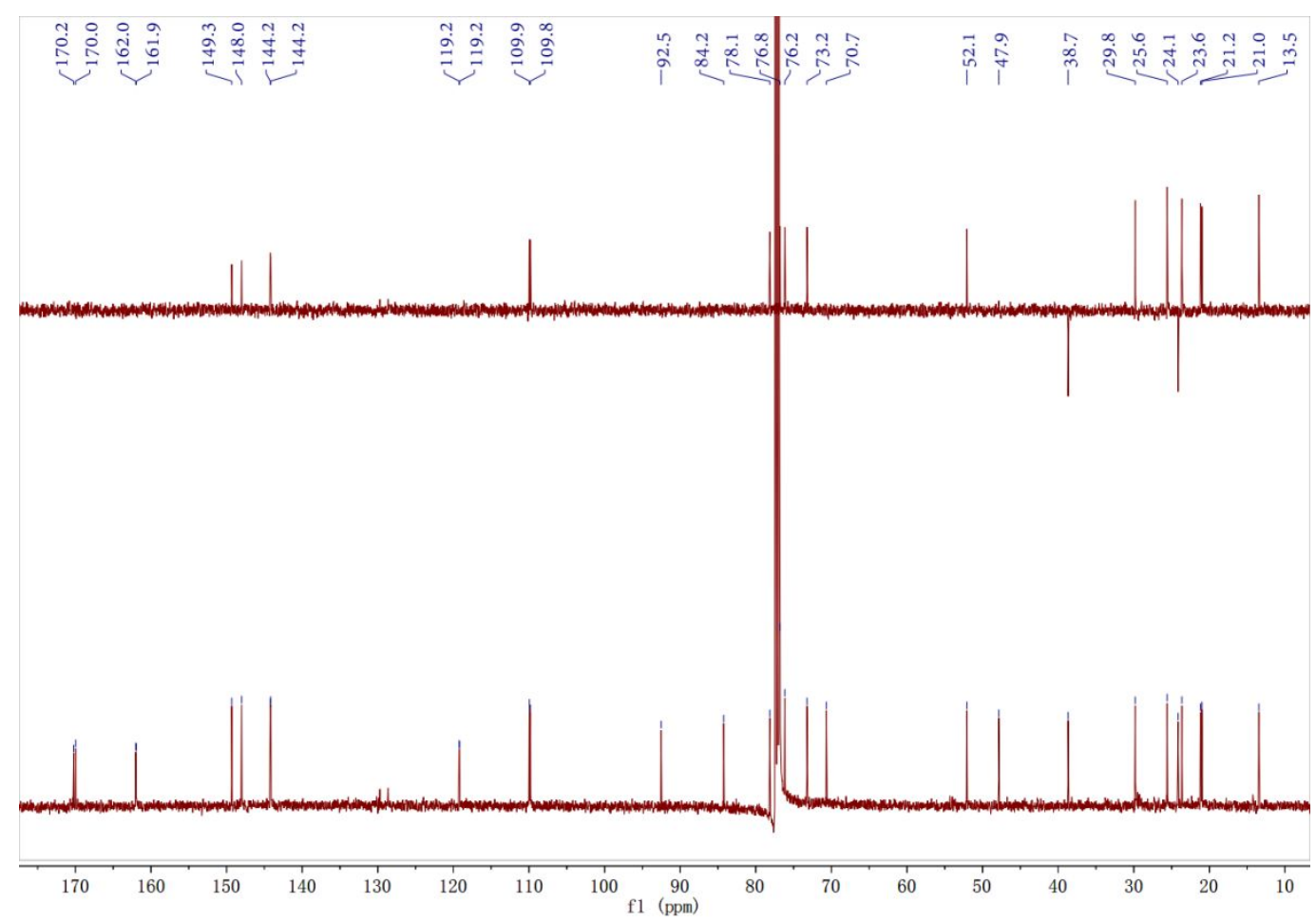

S45. HSQC spectrum of Compound 6 in $\mathrm{CDCl}_{3}$

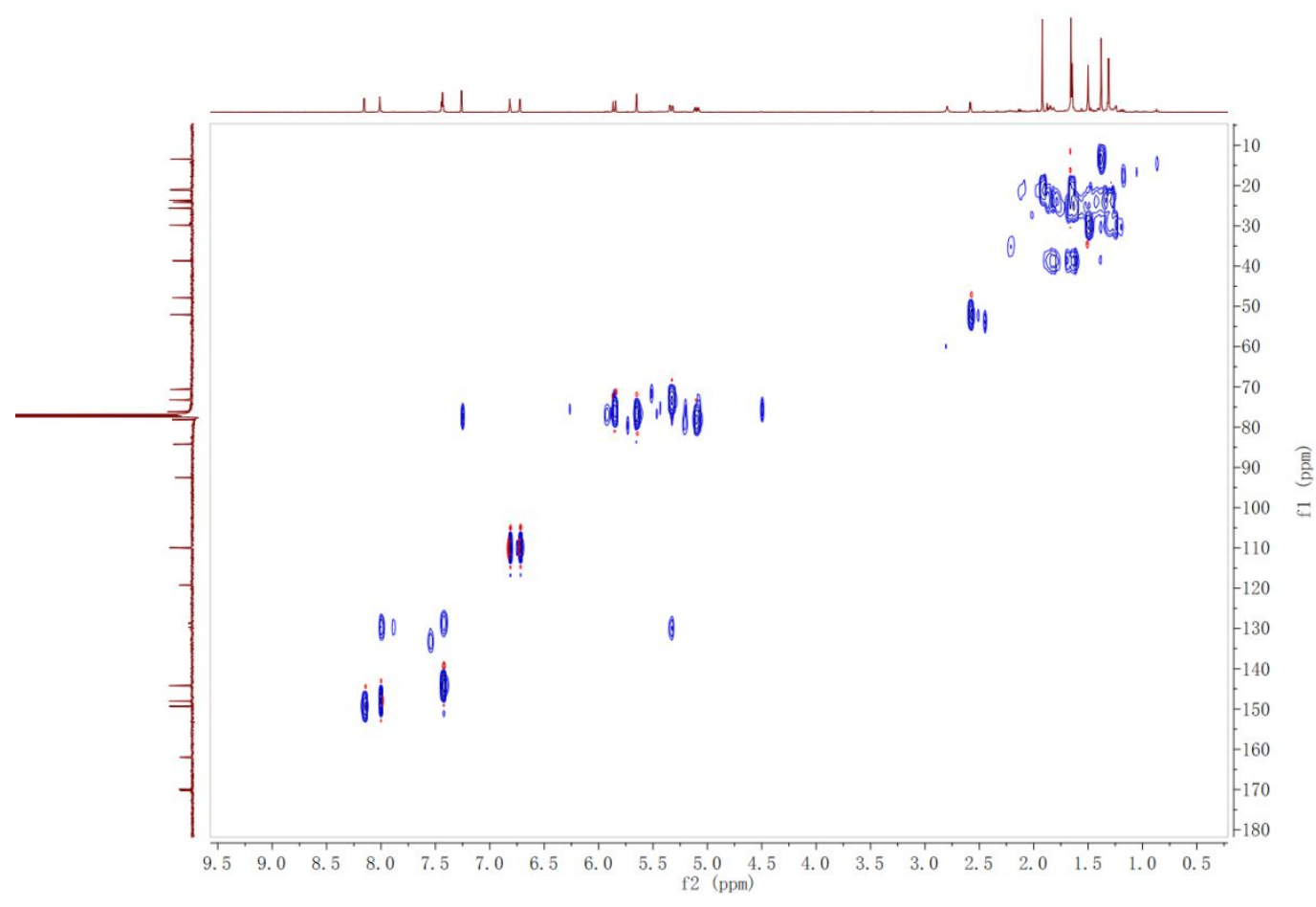


S46. HMBC spectrum of Compound 6 in $\mathrm{CDCl}_{3}$

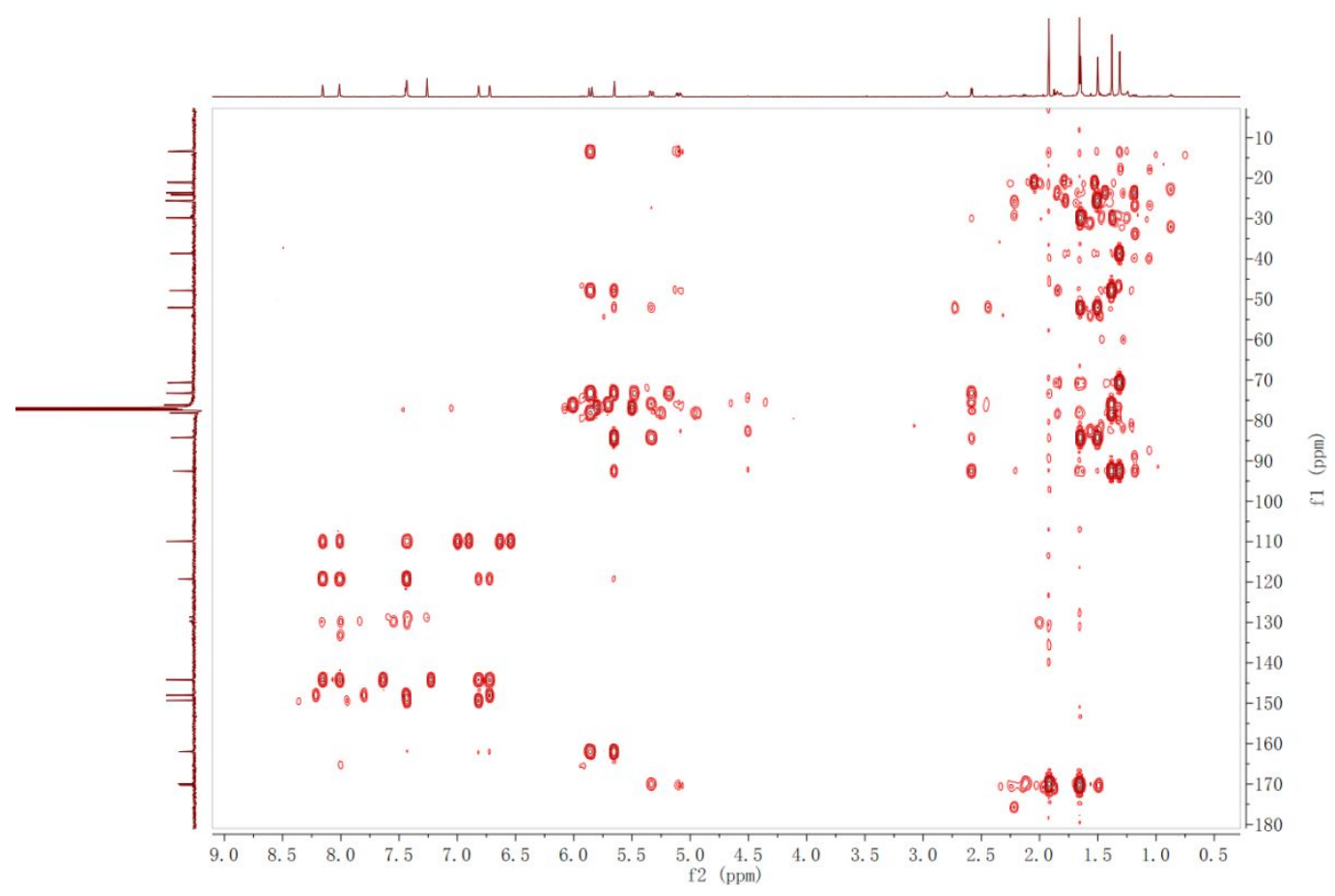

S47. NOESY of Compound 6 in $\mathrm{CDCl}_{3}$

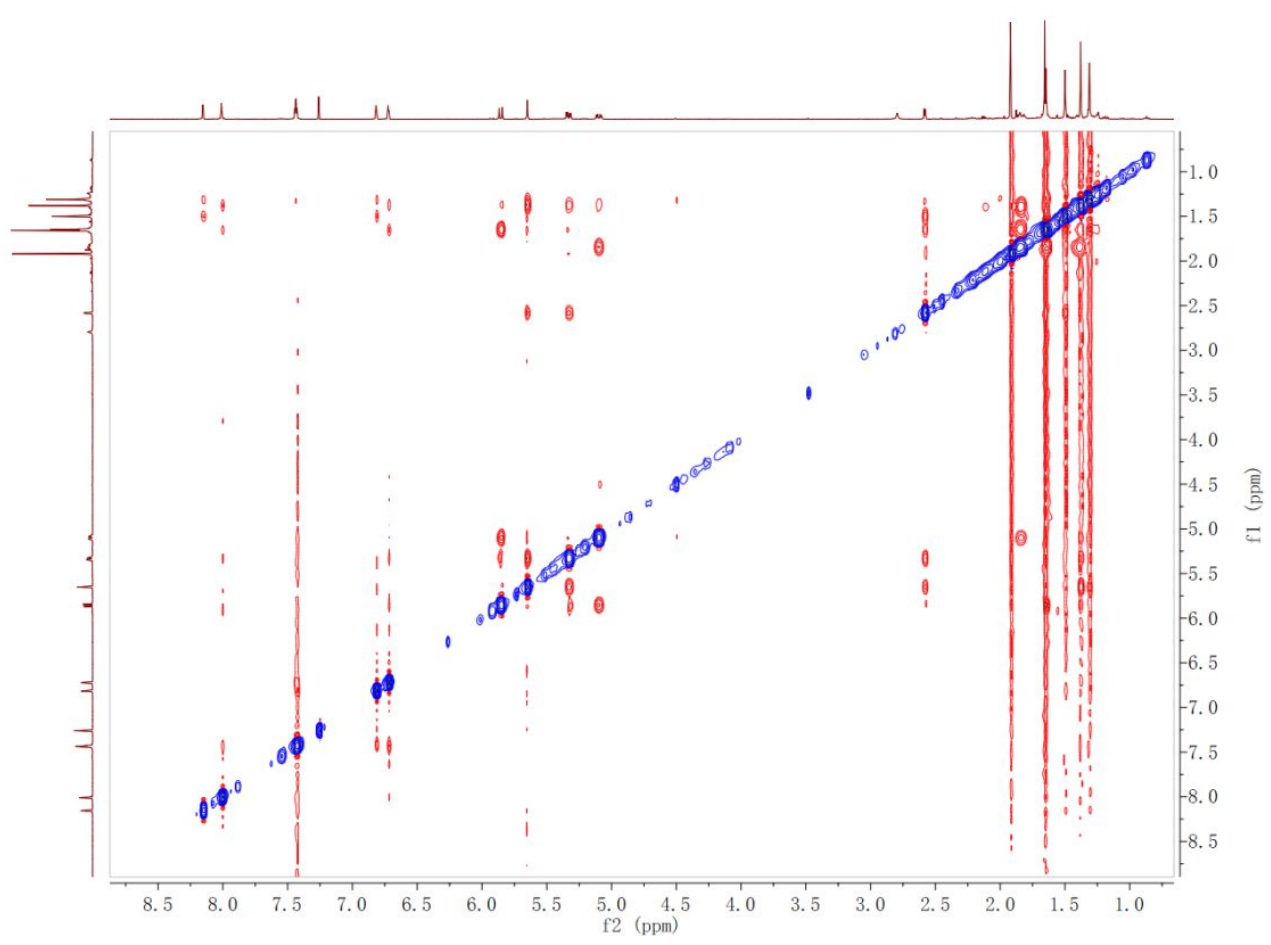


S48. IR spectrum of Compound 6

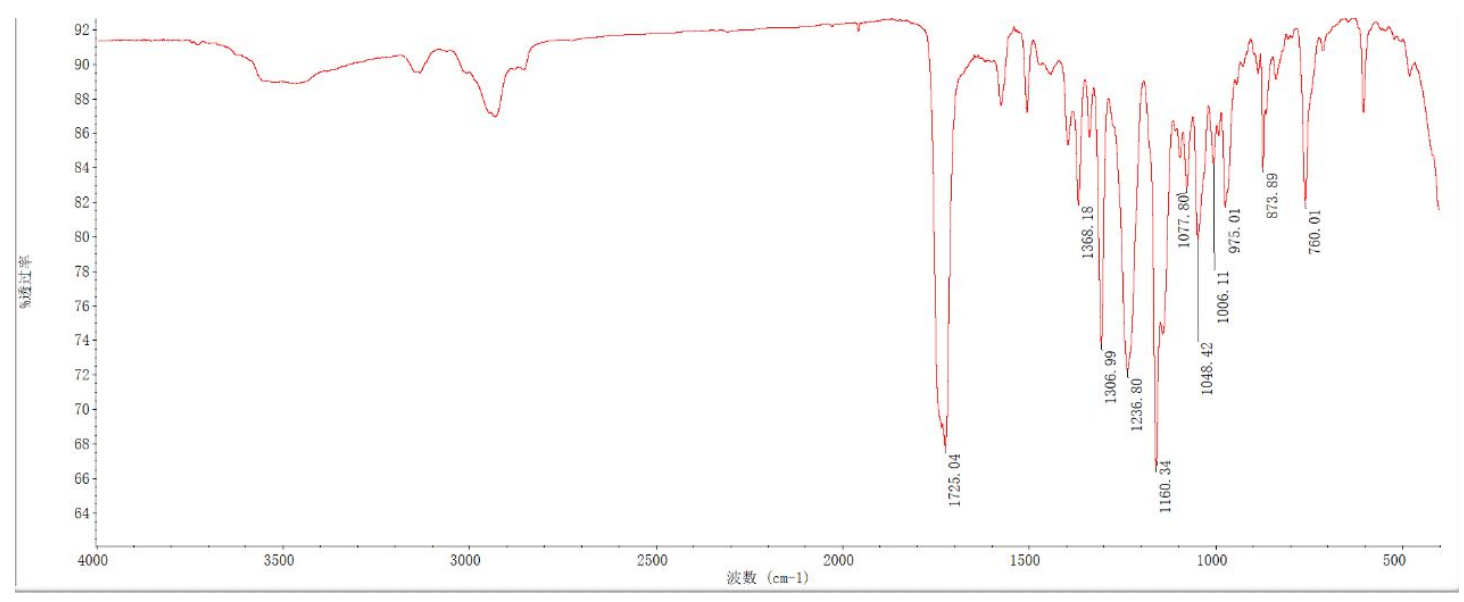

S49. UV spectrum of Compound 6

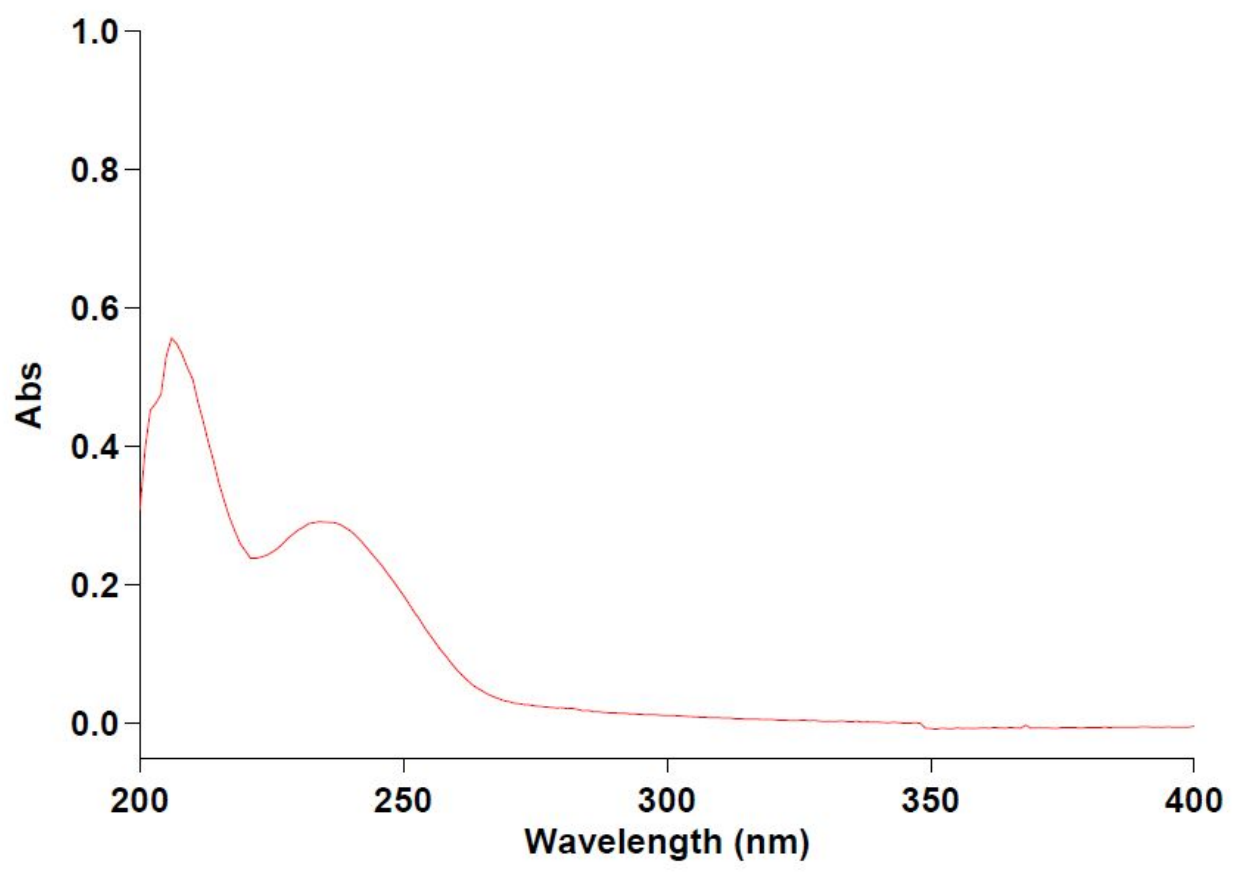


S50. HR-ESIMS of Compound 7

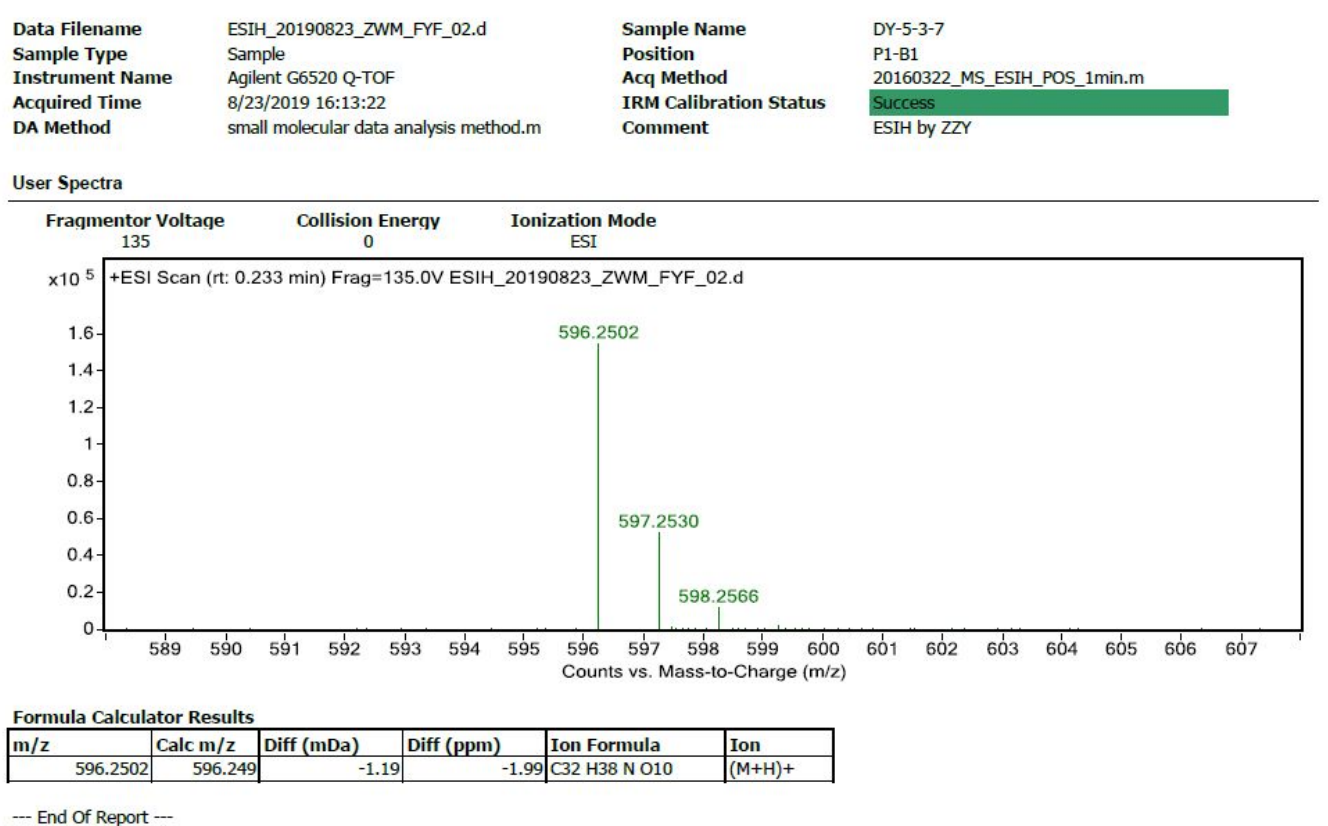


S51. ${ }^{1} \mathrm{H}$ NMR spectrum of Compound 7 in $\mathrm{CDCl}_{3}(500 \mathrm{MHz})$

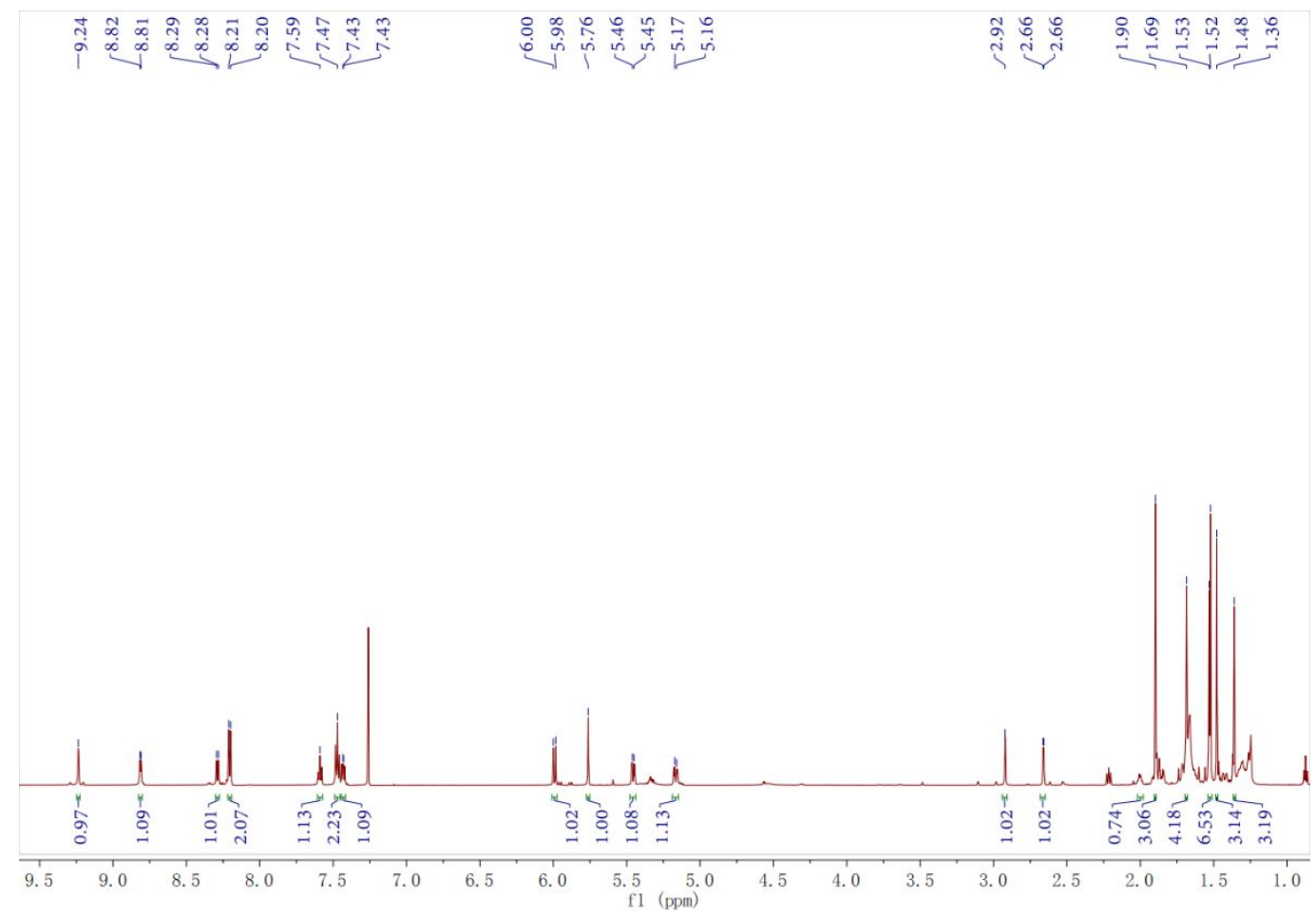


S52. ${ }^{13} \mathrm{C}$ NMR spectrum of Compound 7 in $\mathrm{CDCl}_{3}(125 \mathrm{MHz})$

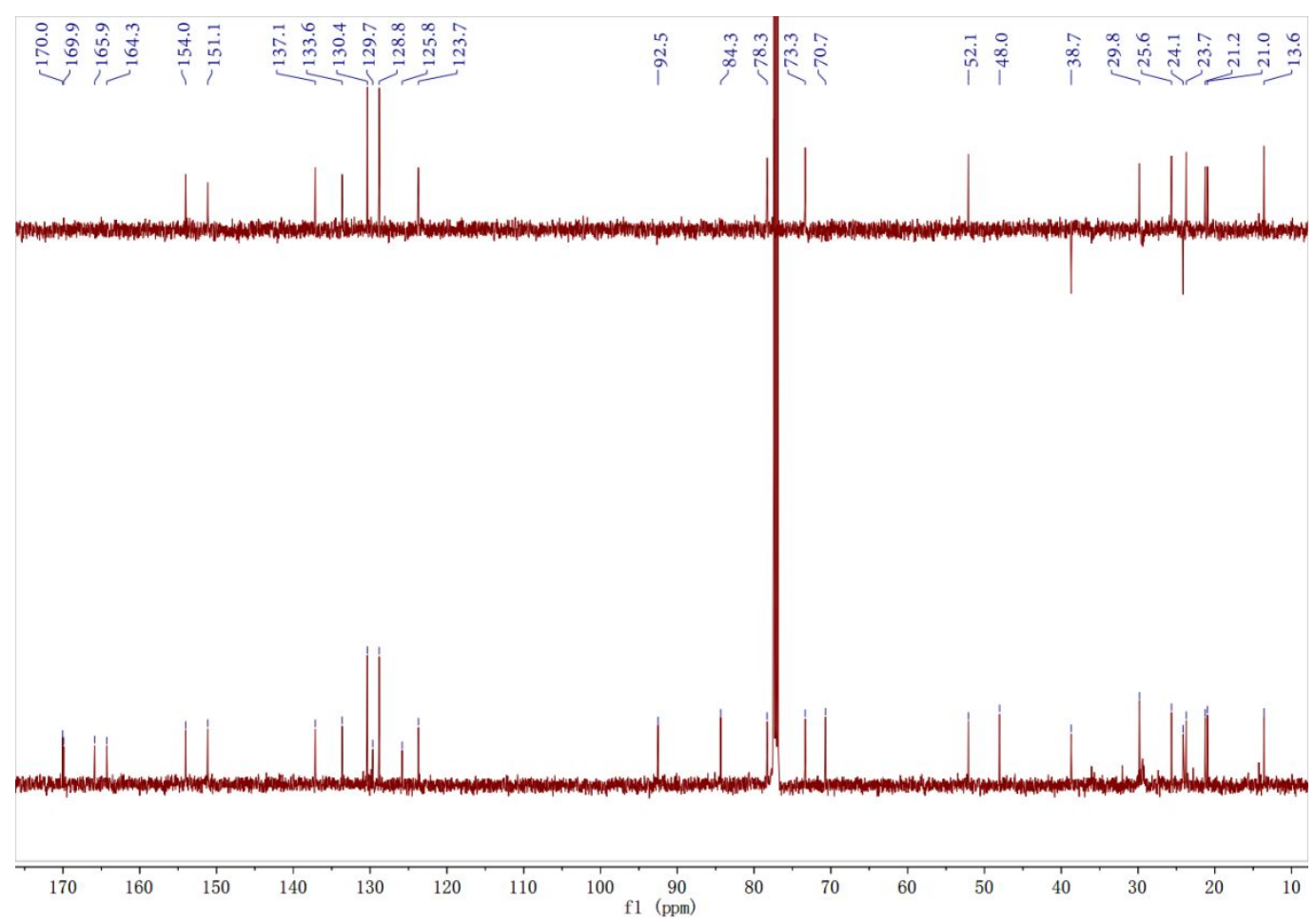

S53. HSQC spectrum of Compound 7 in $\mathrm{CDCl}_{3}$

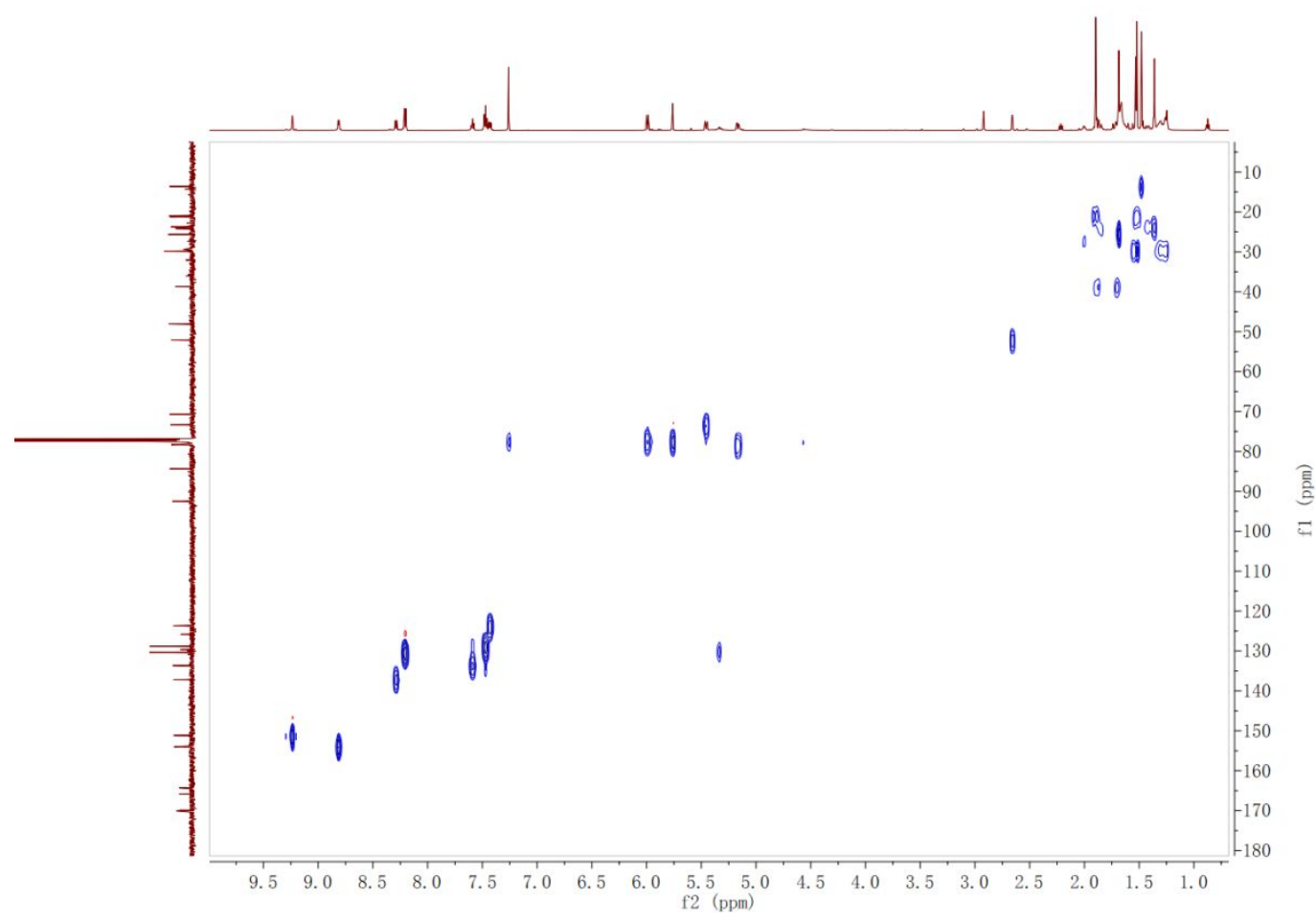


S54. HMBC spectrum of Compound 7 in $\mathrm{CDCl}_{3}$

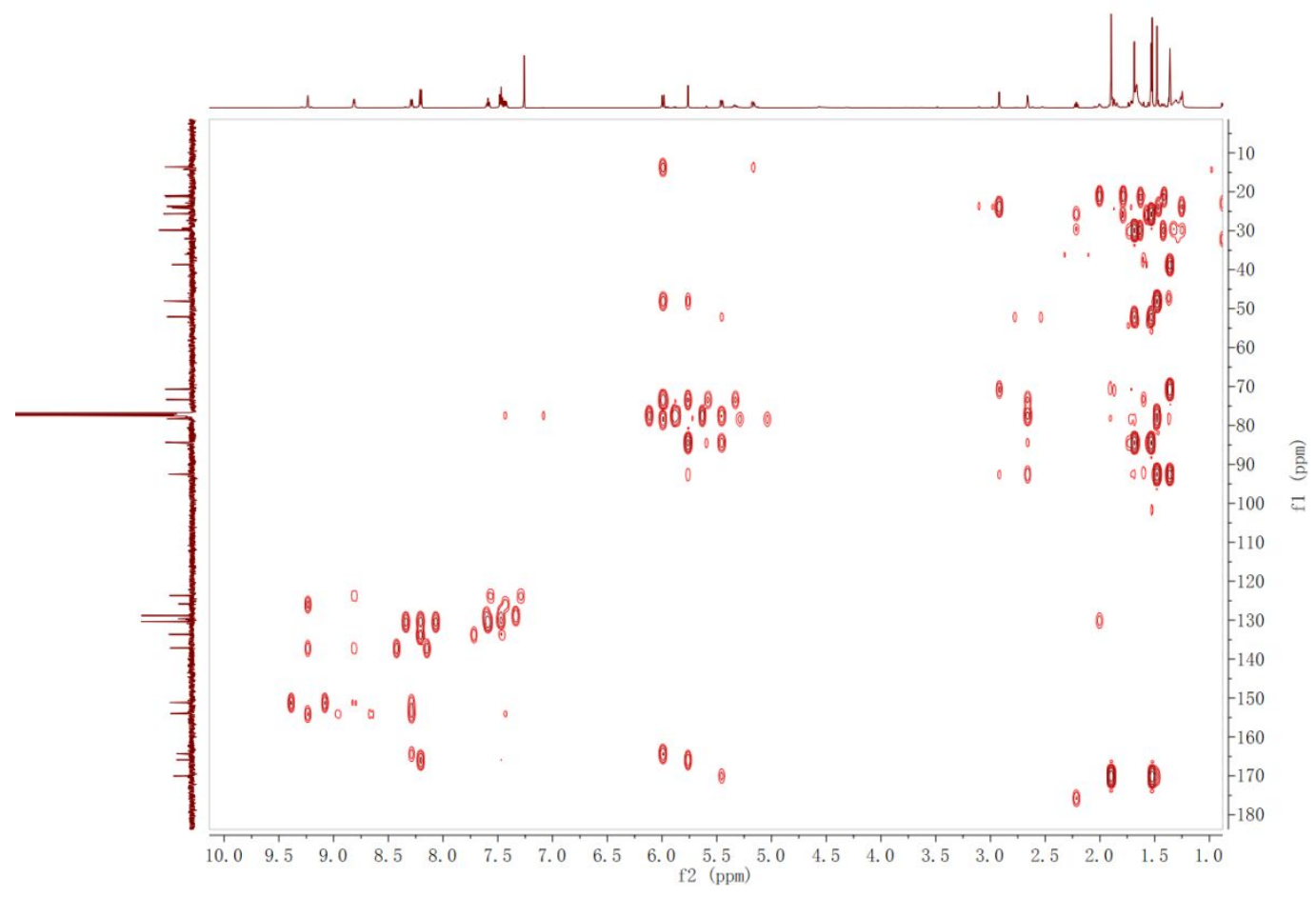

S55. NOESY of Compound 7 in $\mathrm{CDCl}_{3}$

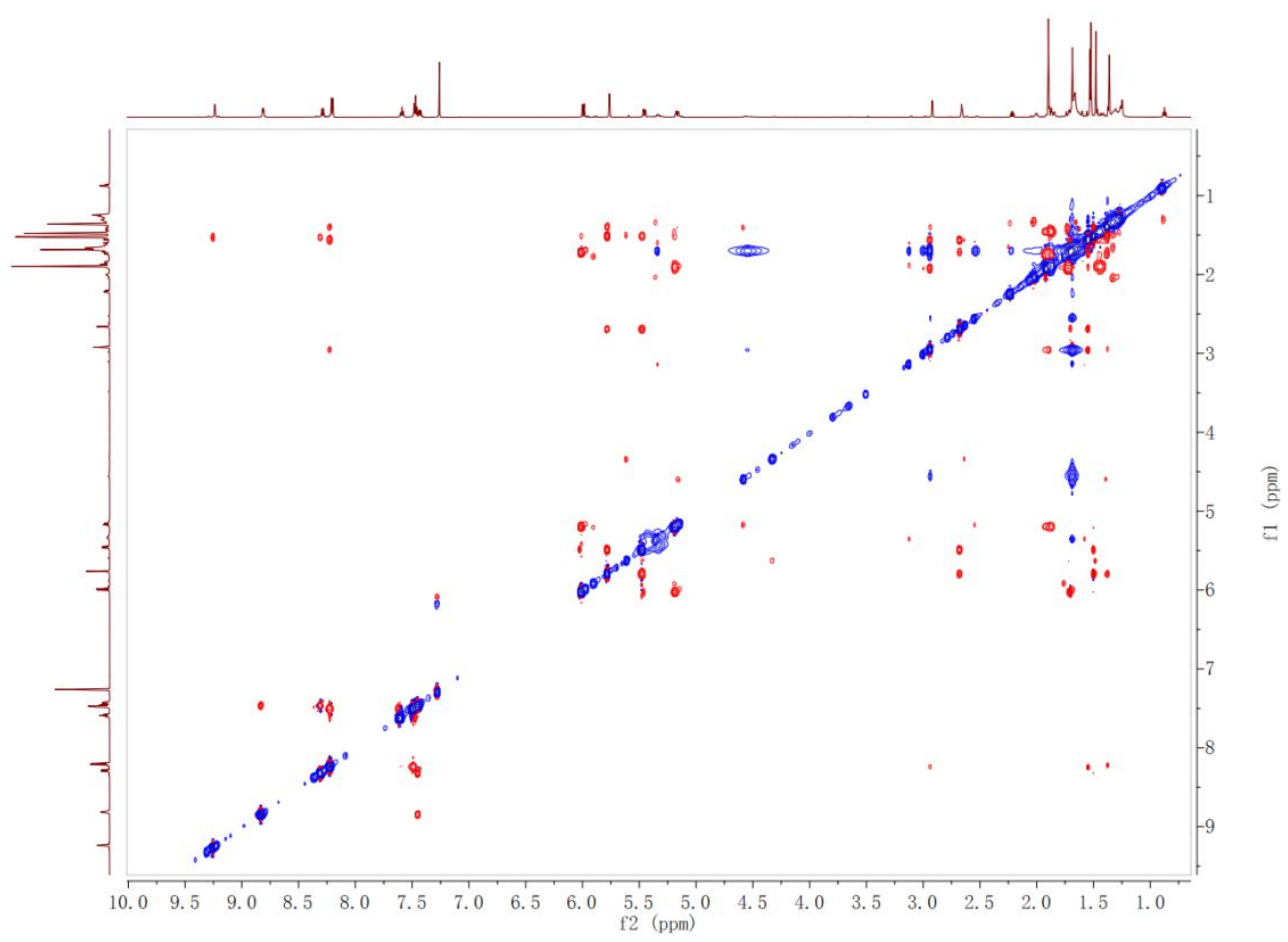


S56. IR spectrum of Compound 7

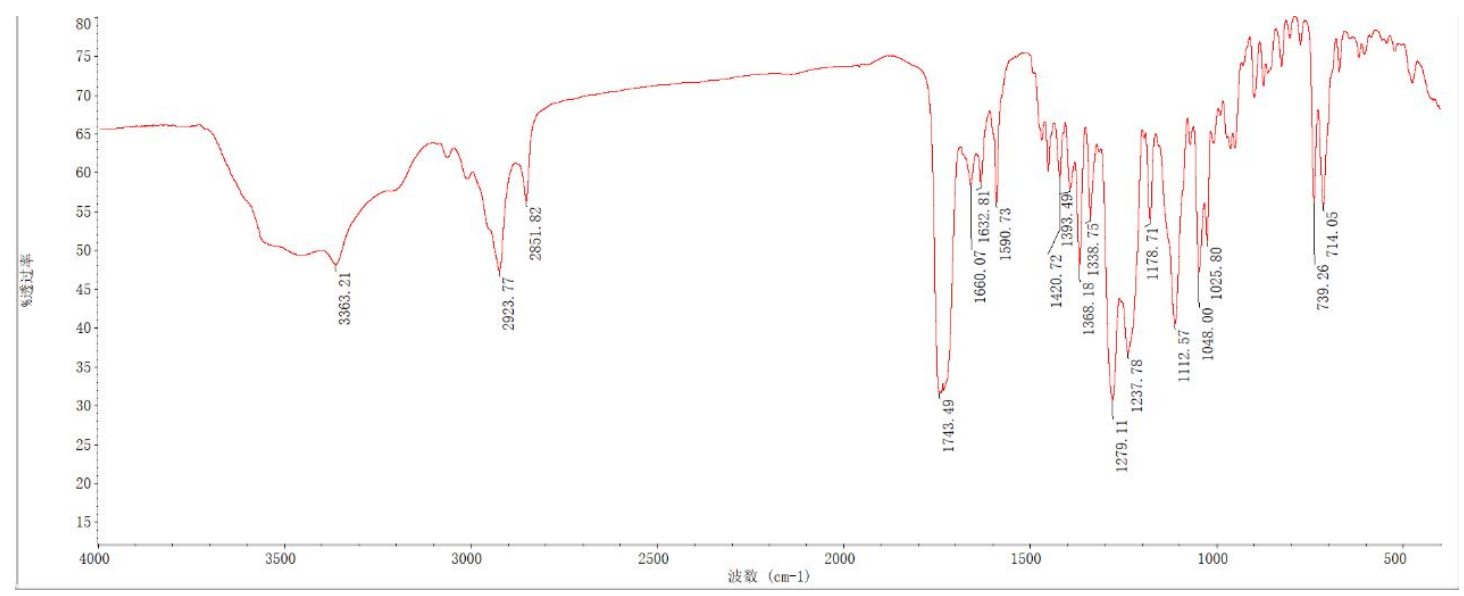

S57. UV spectrum of Compound 7

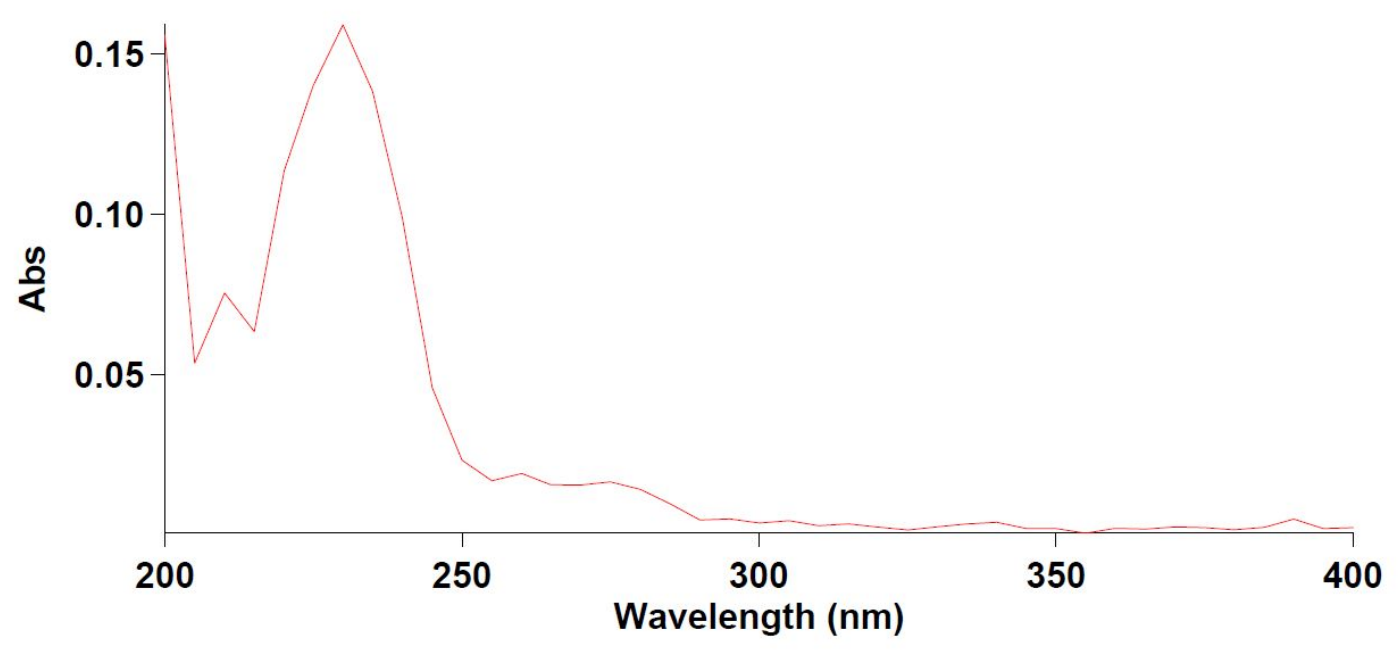


S58. HR-ESIMS of Compound 8

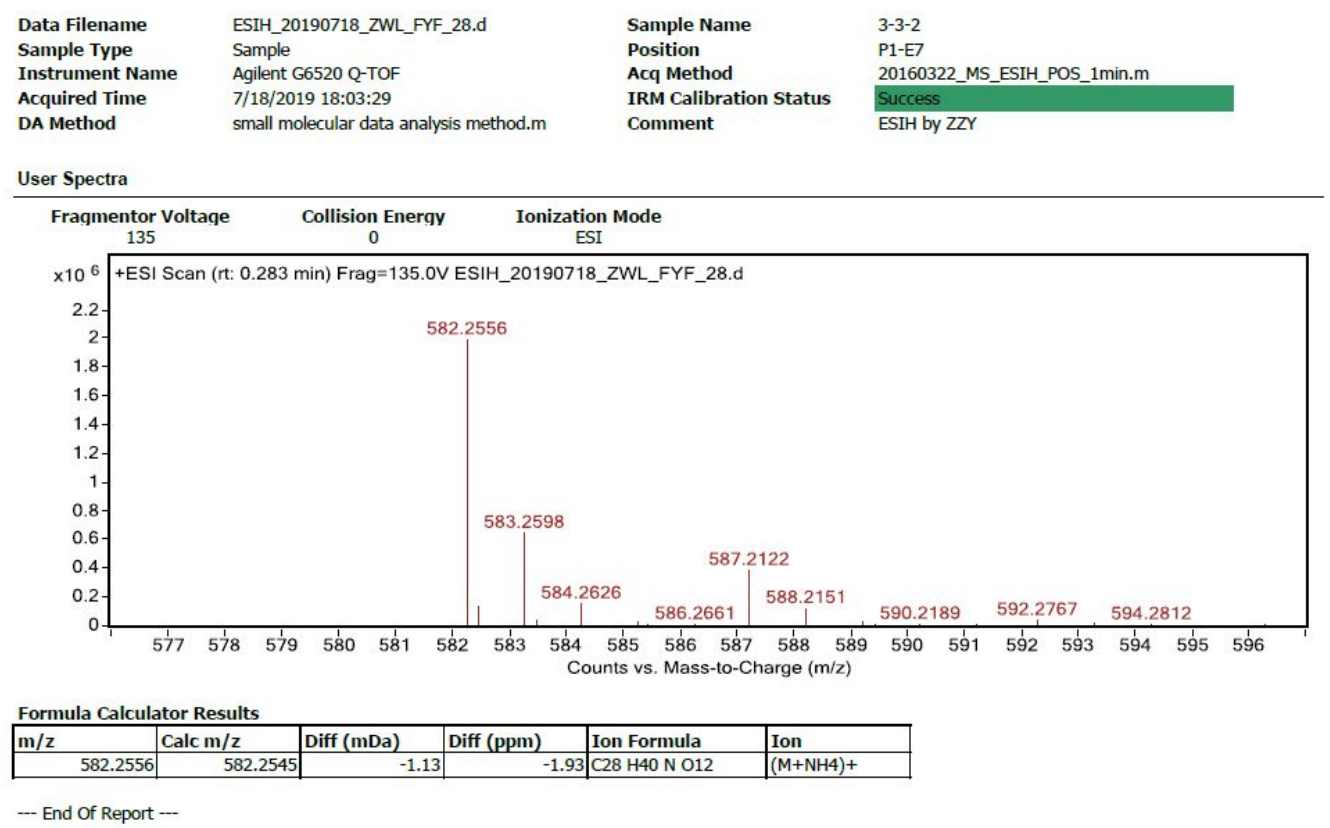

S59. ${ }^{1} \mathrm{H}$ NMR spectrum of Compound 8 in $\mathrm{CDCl}_{3}(500 \mathrm{MHz})$

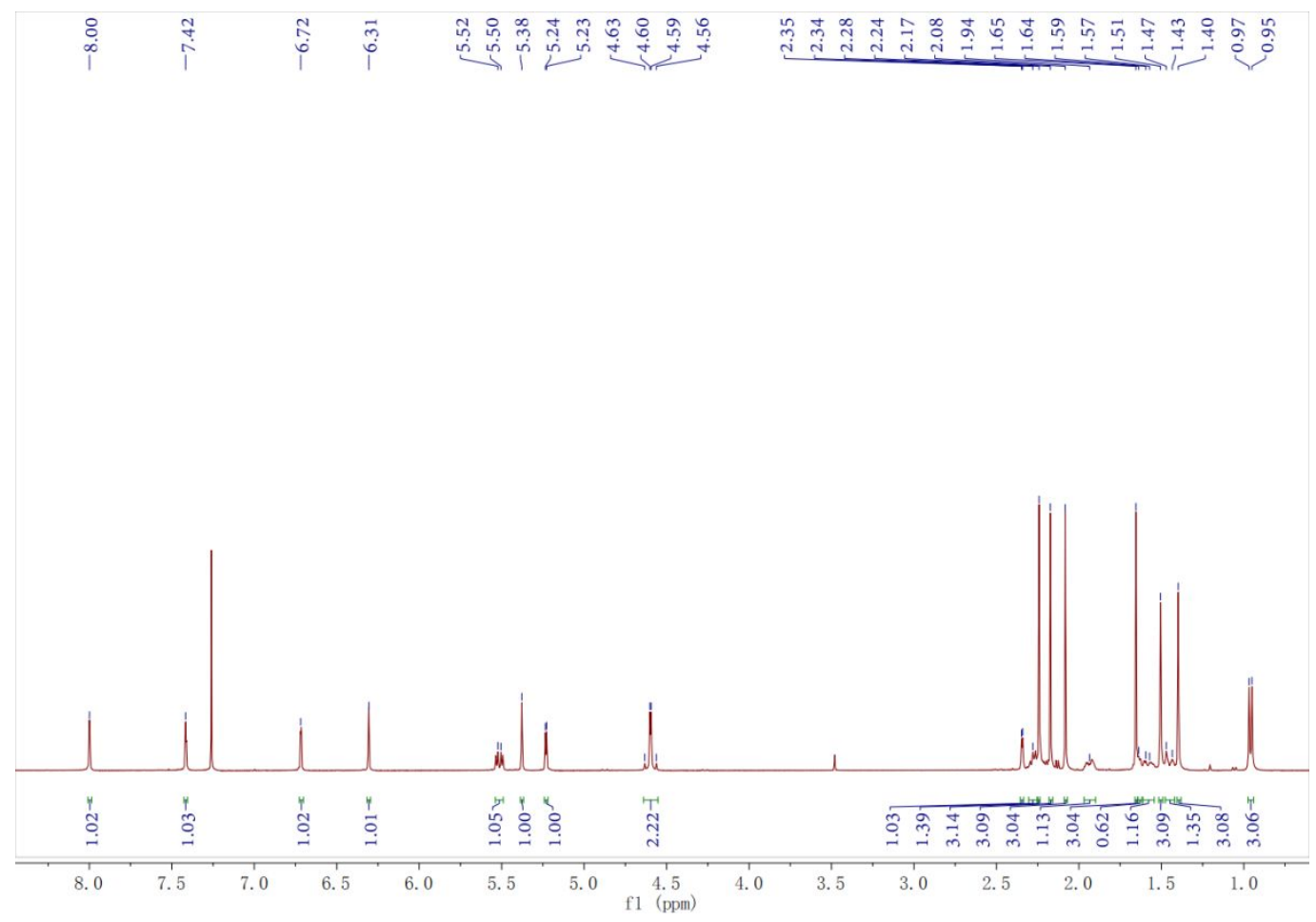


S60. ${ }^{13} \mathrm{C}$ NMR spectrum of Compound 8 in $\mathrm{CDCl}_{3}(125 \mathrm{MHz})$

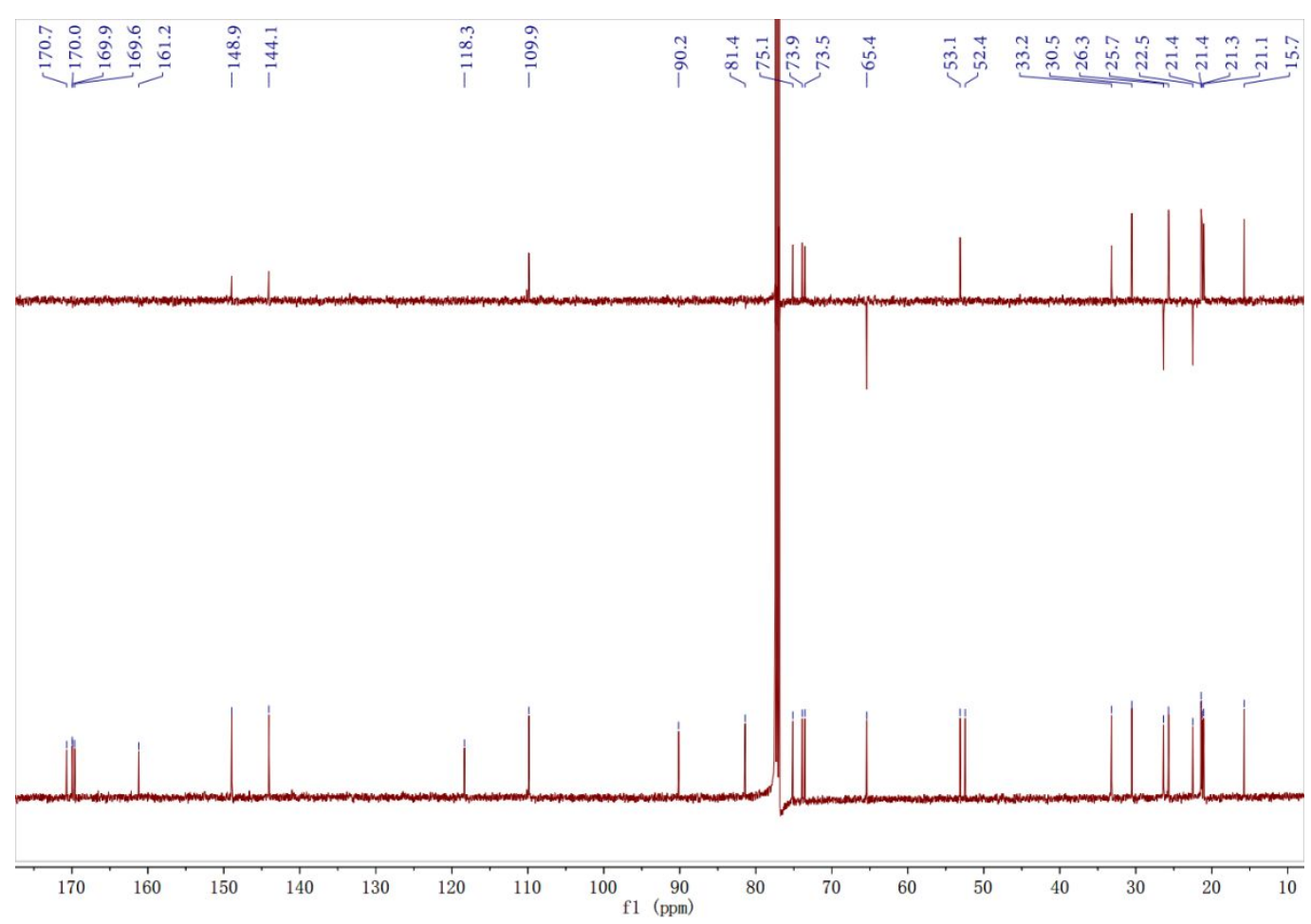


S61. HSQC spectrum of Compound 8 in $\mathrm{CDCl}_{3}$

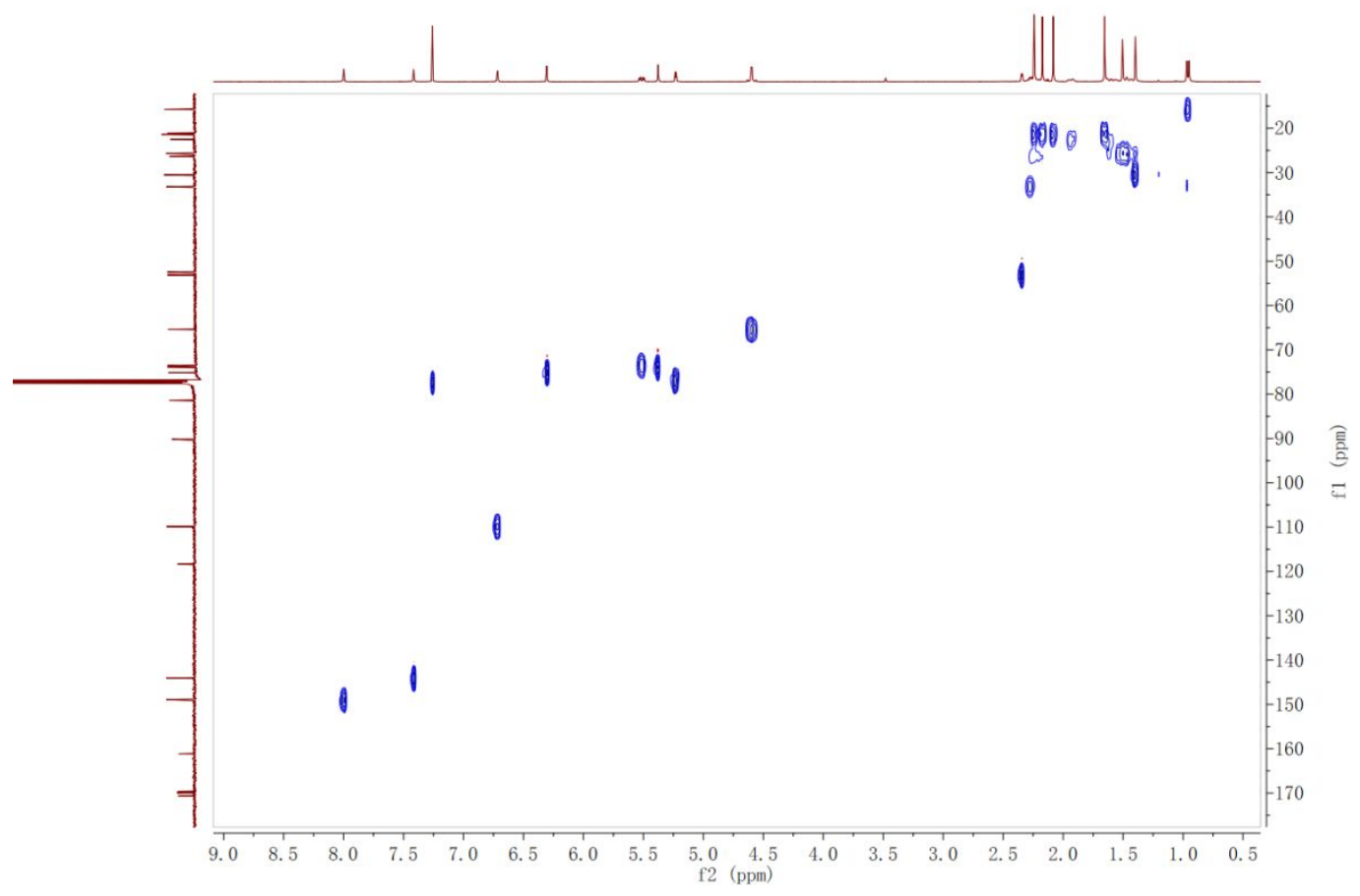

S62. HMBC spectrum of Compound 8 in $\mathrm{CDCl}_{3}$

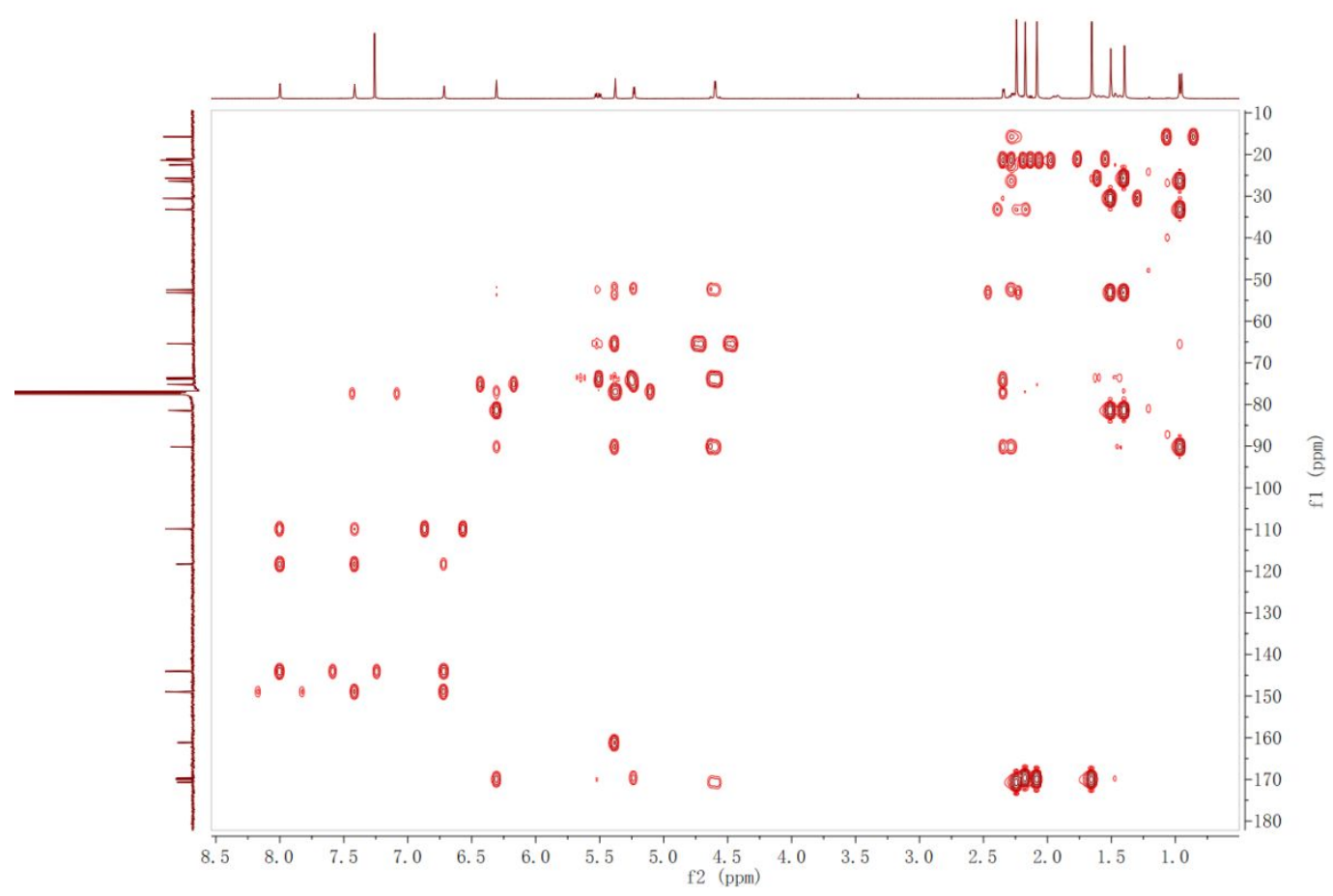


S63. NOESY of Compound 8 in $\mathrm{CDCl}_{3}$

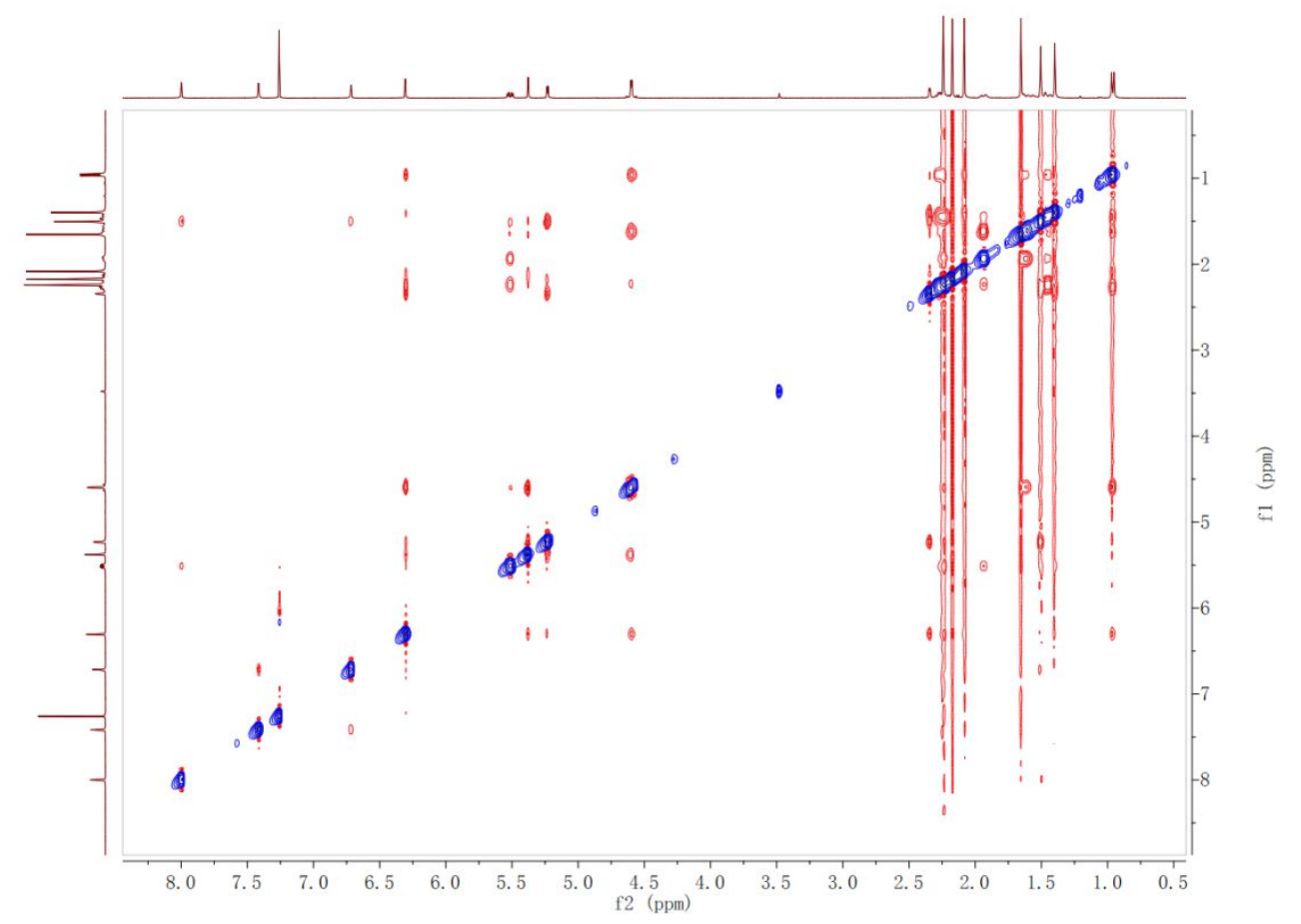

S64. IR spectrum of Compound 8

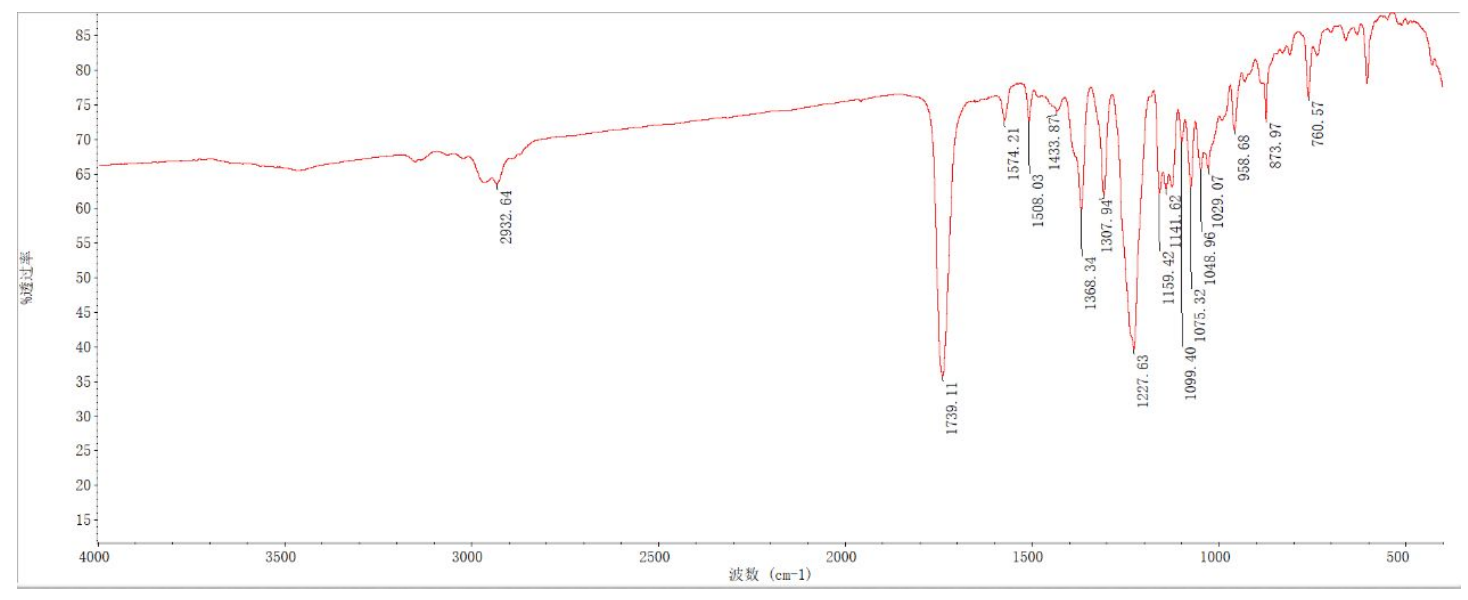


S65. UV spectrum of Compound 8

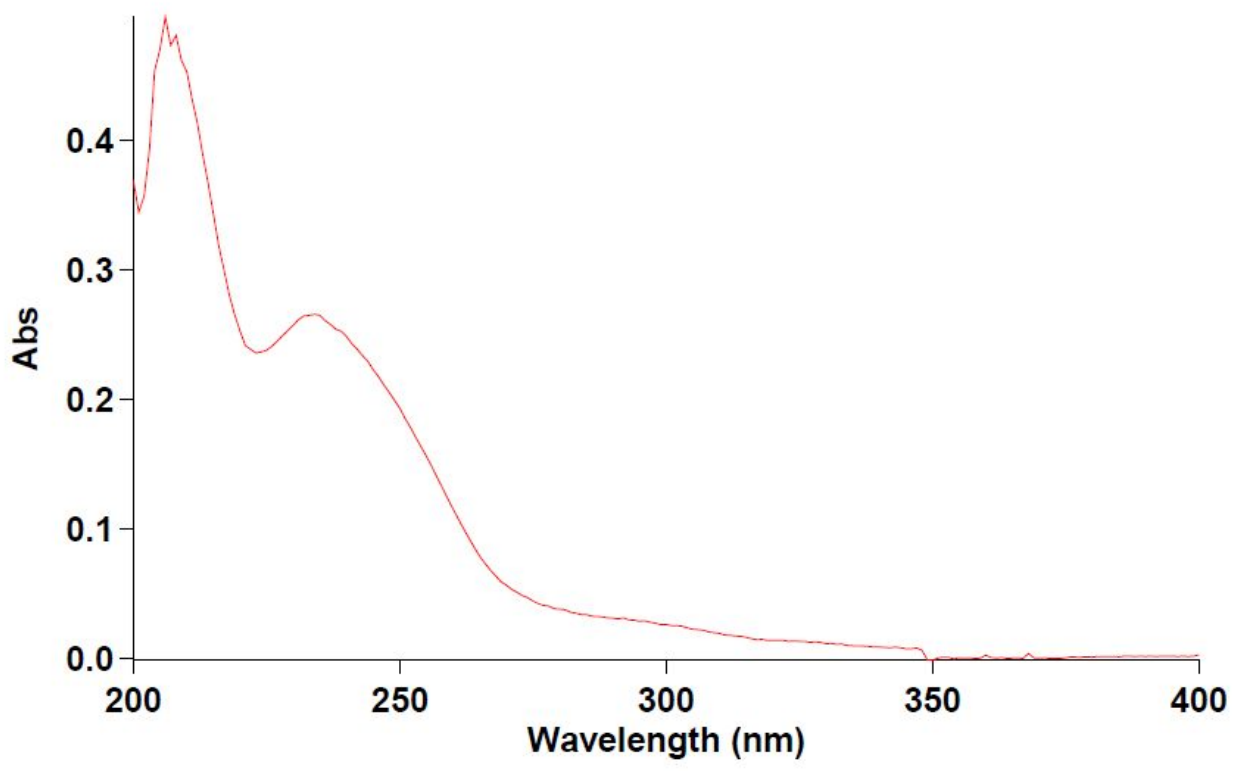


S66. HR-ESIMS of Compound 9

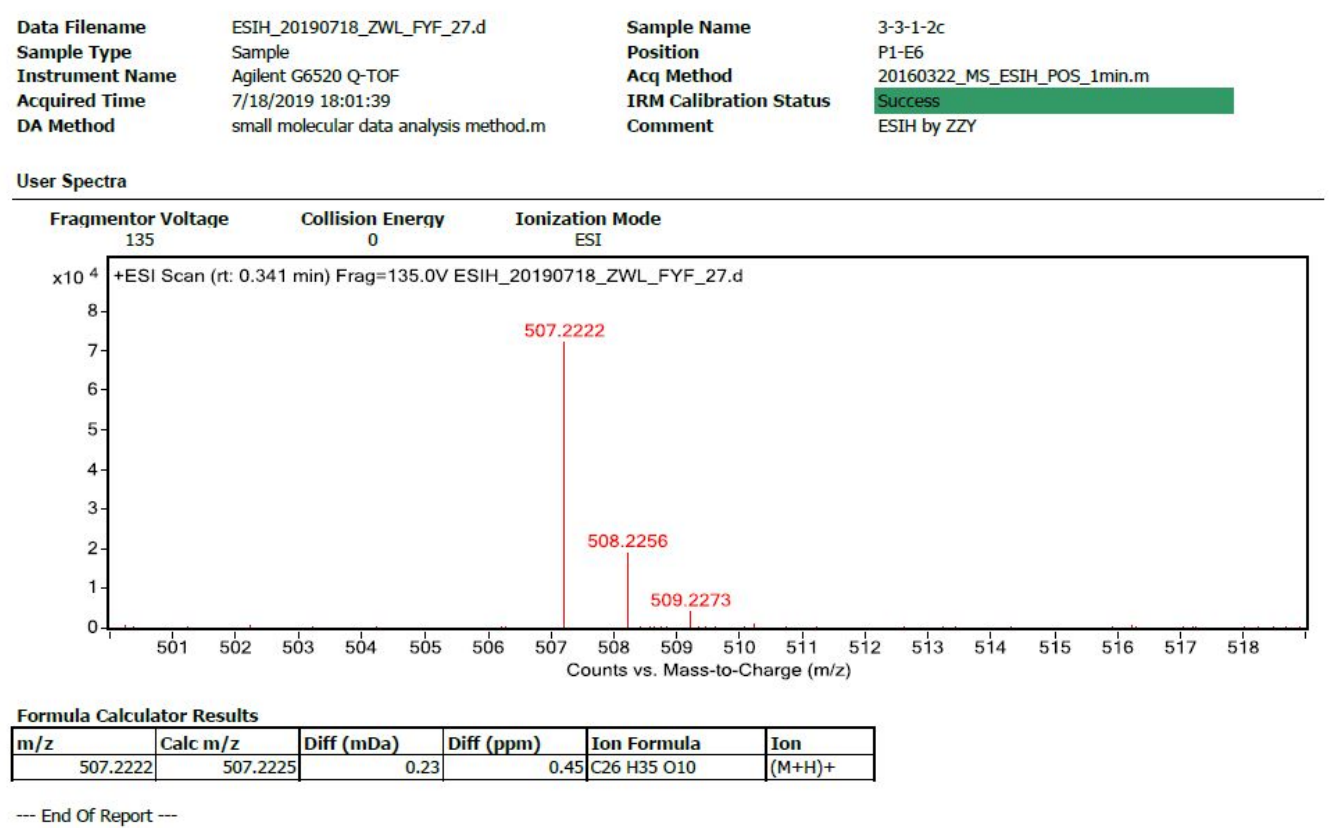

S67. ${ }^{1} \mathrm{H}$ NMR spectrum of Compound 9 in $\mathrm{CDCl}_{3}(500 \mathrm{MHz})$

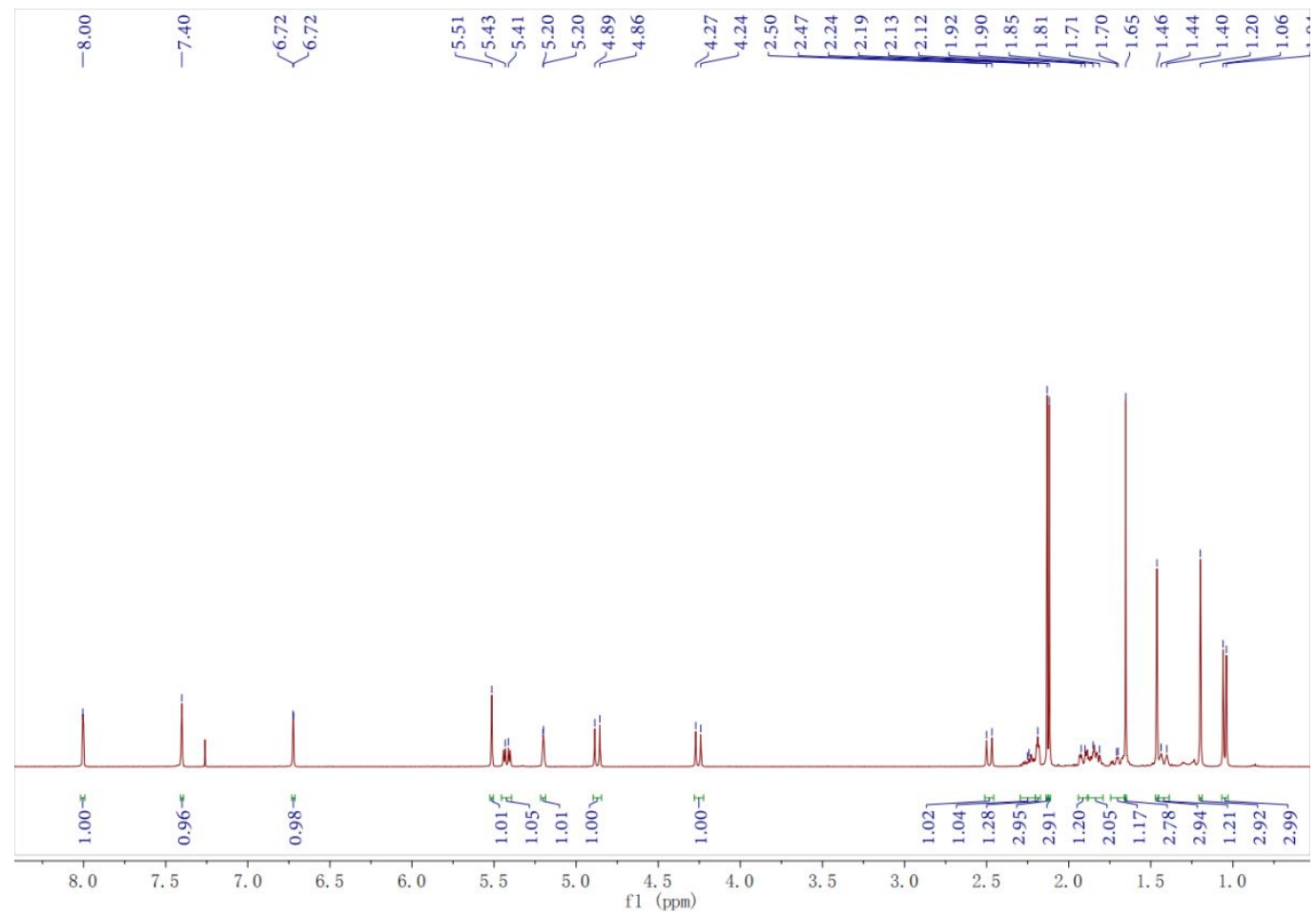


S68. ${ }^{13} \mathrm{C}$ NMR spectrum of Compound 9 in $\mathrm{CDCl}_{3}(125 \mathrm{MHz})$

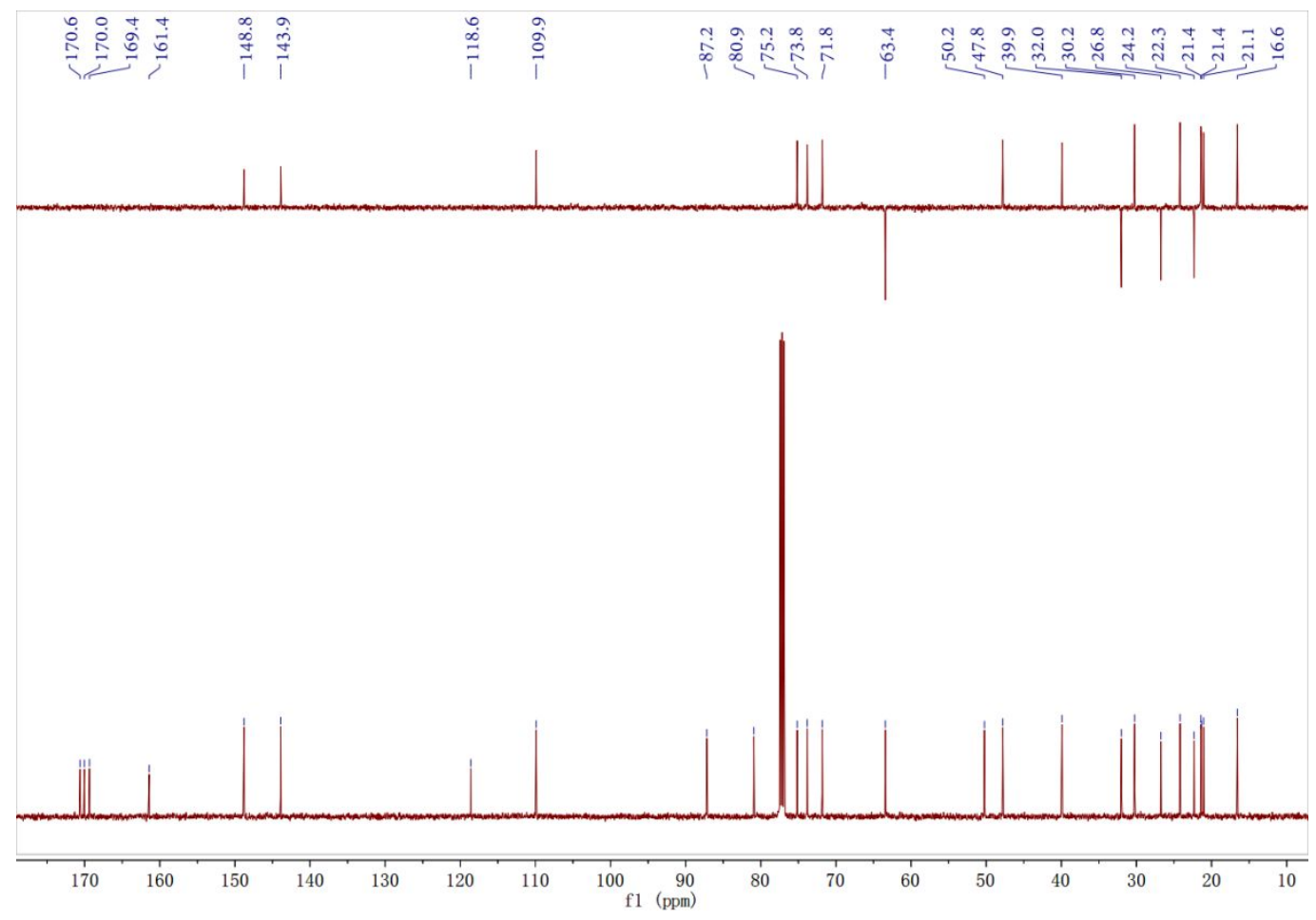


S69. HSQC spectrum of Compound 9 in $\mathrm{CDCl}_{3}$

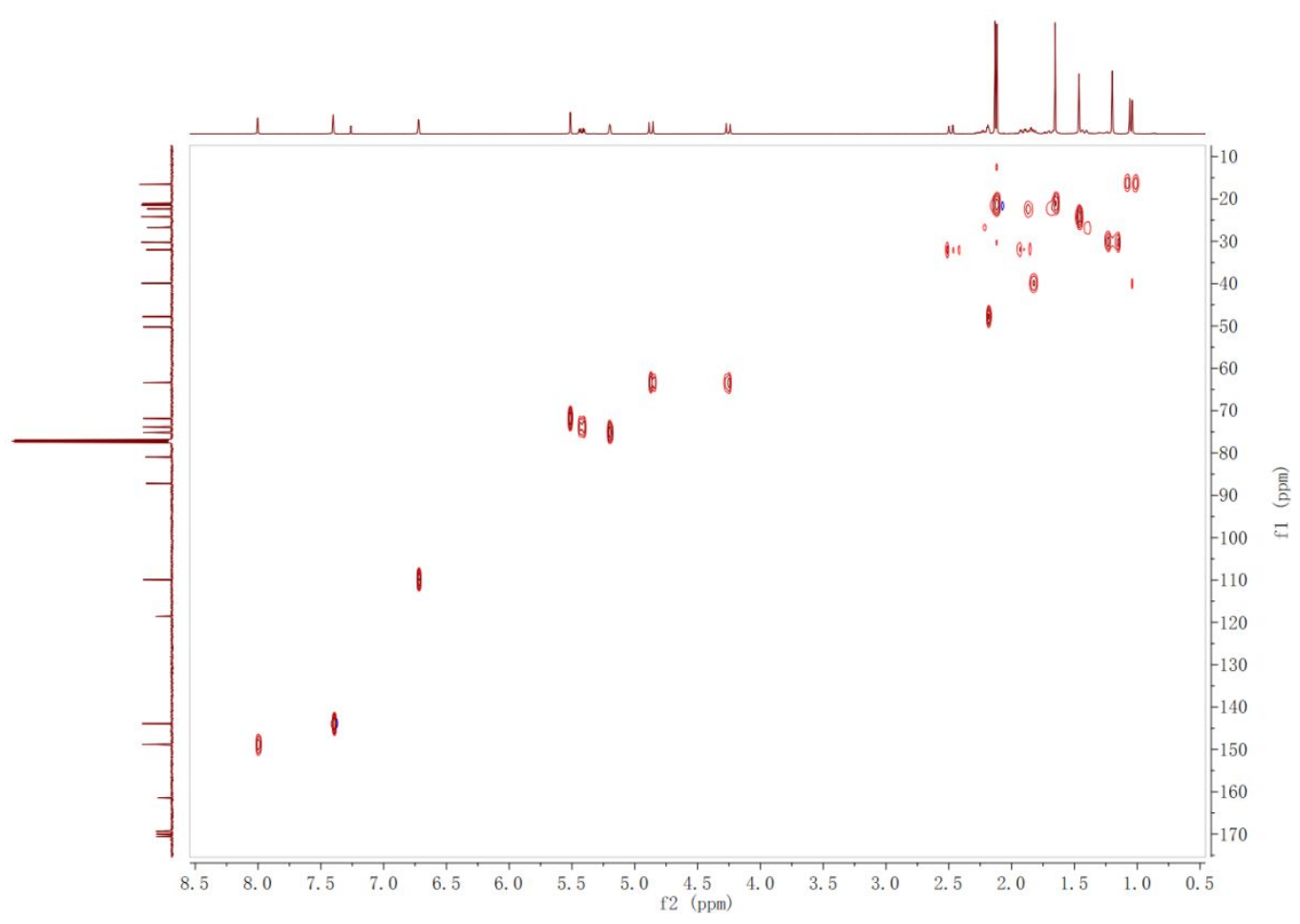

S70. HMBC spectrum of Compound 9 in $\mathrm{CDCl}_{3}$

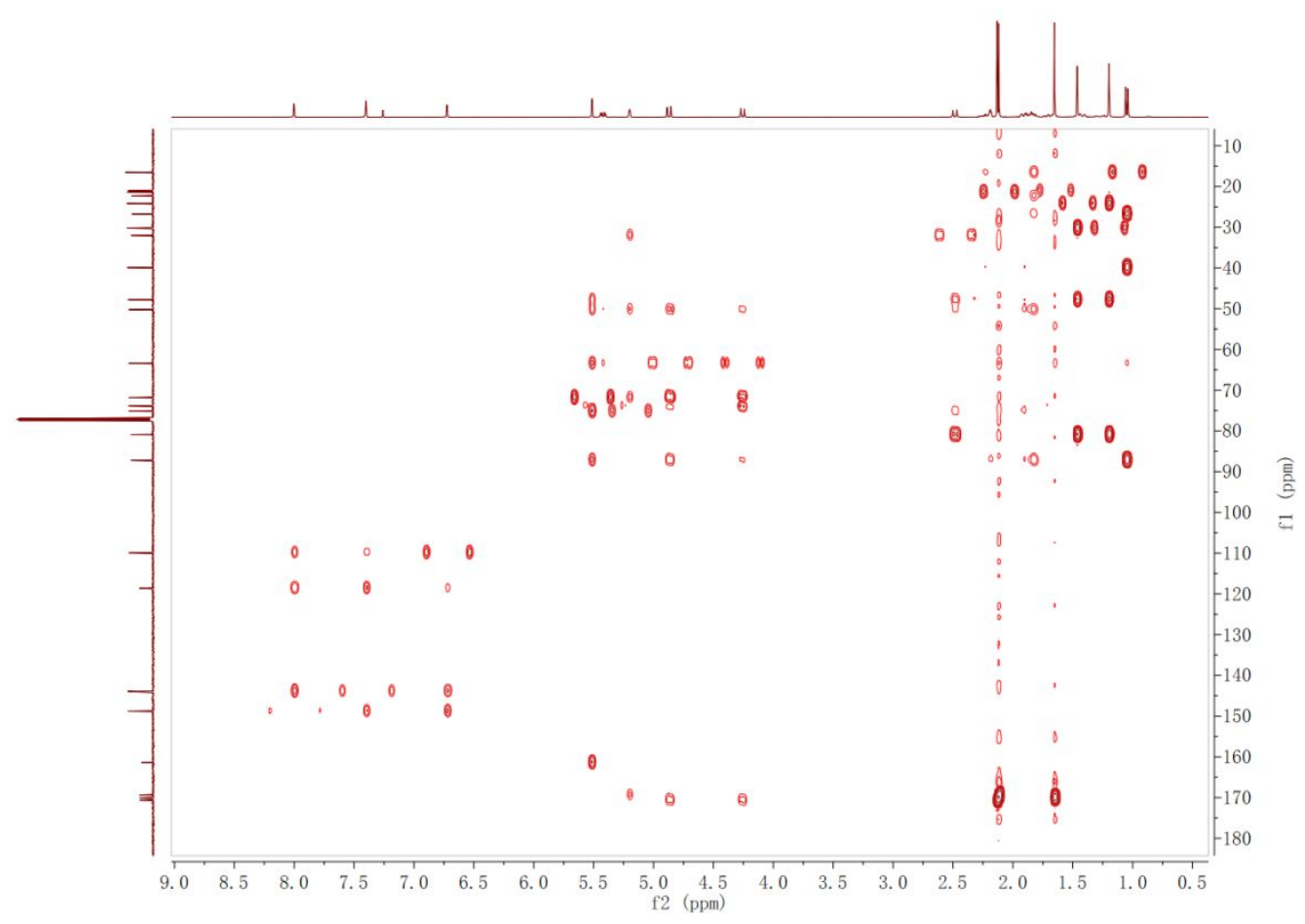


S71. NOESY of Compound 9 in $\mathrm{CDCl}_{3}$

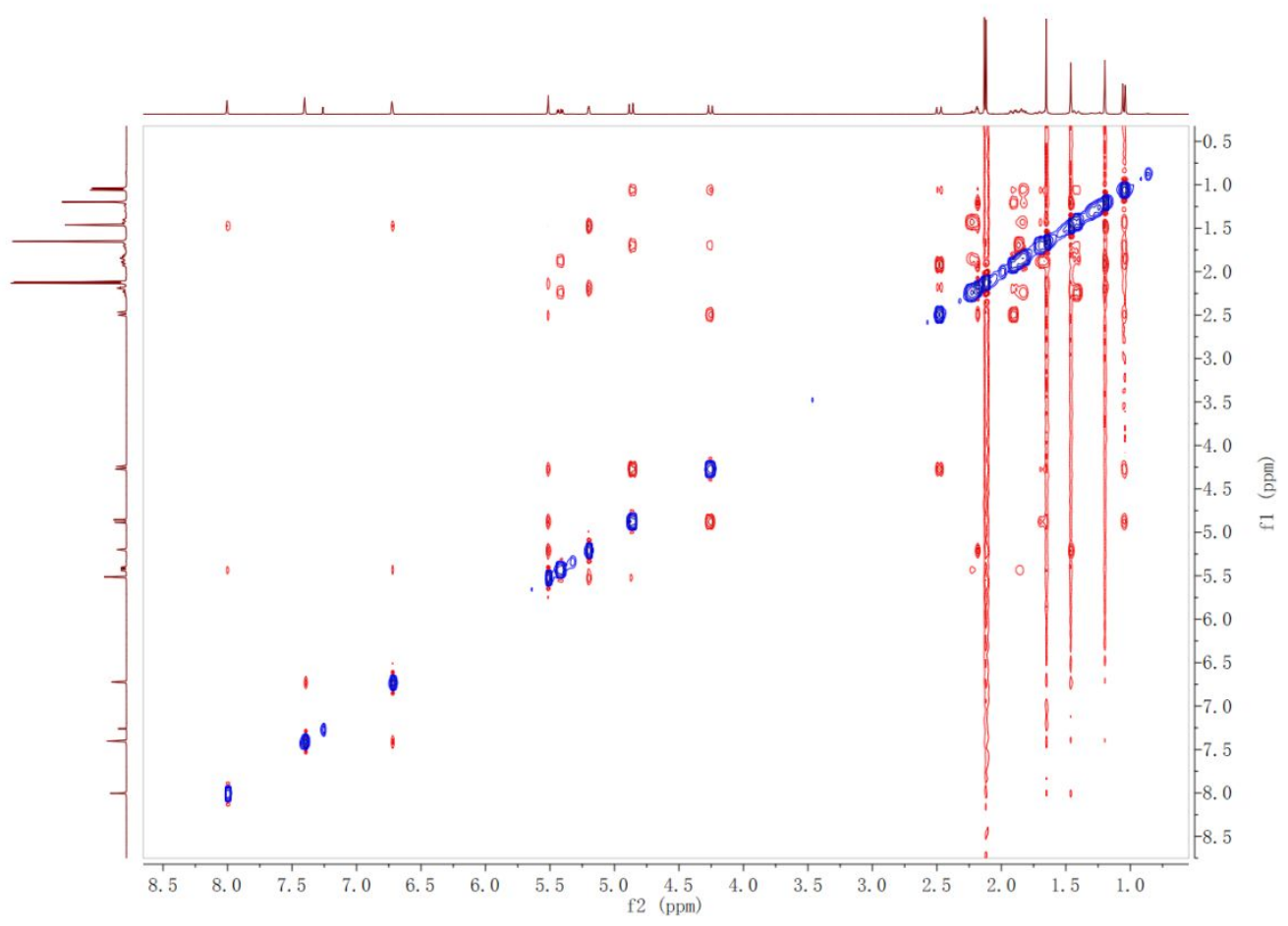

S72. IR spectrum of Compound 9

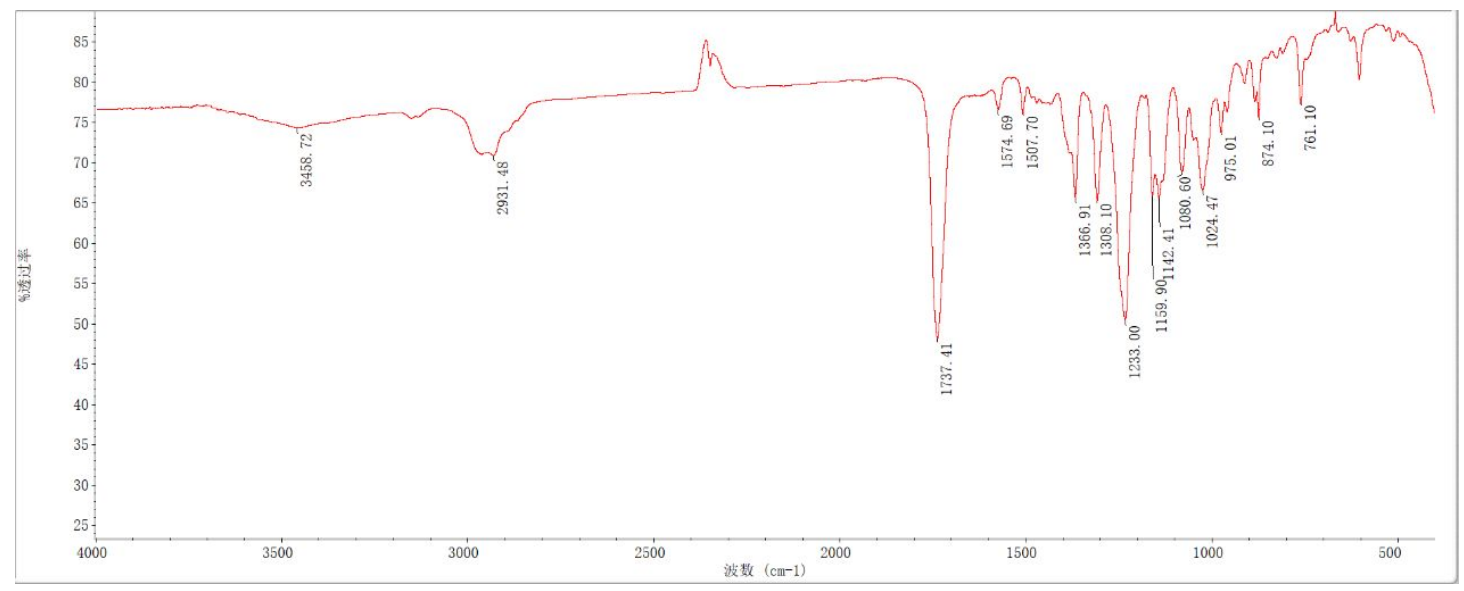

51 
S73. UV spectrum of Compound 9

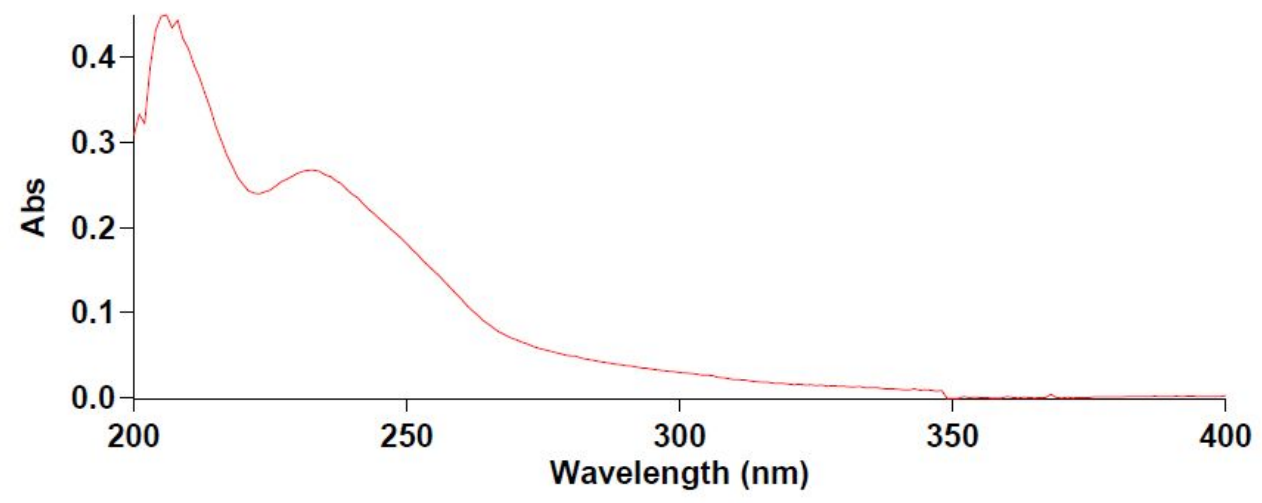


S74. HR-ESIMS of Compound 10

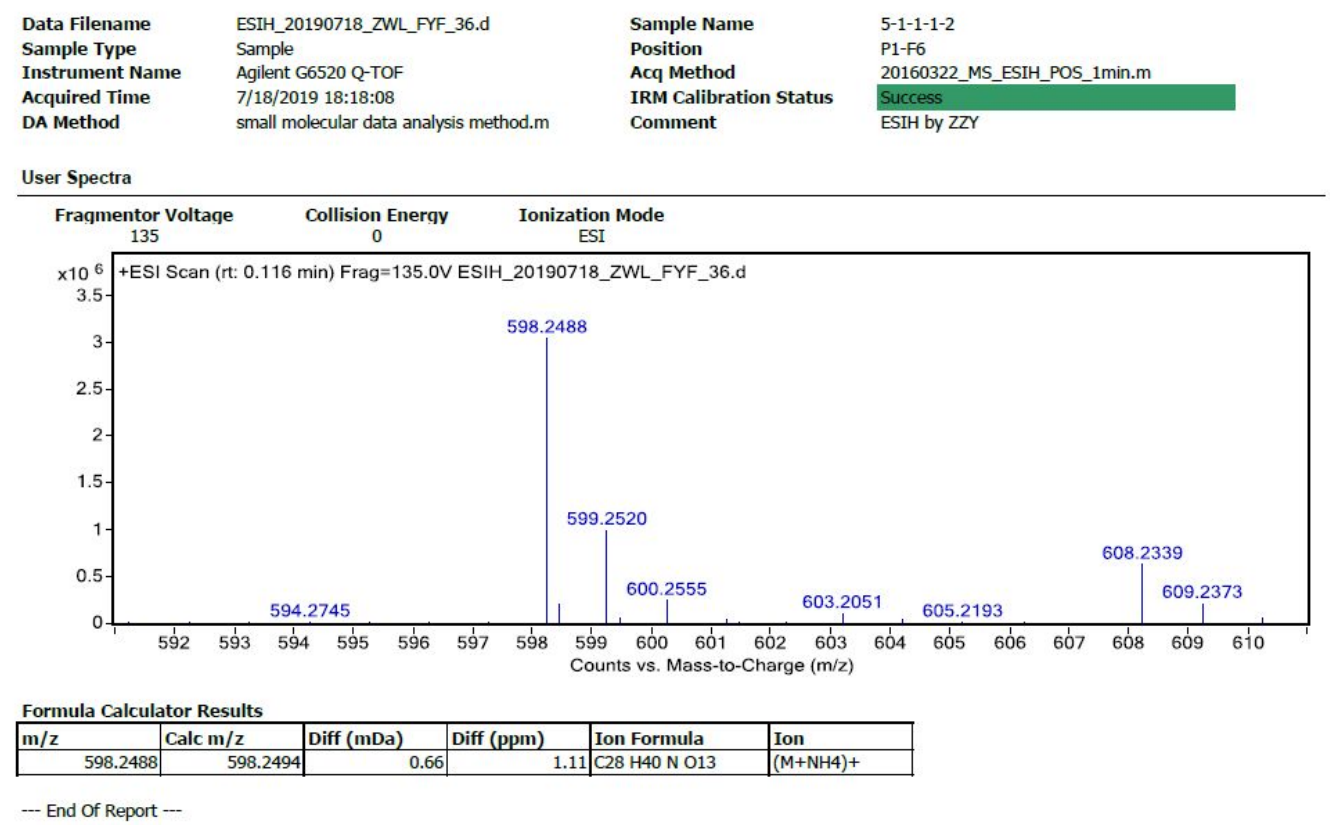

S75. ${ }^{1} \mathrm{H}$ NMR spectrum of Compound 10 in $\mathrm{CDCl}_{3}(500 \mathrm{MHz})$

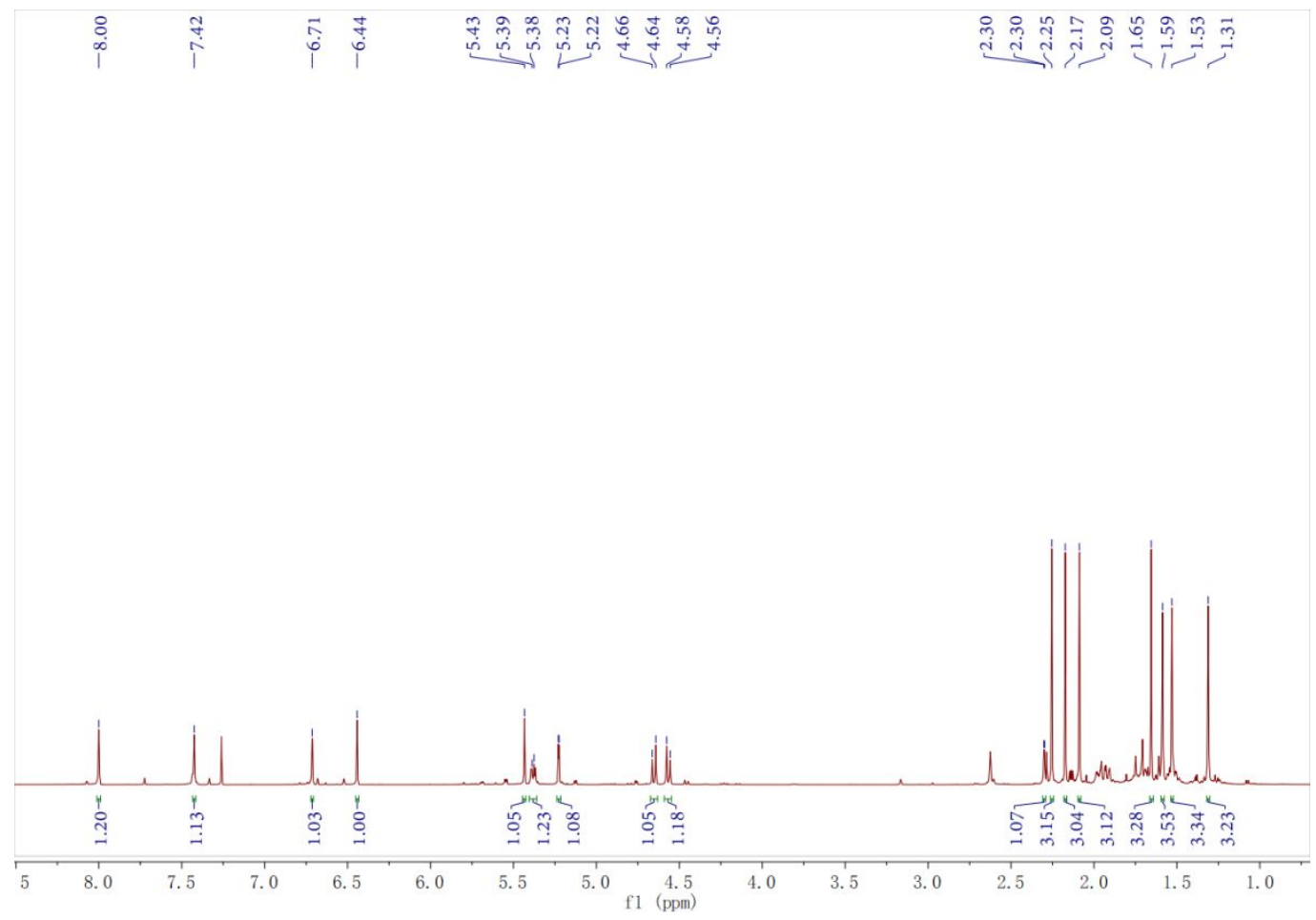


S76. ${ }^{13} \mathrm{C}$ NMR spectrum of Compound 10 in $\mathrm{CDCl}_{3}(125 \mathrm{MHz})$

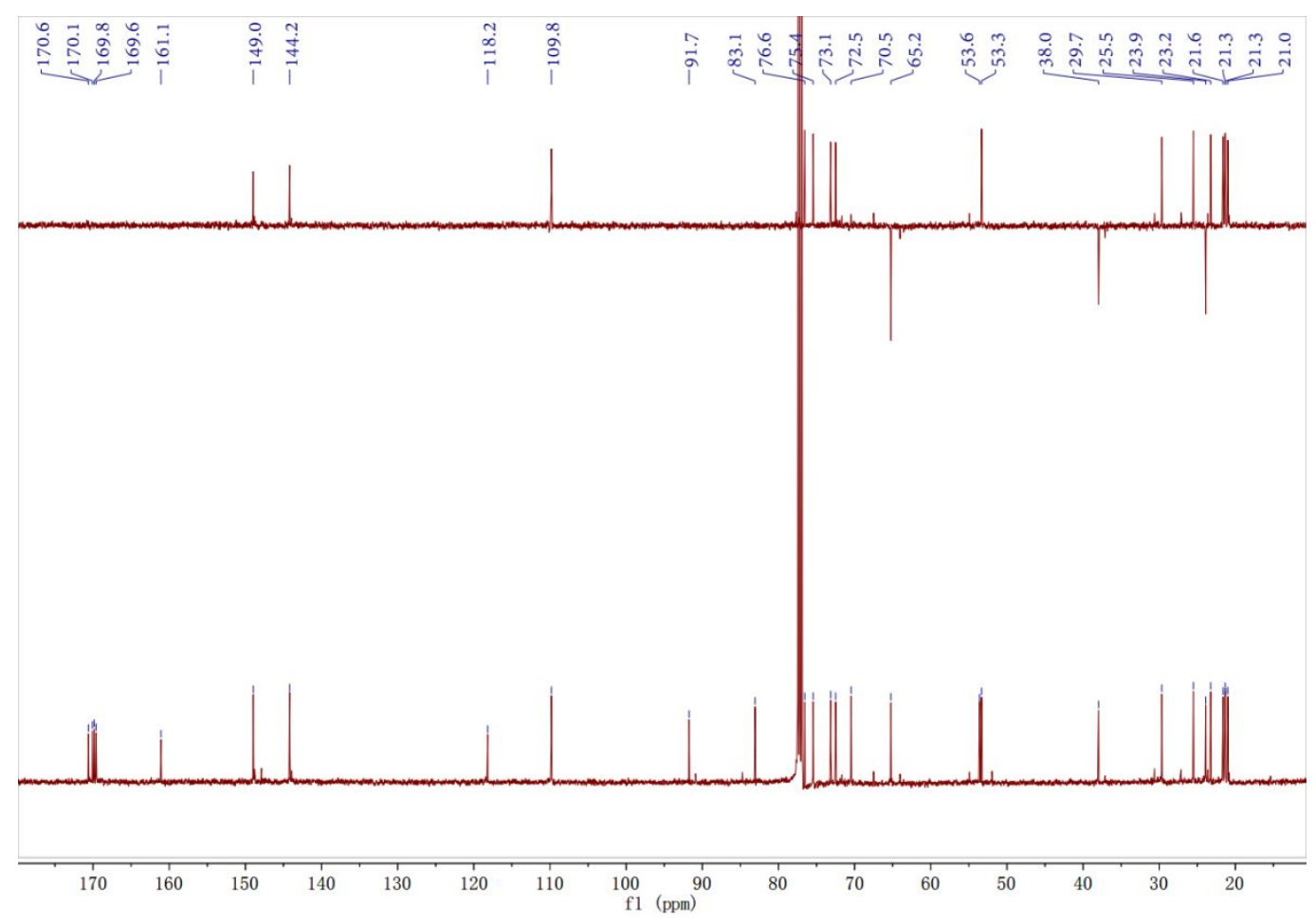


S77. HSQC spectrum of Compound 10 in $\mathrm{CDCl}_{3}$

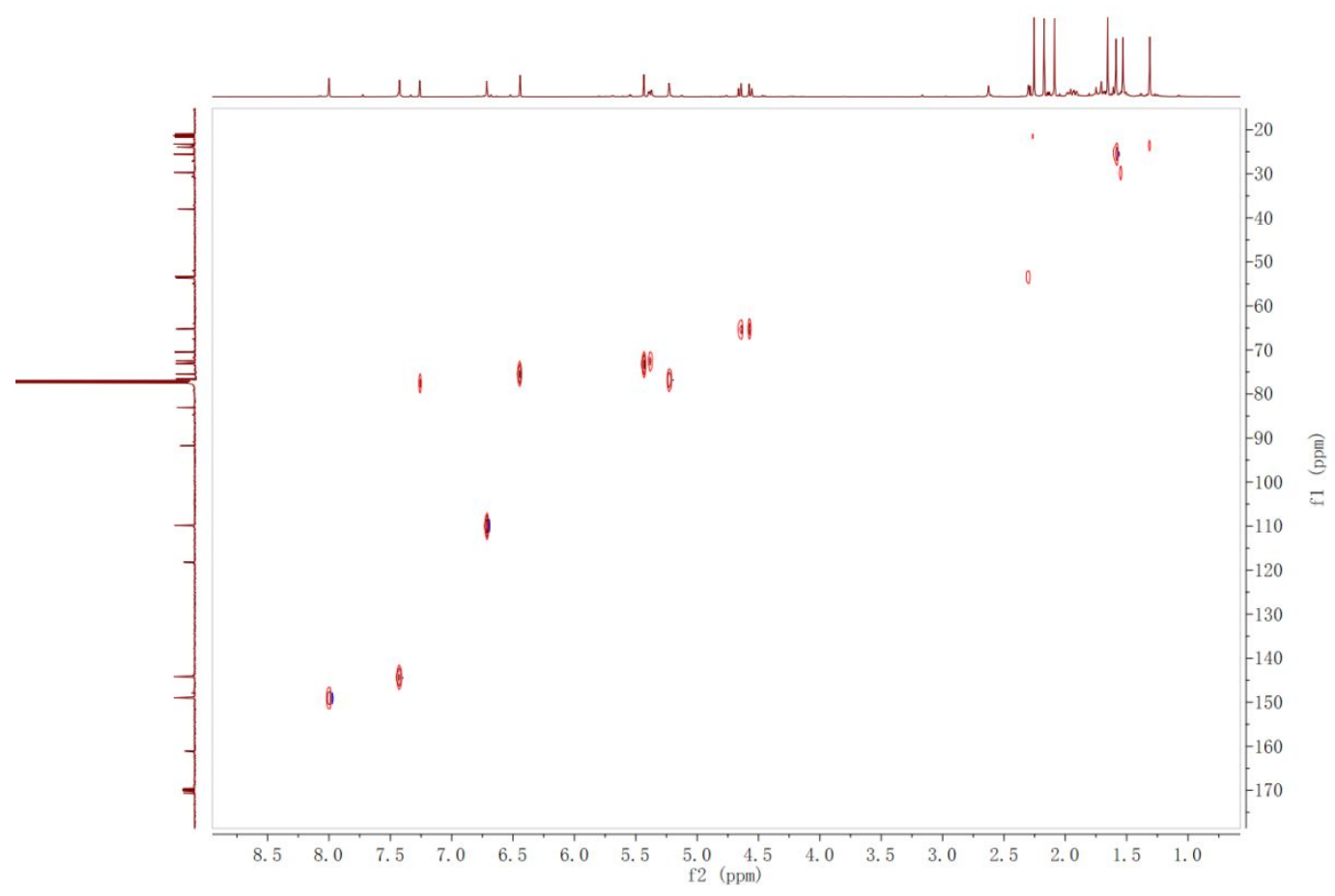

S78. HMBC spectrum of Compound 10 in $\mathrm{CDCl}_{3}$

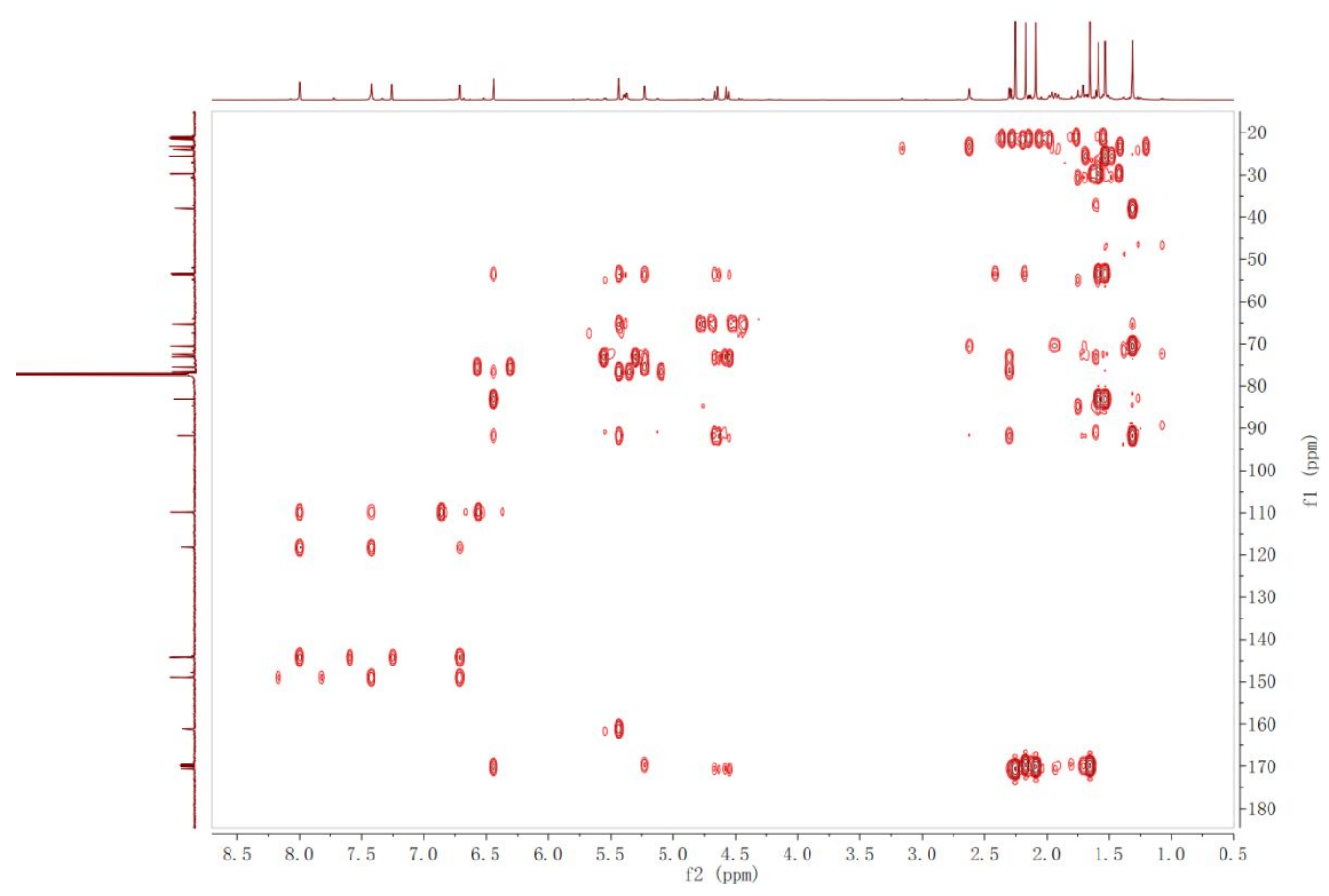


S79. NOESY of Compound 10 in $\mathrm{CDCl}_{3}$

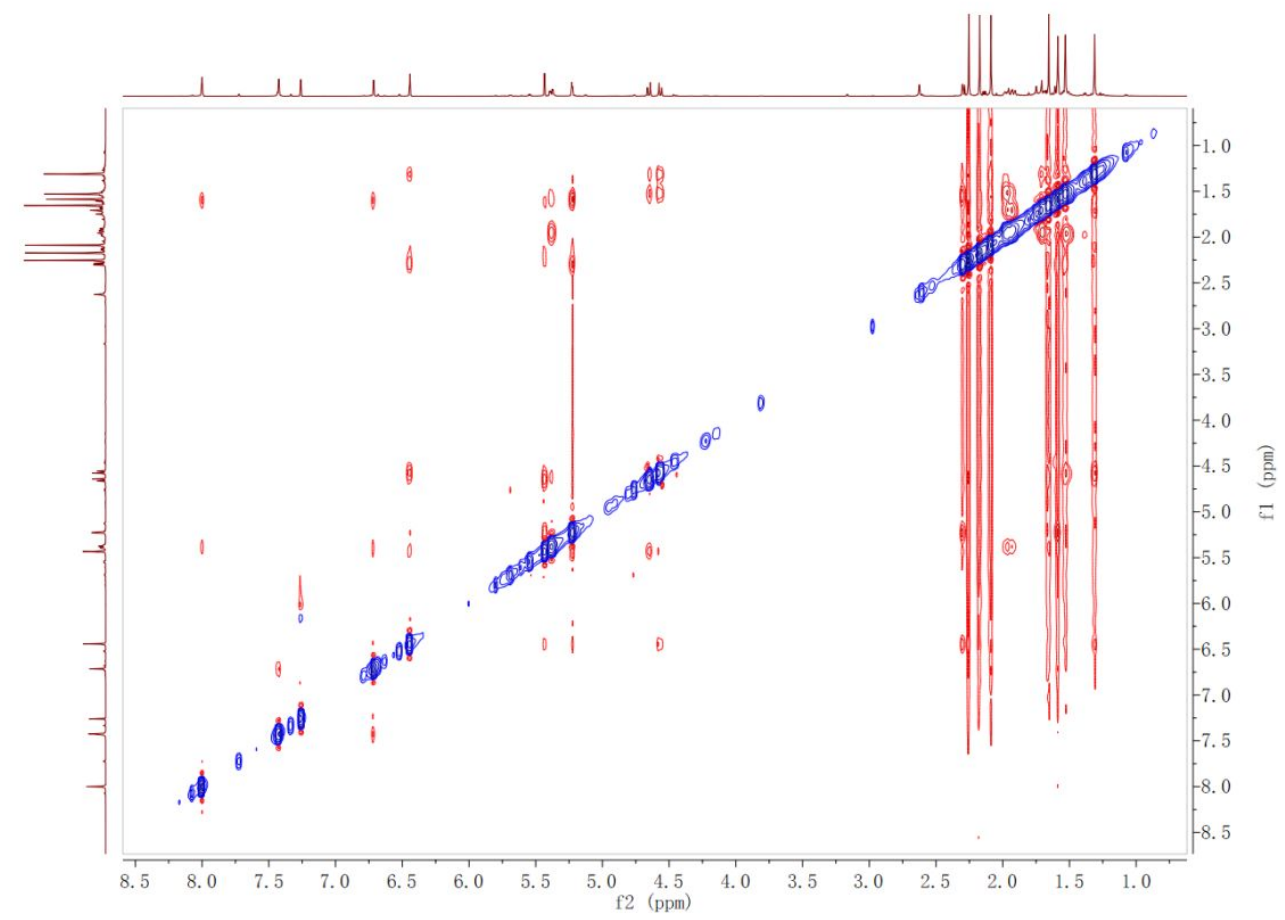

S80. IR spectrum of Compound 10

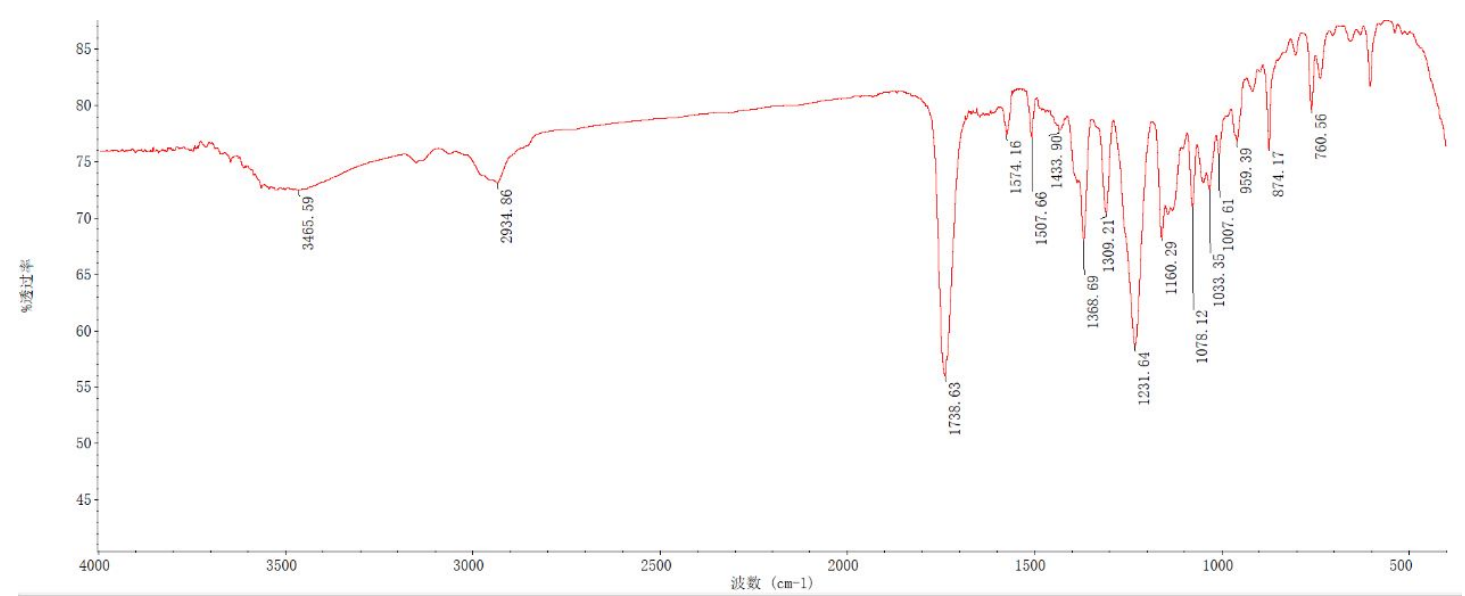


S81. UV spectrum of Compound 10

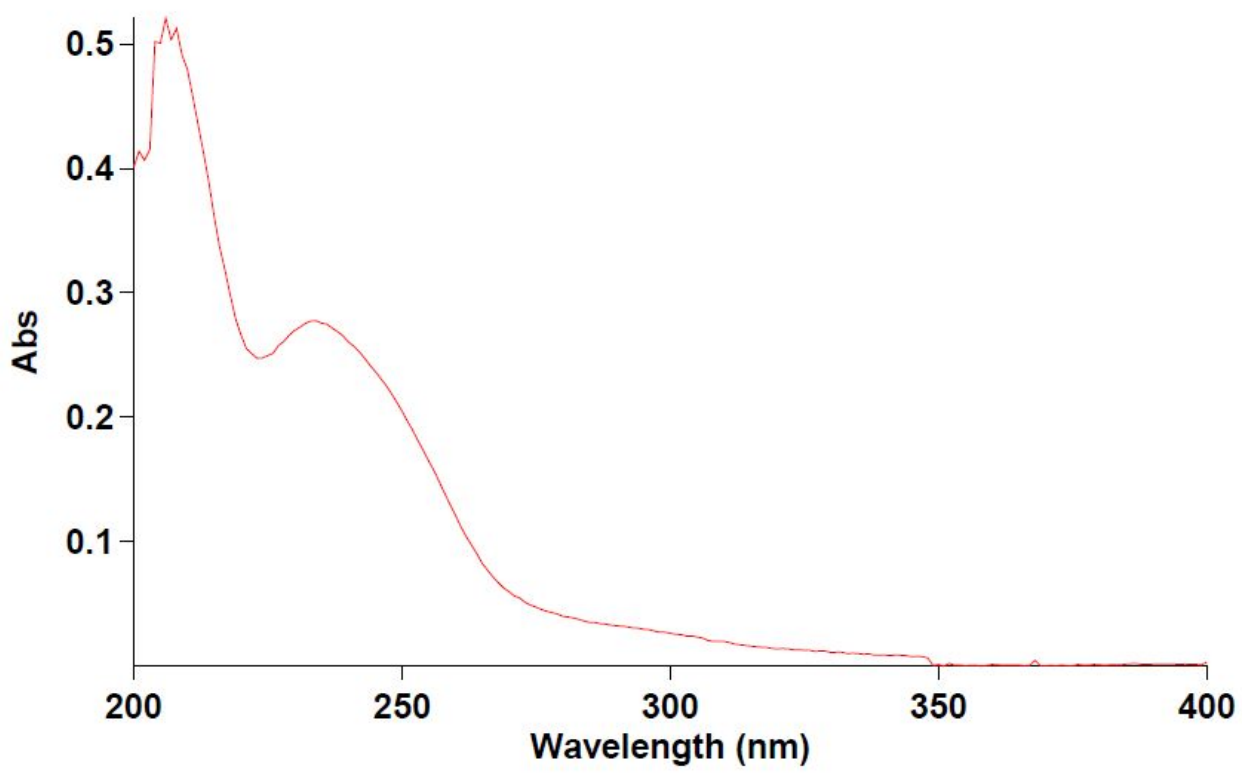


S82. HR-ESIMS of Compound 11

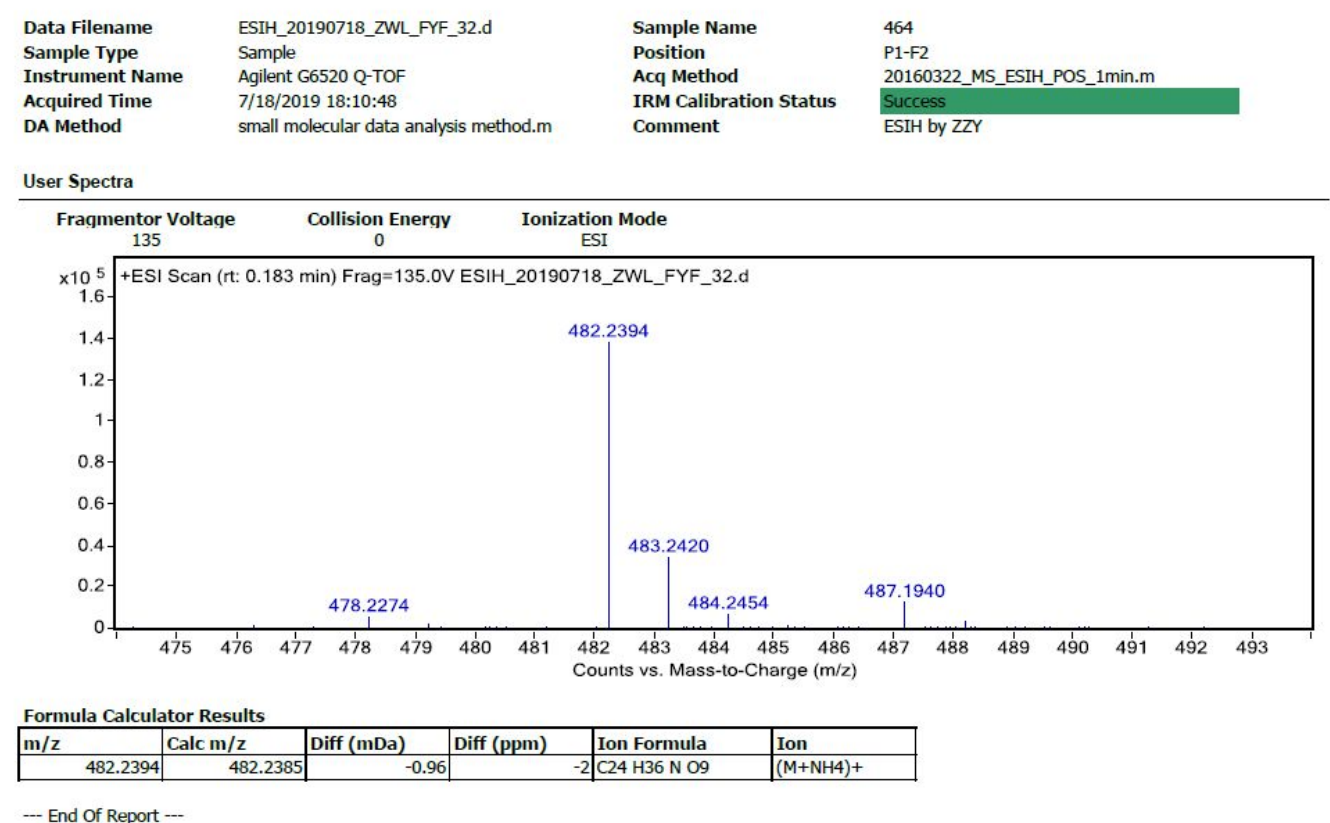

S83. ${ }^{1} \mathrm{H}$ NMR spectrum of Compound 11 in $\mathrm{CDCl}_{3}(500 \mathrm{MHz})$

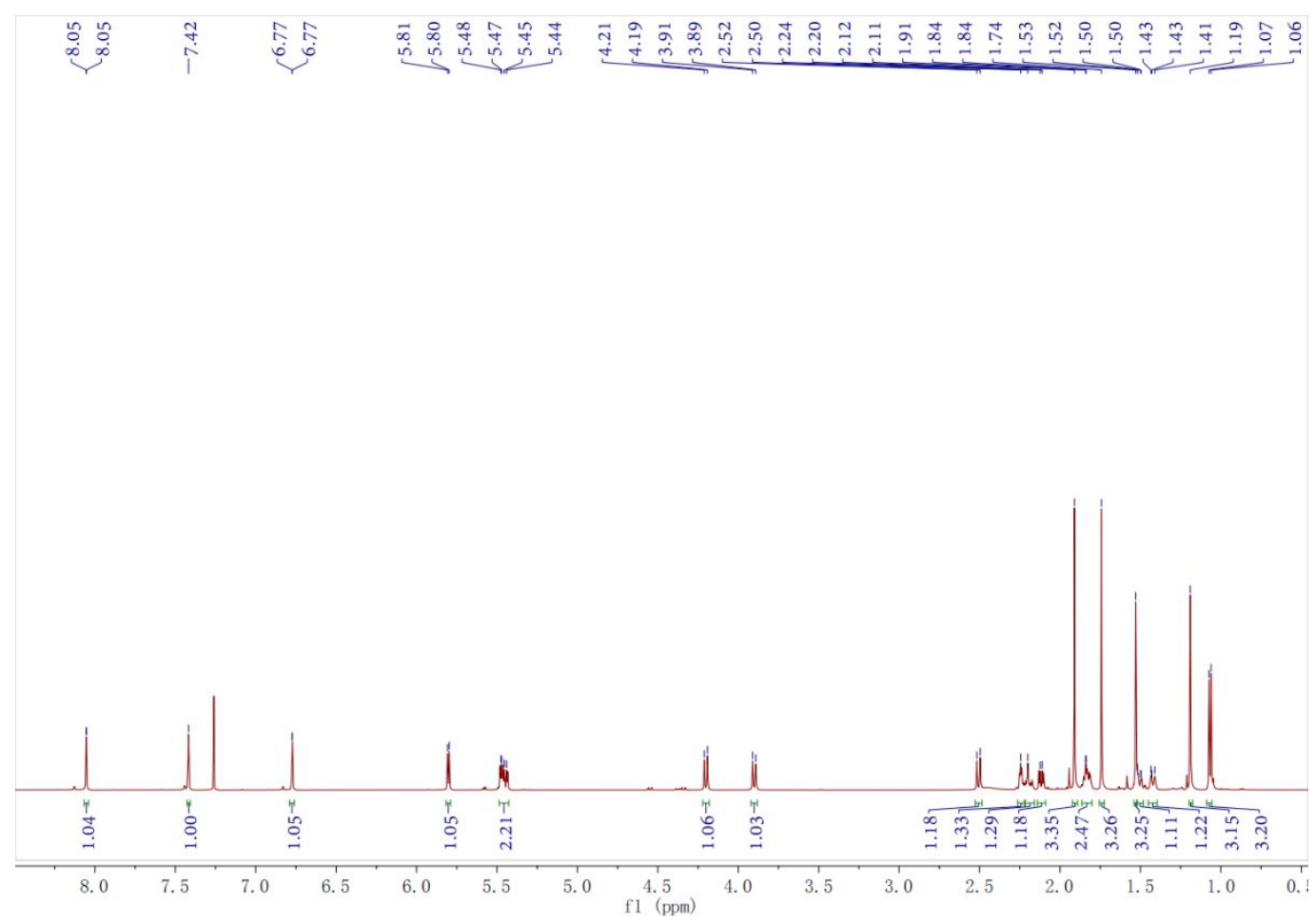


S84. ${ }^{13} \mathrm{C}$ NMR spectrum of Compound 11 in $\mathrm{CDCl}_{3}(125 \mathrm{MHz})$

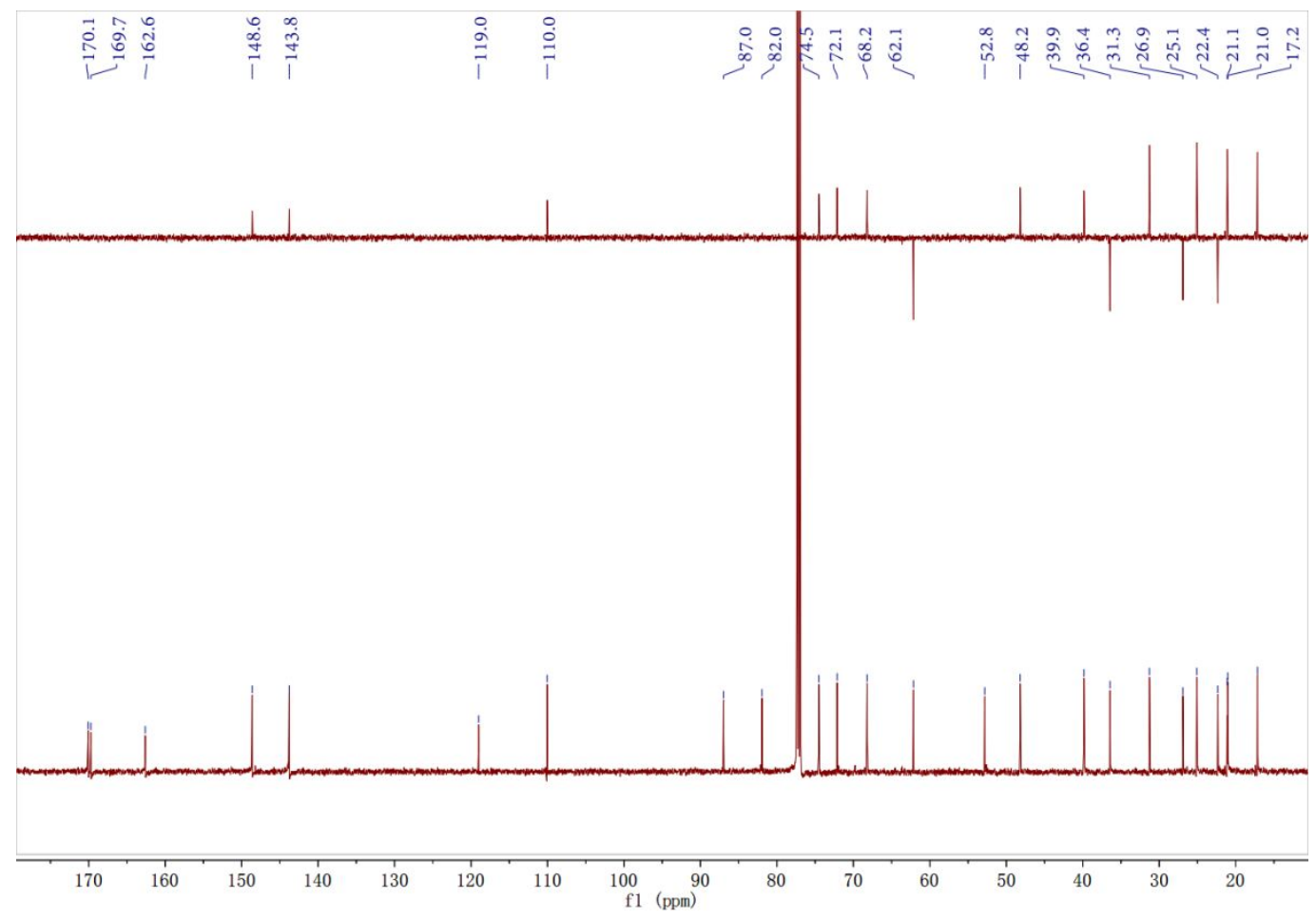


S85. HSQC spectrum of Compound 11 in $\mathrm{CDCl}_{3}$

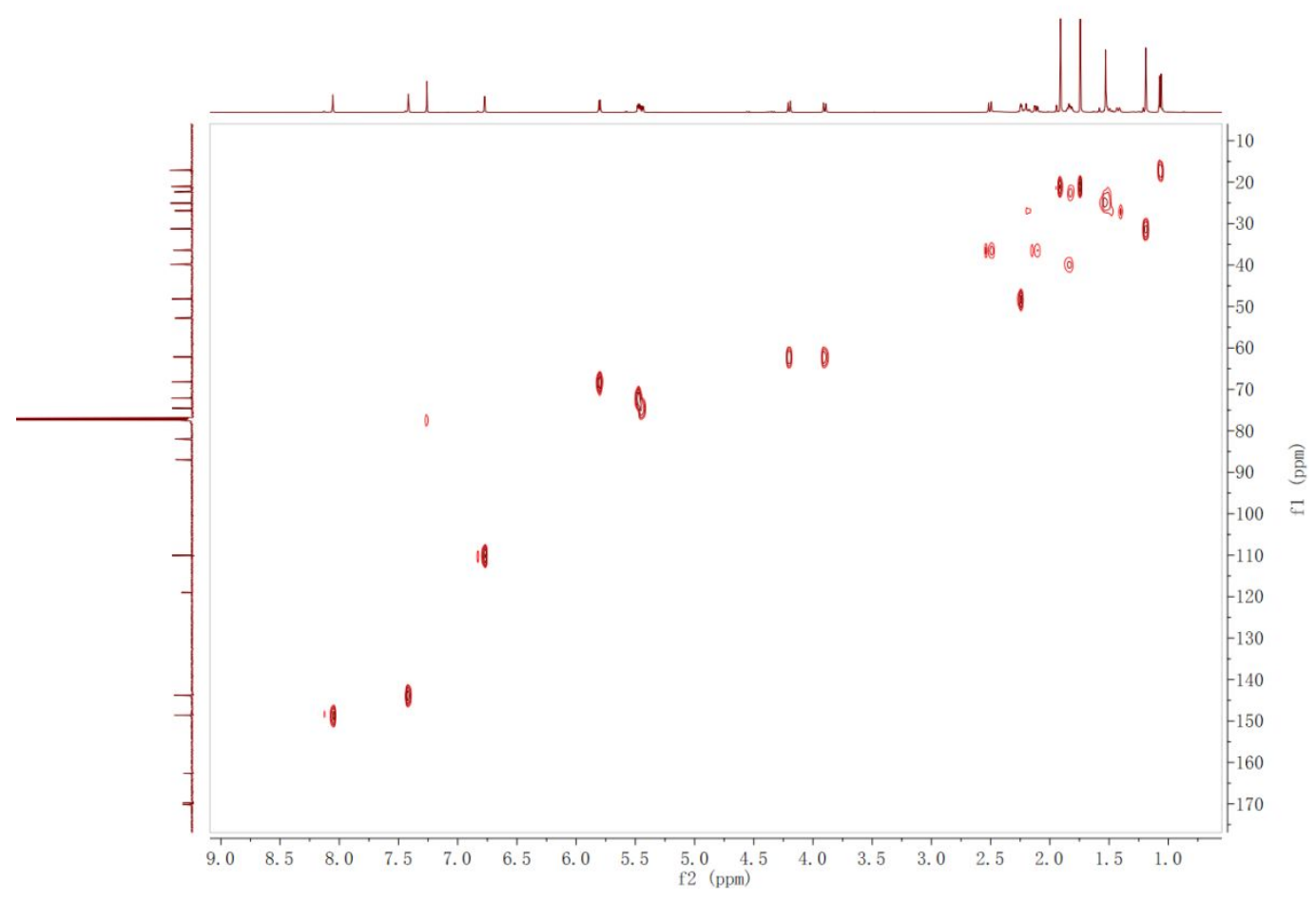

S86. HMBC spectrum of Compound 11 in $\mathrm{CDCl}_{3}$

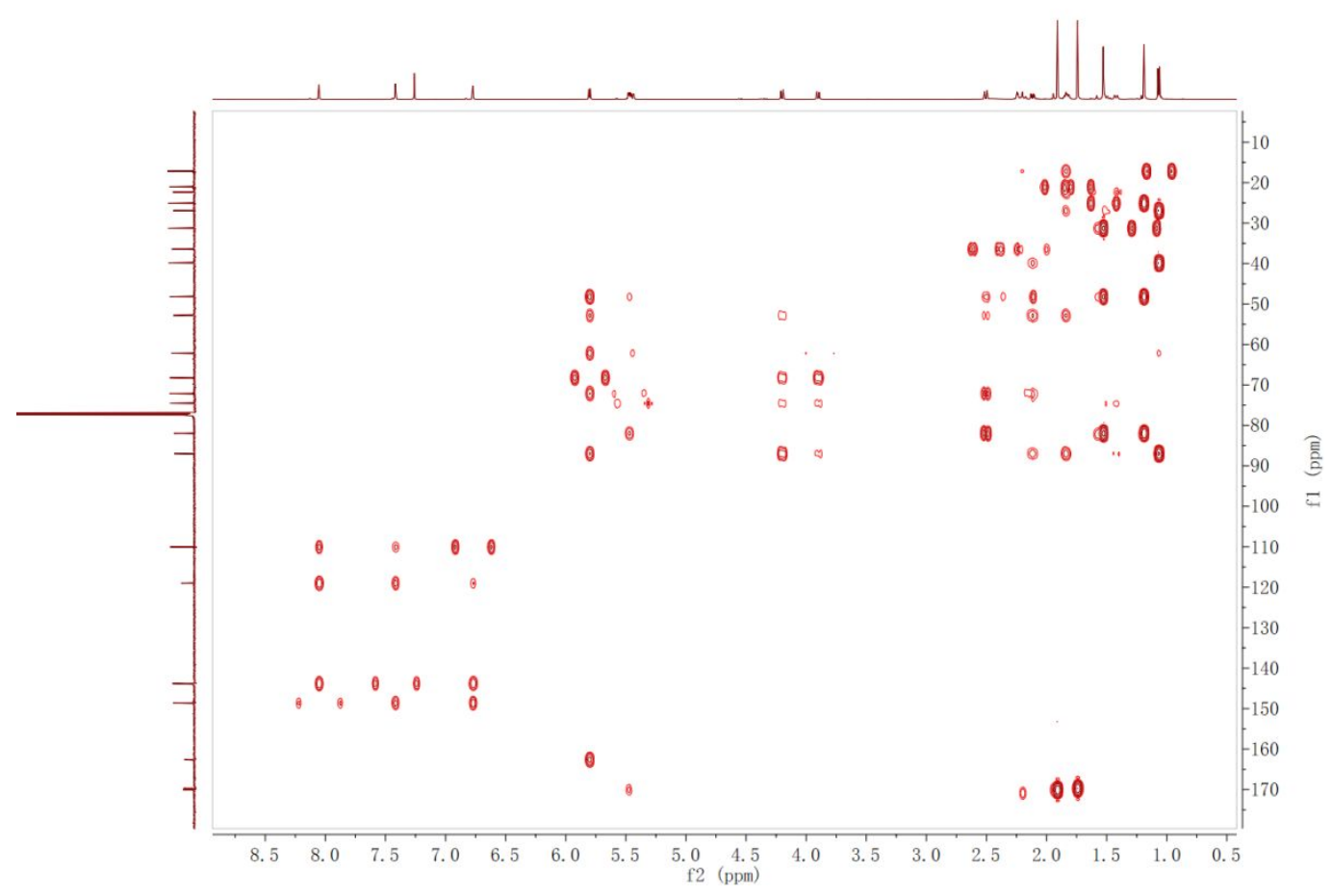


S87. NOESY of Compound 11 in $\mathrm{CDCl}_{3}$

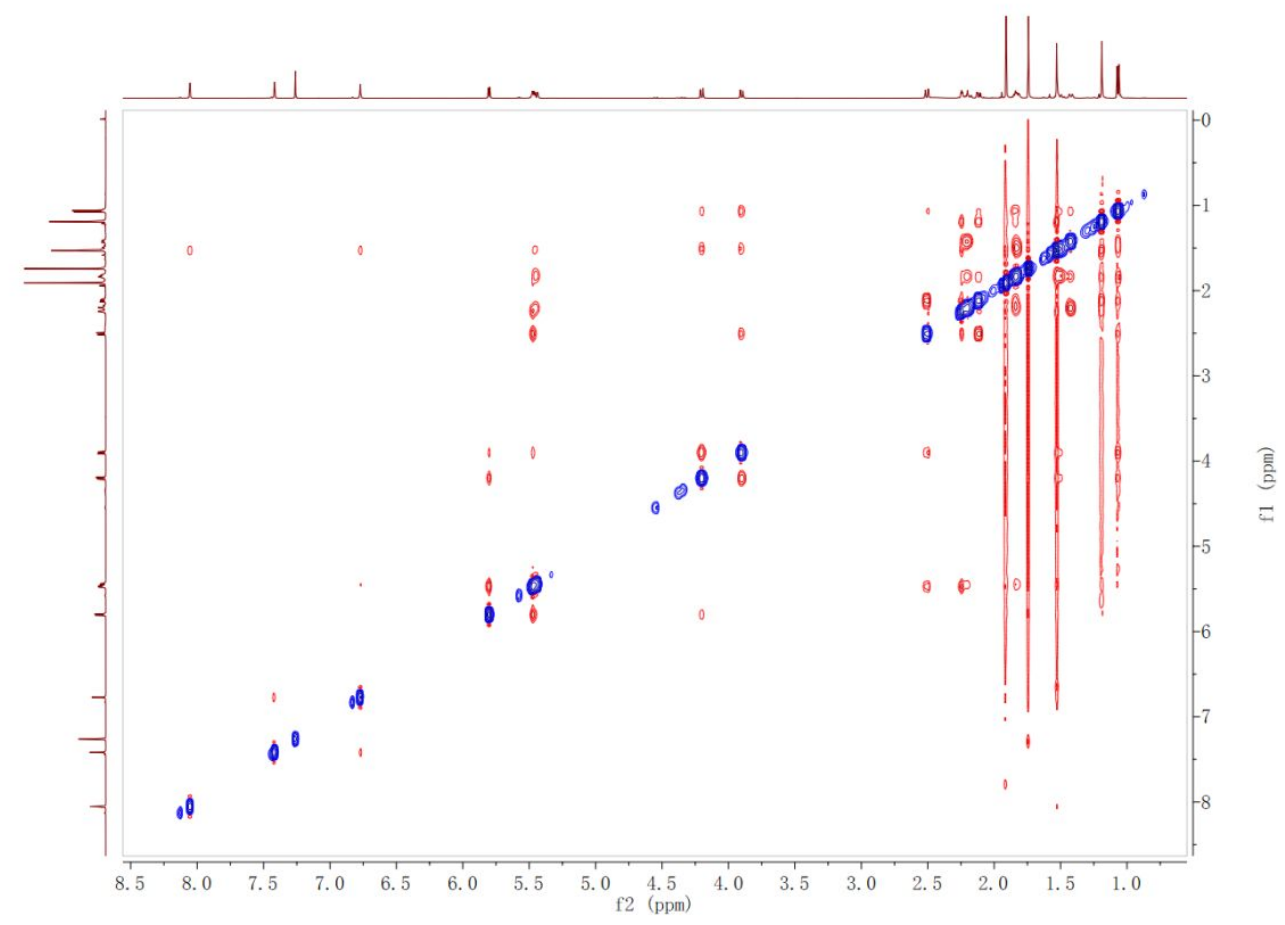

S88. IR spectrum of Compound 11

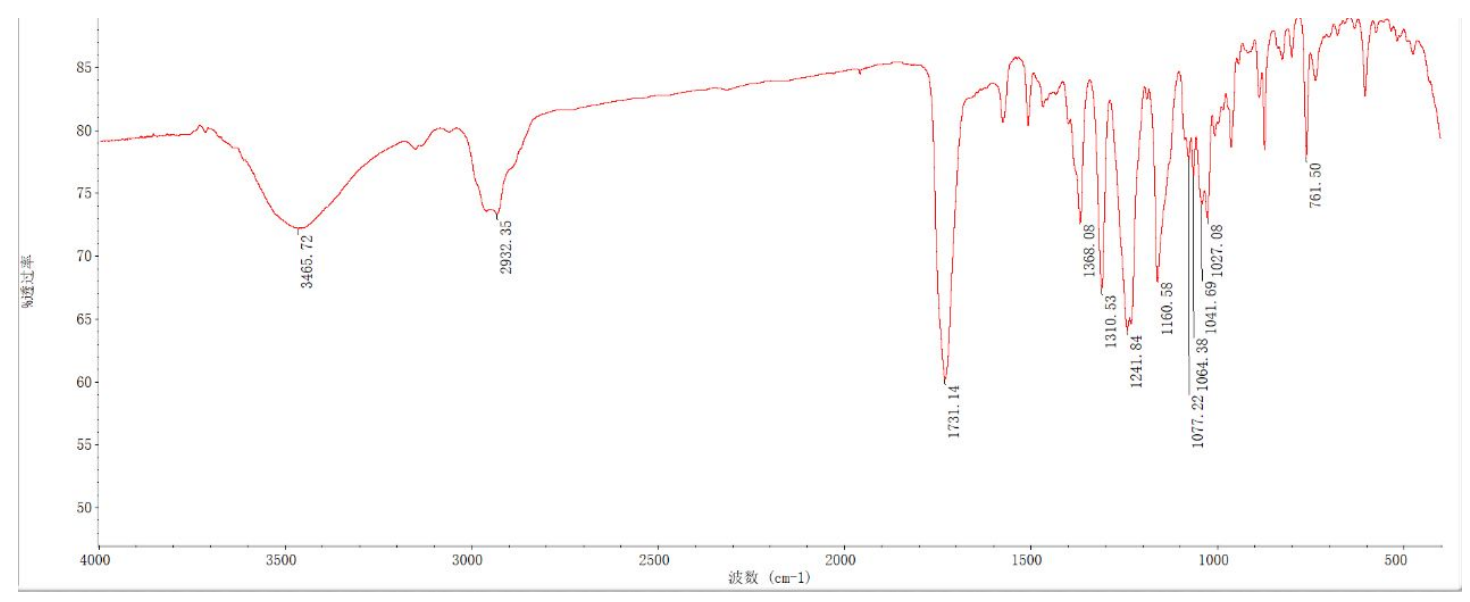


S89. UV spectrum of Compound 11

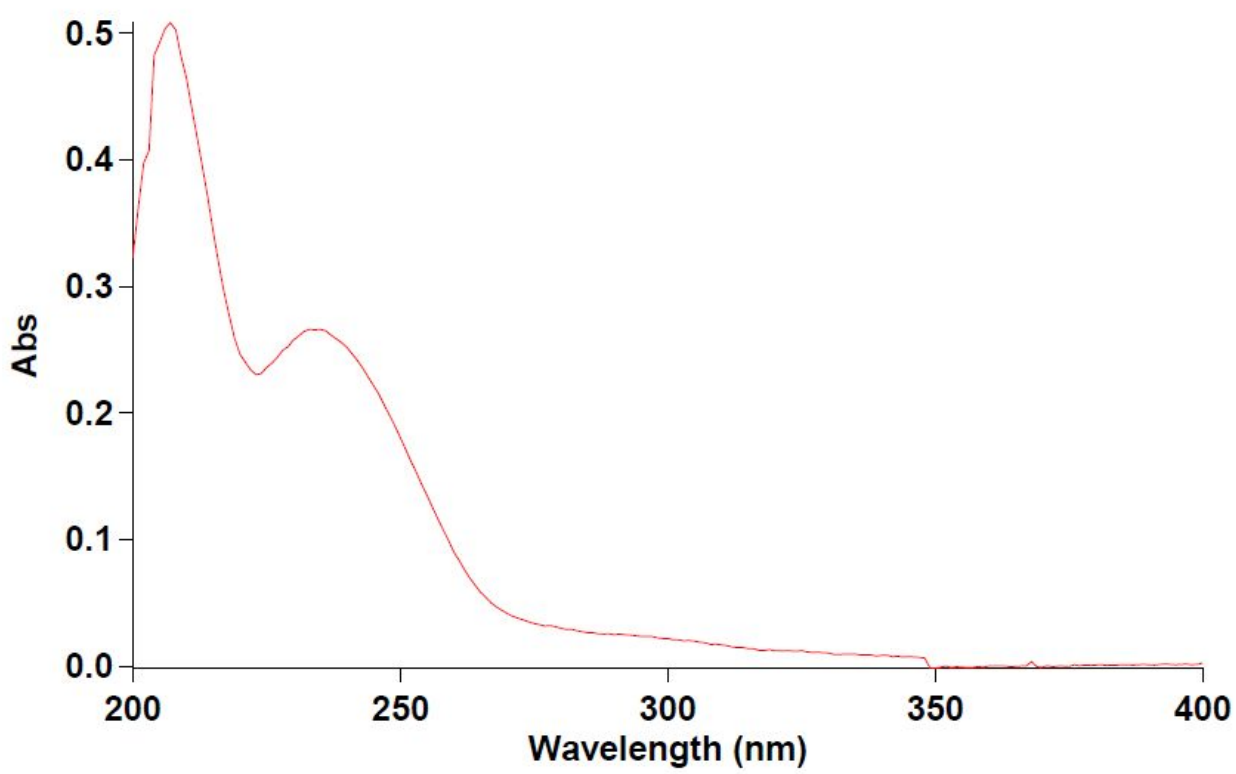


S90. HR-ESIMS of Compound 12

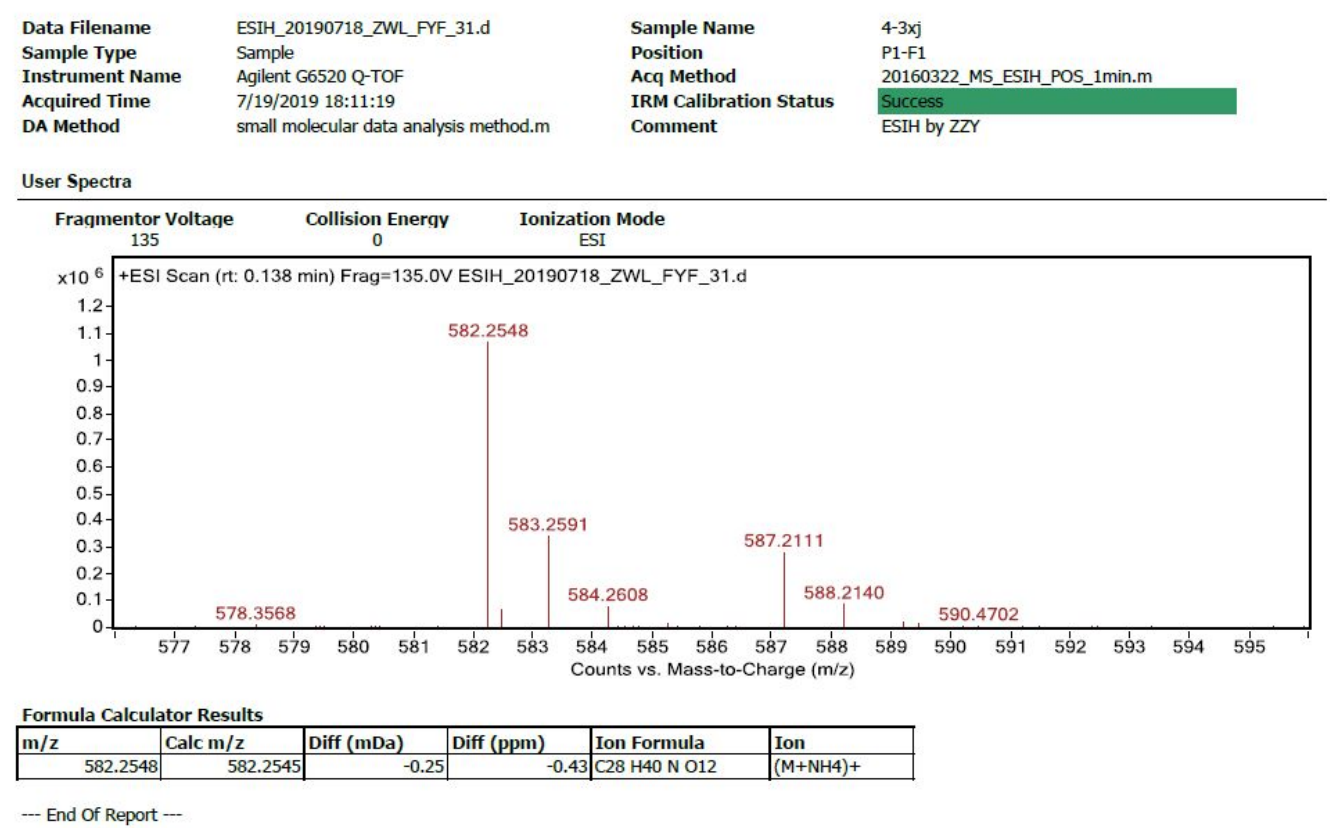

S91. ${ }^{1} \mathrm{H}$ NMR spectrum of Compound 12 in $\mathrm{CDCl}_{3}(500 \mathrm{MHz})$

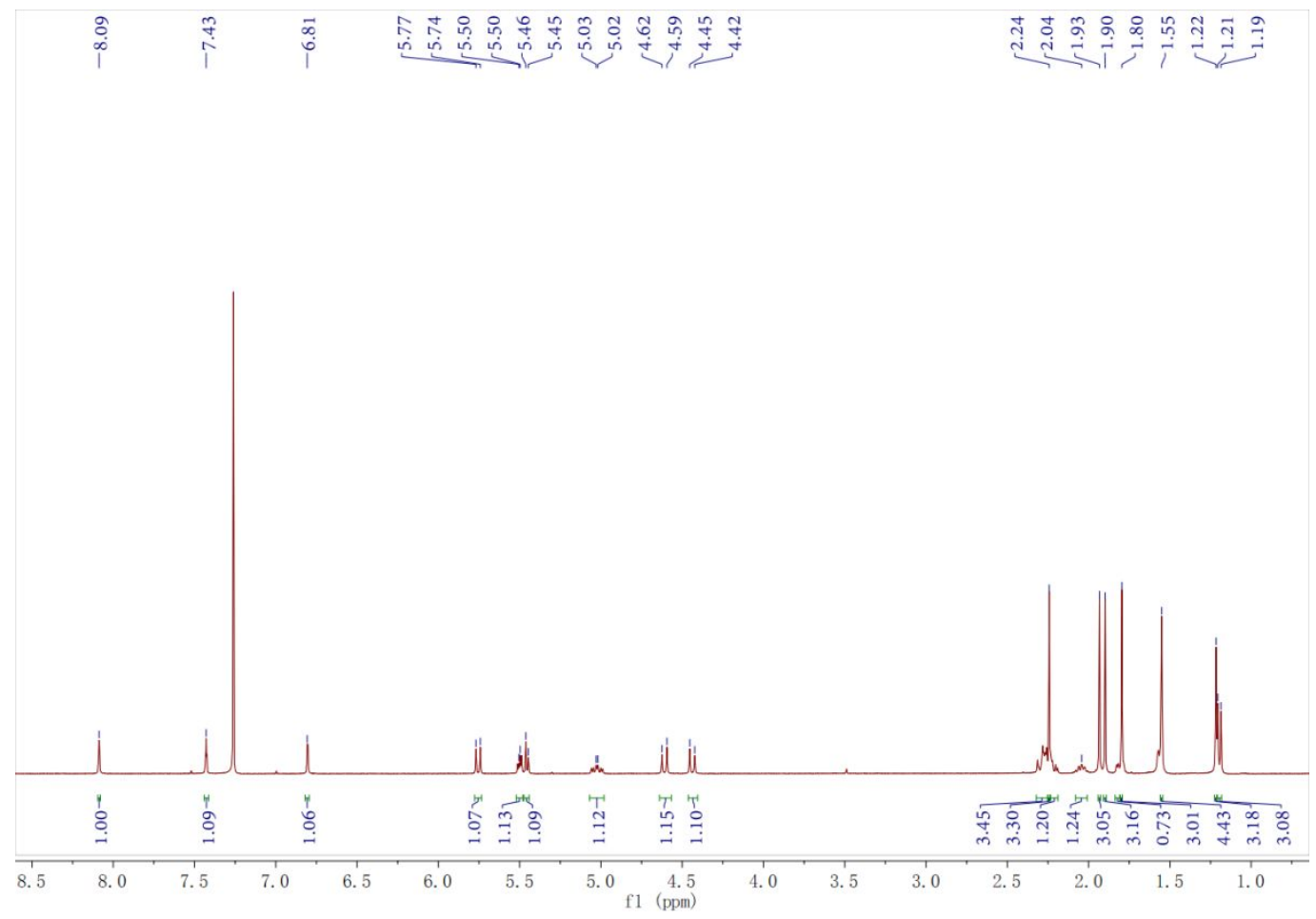


S92. ${ }^{13} \mathrm{C}$ NMR spectrum of Compound 12 in $\mathrm{CDCl}_{3}(125 \mathrm{MHz})$

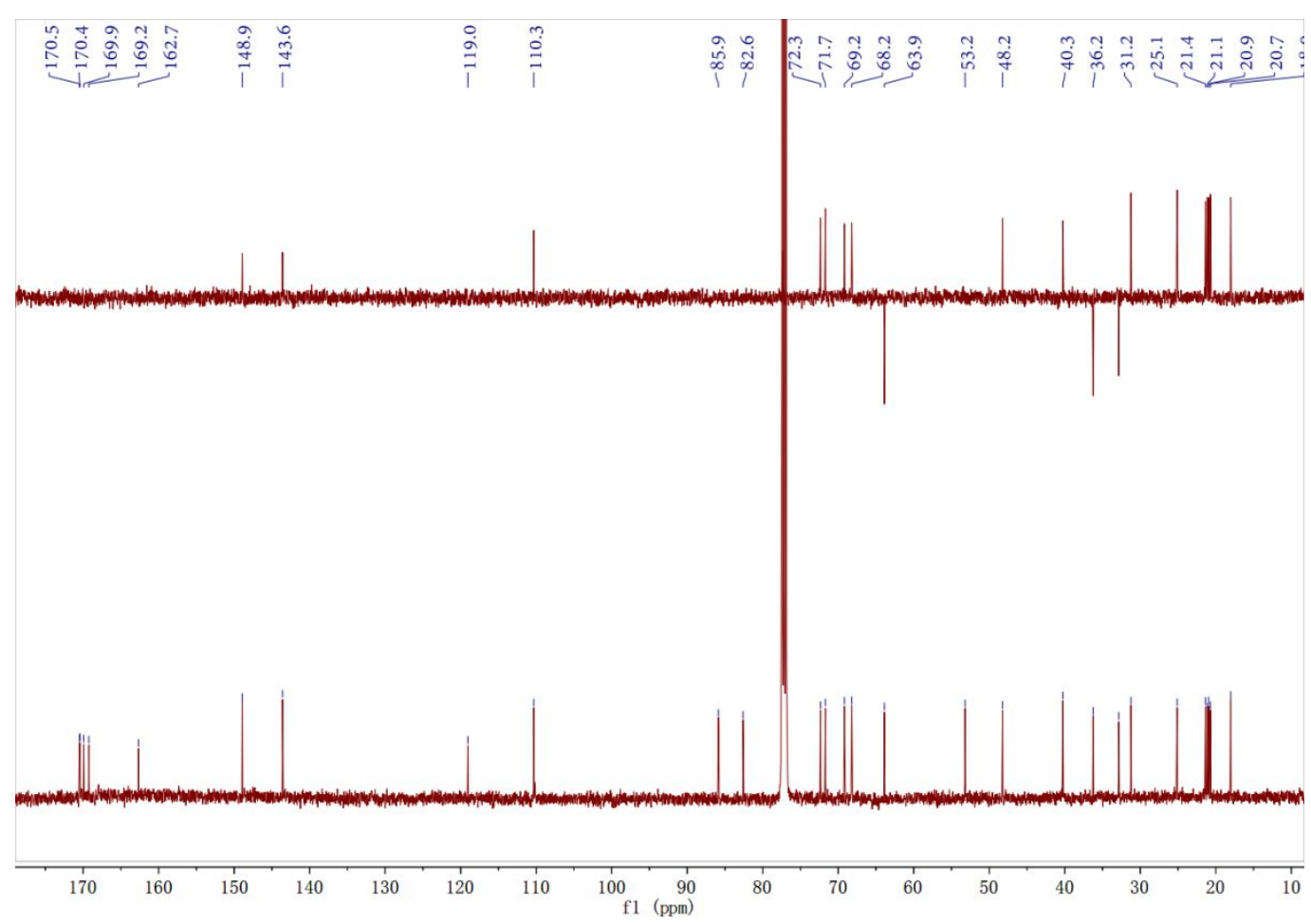


S93. HSQC spectrum of Compound 12 in $\mathrm{CDCl}_{3}$

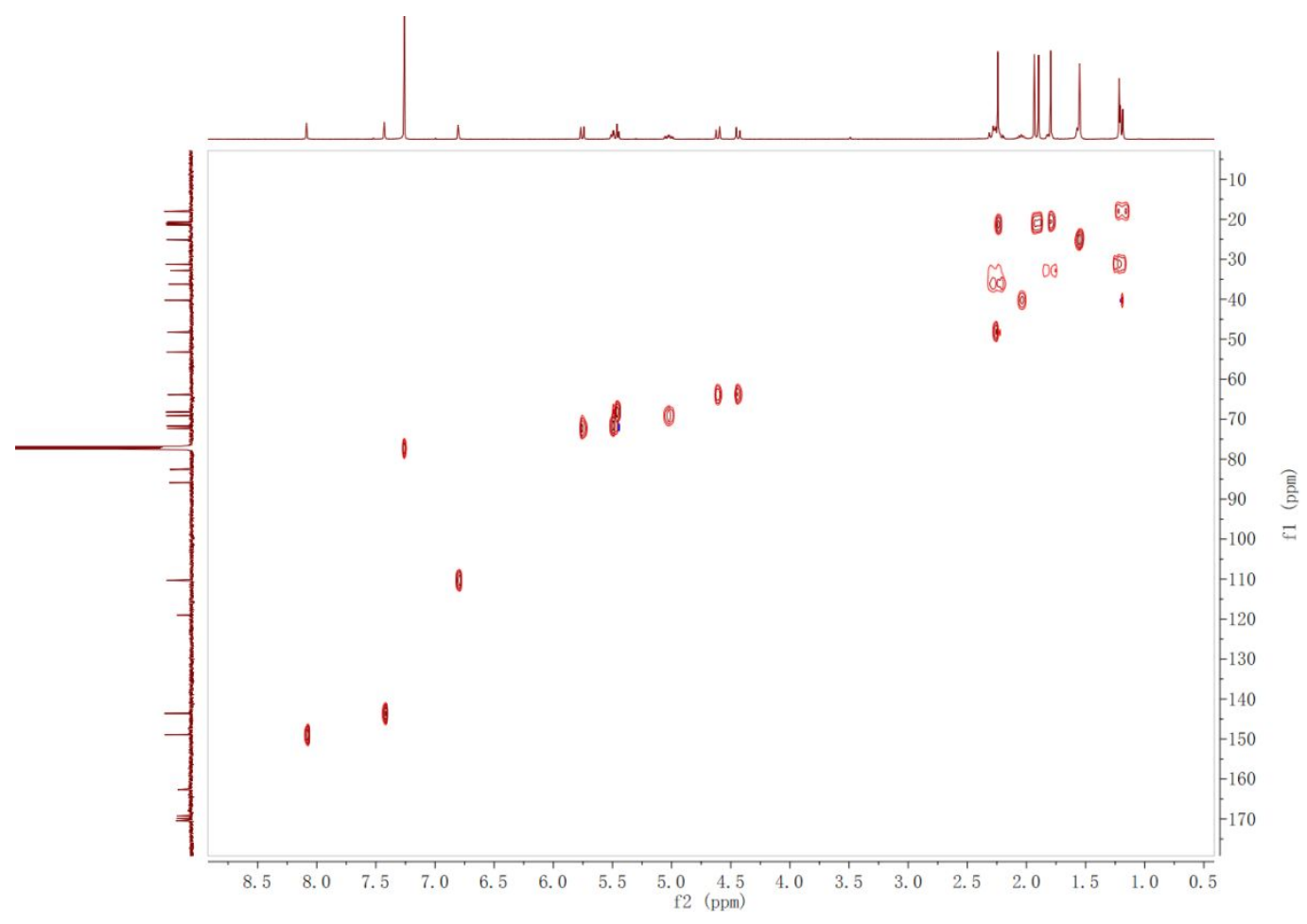

S94. HMBC spectrum of Compound 12 in $\mathrm{CDCl}_{3}$

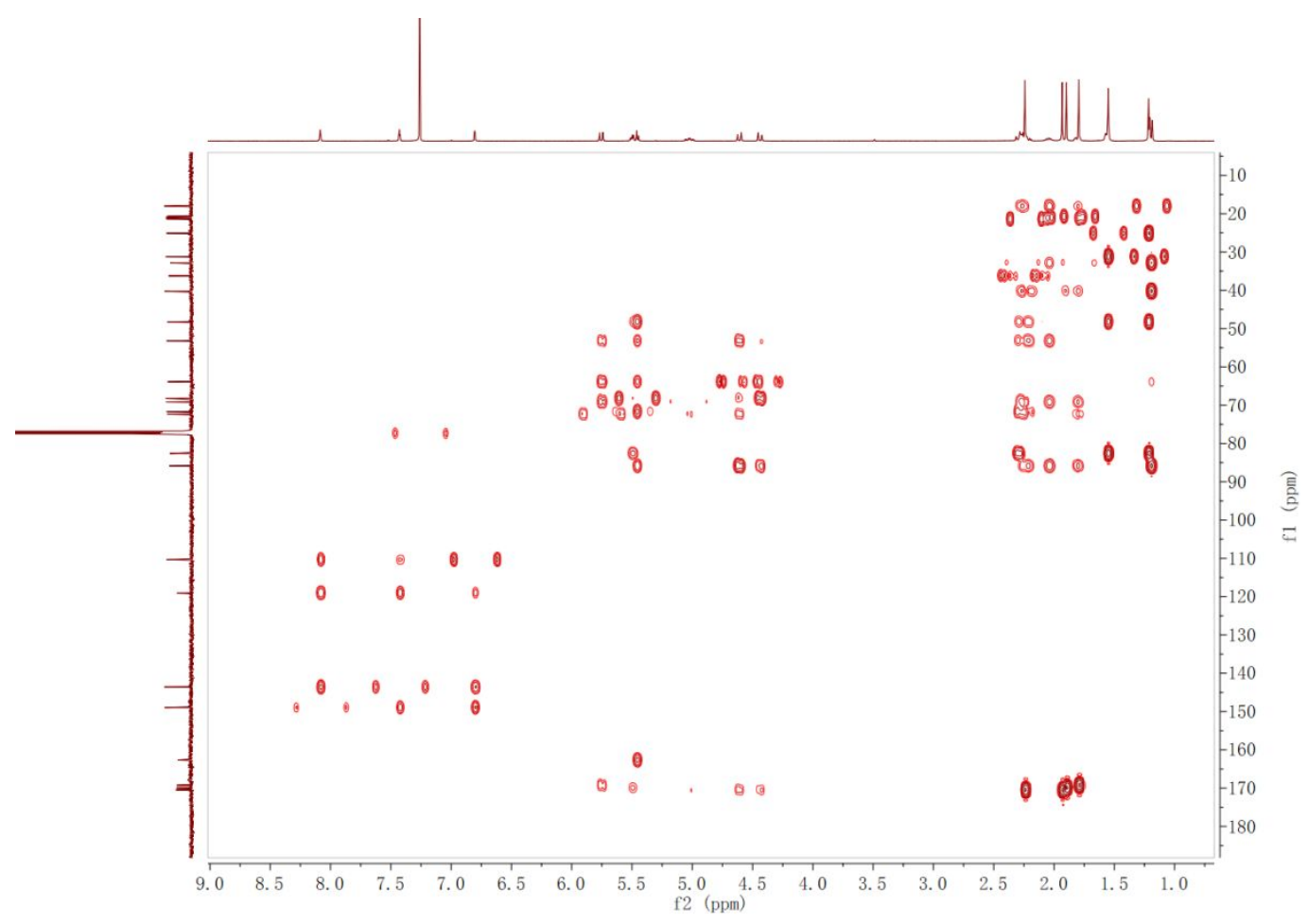


S95. NOESY of Compound 12 in $\mathrm{CDCl}_{3}$

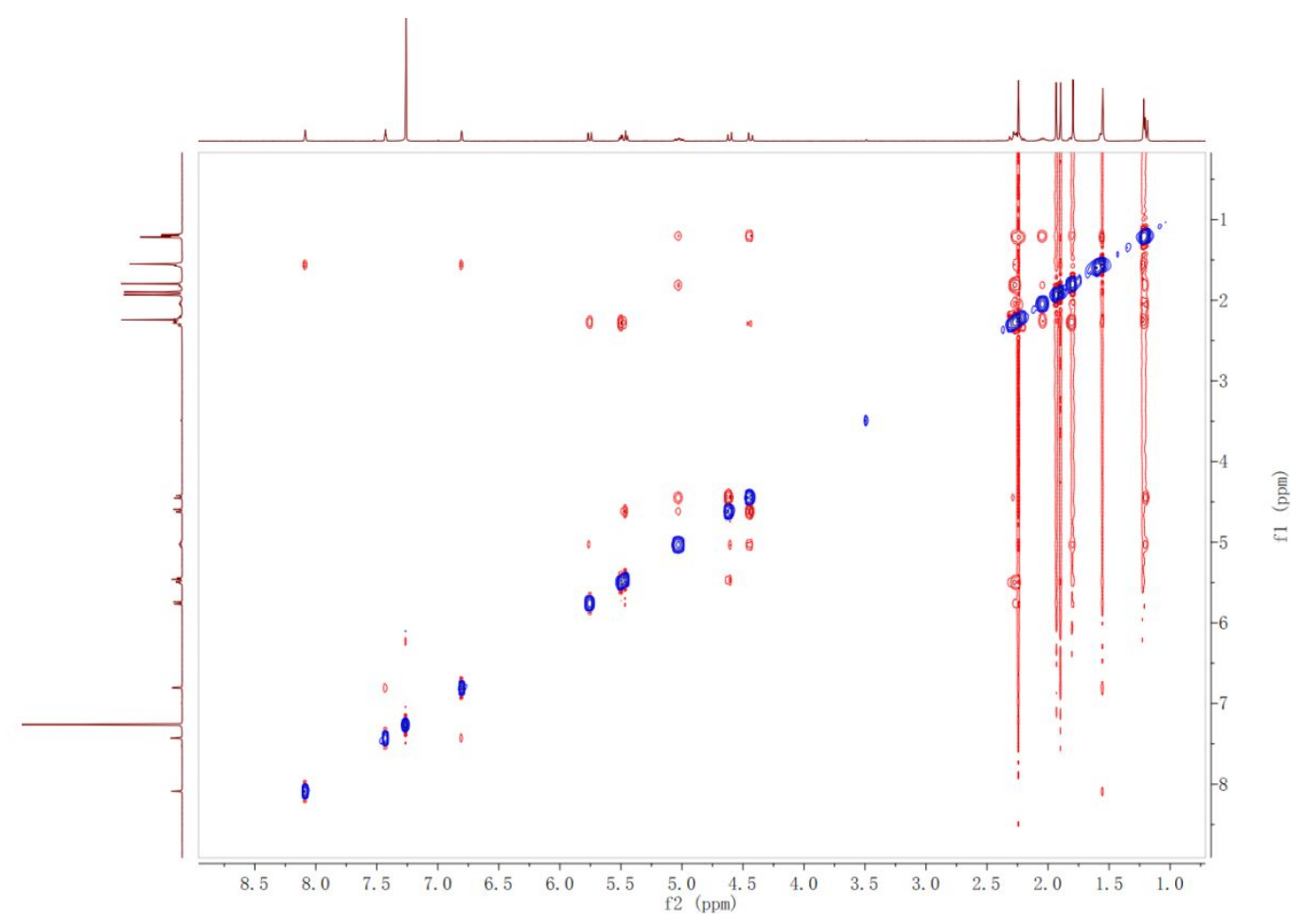

S96. IR spectrum of Compound 12

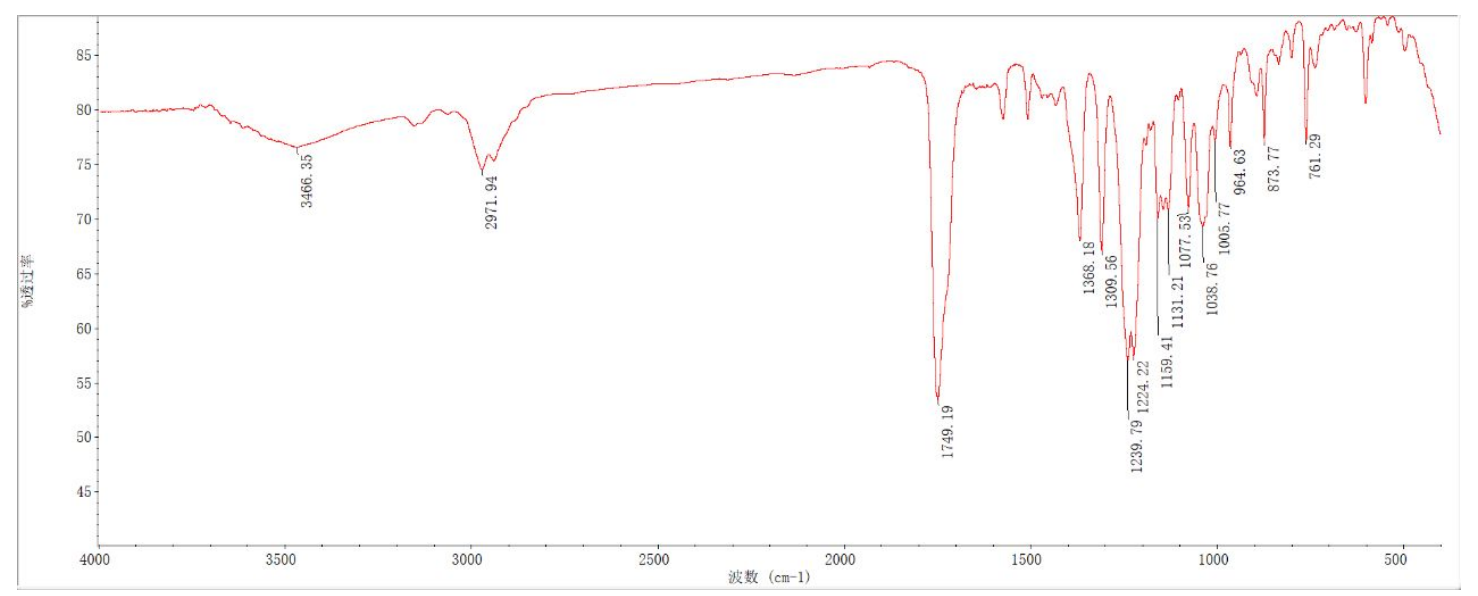

66 
S97. UV spectrum of Compound 12

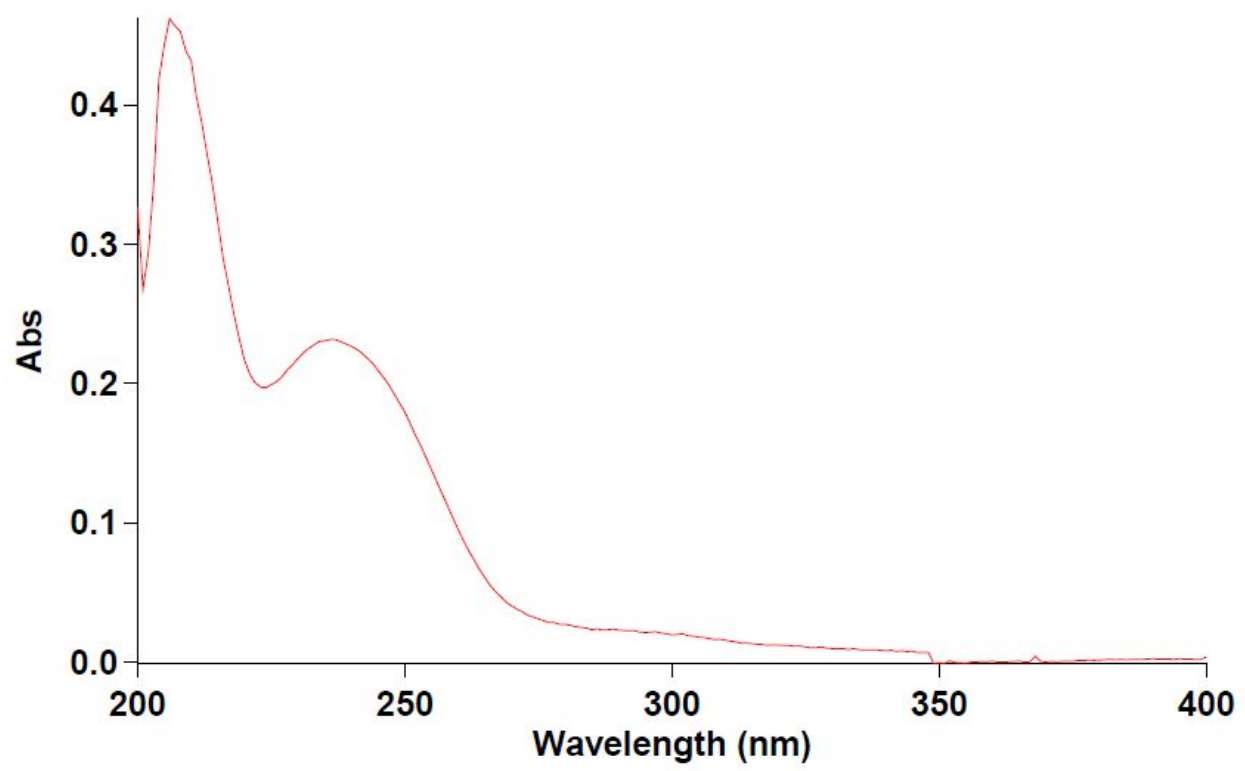


S98. HR-ESIMS of Compound 13

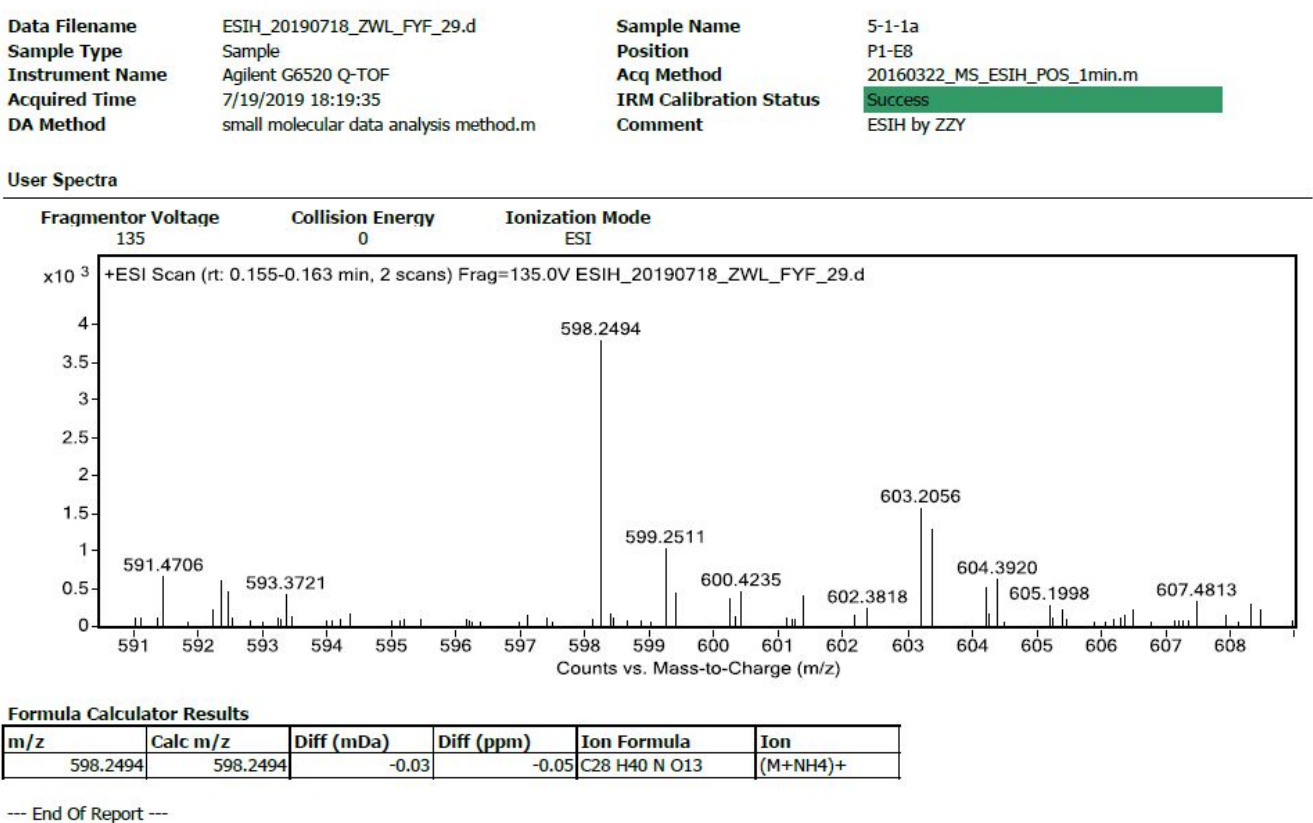

-- End Of Report --

S99. ${ }^{1} \mathrm{H}$ NMR spectrum of Compound 13 in $\mathrm{CDCl}_{3}(500 \mathrm{MHz})$

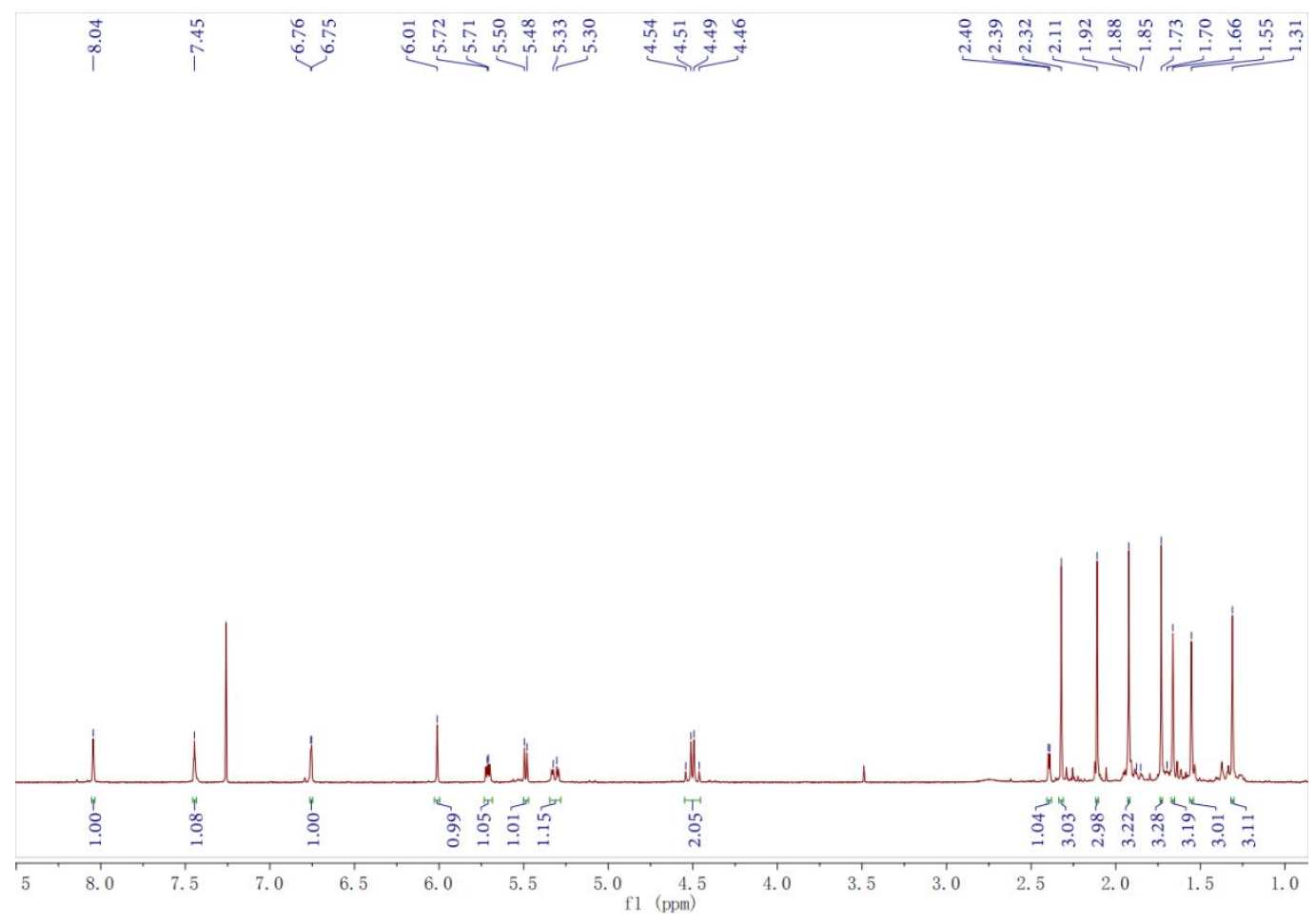


S100. ${ }^{13} \mathrm{C}$ NMR spectrum of Compound 13 in $\mathrm{CDCl}_{3}(125 \mathrm{MHz})$

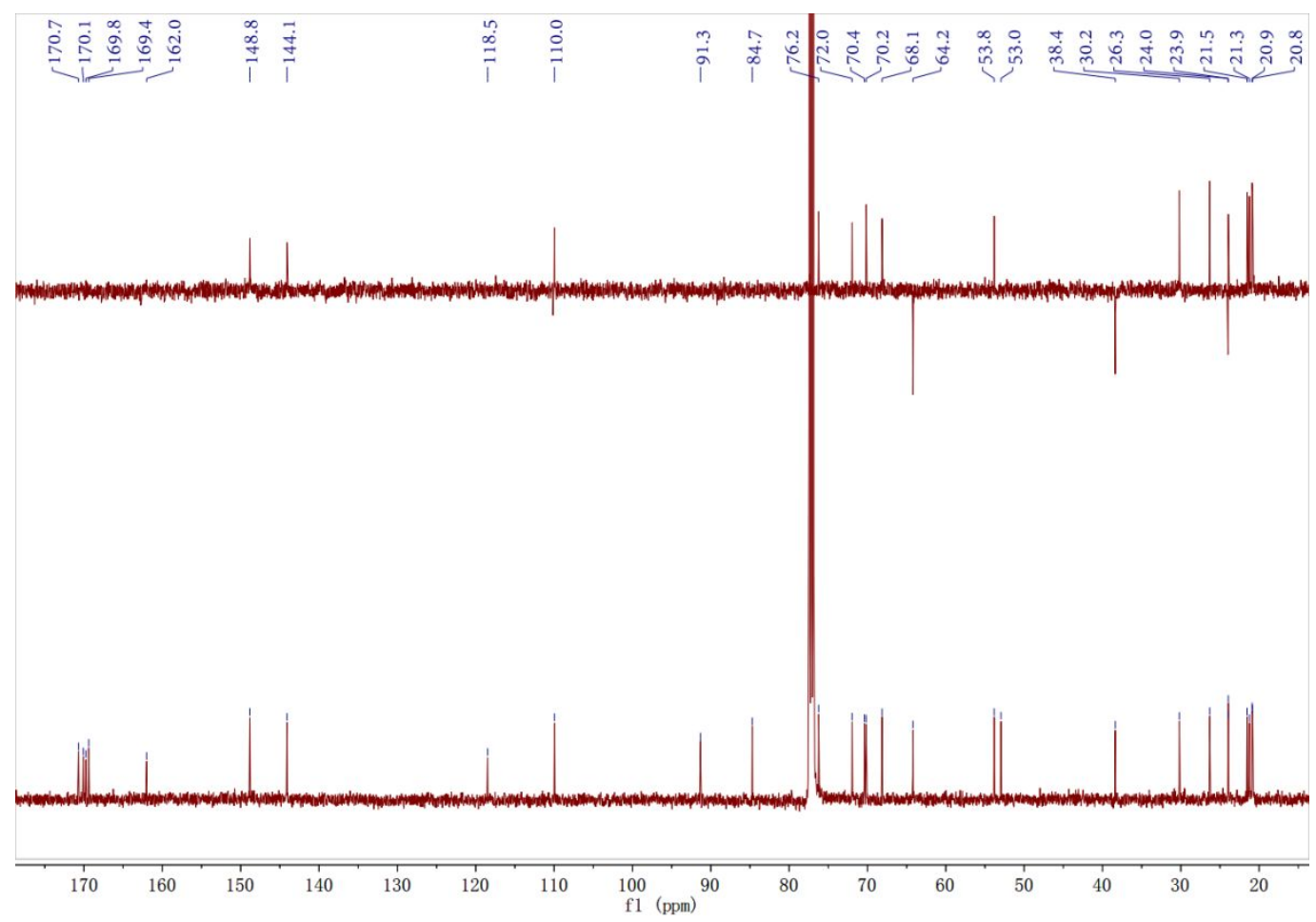


S101. HSQC spectrum of Compound 13 in $\mathrm{CDCl}_{3}$

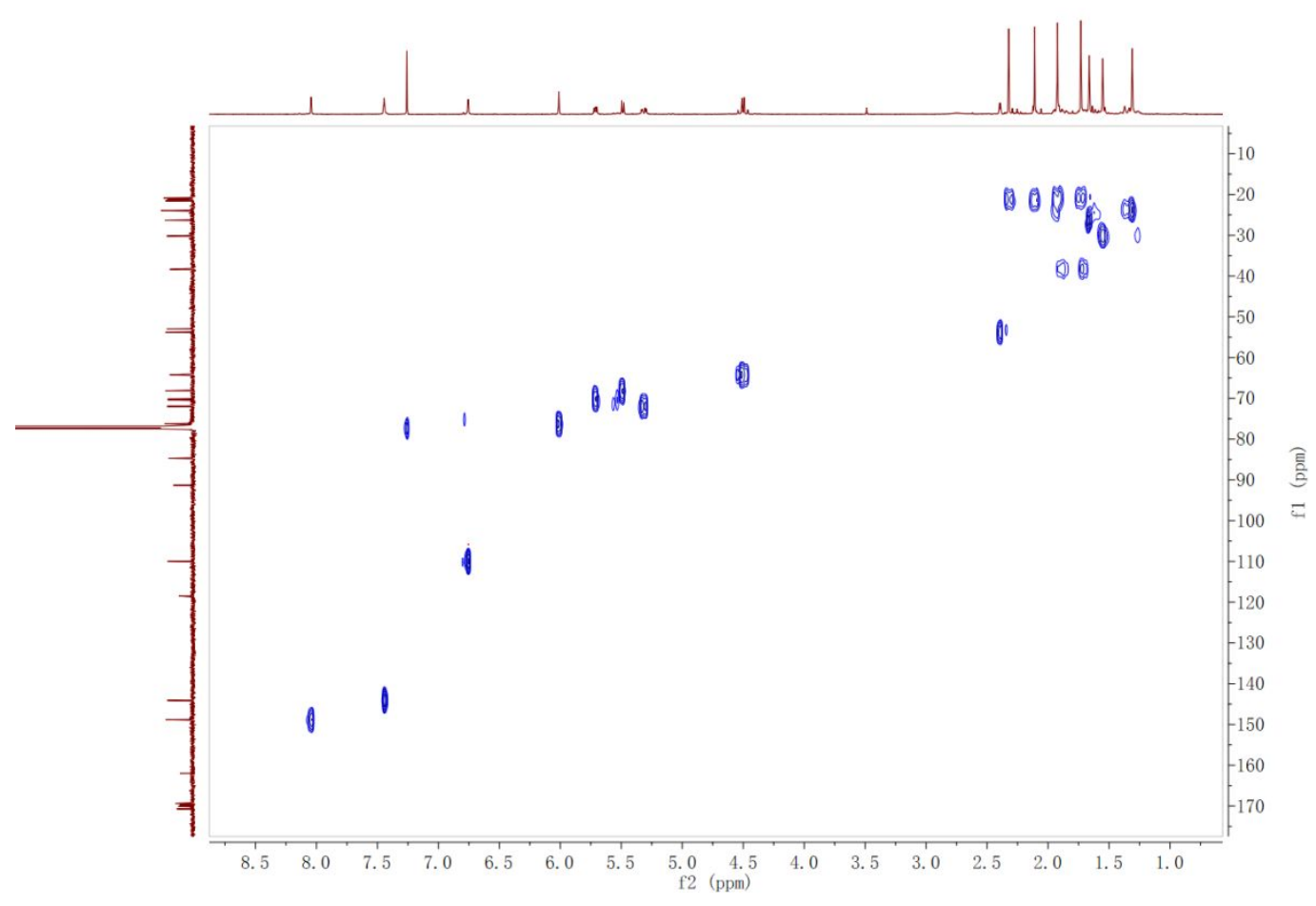

S102. HMBC spectrum of Compound 13 in $\mathrm{CDCl}_{3}$

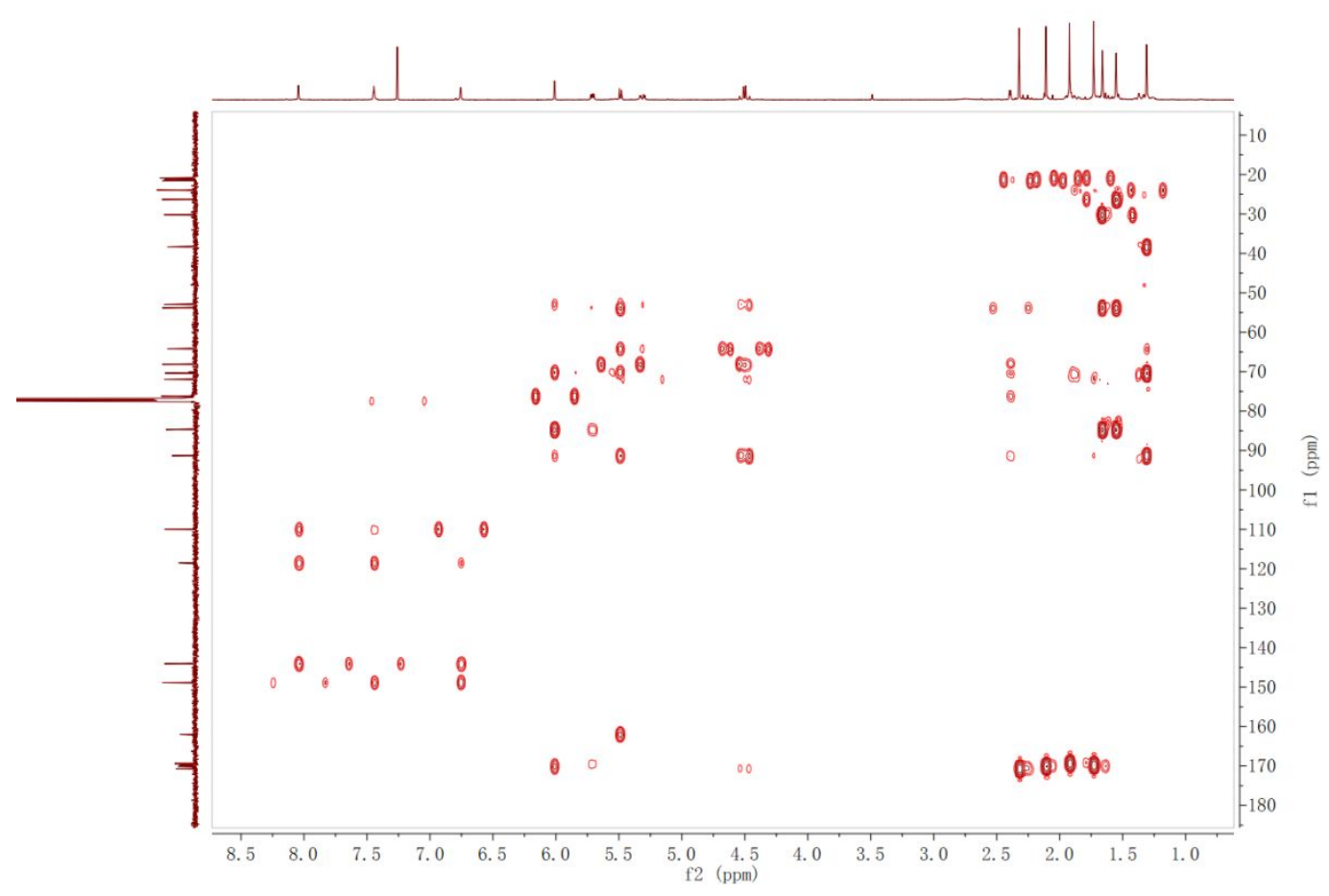


S103. NOESY of Compound 13 in $\mathrm{CDCl}_{3}$

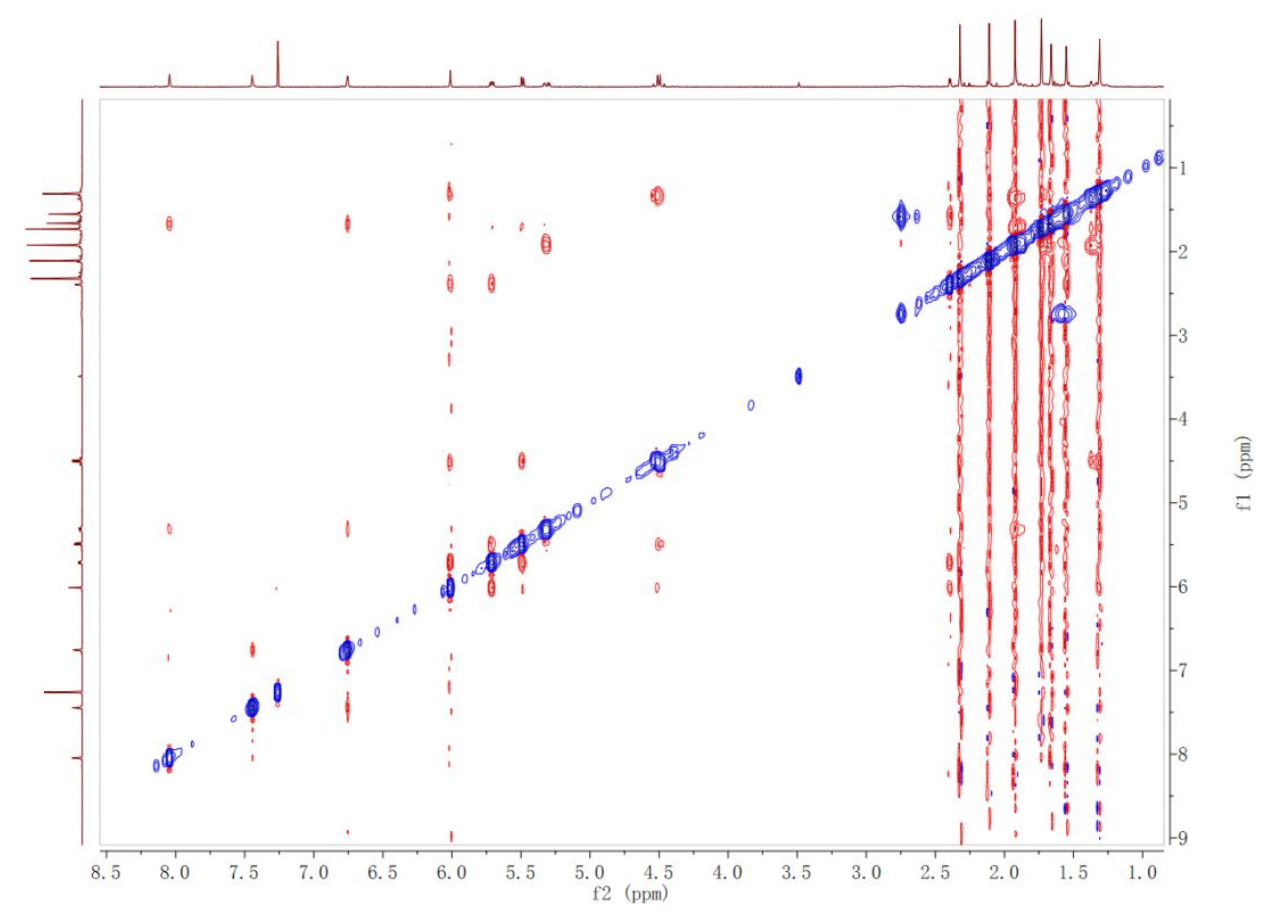

S104. IR spectrum of Compound 13

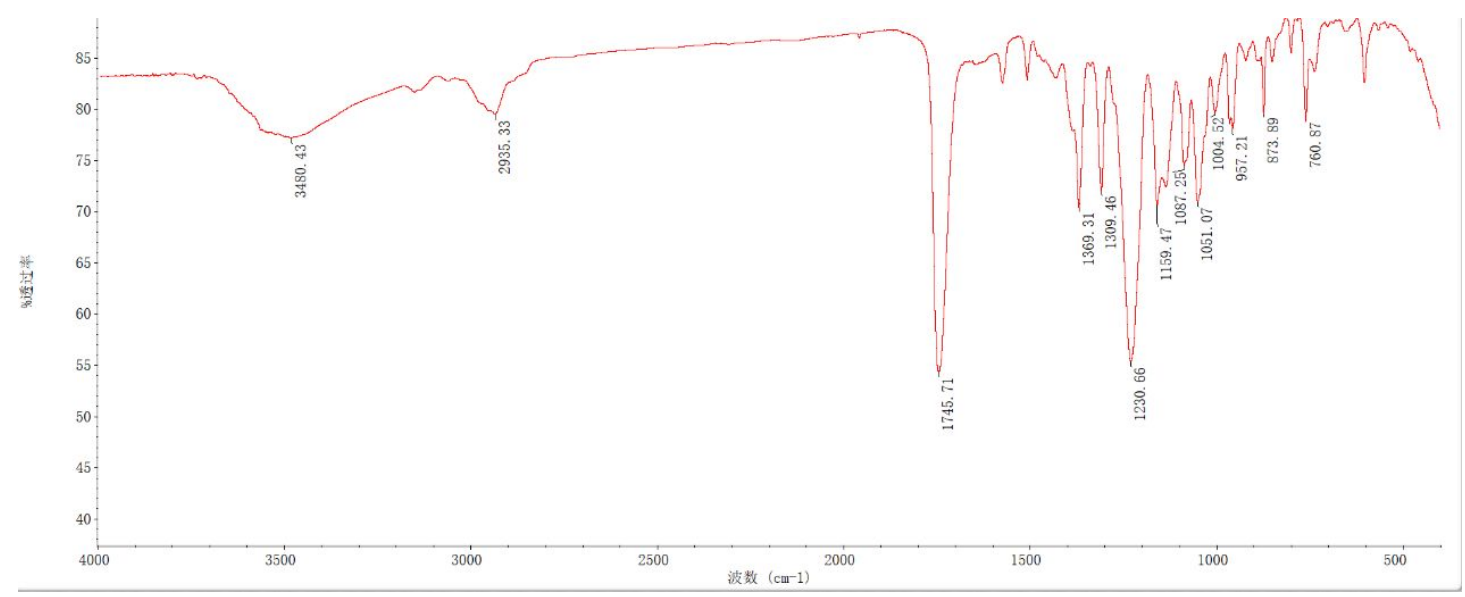


S105. UV spectrum of Compound 13

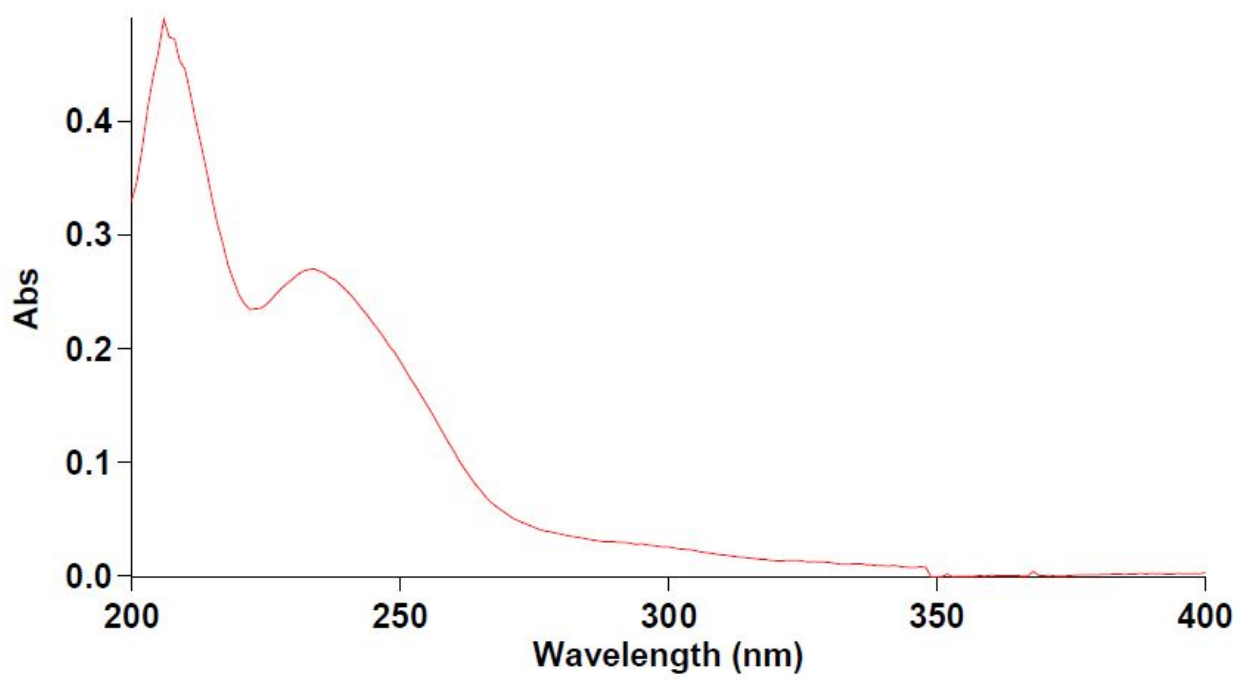


S106. HR-ESIMS of Compound 14

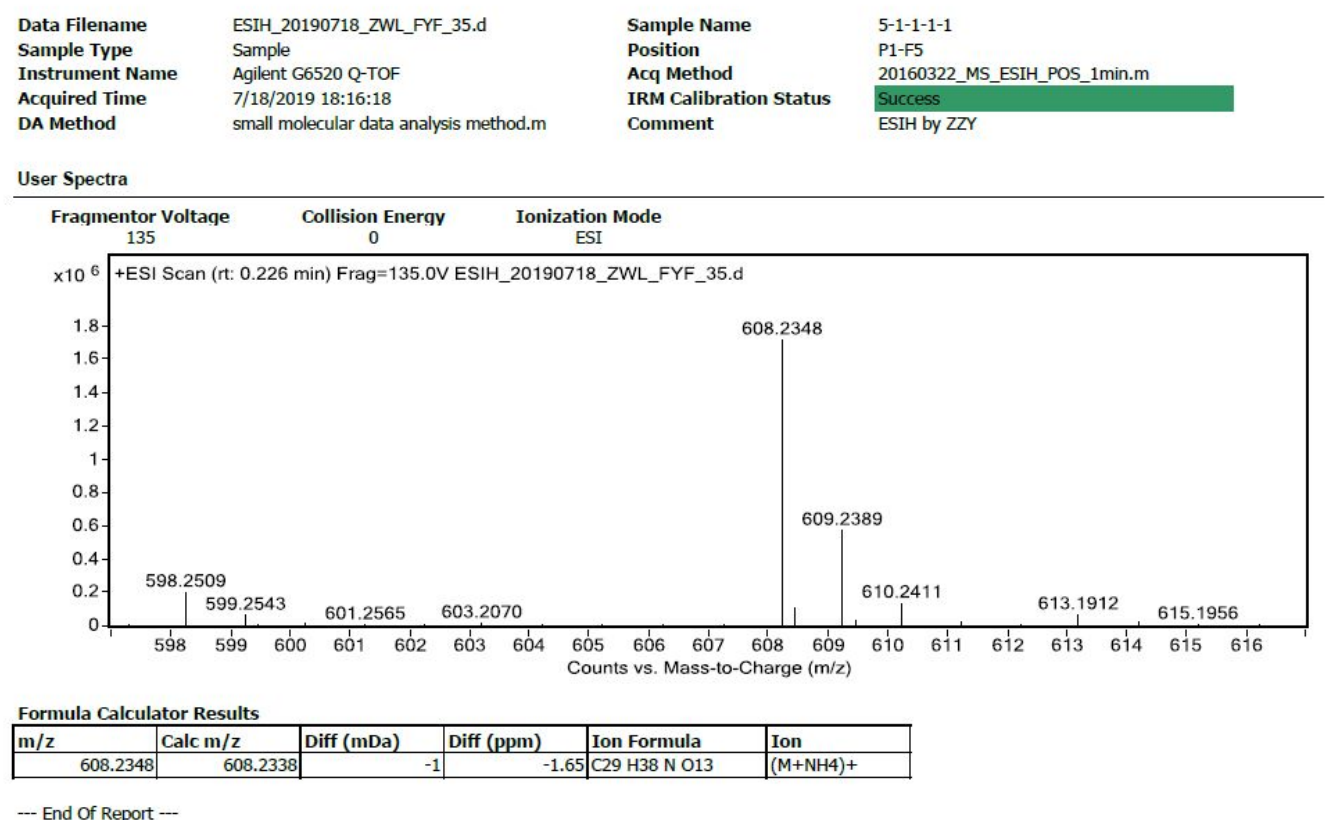

--- End of Report --

S107. ${ }^{1} \mathrm{H}$ NMR spectrum of Compound 14 in $\mathrm{CDCl}_{3}(500 \mathrm{MHz})$

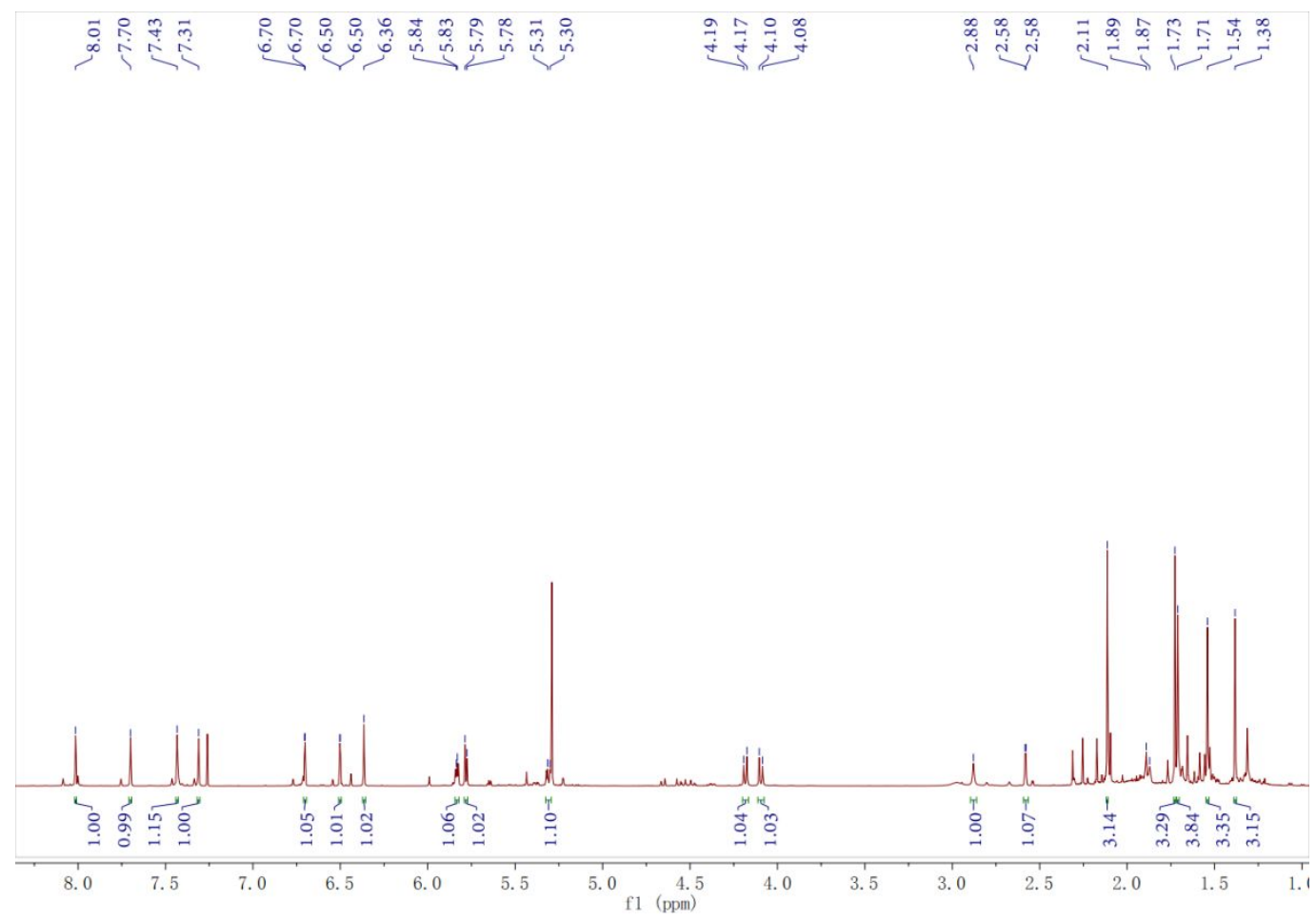


S108. ${ }^{13} \mathrm{C}$ NMR spectrum of Compound 14 in $\mathrm{CDCl}_{3}(125 \mathrm{MHz})$

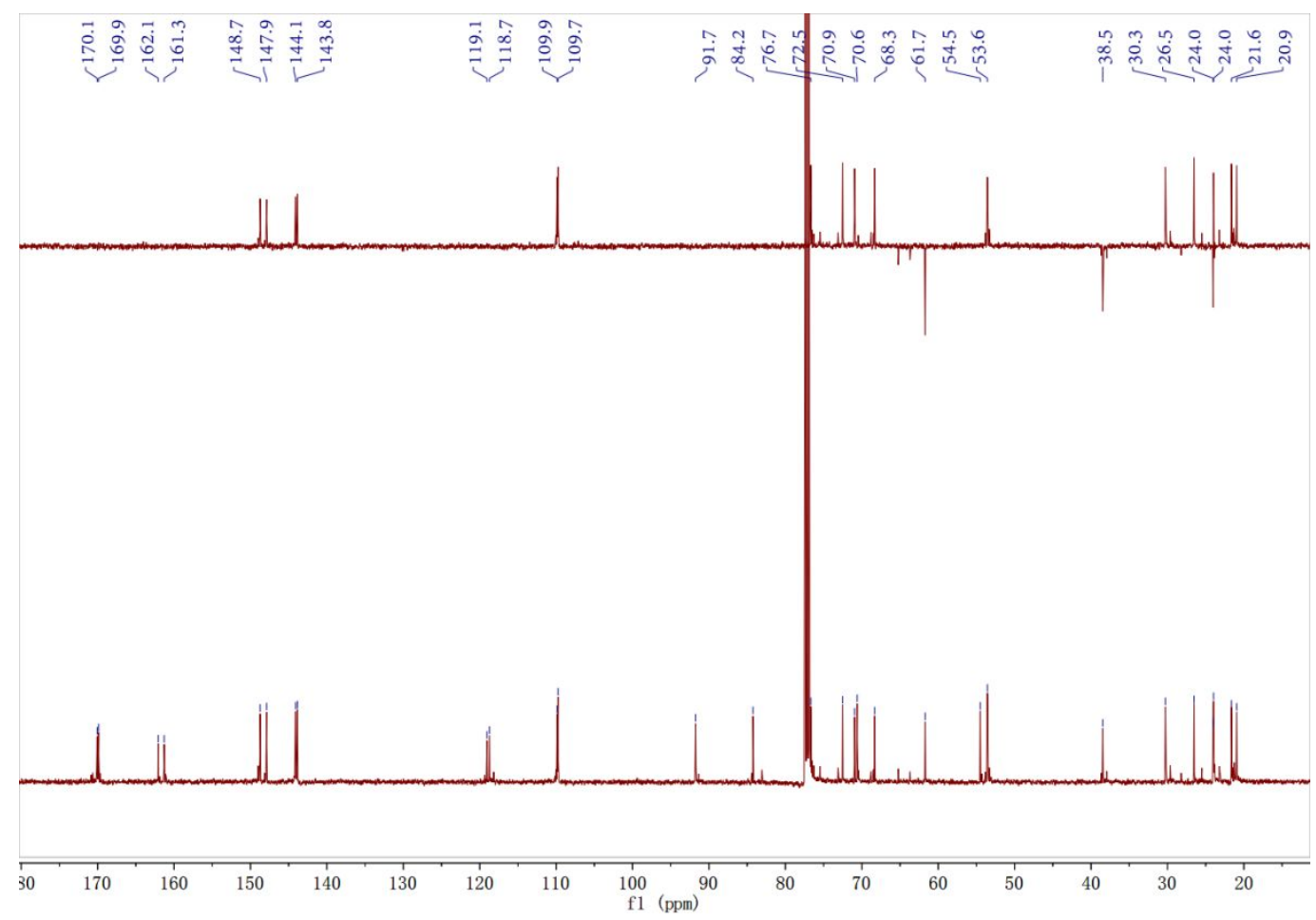


S109. HSQC spectrum of Compound 14 in $\mathrm{CDCl}_{3}$

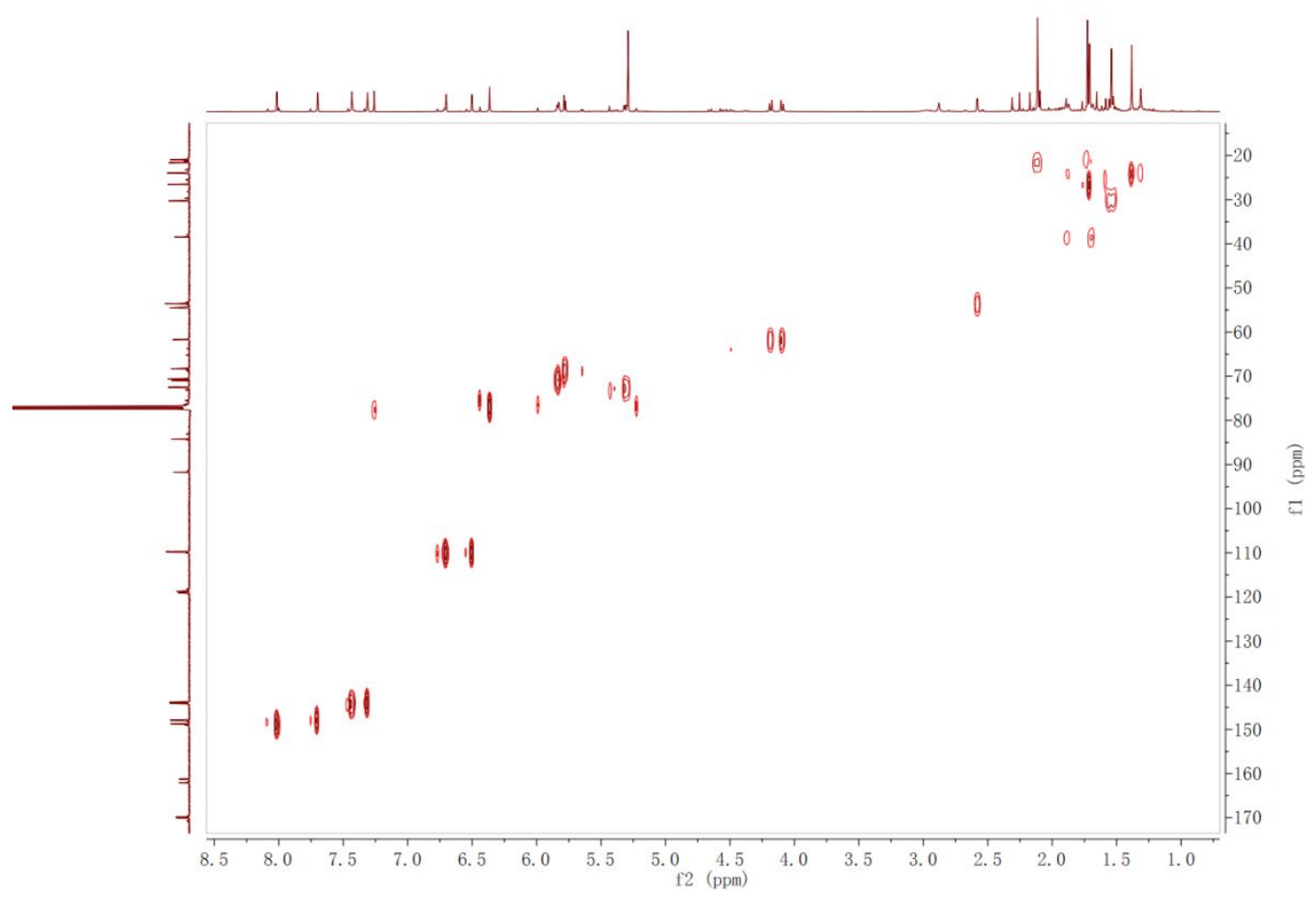

S110. HMBC spectrum of Compound 14 in $\mathrm{CDCl}_{3}$

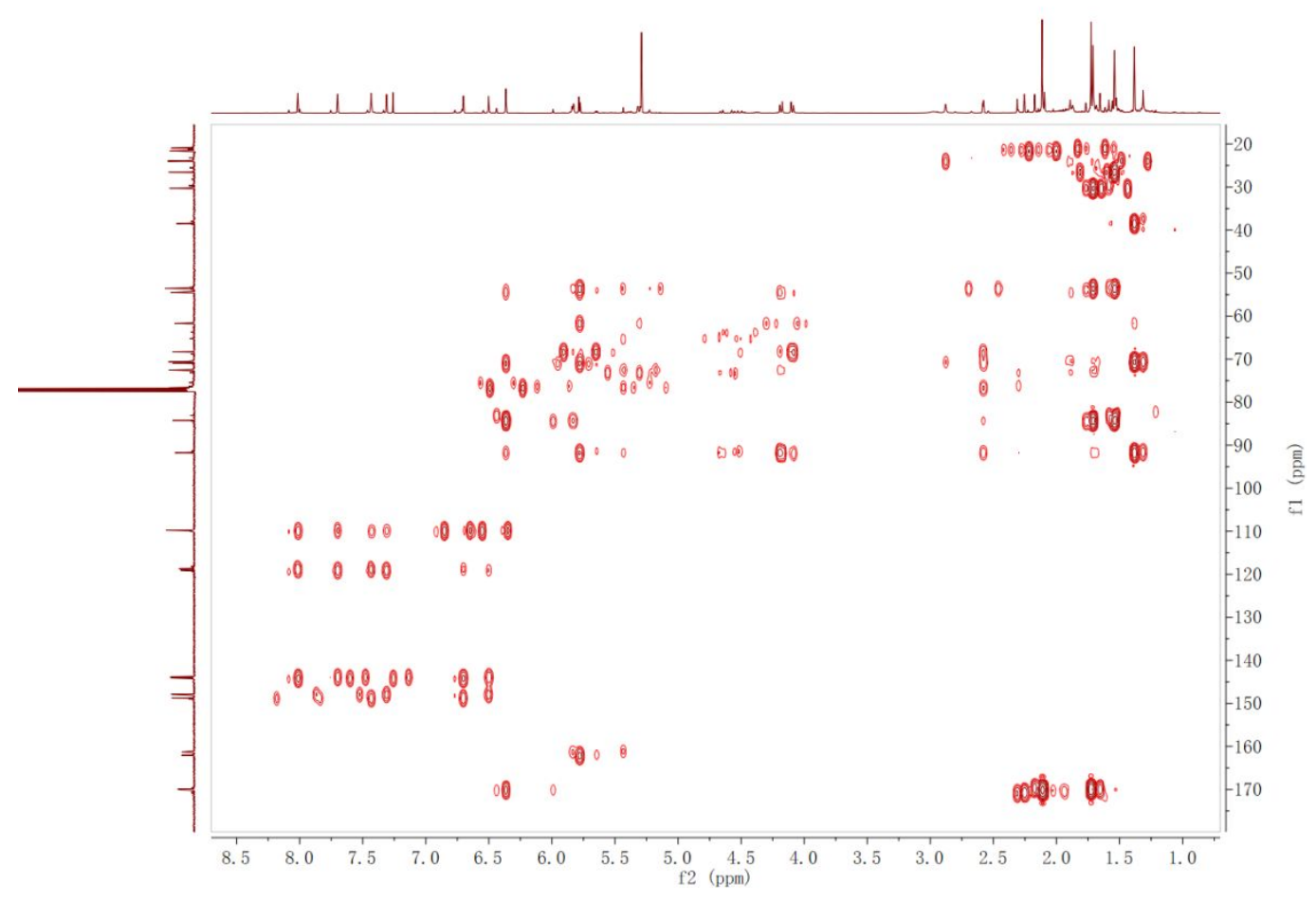


S111. NOESY of Compound 14 in $\mathrm{CDCl}_{3}$

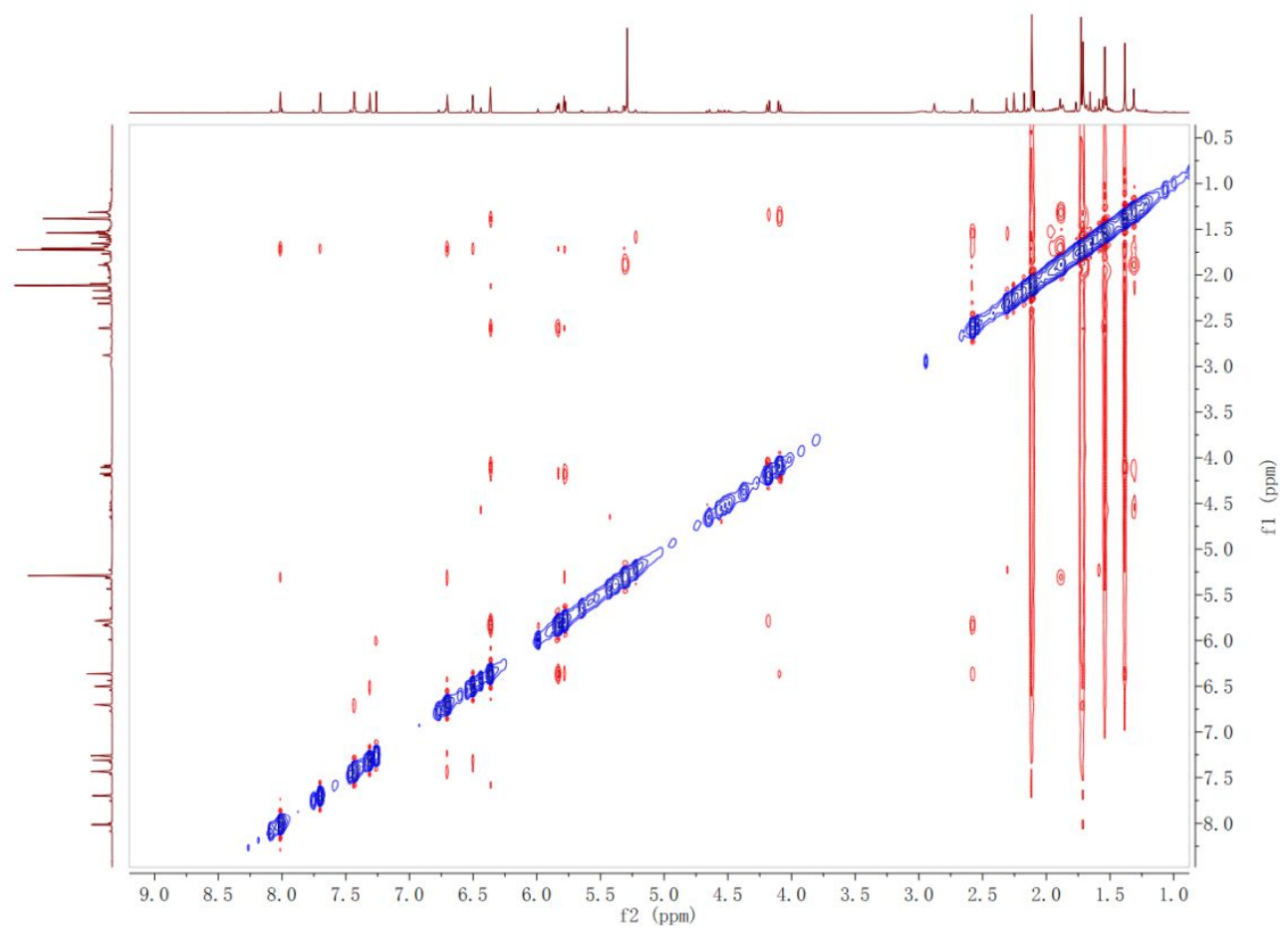

S112. IR spectrum of Compound 14

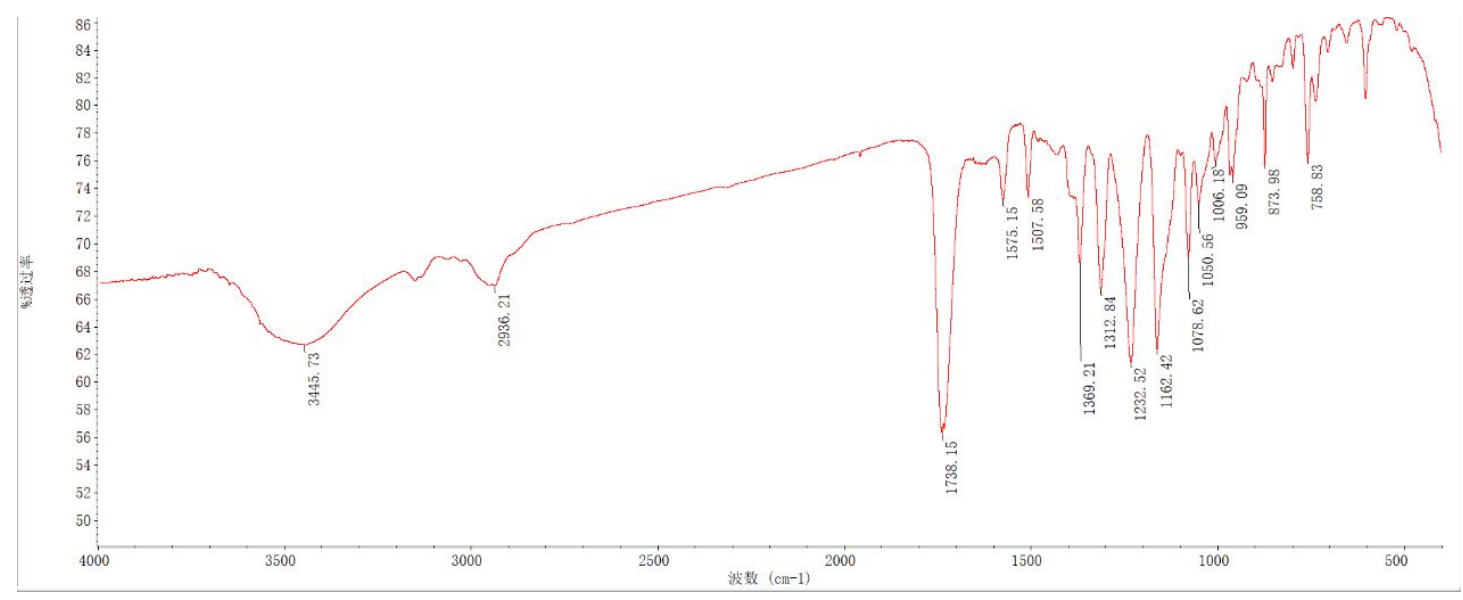


S113. UV spectrum of Compound 14

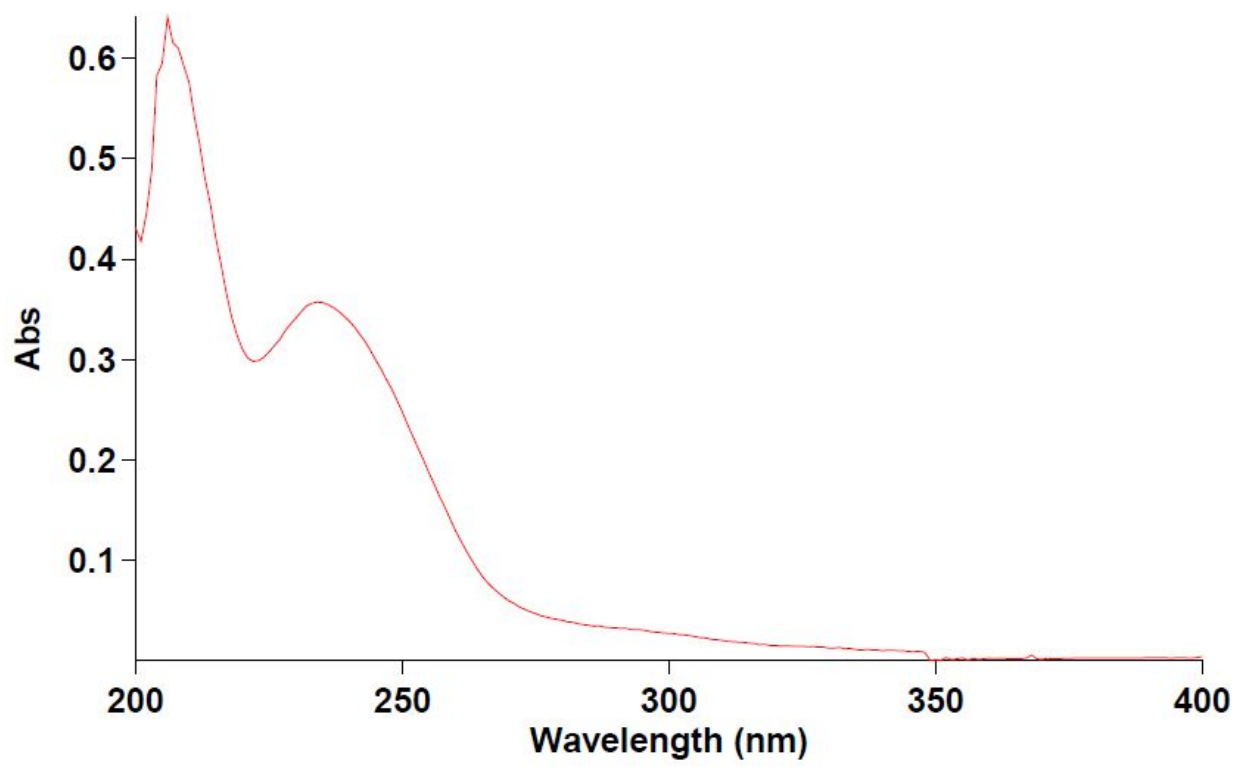


S114. HR-ESIMS of Compound 15

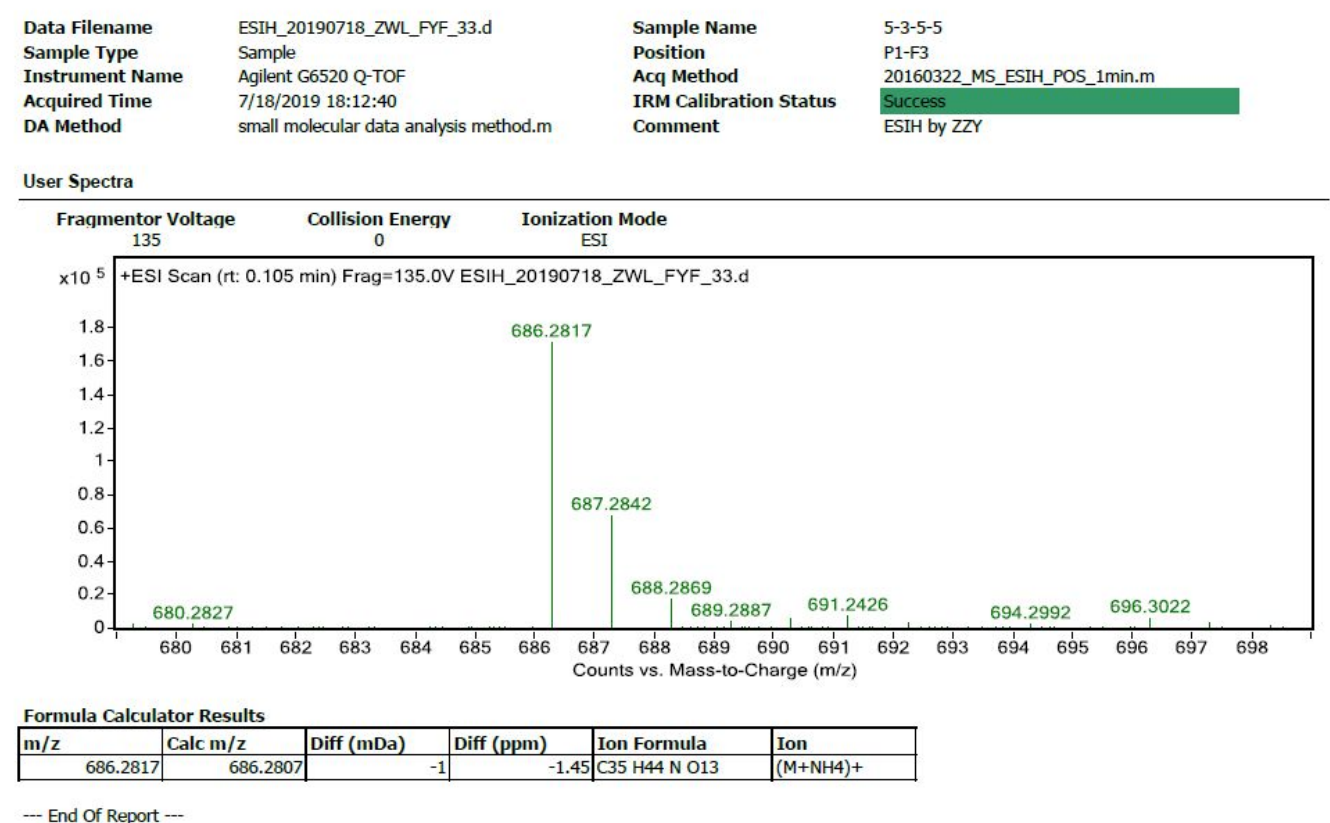

-- End Of Report --

S115. ${ }^{1} \mathrm{H}$ NMR spectrum of Compound 15 in $\mathrm{CDCl}_{3}(500 \mathrm{MHz})$

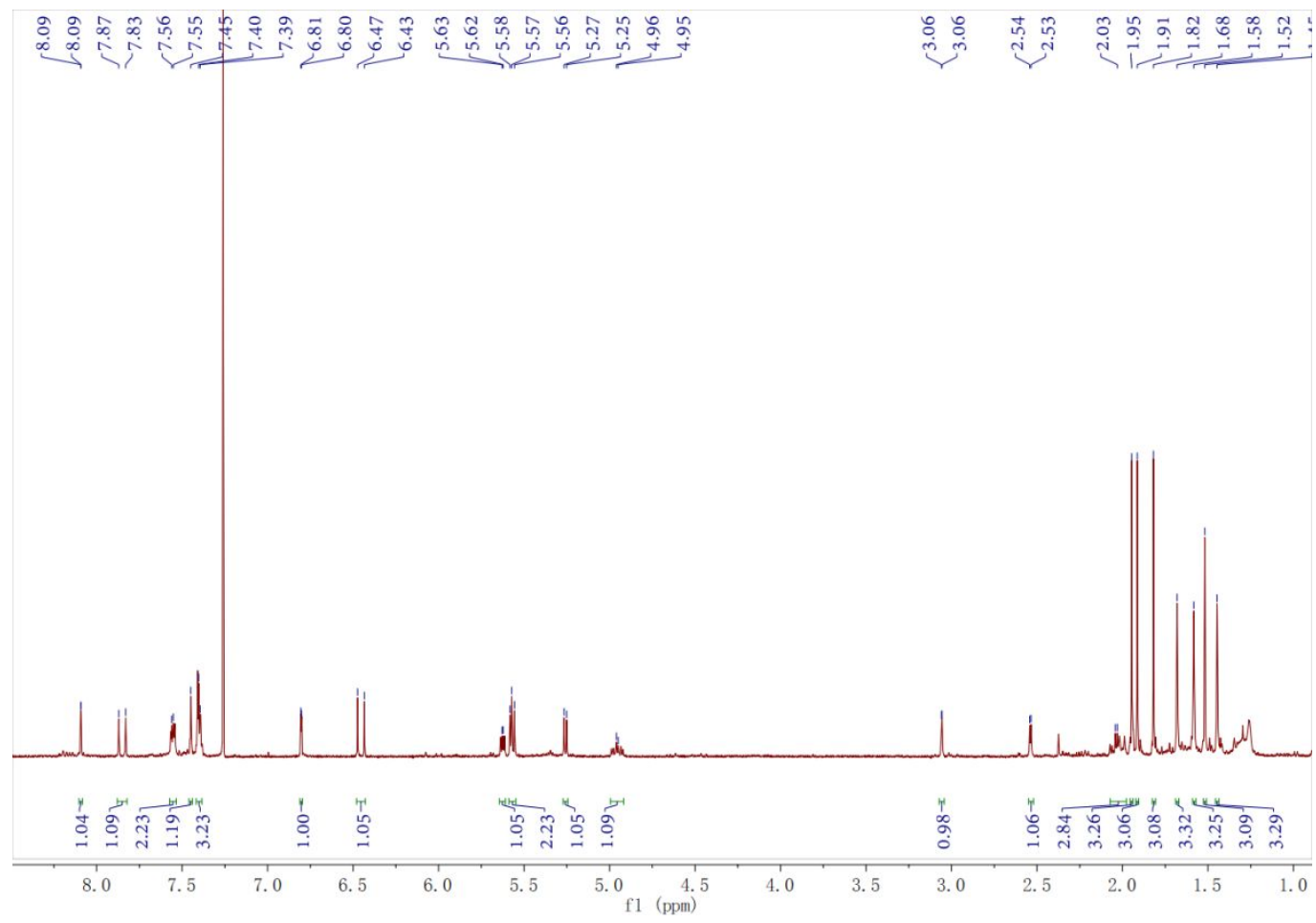


S116. ${ }^{13} \mathrm{C}$ NMR spectrum of Compound 15 in $\mathrm{CDCl}_{3}(125 \mathrm{MHz})$

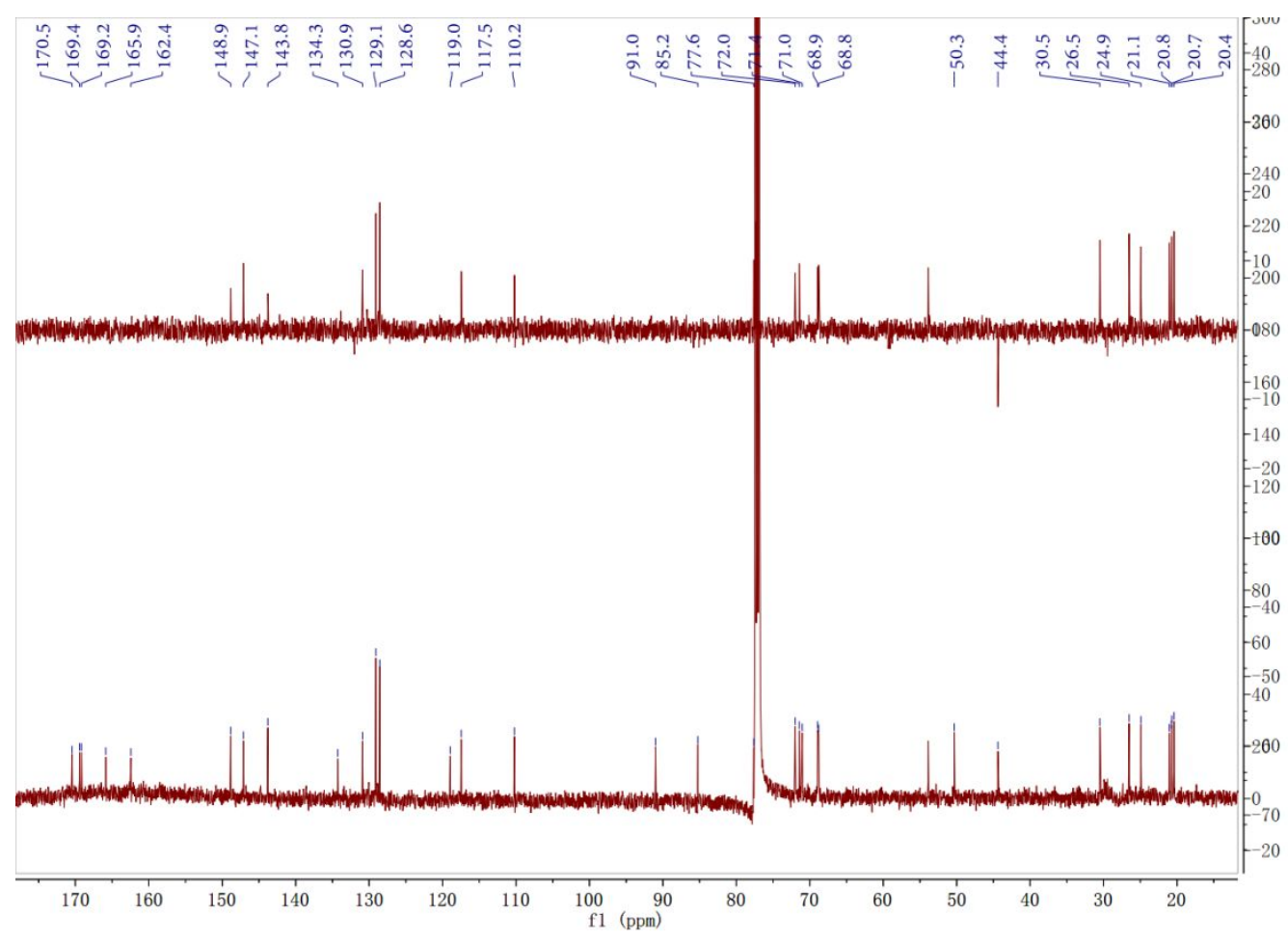


S117. HSQC spectrum of Compound 15 in $\mathrm{CDCl}_{3}$

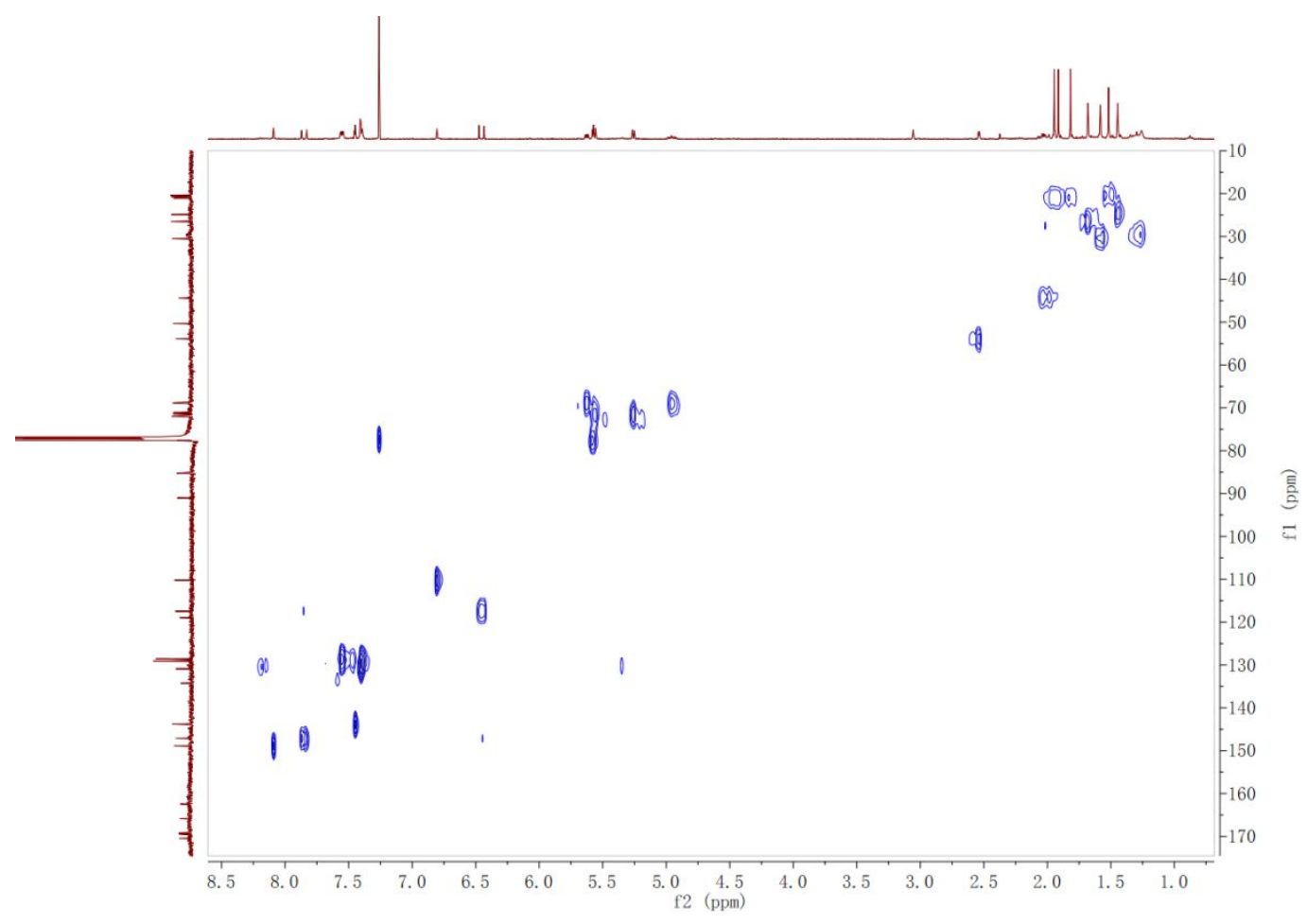

S118. HMBC spectrum of Compound 15 in $\mathrm{CDCl}_{3}$

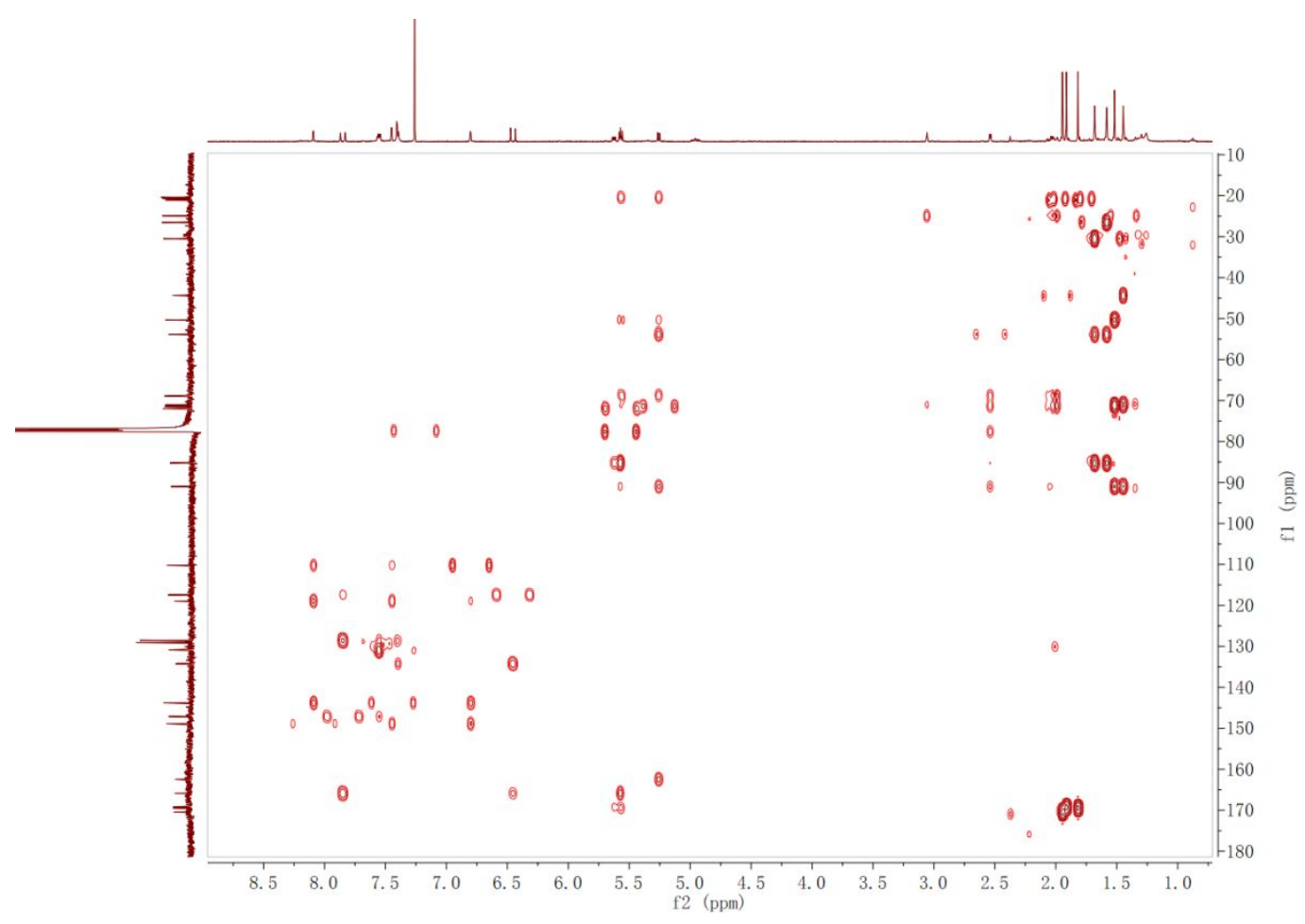


S119. NOESY of Compound 15 in $\mathrm{CDCl}_{3}$

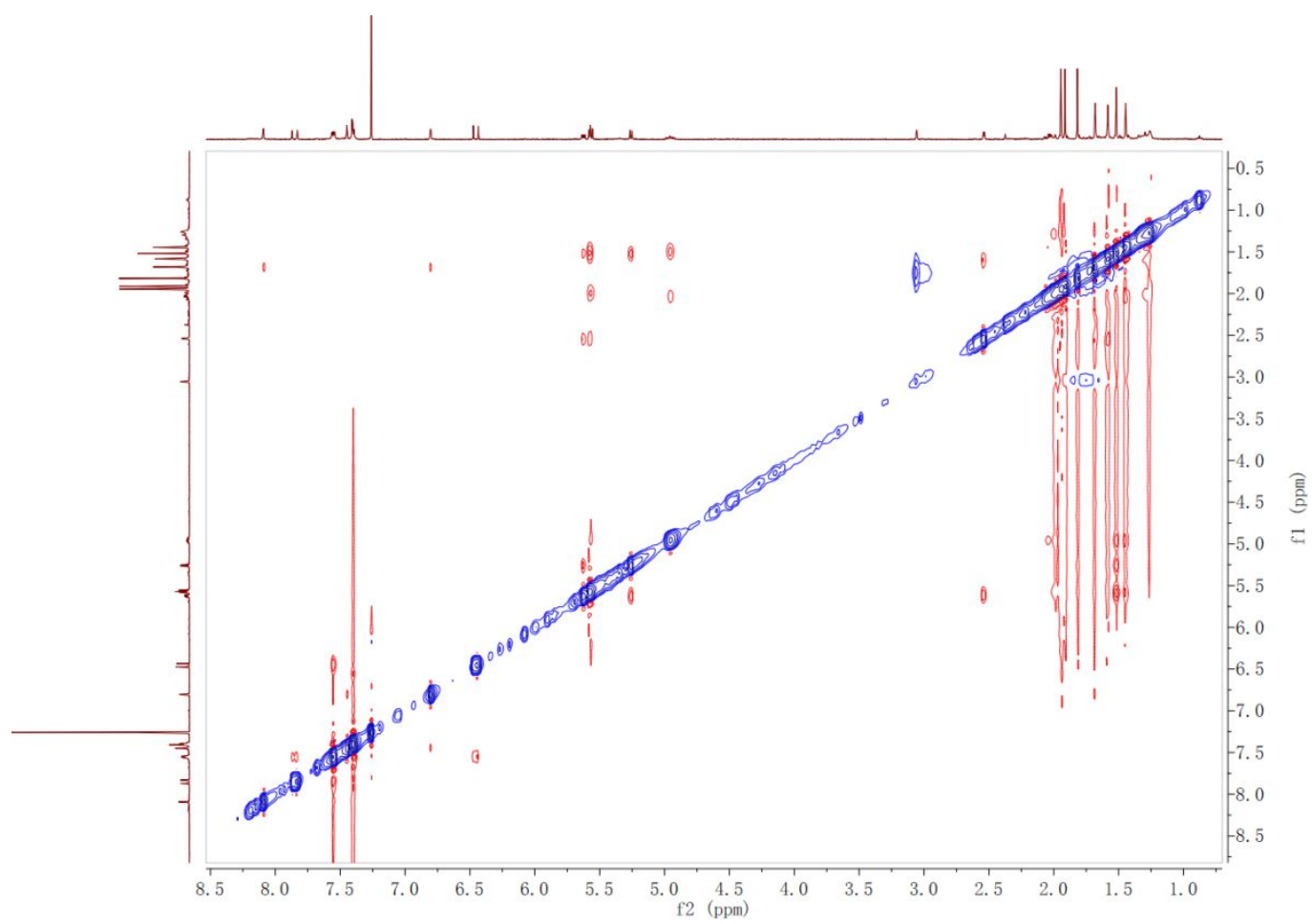

S120. IR spectrum of Compound 15

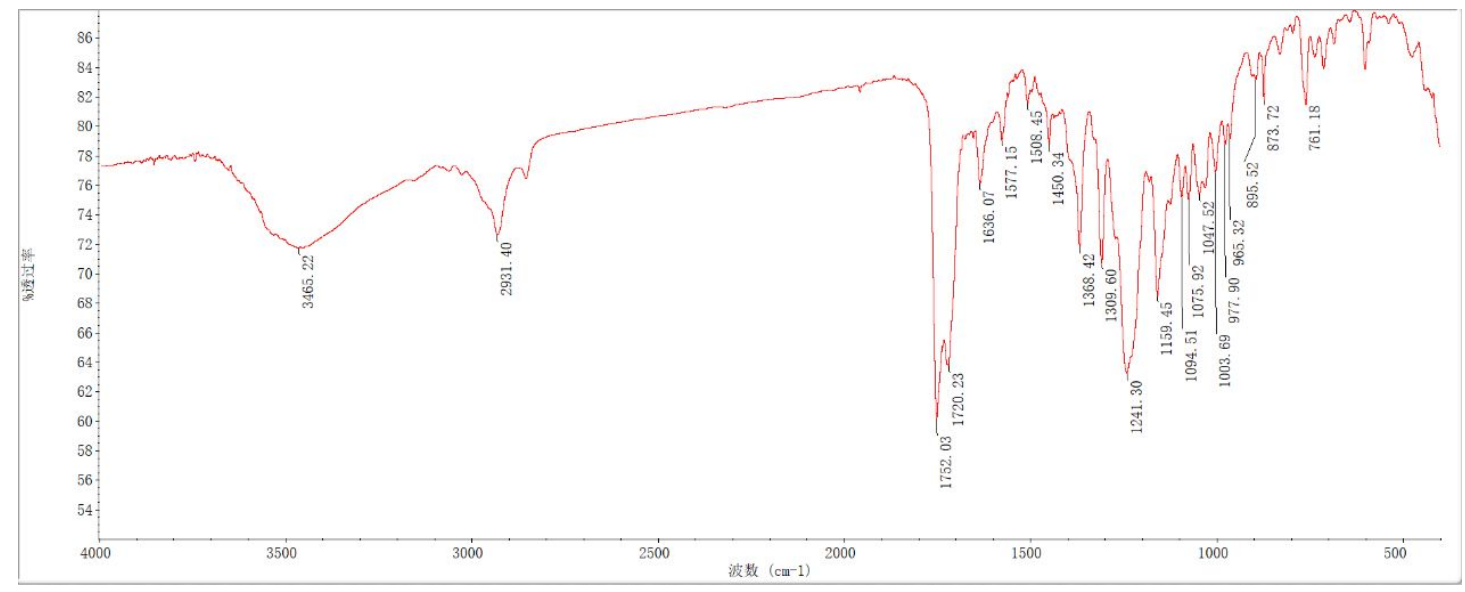


S121. UV spectrum of Compound 15

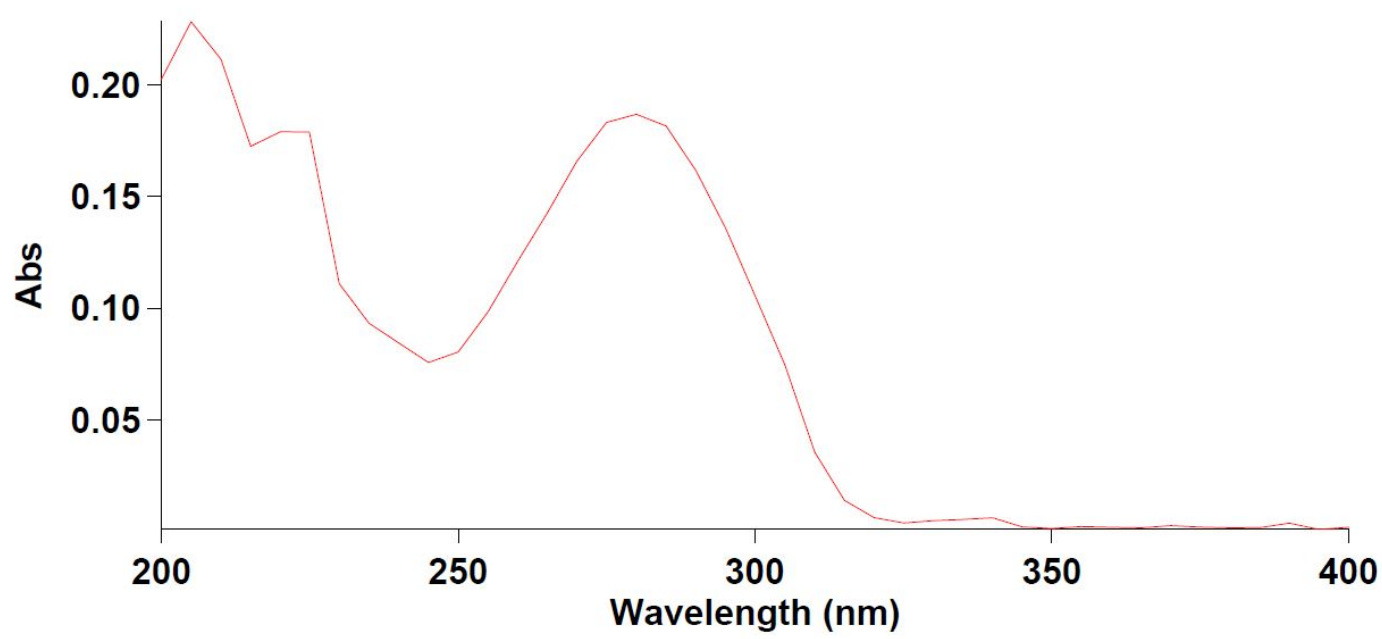

S122. HR-ESIMS of Compound 16

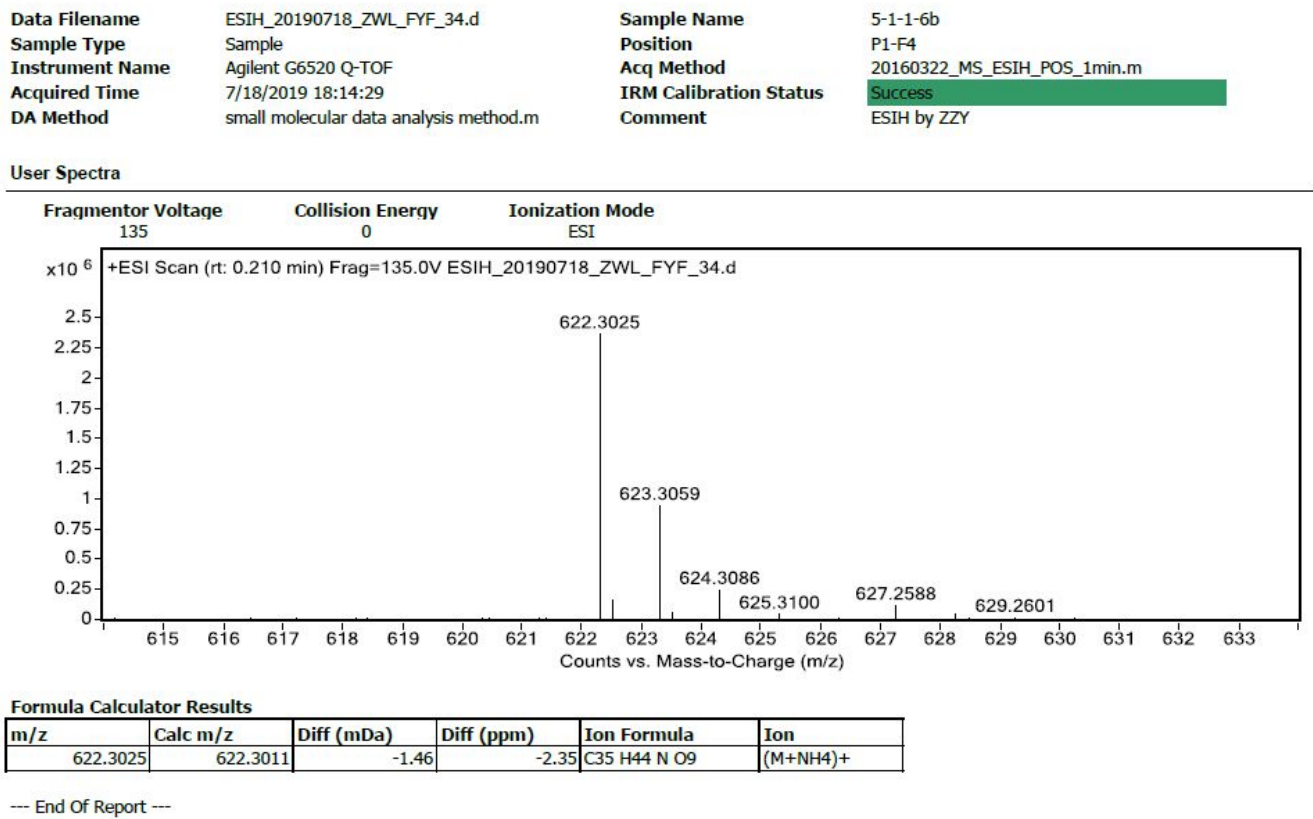


S123. ${ }^{1} \mathrm{H}$ NMR spectrum of Compound 16 in $\mathrm{CDCl}_{3}(500 \mathrm{MHz})$

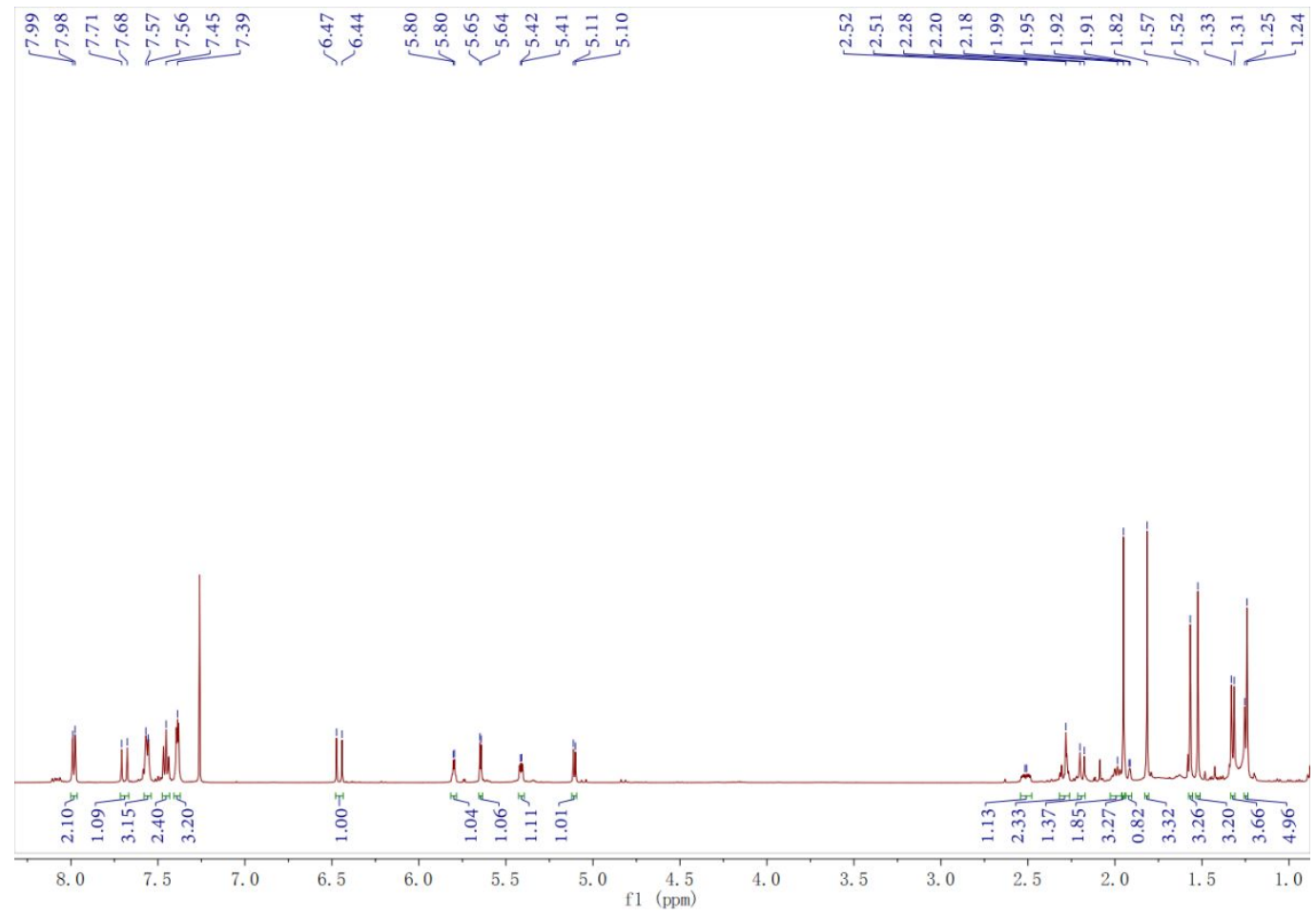


S124. ${ }^{13} \mathrm{C}$ NMR spectrum of Compound 16 in $\mathrm{CDCl}_{3}(125 \mathrm{MHz})$

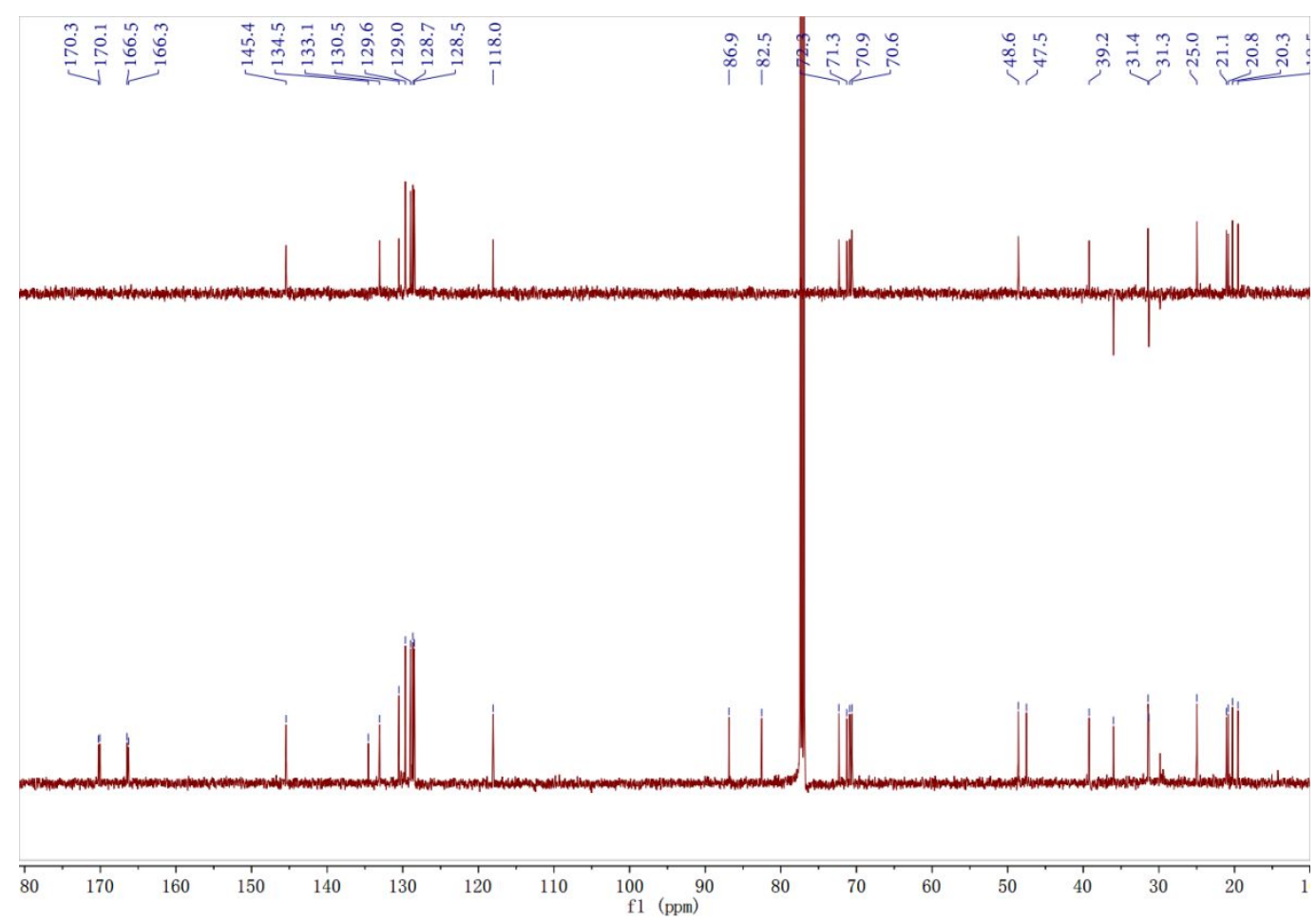

S125. HSQC spectrum of Compound 16 in $\mathrm{CDCl}_{3}$

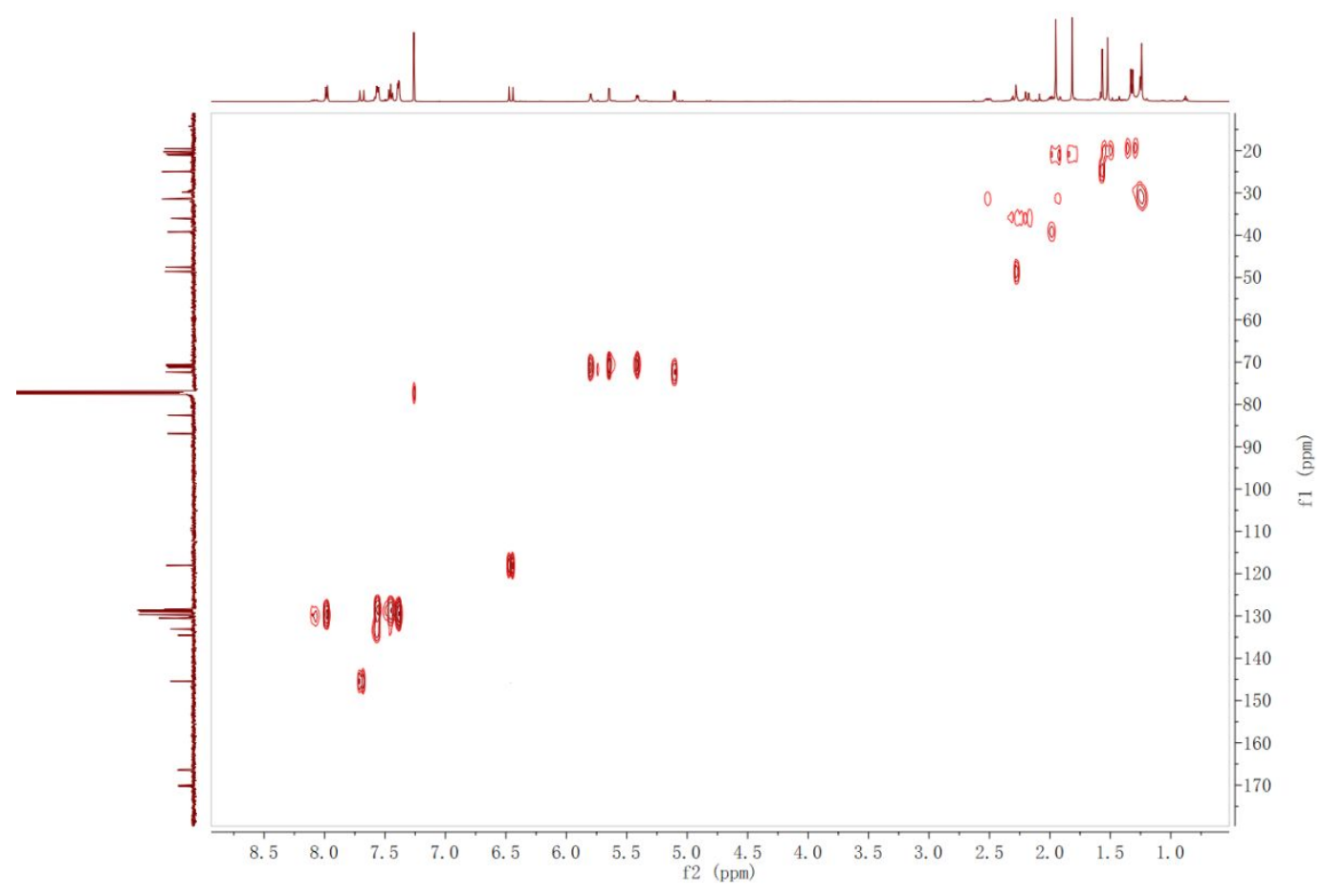




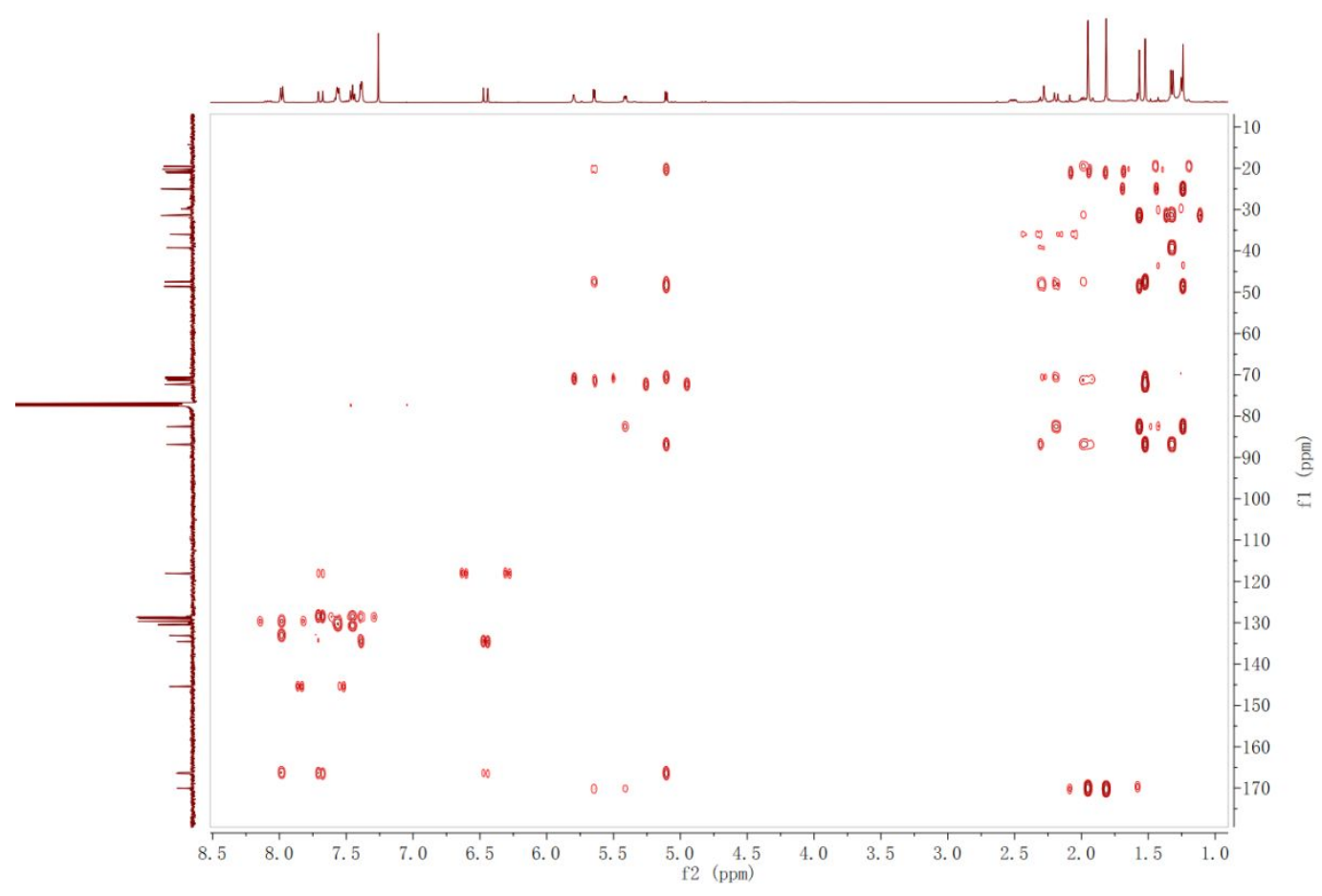

S127. NOESY of Compound 16 in $\mathrm{CDCl}_{3}$

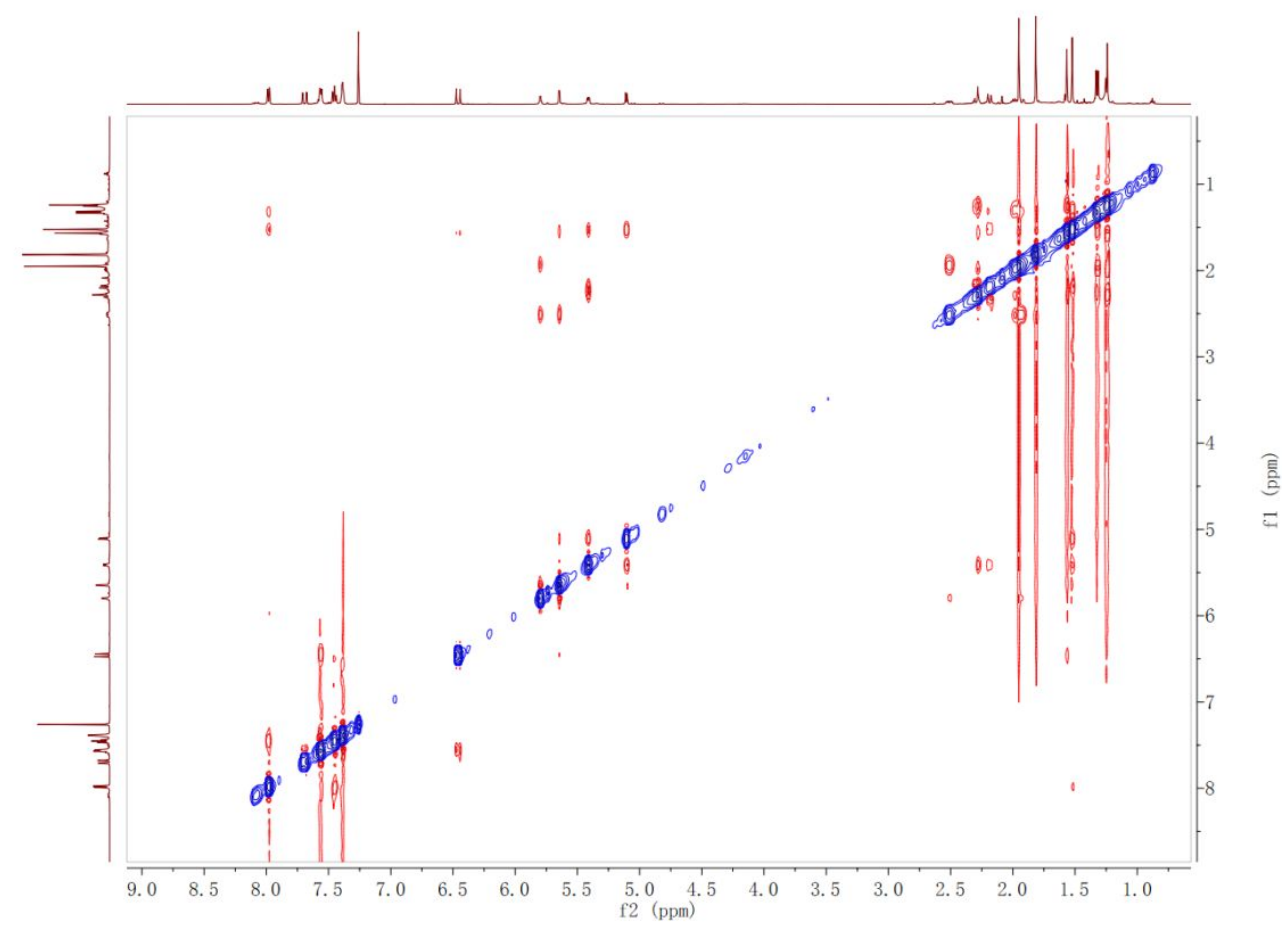


S128. IR spectrum of Compound 16

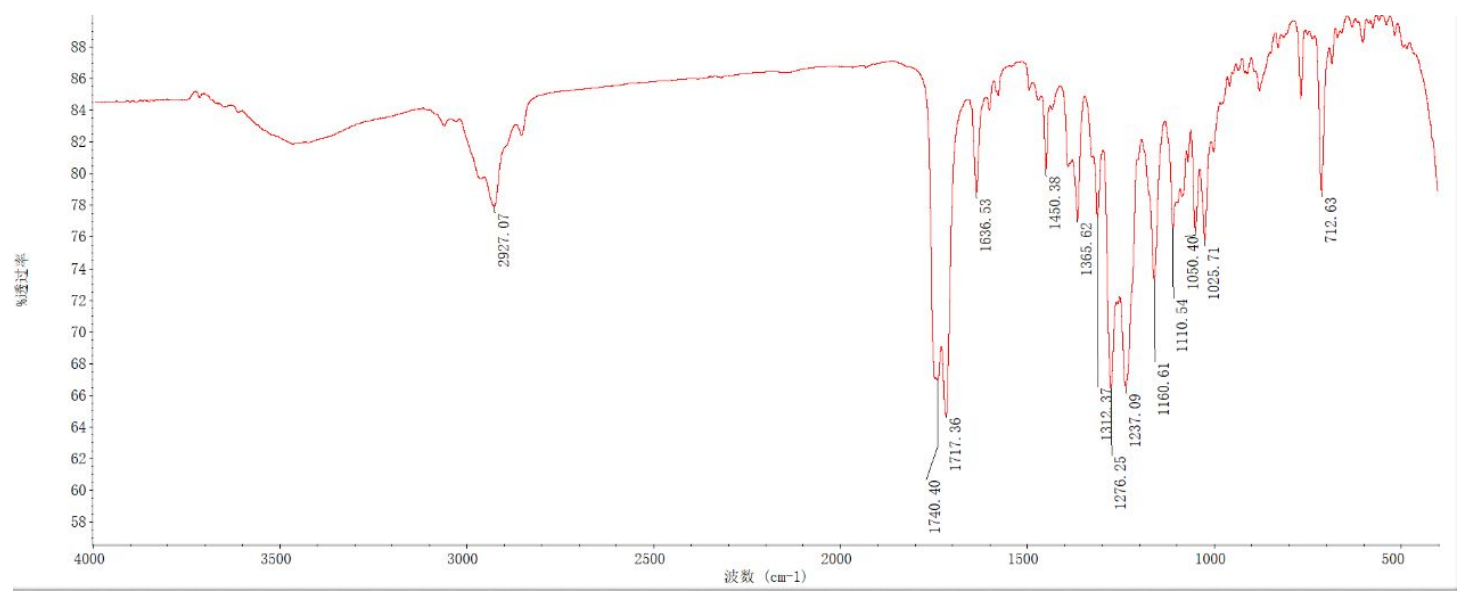

S129. UV spectrum of Compound 16

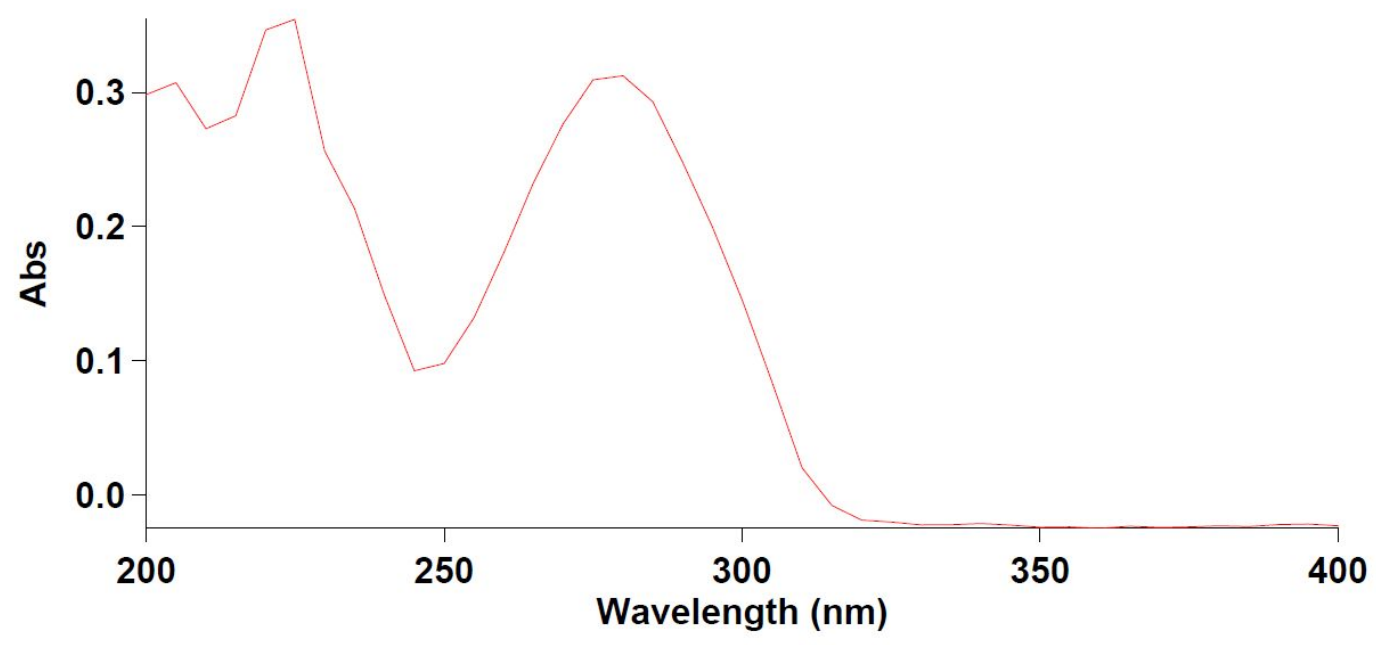


S130. HR-ESIMS of Compound 17

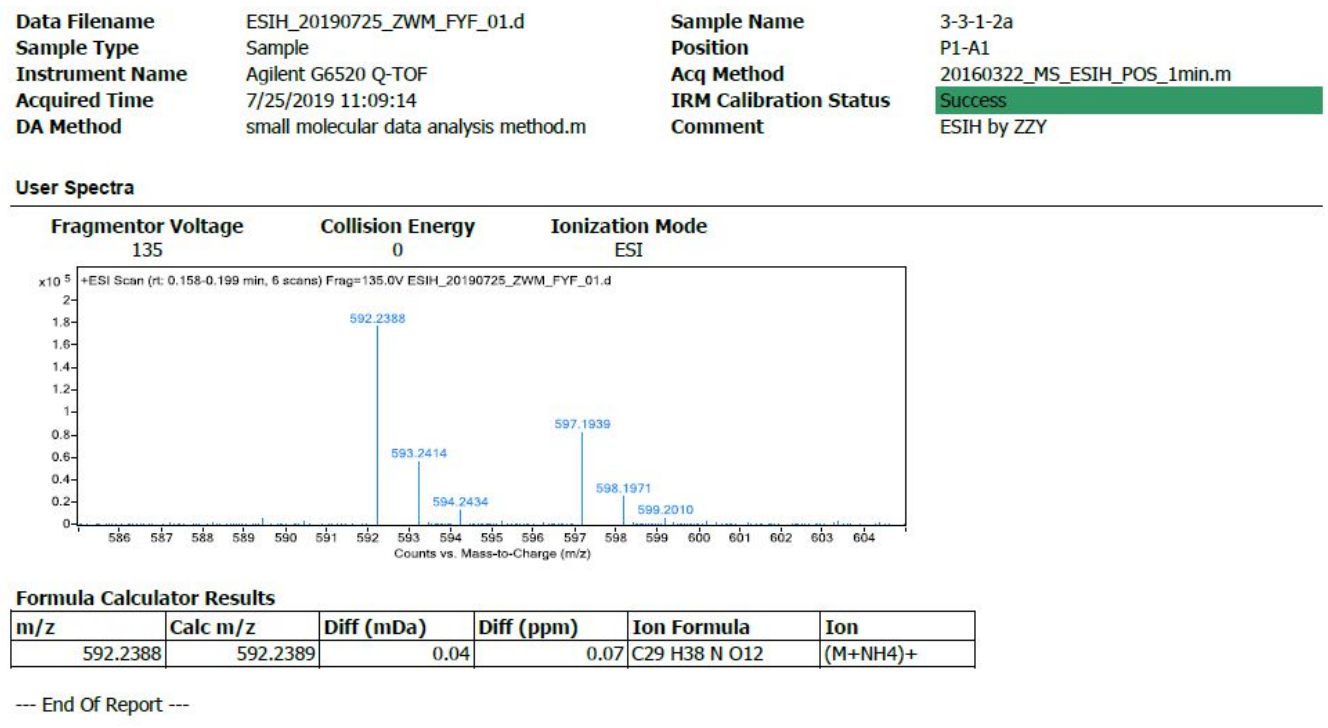

S131. ${ }^{1} \mathrm{H}$ NMR spectrum of Compound 17 in $\mathrm{CDCl}_{3}(500 \mathrm{MHz})$

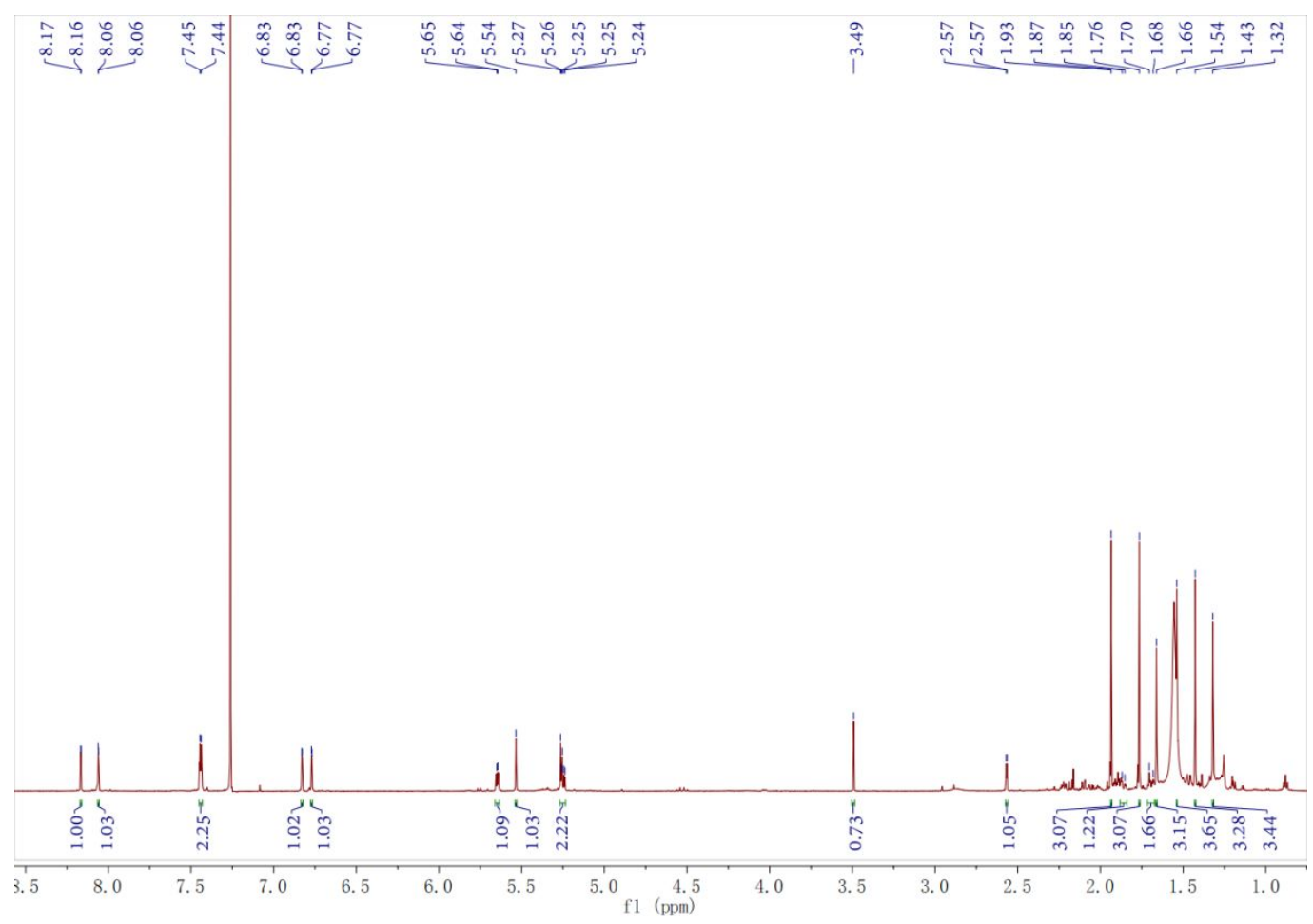


S132. ${ }^{13} \mathrm{C}$ NMR spectrum of Compound 17 in $\mathrm{CDCl}_{3}(125 \mathrm{MHz})$

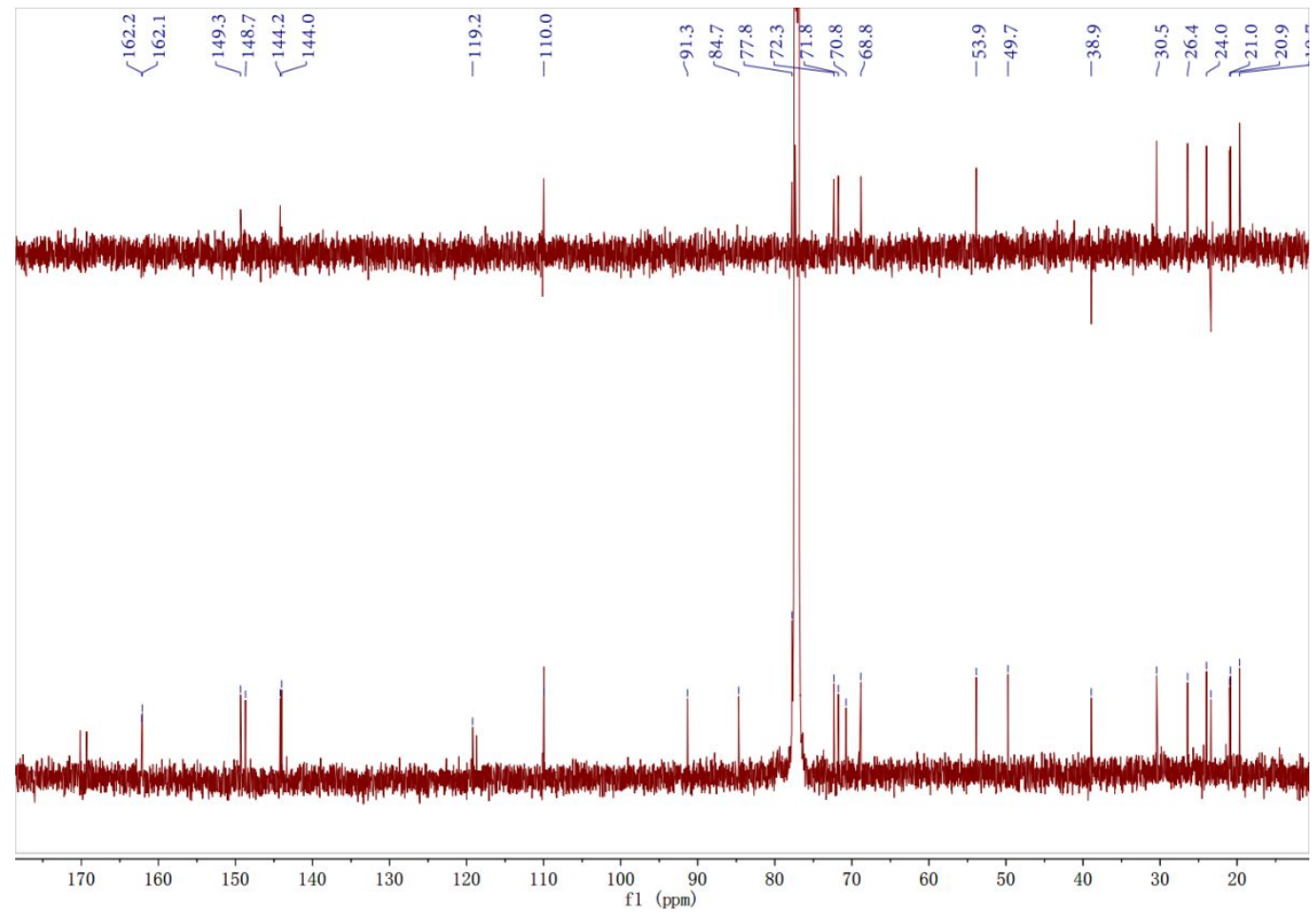


S133. HSQC spectrum of Compound 17 in $\mathrm{CDCl}_{3}$

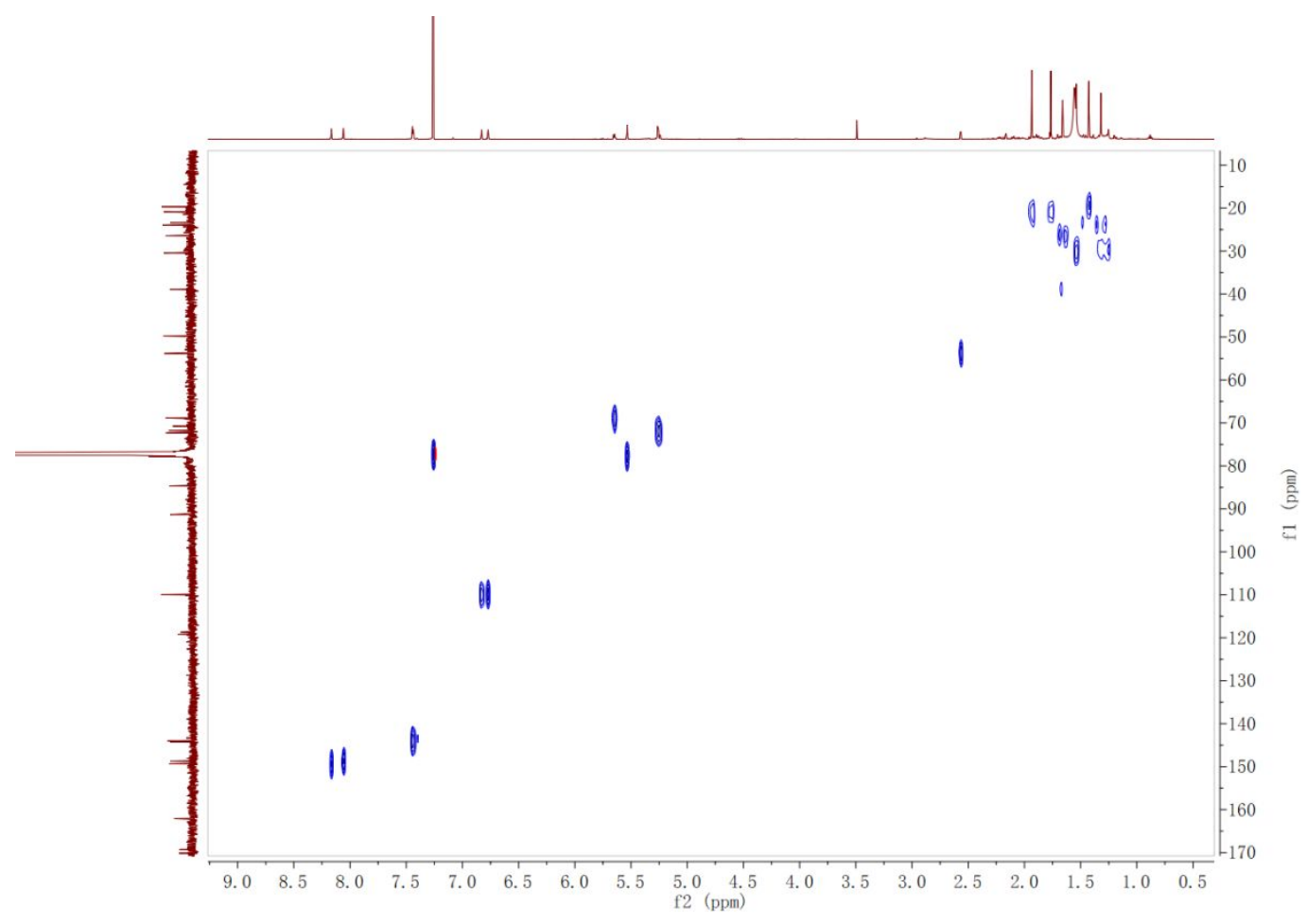

S134. HMBC spectrum of Compound 17 in $\mathrm{CDCl}_{3}$

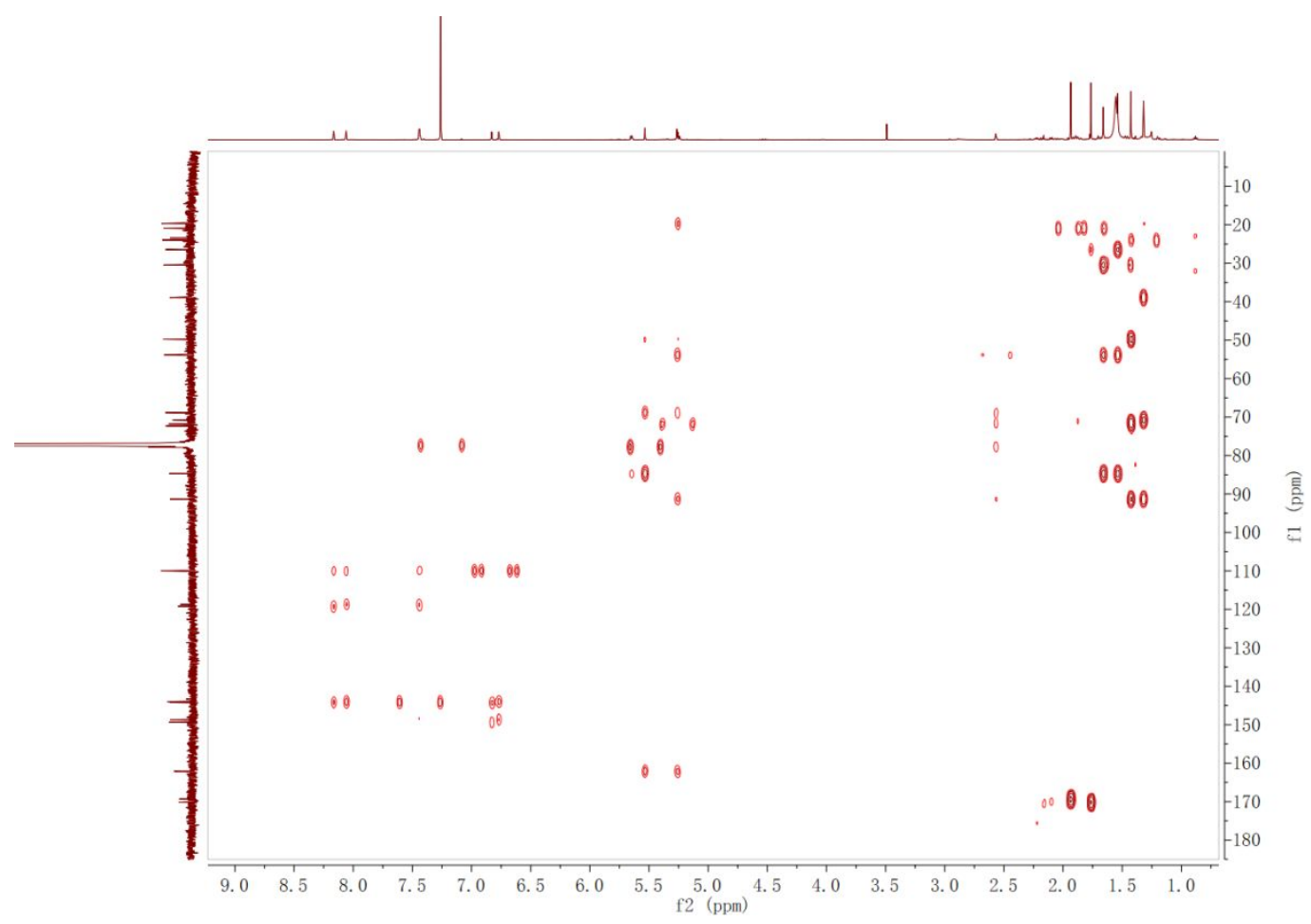


S135. NOESY of Compound 17 in $\mathrm{CDCl}_{3}$

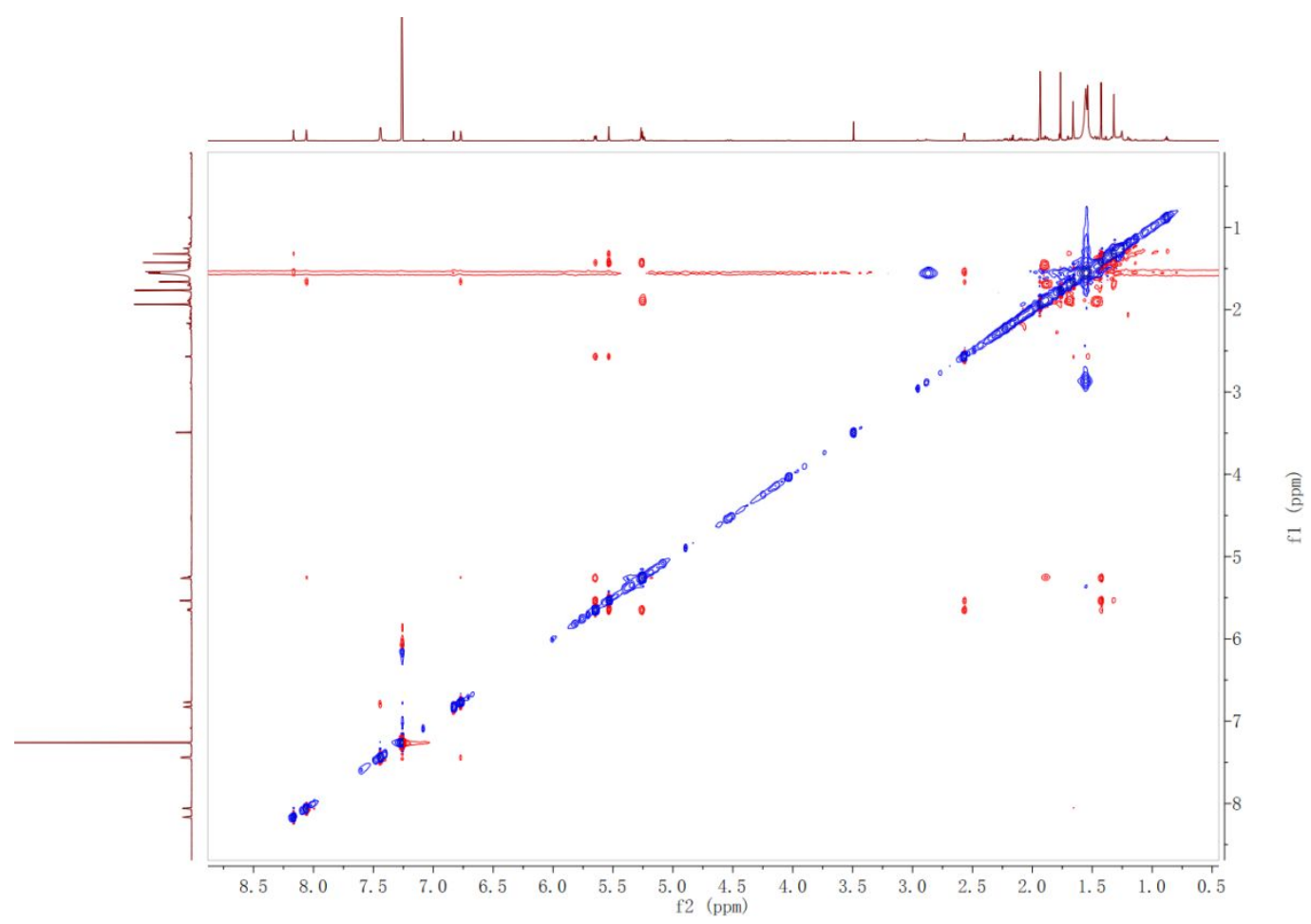

S136. IR spectrum of Compound 17

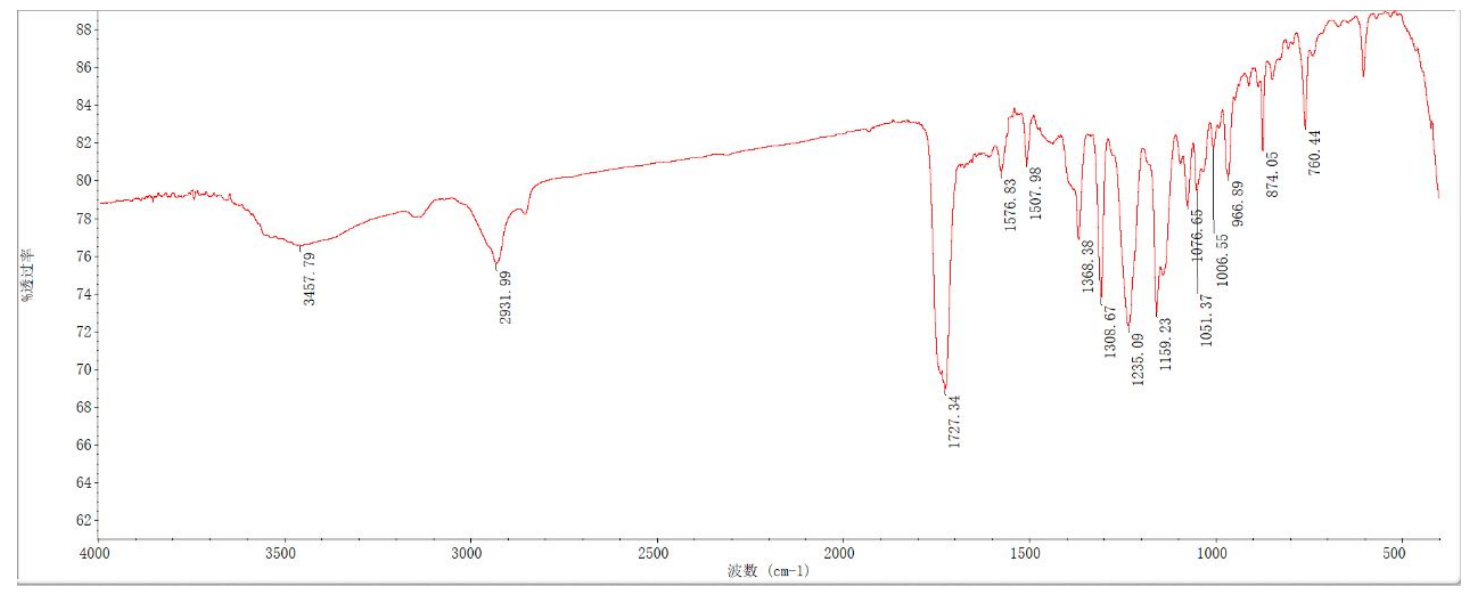


S137. UV spectrum of Compound 17

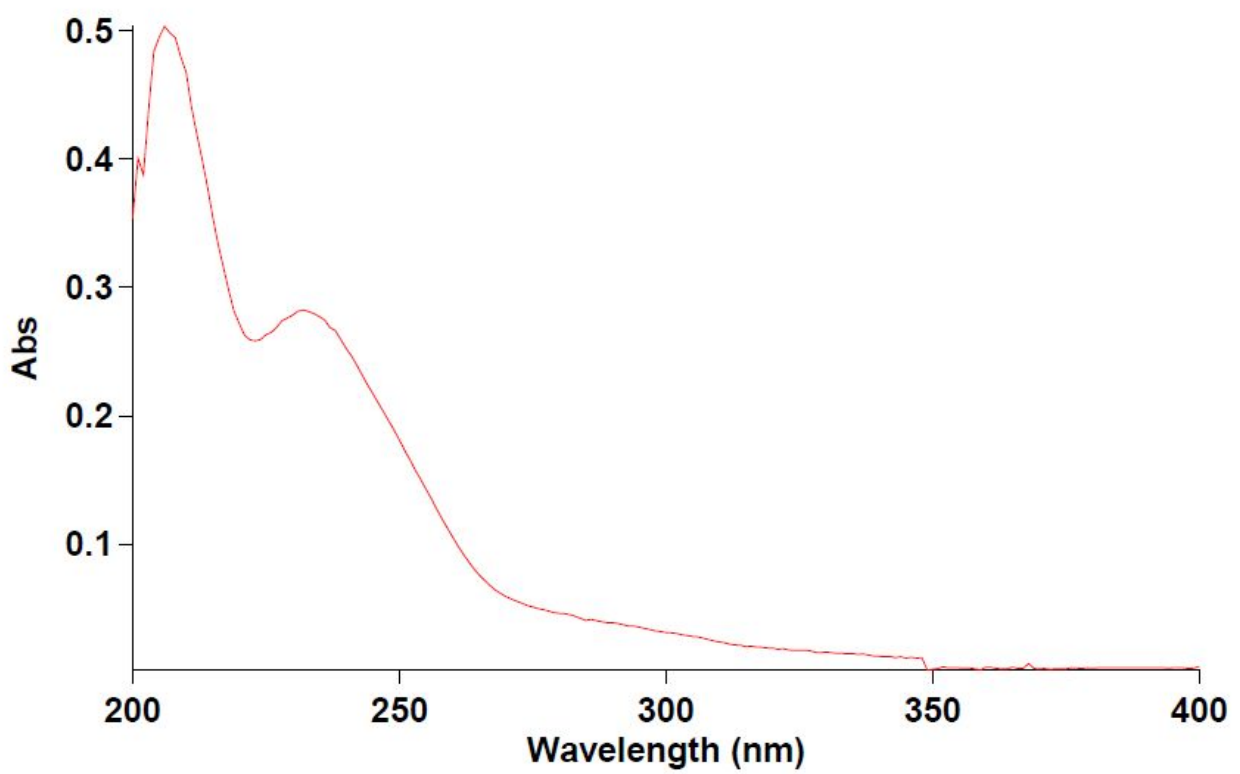


S138. HR-ESIMS of Compound 18

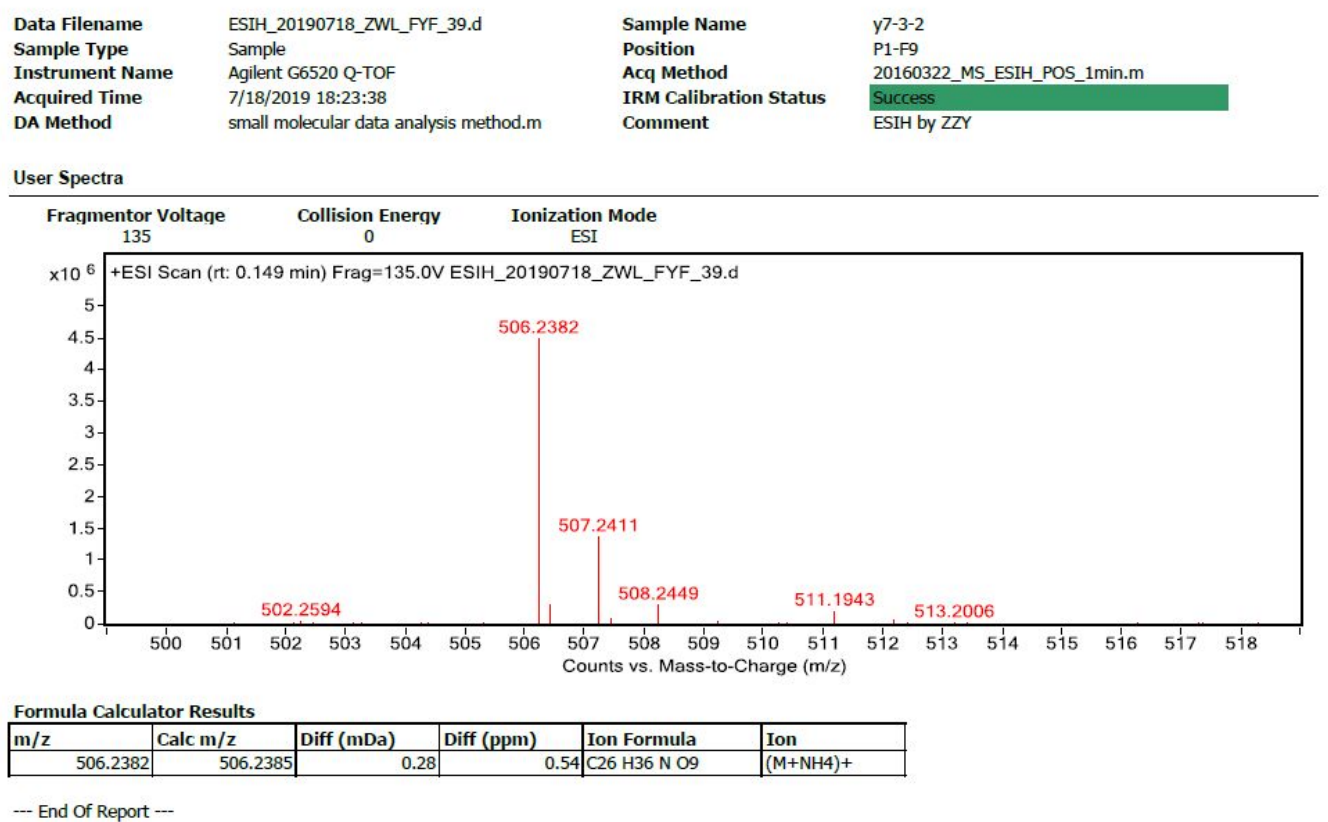

S139. ${ }^{1} \mathrm{H}$ NMR spectrum of Compound 18 in $\mathrm{CDCl}_{3}(500 \mathrm{MHz})$

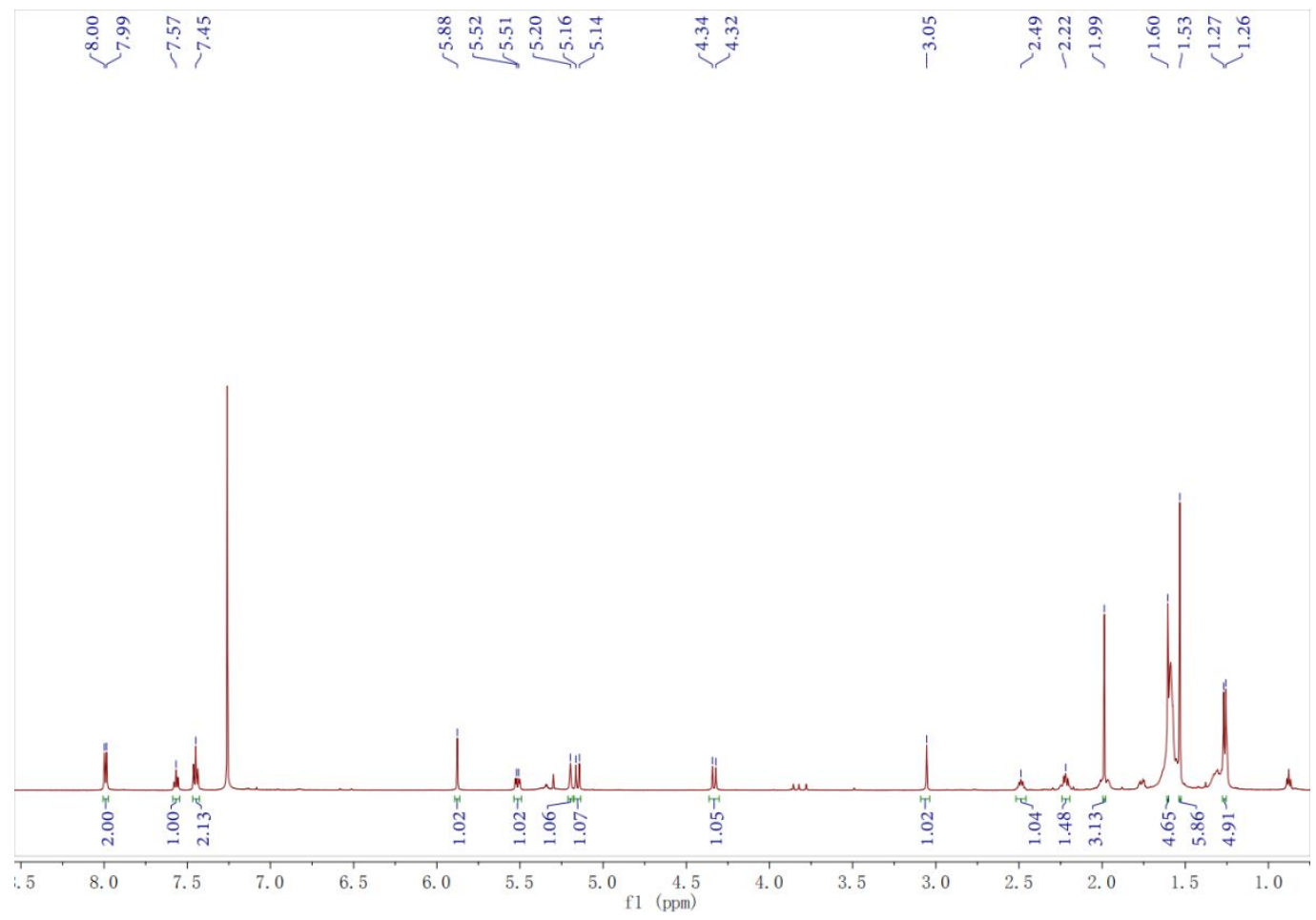


S140. ${ }^{13} \mathrm{C}$ NMR spectrum of Compound 18 in $\mathrm{CDCl}_{3}(125 \mathrm{MHz})$

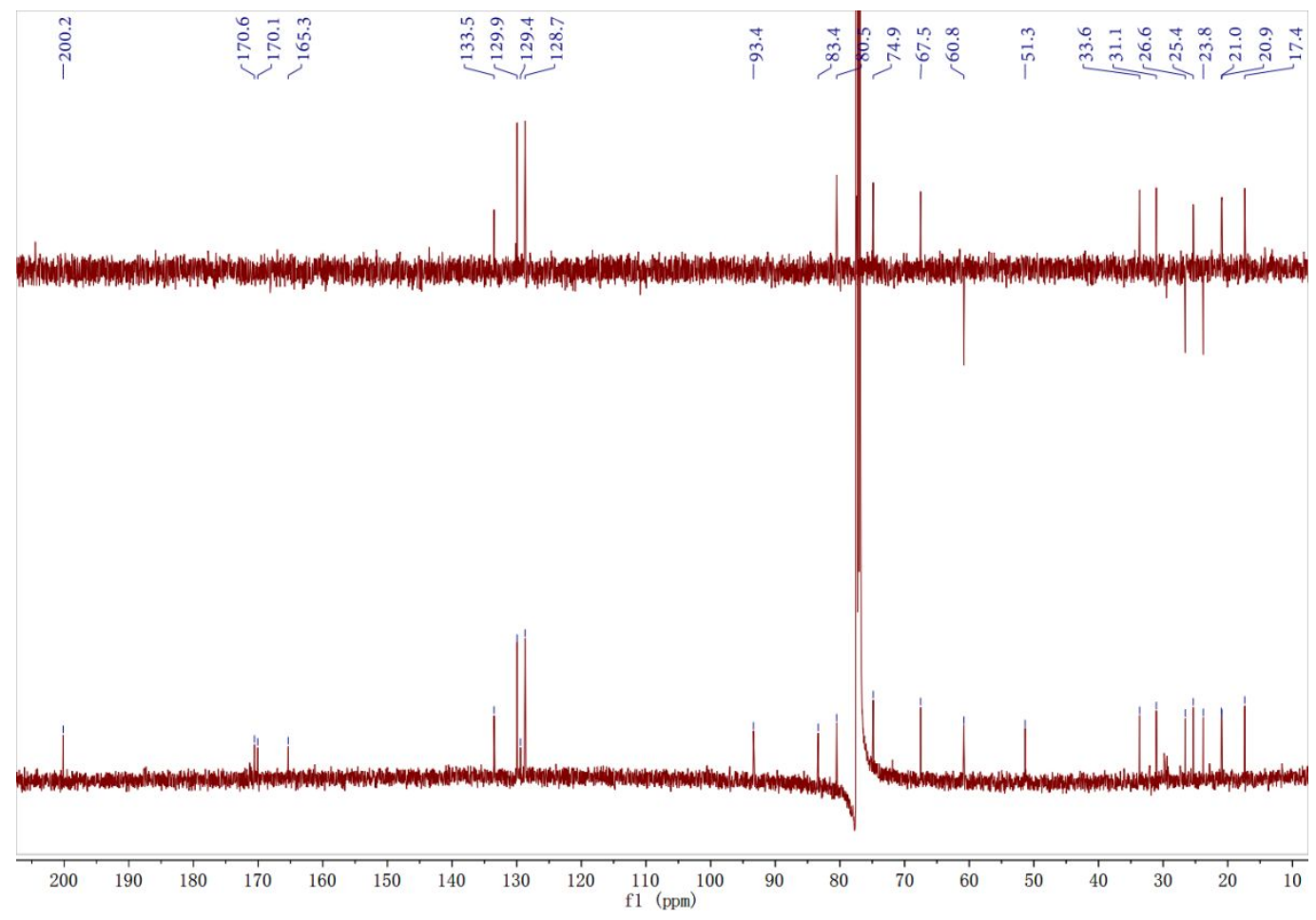


S141. HSQC spectrum of Compound 18 in $\mathrm{CDCl}_{3}$

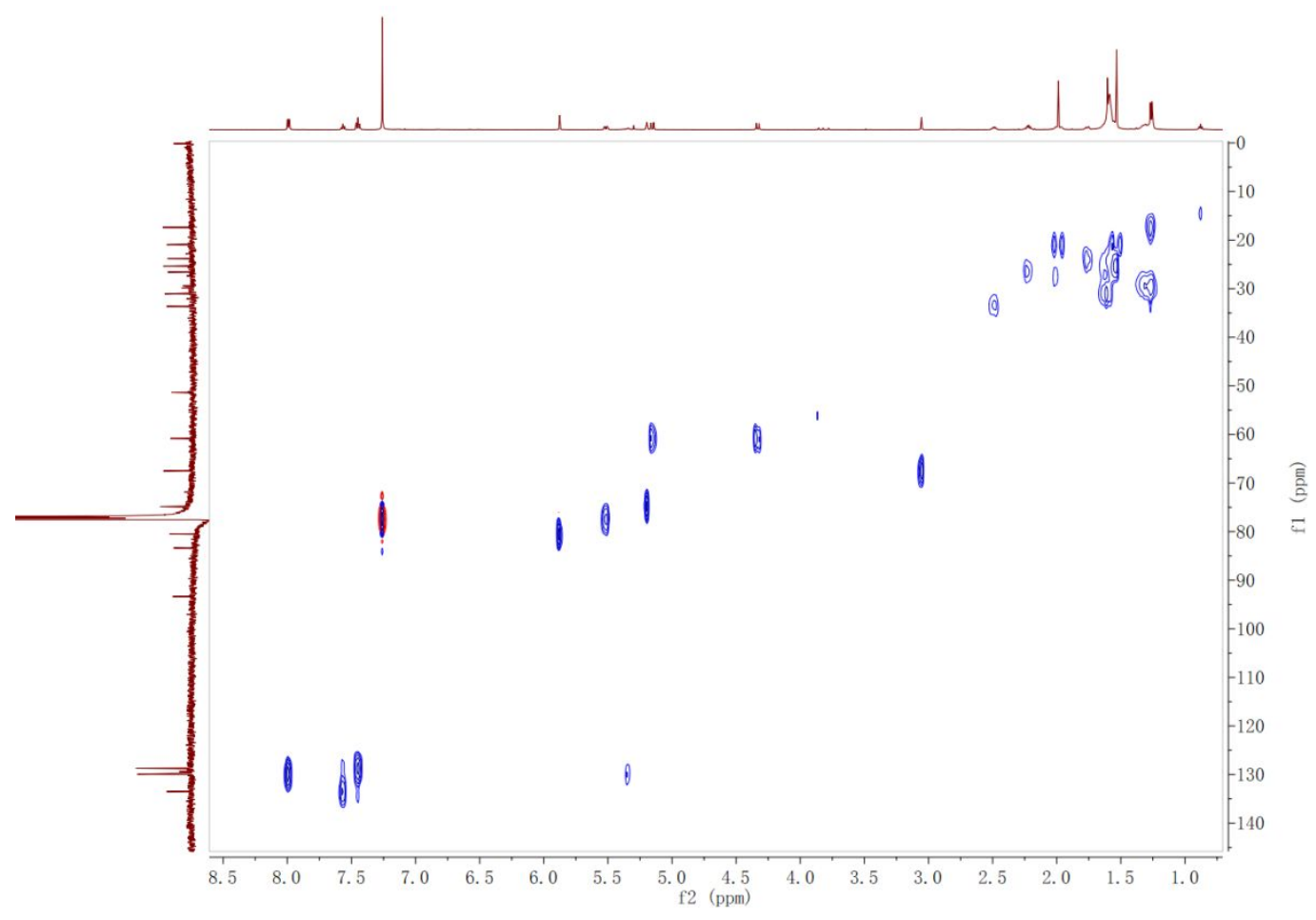

S142. HMBC spectrum of Compound 18 in $\mathrm{CDCl}_{3}$

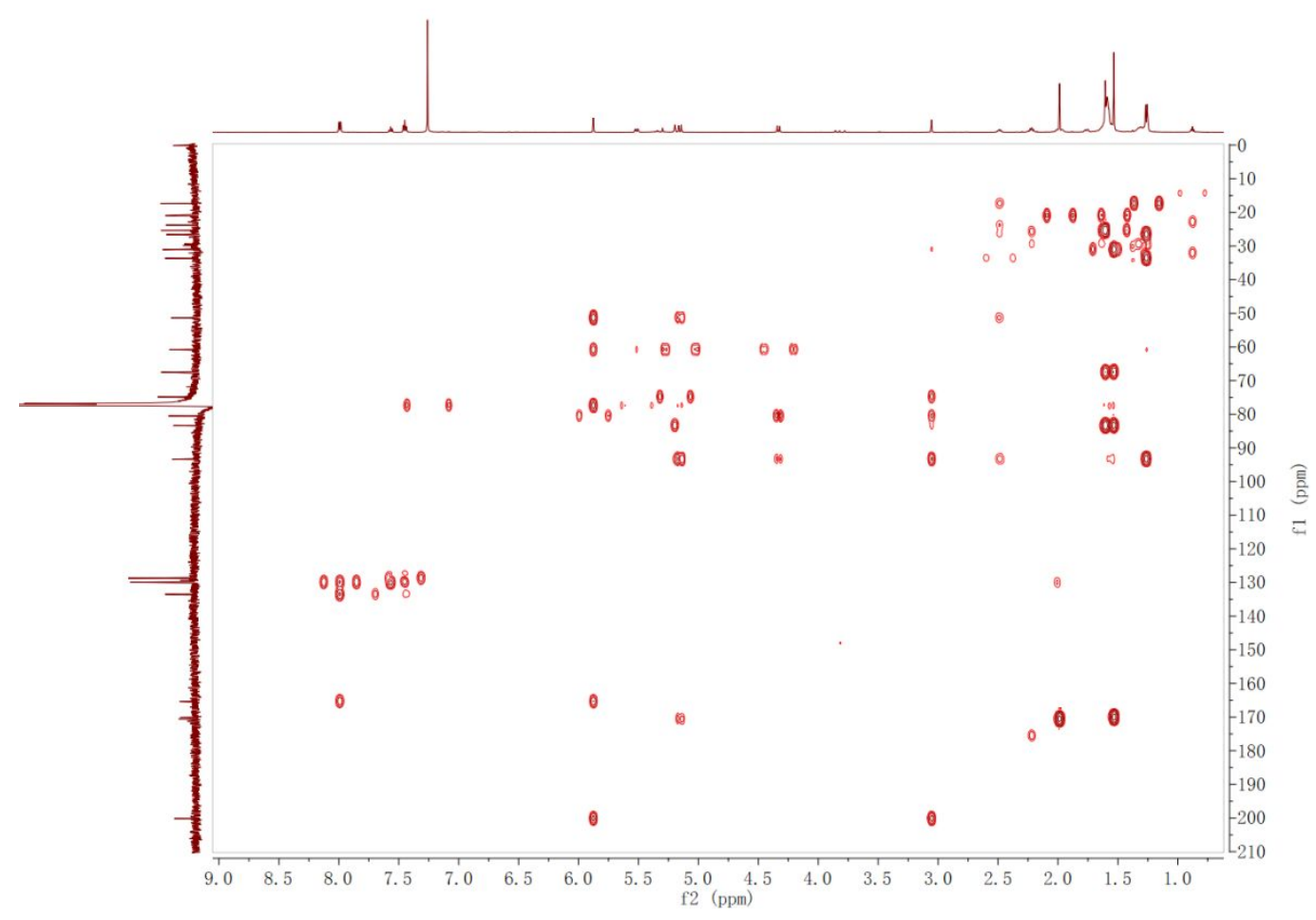


S143. NOESY of Compound 18 in $\mathrm{CDCl}_{3}$

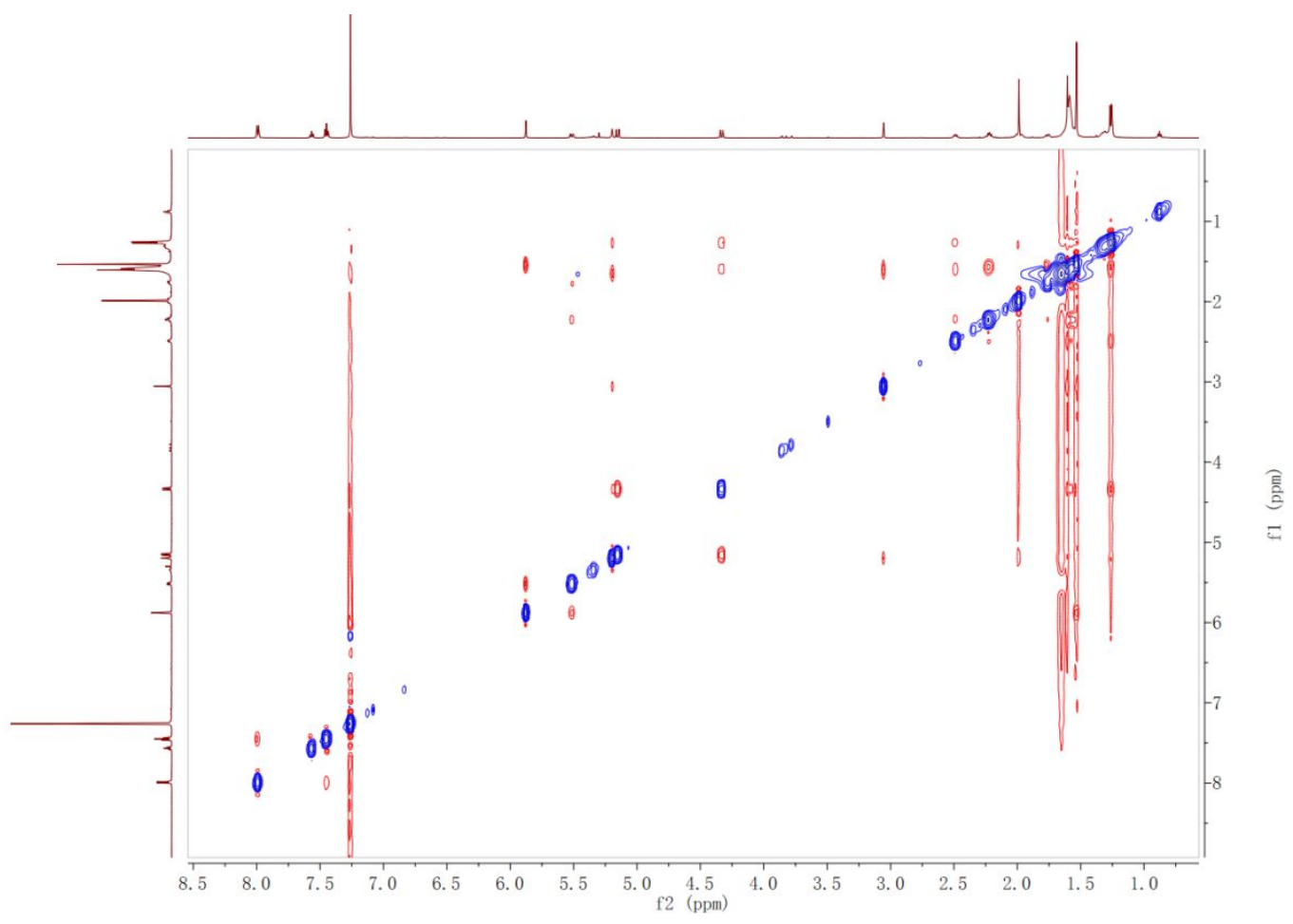

S144. IR spectrum of Compound 18

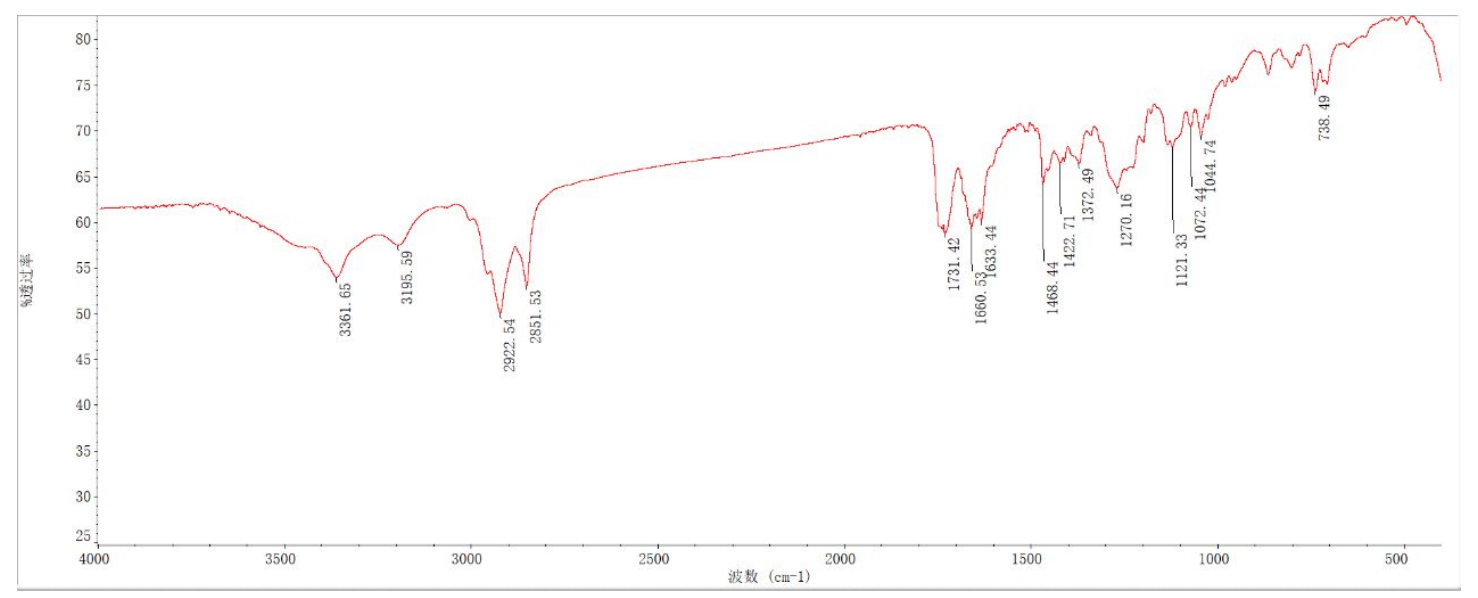

95 


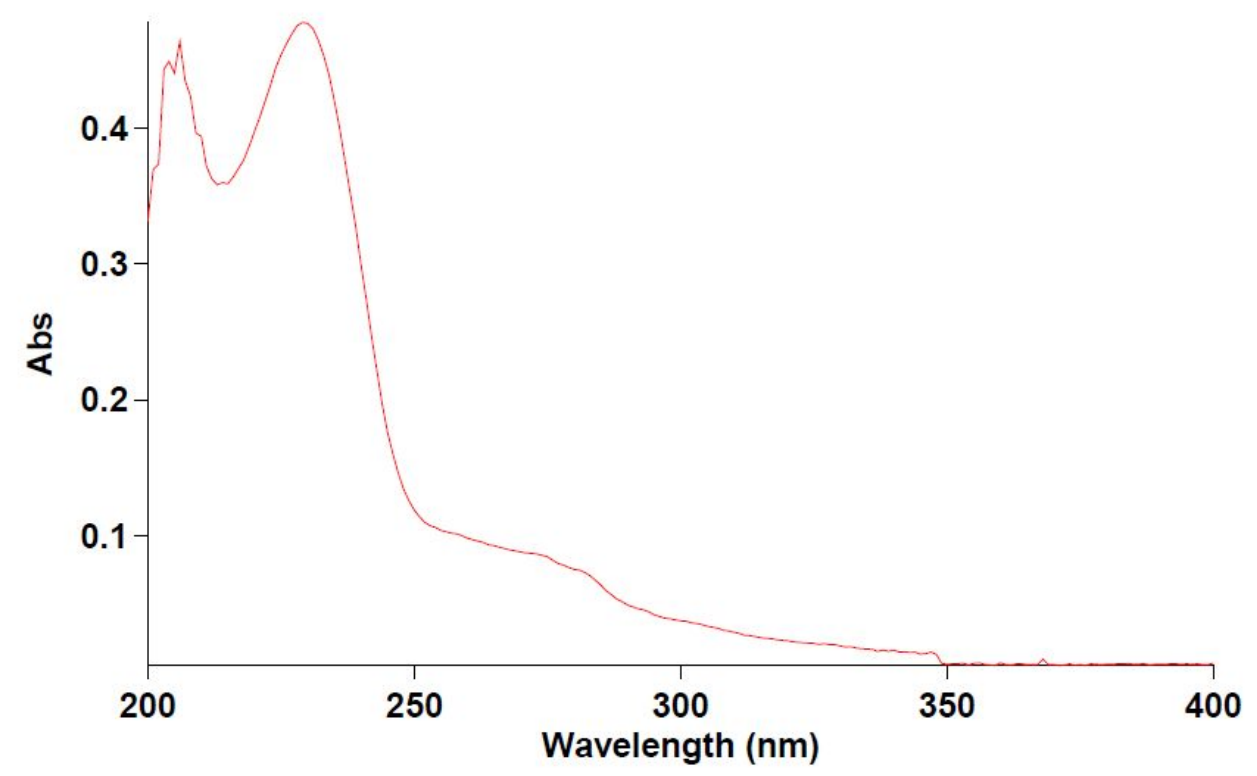

S146. General Experimental Procedures.

Optical rotations were measured on a PerkinElmer 341 polarimeter, and IR spectra were obtained using KBr disks on a PerkinElmer 577 spectrometer (PerkinElmer, Waltham, MA, USA). ECD spectra were obtained on a JASCO J-810 spectrometer (JASCO Corporation, Tokyo, Japan). UV spectra were recorded using a Varian Cary 50-vis spectrophotometer (Varian, Melbourne, Australia). NMR experiments were performed on Bruker AM-400, Bruker Avance I I I 500, Bruker Avance I I I 600 (Bruker, Ettlingen, Germany), or Varian Mercury Plus-400 (Varian, Palo Alto, CA, USA) instruments using TMS as an internal standard. ESIMS analyses were performed on a Shimadzu LC-MS-2020 spectrometer with a Shimadzu SPD-M20 (Shimadzu, Kyoto, 
Japan) diode-array detector using $\mathrm{CNW} \mathrm{C}_{18}(2.1 \times 50 \mathrm{~mm}, 3.5 \mu \mathrm{m})$ or $\mathrm{CNW} \mathrm{C}_{18}(2.1 \times$ $100 \mathrm{~mm}, 3.5 \mu \mathrm{m}$ ) columns (Anpel Scientific Instrument Co., Ltd., Shanghai, People's Republic of China). HRESIMS analyses were performed on a Waters Micromass QTOF Ultima Global mass spectrometer (Waters, Milford, MA, USA). Semipreparative HPLC was performed on a Unimicro EasySep-1010 binary pump system with a Unimicro EasySep-1010 detector (Unimicro, Shanghai, People's Republic of China) using a YMC-Pack ODS-A $(250 \times 20 \mathrm{~mm}, 5 \mu \mathrm{m})$ column (YMC Co., Ltd., Kyoto, Japan). Precoated silica gel GF254 plates, silica gel (300-400 mesh) (Qingdao Haiyang Chemical Co., Ltd., Qingdao, People's Republic of China), and $\mathrm{C}_{18}$ reversedphase silica gel $(40-63 \mu \mathrm{m})$ (Merck, Whitehouse station, NJ) were used for column chromatography (CC) and TLC detection.

\section{S147. X-ray Crystallographic Analyses of 2.}

Colorless crystals of compound $\mathbf{2}$ was obtained by crystallization from $\mathrm{MeOH}$. All data sets for 2 was measured on a Bruker APEX-II CCD diffractometer with graphitemonochromated $\mathrm{Cu} \mathrm{K} \alpha$ radiation $(1.54178 \AA$ ). Their structures were solved by direct methods using SHELXL-97 and were refined using full-matrix least-squares calculation on $F^{2}$ using SHELXL-97. The hydrogen atom positions were geometrically idealized and were allowed to ride on their parent atoms. Non-hydrogen atoms were refined anisotropically. Crystallographic data for $\mathbf{2}$ has been deposited at the Cambridge Crystallographic Data Centre. Copies of these data can be obtained free of charge via the Internet at www.ccdc.cam.ac.uk/conts/retrieving.html or from the CCDC, 12 Union Road, Cambridge CB2 1EZ, U.K. [Tel: (+44) 1223-336-408; fax: (+44) 1223-336-033; e-mail: deposit@ccdc.cam.ac.uk].

Crystal Data for Compound 2: $\mathrm{C}_{35} \mathrm{H}_{40} \mathrm{O}_{12}, M_{\mathrm{r}}=652.67$, triclinic, $P 1, a=8.5050$ (3)
$\AA, b=9.1711$
(4) $\AA, c=10.7701$
(4) $\AA, V=813.86$
(5) $\AA^{3}, Z=1, D_{x}=1.332 \mathrm{Mg} / \mathrm{m}^{3}$.

Crystal dimension: $0.19 \times 0.15 \times 0.12 \mathrm{~mm}^{3}, \mu=0.838 \mathrm{~mm}^{-1}, F(000)=346.0, T=100.0$

K. Independent reflections: $6196\left(R_{\text {int }}=0.0471\right) . R\left[F^{2}>2 \sigma\left(F^{2}\right)\right]=0.0407, w R\left(F^{2}\right)=$ 
0.1087. Flack parameter: -0.01 (7). CCDC number: 1970241.

\section{S148. Biological Assay.}

C. elegans strains were obtained from Caenorhabditis Genetics Center (CGC) of University of Minnesota. Strains were maintained and manipulated under standard conditions. ${ }^{1,2}$ The strain used in this study was Bristol N2 (wild type). To obtain agesynchronized nematodes, self-fertilizing hermaphrodites (3 days old) were left to lay eggs and afterwards removed to set the eggs in synchrony. The eggs were cultivated on NGM agar plates under standard laboratory conditions at $20^{\circ} \mathrm{C}$. After hatching and reaching the late L4 larval stage, worms were transferred to NGM agar plates in the absence (control) or the presence of $50 \mu \mathrm{M}$ of test compounds. The compounds were dissolved in DMSO with the same molar concentration, and to the control group was added the same amount of DMSO, for lifespan assays at $25{ }^{\circ} \mathrm{C}$. Then, $40 \mu \mathrm{M} 5$ fluorodesoxyuridine (FUDR) was added to the NGM plates to prevent the eggs from hatching until the end of the egg-laying period. Worms were transferred to new plates on the seventh and eleventh day of adulthood. During lifespan assays, worms were observed and counted every other day. They were prodded gently with the tip of a thin platinum wire, and an absence of any response was considered evidence of death. Worms that died from causes other than aging, such as sticking to the plate walls, internal hatching or bursting in the vulval region, were not considered in the data analyses. The total number of worms for each lifespan analysis was approximately 60 .

(1) Sayed, A. A. R.; El-Shaieb, K. M.; Mourad, A. F. E. Arch. Pharm. Res. 2012, 35, 69-76.

(2) Brenner, S. Genetics 1974, 77, 71-94. 
Lifespan-extending effects of compounds $(50 \mu \mathrm{M})$ isolated from C. paniculatus with DMSO as a blank control

\begin{tabular}{|l|l|l|l|l|l|l|l|l|l|l|l|l|}
\hline Day & control & $\mathbf{4}(\mathrm{dead})$ & $\mathbf{5}(\mathrm{dead})$ & $\mathbf{8}(\mathrm{dead})$ & $\mathbf{1 0}(\mathrm{dead})$ & $\begin{array}{l}\mathbf{1 1} \\
(\mathrm{dead})\end{array}$ & $\mathbf{1 2}(\mathrm{dead})$ & $\mathbf{1 3}(\mathrm{dead})$ & $\mathbf{1 4}(\mathrm{dead})$ & $\mathbf{2 1}(\mathrm{dead})$ & $\mathbf{2 5}(\mathrm{dead})$ & Fr.A (dead) \\
\hline 7 & 6 & 0 & 3 & 0 & 7 & 6 & 2 & 0 & 1 & 4 & 1 & 0 \\
\hline 8 & 3 & 1 & 0 & 1 & 3 & 1 & 3 & 0 & 0 & 0 & 1 & 1 \\
\hline 10 & 2 & 3 & 0 & 3 & 1 & 1 & 2 & 0 & 0 & 1 & 1 & 2 \\
\hline 12 & 5 & 2 & 10 & 9 & 4 & 2 & 3 & 0 & 4 & 2 & 4 & 3 \\
\hline 14 & 7 & 6 & 2 & 8 & 11 & 3 & 4 & 7 & 3 & 4 & 9 & 2 \\
\hline 15 & 4 & 4 & 5 & 7 & 8 & 9 & 9 & 9 & 5 & 6 & 5 & 2 \\
\hline 17 & 7 & 10 & 11 & 17 & 13 & 25 & 34 & 14 & 16 & 15 & 16 & 12 \\
\hline 18 & 5 & 4 & 7 & 11 & 7 & 6 & 3 & 6 & 8 & 12 & 9 & 7 \\
\hline 19 & 7 & 11 & 9 & 14 & 9 & 9 & 3 & 12 & 12 & 12 & 8 & 7 \\
\hline 21 & 6 & 10 & 14 & 9 & 7 & 8 & & 6 & 17 & 12 & 11 & 21 \\
\hline 23 & & & 7 & 4 & & 2 & & 3 & 3 & 8 & 6 & 10 \\
\hline
\end{tabular}


